UNIVERSIDADE DE SÃO PAULO

Réabido my 04/06/0s

INSTITUTO DE QUÍMICA

BIBLIOTECA

INSTITUTO DE QUIMICA

Universidado de São Panlo

t. 19.593

\title{
QUÍMICA SUPRAMOLECULAR DE PORFIRINO-CLUSTERS
}

SERGIO DOVIDAUSKAS

Tese de Doutorado

Orientador:

PROF. DR. HENRIQUE EISI TOMA

SÃO PAULO

2001 
DEDALUS - Acervo - CQ

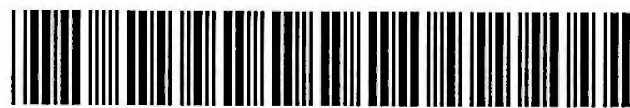

30100003812

Ficha Catalografica

Elaborada pela Divisão de Biblioteca e

Documentação do Conjunto das Químicas da USP.

Dovidauskas, Sergio

Química supramolecular de porfirino-clusters / Sergio

Dovidauskas. -. Så Paulo, 2001.

143p.

Tese (doutorado) - Instituto de Química da Universidade de São Paulo. Departamento de Química Fundamental.

Orientador: Toma, Henrique Eisi

1. Catálise: Química inorgânica 2. Química bioinorgânica

I. T. II. Toma, Henrique Eisi, orientador. 


\section{“Química Supramolecular de Porfirino- Clusters"}

\section{SÉRGIO DOVIDAUSKAS}

Tese de Doutorado submetida ao Instituto de Química da Universidade de São Paulo como parte dos requisitos necessários à obtenção do grau de Doutor em Ciências - Área: Química Inorgânica

Aprovado por:

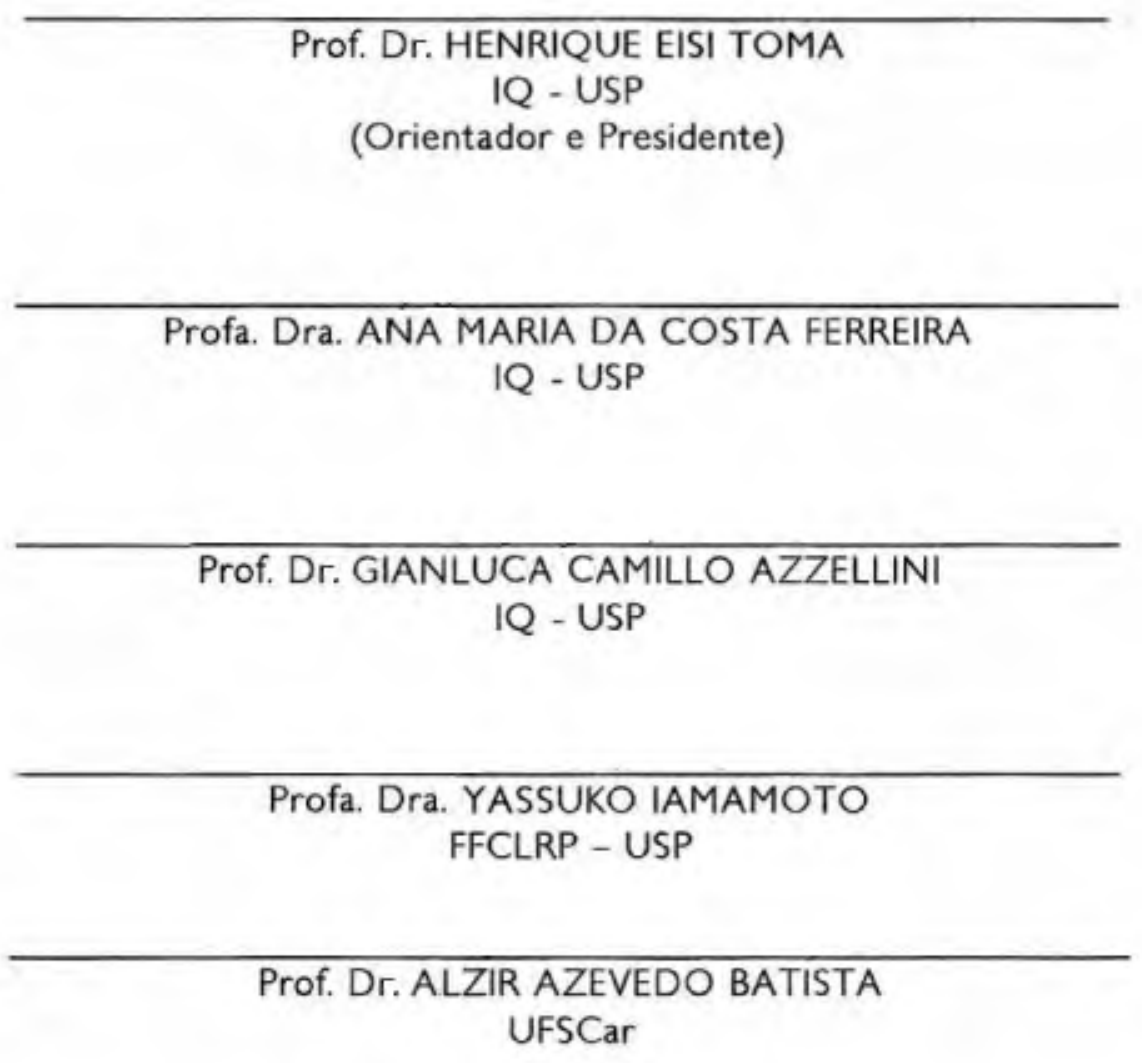


Aos meus pais,

aos meus irmãos,

à minha pequena Isaura,

ao meu caro Tadao, e Ricardo, e Aparecida, e Catarina, e Irene, e Rosa,

e à minha prima Márcia,

não tenho palavras para expressar o meu imenso carinho;

à amiga Alice, compreensiva amiga, cujo incentivo e apoio foram decisivos para o meu retorno à vida acadêmica;

à amiga Franca, sincera amiga;

ao amigo Paulo, paciente amigo;

e ao amigo Jorge, catalisador amigo,

enfim,

a todos vocês,

eu devo muito.

A todos vocês eu dedico este trabalho. 


\section{AGRADECIMENTOS}

Ao Prof. Dr. Henrique Eisi Toma, pela oportunidade e orientação.

Ao Prof. Dr. Koiti Araki, pelas inúmeras discussões e contribuições a respeito da química das porfirinas e metaloporfirinas.

À Prof. Dra. Anamaria Dias Pereira Alexiou, pelo inestimável apoio na química dos clusters trinucleares de acetato de rutênio.

À Prof. Dra. Yassuko lamamoto e à Dra. Hérica Cristina Sacco, pela colaboração nos estudos catalíticos de oxidações de substratos orgânicos.

À Sofia Nikolaou, pelo auxílio na síntese de clusters.

Ao Grégoire Jean-François Demets e ao Fauze Jacó Anaissi, por superestimarem a minha pequena colaboração em seu trabalho.

Ao Herbert Winnischofer, pela angular colaboração no estudo da redução catalítica de dioxigênio.

Aos demais membros do grupo do Prof. Henrique, em especial à Francisca N. Rein, Reginaldo César Rocha, Marcos Makoto Toyama e Vagner Roberto de Souza, pelas discussões e sugestões.

Aos Profs. Drs. Gianluca C. Azzellini e Suzana I. C. Torresi, pelas contribuições quando do Exame de Qualificação.

À CAPES, pelo auxilio financeiro. 


\section{RESUMO}

Três novas supermoléculas, aqui designadas por $\mathrm{ZnTCP}^{4+}, \mathrm{MnTCP}^{5+}$ e CoTCP ${ }^{5+}$, foram obtidas pela coordenação de quatro acetatos trinucleares assimétricos de rutênio, $\left[\mathrm{Ru}_{3} \mathrm{O}\left(\mathrm{CH}_{3} \mathrm{CO}_{2}\right)_{6}(\mathrm{py})_{2}\left(\mathrm{CH}_{3} \mathrm{OH}\right)\right]^{+}$, aos resíduos piridínicos de meso-tetra(4piridil)porfirinato de $\mathrm{Zn}^{\prime \prime}, \mathrm{Mn}^{\text {III }}$ e Co ${ }^{\mathrm{II \prime}}$, respectivamente (ZnTPyP, MnTPyP e CoTPyP). A caracterização destas supermoléculas foi efetuada por espectroscopia de ressonância magnética nuclear e espectroscopia eletrônica. O comportamento eletroquímico foi investigado por voltametria cíclica e espectroeletroquímica.

Os efeitos dos acetatos trinucleares periféricos sobre a reatividade do núcleo porfirínico foram analisados: (i) para $\mathrm{ZnTCP}^{4+}$, além da supressão da luminescência, verificou-se que as constantes de coordenação axial determinadas em diclorometano para piridina e imidazol, quando comparadas às respectivas constantes de ZnTPyP e de meso-tetra(fenil)porfirinato de zinco, indicaram um aumento significativo da acidez de Lewis do íon $\mathrm{Zn}^{2+}$; (ii) $\mathrm{MnTCP}^{5+}$ revelou-se um catalisador mais seletivo que MnTPyP na oxidação de ciclohexano em fase homogênea, utilizando-se iodosilbenzeno como doador de oxigênio; (iii) os eletrodos modificados por filmes de CoTCP ${ }^{5+}$ apresentaram uma eficiente atividade catalítica na redução tetra-eletrônica de dioxigênio a água, comportamento que contrasta com o descrito na literatura para filmes de CoTPyP. A redução tetra-eletrônica de dioxigênio catalisada pelos filmes de CoTCP ${ }^{5+}$ foi confirmada por voltametria cíclica, voltametria de eletrodo disco rotatório e voltametria de eletrodo de anel e disco rotatórios. 


\section{ABSTRACT}

Three novel supermolecules designated as $\mathrm{ZnTCP}^{4+}, \mathrm{MnTCP}^{5+}$, and CoTCP ${ }^{5+}$ were obtained by coordination of four assymetric trinuclear ruthenium acetate species, $\left[\mathrm{Ru}_{3} \mathrm{O}\left(\mathrm{CH}_{3} \mathrm{CO}_{2}\right)_{6}(\mathrm{py})_{2}\left(\mathrm{CH}_{3} \mathrm{OH}\right)\right]^{+}$, to pyridine residues of $\mathrm{Zn}^{\prime \prime}$-, $\mathrm{Mn}^{\mathrm{III}}$-, and $\mathrm{Co}^{\mathrm{III}} \mathrm{TPyP}$, respectively (TPyP $=$ meso-tetra(4-pyridil)porphyrinate). These new compounds were characterized by nuclear magnetic resonance spectroscopy and electronic spectroscopy. The electrochemical behavior was investigated by cyclic voltammetry, and spectroelectrochemistry.

The influence of the peripheral trinuclear acetate on the porphyrin core reactivity was assayed: (i) for $\mathrm{ZnTCP}^{4+}$, besides the luminescence quenching, the calculated equilibrium constants for axial coordination of pyridine and imidazole in dichloromethane demonstrated a significant increase in the $\mathrm{Zn}^{2+}$ Lewis acidity in comparison with the respective constants from ZnTPyP and zinc meso-tetra(phenyl)porphyrinate; (ii) $\mathrm{MnTCP}^{5+}$ exhibited improved selectivity as catalyst for ciclohexane oxidation (homogeneous phase) in comparison with MnTPyP using iodosylbenzene as oxygen donor; (iii) modified electrodes by $\mathrm{CoTCP}^{5+}$ films showed an outstanding catalytic activity in the tetraelectronic reduction of dioxygen to water, in contrast with CoTPyP films described in the literature; the dioxygen tetraelectronic reduction was confirmed by cyclic voltammetry, rotating disk electrode voltammetry, and rotating ring and disk electrode voltammetry. 


\section{ABREVIATURAS}

\begin{tabular}{|c|c|}
\hline MP & metaloporfirina \\
\hline TPP & meso-tetra(fenil)porfirina \\
\hline $\mathrm{H}_{2} \mathrm{TPyP}$ & meso-tetra(4-piridil)-21H, 23H-porfirina \\
\hline MTPyP ${ }^{n+}$ & meso-tetra(4-piridil)metaloporfirina \\
\hline ZnTPyP & meso-tetra(4-piridil)porfirinato de zinco \\
\hline MnTPyP ${ }^{+}$ & meso-tetra(4-piridil)porfirinato de manganês III \\
\hline CoTPyP ${ }^{+}$ & meso-tetra(4-piridil)porfirinato de cobalto III \\
\hline MTCP $^{n+}$ & meso-tetra(cluster)metaloporfirina \\
\hline $\mathrm{H}_{2} \mathrm{TCP}^{4+}$ & meso-tetra(cluster)porfirina base livre \\
\hline $\mathrm{ZnTCP}{ }^{4+}$ & meso-tetra(cluster)porfirinato de zinco \\
\hline $\mathrm{MnTCP}{ }^{5+}$ & meso-tetra(cluster)porfirinato de manganês \\
\hline CoTCP ${ }^{5+}$ & meso-tetra(cluster)porfirinato de cobalto \\
\hline TFE & 2,2,2-trifluoretanol \\
\hline DMSO & dimetilsulfóxido \\
\hline DMF & $\mathrm{N}, \mathrm{N}^{\prime}$-dimetilformamida \\
\hline OAc & ion acetato \\
\hline $\mathrm{TEAClO}_{4}$ & perclorato de tetraetilamônio \\
\hline TBAPF $_{6}$ & hexafluorofosfato de tetrabutilamônio \\
\hline Phio & iodosilbenzeno, $\mathrm{C}_{6} \mathrm{H}_{5} \mathrm{IO}$ \\
\hline EPH & eletrodo padrão de hidrogênio \\
\hline UV & ultravioleta \\
\hline TCML & transferência de carga metal-ligante \\
\hline RMN & ressonância magnética nuclear \\
\hline $\mathrm{pz}$ & pirazina \\
\hline py & piridina \\
\hline im & imidazol \\
\hline$\varepsilon$ & absortividade por mol \\
\hline
\end{tabular}




\section{ÍNDICE \\ CAPÍTULO 1-Introdução}

1.1 Apresentação da Tese 2

1.2 Química supramolecular 3

1.3 Acetatos trinucleares de rutênio 8

1.3.1 Aspectos sintéticos 8

1.3.2 Aspectos estruturais 10

1.3.3 Espectro eletrônico 13

1.3.4 Comportamento eletroquímico 17

1.3.5 Supermoléculas: clusters trinucleares de rutênio como $\begin{array}{ll}\text { unidades estruturais } & 19\end{array}$

1.4 Porfirinas e metaloporfirinas $\quad 22$

1.4.1 Aspectos gerais 22

1.4.2 Espectro eletrônico: o modelo dos quatro orbitais de fronteira 24

1.4.3 Metaloporfirinas como catalisadores em oxidações de substratos orgânicos $\quad 32$

1.4.4 Porfirinas de cobalto: catalisadores para a redução de dioxigênio $\quad 36$

1.4.5 A utilização de porfirinas e metaloporfirinas em quimica supramolecular 39

$\begin{array}{lll}1.5 & \text { Objetivos } & 41\end{array}$

CAPÍTULO 2 - Experimental

2.1 Reagentes 44

2.2 Equipamentos e procedimentos 46

2.2.1 Ressonância magnética nuclear e espectroscopia eletrônica $\quad 46$

2.2.2 Voltametria cíclica e espectroeletroquímica 46

2.2.3 Determinação de constante de equilíbrio de coordenação axial por titulação espectrofotométrica $\quad 47$

2.2.4 Oxidações de substratos orgânicos: cromatografia 47 
2.2.5 Redução de dioxigênio: voltametria cíclica, espectroeletroquímica, voltametria de eletrodo de disco rotatório e voltametria de eletrodo de anel e disco rotatórios

2.3 Sínteses

2.3.1 Síntese de $\left[\mathrm{Ru}_{3} \mathrm{O}\left(\mathrm{H}_{3} \mathrm{CCOO}\right)_{6}(\mathrm{py})_{2}\left(\mathrm{CH}_{3} \mathrm{OH}\right)\right] \mathrm{PF}_{6}$

2.3.2 Sínteses das metaloporfirinas

2.3.3 Síntese das supermoléculas $\mathrm{ZnTCP}^{4+}, \mathrm{MnTCP}^{5+}$ e $\mathrm{CoTCP}^{5+}$

3.1 ZnTCP $\left(\mathrm{PF}_{6}\right)_{4}$

3.2 $\left[\mathrm{MnTCP}(\mathrm{OAC})\left(\mathrm{H}_{2} \mathrm{O}\right)\right]\left(\mathrm{PF}_{6}\right)_{4}$

$3.3 \quad\left[\mathrm{CoTCP}(\mathrm{Cl})\left(\mathrm{H}_{2} \mathrm{O}\right)\right] \mathrm{Cl}_{4}$

CAPÍTULO 4-Espectroscopia eletrônica

4.1 $\mathrm{ZnTCP}\left(\mathrm{PF}_{6}\right)_{4}$

$4.2\left[\mathrm{MnTCP}(\mathrm{OAc})\left(\mathrm{H}_{2} \mathrm{O}\right)\right]\left(\mathrm{PF}_{6}\right)_{4}$

65

4.3 [CoTCP $\left.(\mathrm{OAC})\left(\mathrm{H}_{2} \mathrm{O}\right)\right]\left(\mathrm{PF}_{6}\right)_{4}$

CAPÍTULO 5 - Comportamento eletroquímico: voltametria cíclica e espectroeletroquímica

5.1 Sobre a voltametria cíclica

5.2 Sobre a espectroeletroquímica

$5.3 \quad \mathrm{ZnTCP}\left(\mathrm{PF}_{6}\right)_{4}$

$5.4 \quad\left[\mathrm{MnTCP}(\mathrm{OAc})\left(\mathrm{H}_{2} \mathrm{O}\right)\right]\left(\mathrm{PF}_{6}\right)_{4}$ 78

$5.5\left[\mathrm{CoTCP}(\mathrm{OAC})\left(\mathrm{H}_{2} \mathrm{O}\right)\right]\left(\mathrm{PF}_{6}\right)_{4}$ 85

CAPÍTULO 6-Reatividade

6.1 Coordenação axial de $\mathrm{ZnTCP}^{4+}$ 
6.1.1 Método de cálculo utilizado na determinação das constantes de equilíbrio de formação de complexos $\mathrm{ZnTCP}(\mathrm{L})^{4+}$, $\mathrm{L}=$ ligante axial, e das constantes de equilíbrio de substituição axial

6.1.2 Resultados

6.2 MnTCP ${ }^{5+}$ : comportamento catalítico na oxidação de substratos orgânicos em fase homogênea

6.2.1 Oxidação de cicloocteno a ciclooctano-óxido 102

6.2.2 Oxidação de ciclohexano a ciclohexanol e ciclohexanona 102

6.2.3 Algumas considerações a respeito das oxidações catalisadas por porfirinas de $\mathrm{Mn}^{\text {III }}$

6.2.4 Acompanhamento por espectroscopia eletrônica das reações de oxidação de ciclohexano catalisadas por MnTPyP ${ }^{+}$ e MnTCP ${ }^{5+}$

6.3 Filmes de CoTCP $^{5+}$ : comportamento catalítico na redução tetra-eletrônica de dioxigênio

6.3.1 Preparação, voltametria cíclica e espectroeletroquímica de filme de $\mathrm{CoTCP}^{5+}$ sobre eletrodo de carbono vítreo

6.3.2 Redução de $\mathrm{O}_{2}$ pelo filme de CoTCP ${ }^{5+}$ : estudo por voltametria cíclica

6.3.3 Redução de $\mathrm{O}_{2}$ pelo filme de $\mathrm{CoTCP}^{5+}$ : estudo por voltametria de eletrodo de disco rotatório

6.3.4 Redução de $\mathrm{O}_{2}$ pelo filme de $\mathrm{CoTCP}^{5+}$ : estudo por voltametria de eletrodo de anel e disco rotatórios

CAPITULO 7 - Considerações finais e perspectivas.

7.1 A respeito das supermoléculas $\mathrm{ZnTCP}^{4+}, \mathrm{MnTCP}^{5+}$ e CoTCP ${ }^{5+}$

7.2 A respeito de outros possiveis sistemas baseados em metaloporfirinas e clusters trinucleares de acetato de rutênio 
CAPÍTULO 1

INTRODUÇÃO 


\subsection{Apresentação da Tese}

Desta Tese de Doutoramento pode-se extrair um mínimo de três conjuntos de palavras-chave: química supramolecular, acetatos trinucleares de rutênio, e porfirinas/metaloporfirinas. Julgou-se adequado anteceder a apresentação dos objetivos deste trabalho por breves considerações a respeito dos extensos tópicos embutidos nestes três conjuntos de palavras-chave, o que é feito nos próximos itens deste primeiro capítulo.

No Capítulo 2 estão descritas as sínteses e as condições experimentais em que os mais diversos resultados foram obtidos. Considerações teóricas mais detalhadas sobre as técnicas utilizadas (por exemplo, voltametria cíclica, cromatografia gasosa, etc) foram omitidas desta Tese. Contudo, sempre que se julgou conveniente, bibliografia específica foi sugerida.

Os Capítulos 3 e 4 relacionam-se à caracterização dos três compostos sintetizados. Embora cristais adequados para a resolução das estruturas por difração de raios-X não tenham sido obtidos até o momento, os dados de ressonância magnética nuclear (Capítulo 3) e os de espectroscopia eletrônica (Capítulo 4), aliados àqueles oriundos dos estudos eletroquímicos (voltametria cíclica e espectroeletroquímica, Capítulo 5), concordam com as estruturas propostas para os três compostos: quatro acetatos trinucleares de rutênio coordenados na periferia do núcleo de uma porfirina de zinco, outra de manganês, e uma terceira, de cobalto.

O capítulo 6 compreende uma análise preliminar da reatividade dos três compostos: (i) para o derivado contendo a porfirina de zinco, estudos de coordenação axial foram realizados; (ii) reações de oxidação de substratos orgânicos foram efetuadas com o derivado envolvendo a porfirina de manganês; e (iii) filmes do derivado contendo a porfirina de cobalto foram investigados frente à redução catalítica de oxigênio a água.

Finalmente, o Capítulo 7 procura salientar o grande número de estudos que ainda podem ser realizados com os sistemas constituídos por metaloporfirinas e acetatos trinucleares de rutênio. 


\subsection{Química supramolecular}

Nos últimos anos, principalmente após o Prêmio Nobel de Química de 1987 atribuído a Jean-Marie Lehn ${ }^{1}$, Donald J. Cram $^{2}$ e Charles J. Pedersen ${ }^{3}$ por suas pesquisas no campo, a química supramolecular tem experimentado uma expansão notável, tornando-se uma área interdisciplinar em que se reconhecem fenômenos químicos, físicos e biológicos passíveis de uma abordagem segundo a sua ótica. Acompanhando esta evolução, enriquecida pela descrição de numerosos exemplos de sistemas supramoleculares ${ }^{4}$, ocorreu (e continua ocorrendo) a adição de termos ao que poderíamos denominar hoje de um "vocabulário da química supramolecular". Por exemplo, Lehn utiliza os termos "receptor" e "substrato" para designar os componentes maior e menor, respectivamente, de uma supermolécula ${ }^{5}$. A analogia com sistemas biológicos é evidente, mas não surpreende se destacarmos uma frase do Prêmio Nobel de $1987^{5}$ :

"Chemistry is the science of matter and of its transformations, and life is its highest expression"

Contudo, uma aceitação homogênea de termos e definições entre a química orgânica supramolecular, intimamente relacionada com a bioorgânica, e a química inorgânica supramolecular (e a bioinorgânica), ainda permanece por ser atingida. Por exemplo, Desiraju ${ }^{6}$, ao considerar a engenharia de cristais de compostos orgânicos pela abordagem de retro-síntese da química orgânica ${ }^{7}$, introduziu o termo "supramolecular synthons" para designar os fragmentos que originariam a rede cristalina que se planeja como alvo. A designação para os análogos inorgânicos foi proposta como "tectons" 8 .

Desta forma, parece conveniente aqui tecer considerações a respeito de alguns termos que serão utilizados ao longo do texto, considerações estas baseadas na concepção de química supramolecular de Jean-Marie Lehn ${ }^{5}$.

Afinal, o que é química supramolecular?

Definida inicialmente por Lehn em $1978^{\circ}$, a química supramolecular pode ser entendida como a "química além da molécula": enquanto a "química molecular" é a 
química da ligação covalente, cujos objetivos são descobrir e controlar as regras que governam as estruturas, propriedades e transformações de espécies moleculares, a química supramolecular está direcionada para entidades organizadas, complexas, que resultam da associação de duas ou mais espécies químicas mantidas unidas por forças intermoleculares (não-covalentes). Seu objetivo é justamente adquirir controle sobre as interações intermoleculares.

\section{E supermoléculas? E espécies supramoleculares?}

Supermoléculas são o resultado da união de duas ou mais unidades estruturais ("building blocks") através de interações não covalentes, produzindo uma espécie química com características e propriedades tão bem definidas quanto às de uma molécula. Para Lehn, numa escala crescente de complexidade de estrutura da matéria, uma supermolécula colocar-se-ia após as partículas elementares, o núcleo, o átomo e a molécula, podendo-se dizer que as supermoléculas estão para as moléculas e as ligações intermoleculares assim como as moléculas estão para os átomos e as ligações covalentes. Em outras palavras, a ligação seletiva de um específico substrato ao seu receptor produz a supermolécula, envolvendo um processo de reconhecimento molecular. Se, em adição ao sítios de ligação, o receptor também apresenta funções reativas, este pode efetuar uma transformação química no substrato, tornando-se, então, um reagente supramolecular ou catalisador. Alternativamente, o receptor pode ser capaz de transportar o substrato de um meio a outro, por exemplo. Portanto, considera-se como funções básicas de uma espécie supramolecular o reconhecimento molecular, a transformação e o transporte químico. Uma supermolécula que apresente uma destas funções, ou uma combinação delas, é uma espécie supramolecular.

\section{Estruturas supramoleculares...}

Segundo Lehn, são entidades polimoleculares que resultam da associação espontânea de um número indefinido de componentes em uma específica fase, apresentando organização microscópica e características macroscópicas razoavelmente bem definidas dependendo de sua natureza (filmes, camadas, membranas, vesículas, micelas, etc). Reserva-se a designação dispositivos moleculares ou supramoleculares para sistemas químicos estruturalmente organizados 
e integrados do ponto de vista funcional, com a capacidade de realizar as funções supramoleculares básicas: reconhecimento, transformação e transporte ${ }^{10}$.

Para ilustrar estes conceitos, tomemos dois exemplos.

\section{$1^{0}$ exemplo}

Em vista da importância química e biológica de íons amônio substituídos, tornouse atraente o desenvolvimento de moléculas receptoras capazes de reconhecer tais substratos. Em 1967, Pedersen verificou que poli-éteres macrocíclicos [18]-O 6 coordenam o grupo $\mathrm{NH}_{3}{ }^{+}$em sua cavidade circular através de três ligações de hidrogênio ${ }^{+} \mathrm{N}-\mathrm{H}^{\cdots \cdots} \cdot \mathrm{O}^{11}$ (figura 1.1).

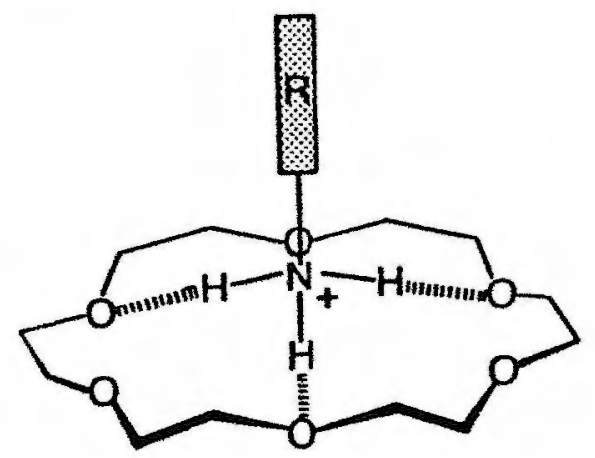

Figura 1.1 - Reconhecimento de íon amônio primário por poli-éter macrocíclico.

Constatada esta habilidade de reconhecimento, o próximo passo foi planejar transformações químicas induzidas pela reação entre o substrato coordenado e grupos funcionais presentes no receptor macrocíclico ${ }^{12}$ (figura 1.2).

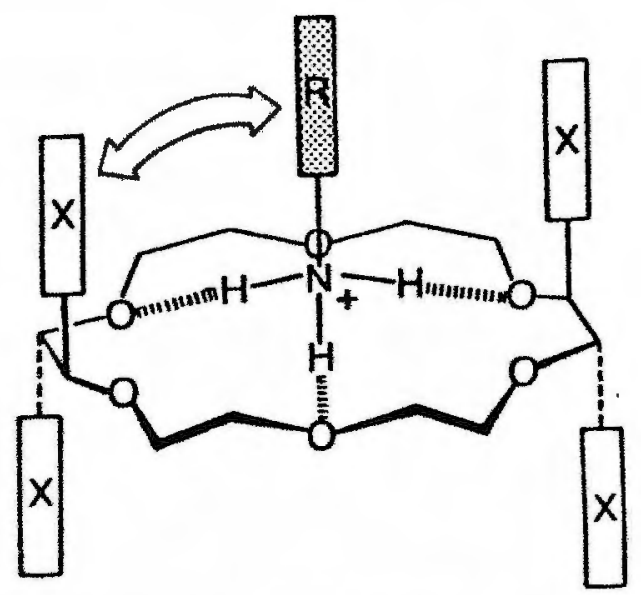

Figura 1.2 - Possível interação entre um substrato coordenado e grupo funcional lateral de um receptor macrocíclico. 
Finalmente, a figura 1.3 apresenta um catalisador supramolecular descrito por Lehn e Sirlin ${ }^{13}$ como resultado dos conceitos apresentados neste exemplo: um poli-éter macrocíclico com cadeias laterais apresentando resíduos de L-cisteína coordena $p$ nitrofenil ésteres de aminoácidos e peptídeos, reagindo com o substrato e liberando $p$ nitrofenol. A reação promovida na presença deste catalisador apresenta (i) seletividade em favor de ésteres de dipeptídeos, (ii) significativo aumento na velocidade de reação, (iii) inibição por cátions metálicos $\left(\mathrm{K}^{+}\right.$, por exemplo), que deslocam o substrato, (iv) reconhecimento quiral entre ésteres de dipeptídeos enantioméricos e (v) um ciclo catalítico bem definido, embora lento 5 .

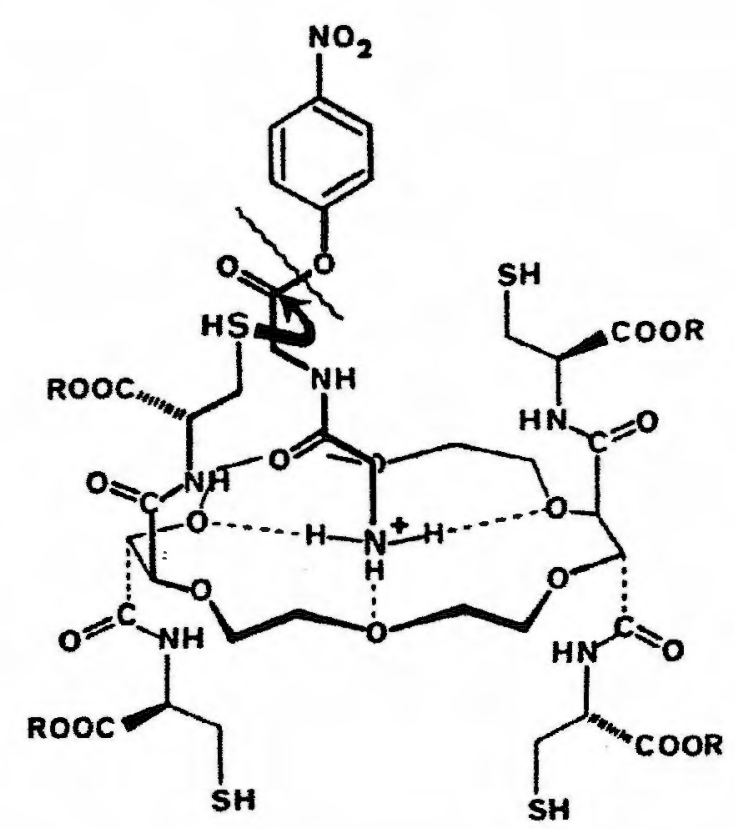

Figura 1.3 - Exemplo de catalisador supramolecular.

\section{$2^{\circ}$ Exemplo}

Nos últimos vinte anos, porfirinas de manganês têm sido extensivamente estudadas como catalisadores de reações de oxidação de substratos orgânicos ${ }^{1416}$; parte considerável deste trabalho, com enfoque bioinorgânico ${ }^{17-20}$, procura mimetizar a enzima mono-oxigenase citocromo P-450, uma heme-proteina que catalisa a ativação redutiva de di-oxigênio ${ }^{21}$ e que será discutida em maiores detalhes mais adiante, no item 1.4.3 deste capítulo. 
Assim, com este enfoque biomimético, uma metaloporfirina hidrofóbica, Mn(III)THPP (THPP = tetra-[4-hexadecil-oxi-fenil]-porfirinato), foi incorporada nas bicamadas de vesículas constituídas de um surfactante derivado do cloreto de dihexadecil-di-metilamônio contendo grupos isociano, dentro das quais platina coloidal foi encapsulada, juntamente com azul de metileno (AM) como transportador de elétrons e $\mathrm{N}$-metil-imidazol como ligante axial da porfirina de manganês (figura 1.4) ${ }^{22}$.
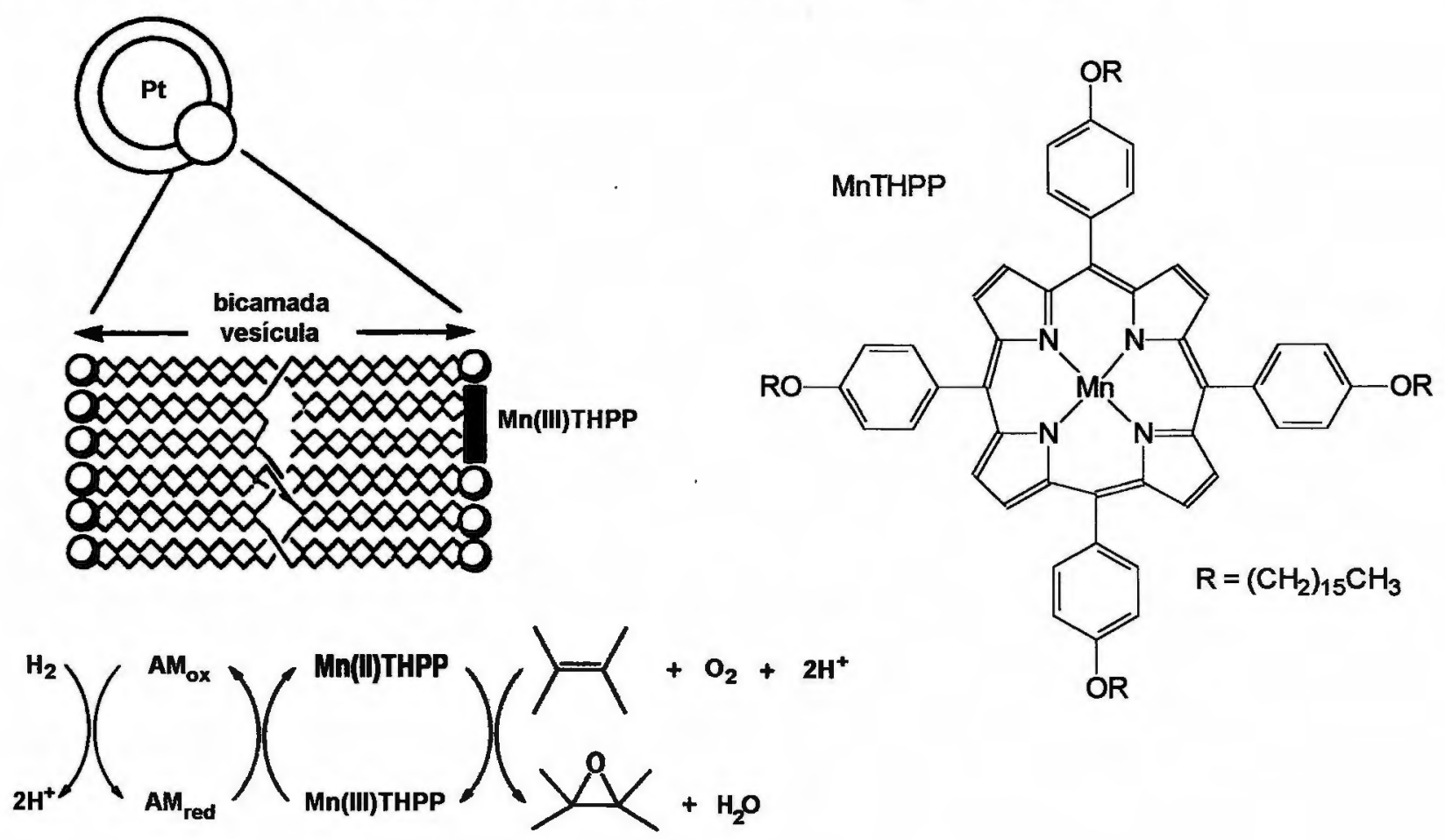

Figura 1.4 - Mimetização da citocromo P-450: um micro-reator.

Este sistema supramolecular catalisa a $20^{\circ} \mathrm{C}$, sob uma atmosfera de hidrogênio e oxigênio (1:1), a ativação redutiva deste último, formando epóxidos a partir de alcenos solúveis ou não em água, incluindo todas as características do sistema enzimático natural: a metaloporfirina, o ligante axial, um doador de elétrons, um transportador de elétrons e a membrana. 


\subsection{Acetatos trinucleares de rutênio}

Recentemente publicamos uma revisão a respeito da química dos carboxilatos trinucleares de rutênio ${ }^{23}$, também denominados "clusters trinucleares de carboxilatos de rutênio"; aqui, serão salientados os tópicos mais importantes, intimamente relacionados aos propósitos desta Tese.

Conhecidos desde a década de $30^{24}$, os carboxilatos de rutênio formam uma extensa série de complexos trinucleares do tipo $\left[\mathrm{Ru}_{3} \mathrm{O}\left(\mathrm{RCO}_{2}\right)_{6}(\mathrm{~L})_{3}\right]^{\mathrm{n}}$, onde $\mathrm{R}=\mathrm{H}^{25}, \mathrm{CH}_{3}$ ${ }^{26-28}, \mathrm{C}_{2} \mathrm{H}_{5}{ }^{26,29}, \mathrm{C}_{3} \mathrm{H}_{7}{ }^{26}, \mathrm{C}_{3} \mathrm{~F}_{7}{ }^{30}, \mathrm{C}_{6} \mathrm{H}_{5}{ }^{26,31,32}, \mathrm{C}_{7} \mathrm{H}_{15}{ }^{26}, \mathrm{C}_{8} \mathrm{H}_{16}{ }^{26}, \mathrm{e} \mathrm{L}=\mathrm{H}_{2} \mathrm{O}, \mathrm{PPh}_{3}(\mathrm{Ph}=$ fenil), $\mathrm{CO}, \mathrm{N}$-heterocíclicos como piridina (py), pirazina (pz), 4,4'-bipiridina (4,4'-bipy), etc. Tais compostos apresentam um arranjo triangular dos átomos de rutênio, mantido por seis pontes laterais $\mu-\mathrm{RCO}_{2}$ e uma ponte central $\mu_{3}$-oxo (figura 1.5). Além das espécies homonucleares, compostos heteronucleares do tipo $\left[\mathrm{Ru}_{2} \mathrm{MO}\left(\mathrm{CH}_{3} \mathrm{CO}_{2}\right)_{6} \mathrm{~L}_{3}\right]$ também foram investigados $\left(\mathrm{M}^{\prime \prime}=\mathrm{Mg}^{33-35}, \mathrm{Mn}^{32,34,36}, \mathrm{Co}^{32,34,36-38}, \mathrm{Ni}^{32,34,36}\right.$, e $\mathrm{M}^{\prime \prime \prime}=$ $\left.\mathrm{Cr}^{36,39}, \mathrm{Fe}^{36}, \mathrm{Co}^{37}, \mathrm{Rh}^{35,40-42}\right)$.

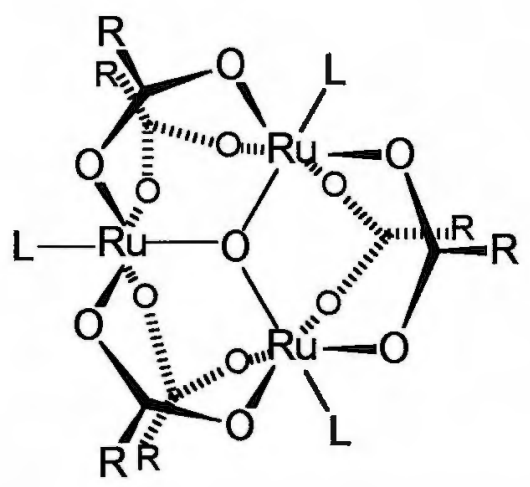

Figura 1.5 - Estrutura esquematizada de $\left[\mathrm{Ru}_{3} \mathrm{O}\left(\mathrm{RCO}_{2}\right)_{6}(\mathrm{~L})_{3}\right]^{\mathrm{n}}$.

\subsubsection{Aspectos sintéticos.}

A preparação dos carboxilatos trinucleares de rutênio envolve inicialmente a formação do cluster precursor $\left[\mathrm{Ru}_{3} \mathrm{O}\left(\mathrm{RCO}_{2}\right)_{6}(\mathrm{~S})_{3}\right]^{+}$, onde $\mathrm{S}=\mathrm{H}_{2} \mathrm{O}$, metanol ou etanol. $\mathrm{O}$ procedimento geralmente utilizado é baseado no descrito por Spencer e Wilkinson ${ }^{26}$, consistindo no aquecimento sob refluxo de uma solução etanólica contendo $\mathrm{RuCl}_{3} \cdot \mathrm{nH}_{2} \mathrm{O}, \mathrm{RCO}_{2} \mathrm{H}$ e RCO${ }_{2}^{-}$(esquema 1.1). Fontes alternativas de rutênio $\left(\mathrm{RuO}_{4}{ }^{43-46}\right.$ ou Ru metálico ${ }^{47}$, por exemplo) também são utilizadas. 


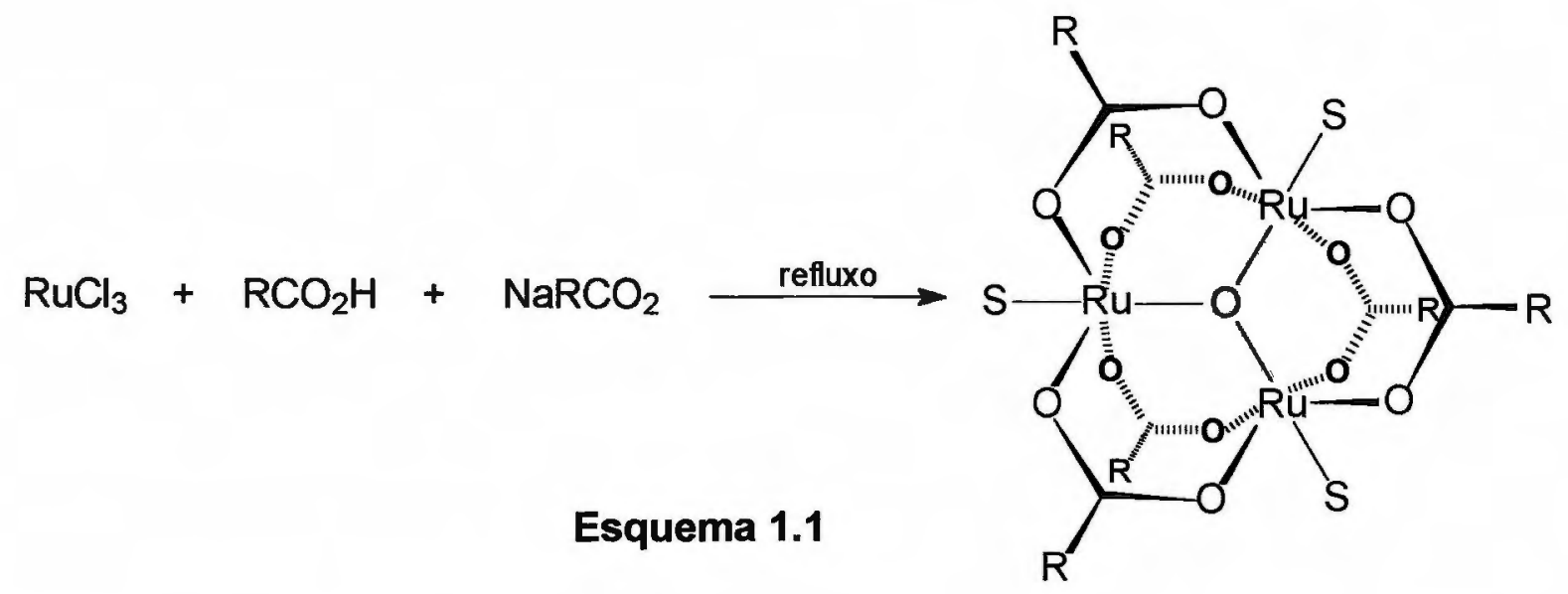

O cluster $\left[\mathrm{Ru}_{3} \mathrm{O}\left(\mathrm{RCO}_{2}\right)_{6}(\mathrm{~S})_{3}\right] \mathrm{X}\left(\mathrm{X}=\mathrm{RCO}_{2}^{-26}, \mathrm{ClO}_{4}^{-41,48}, \mathrm{BF}_{4}^{-25}\right.$ ou $\left.\mathrm{PF}_{6}^{-{ }^{40}}\right)$ é facilmente isolável, podendo ser armazenado por longos períodos, seja na foma sólida como em solução metanólica $^{27}$. Embora ainda não existam estudos cinéticomecanísticos a respeito de sua formação, Sasaki et al ${ }^{39,49}$ afirmaram ser possível a ocorrência do intermediário dinuclear $\mathrm{Ru}_{2} \mathrm{O}\left(\mathrm{RCO}_{2}\right)_{2}$, cuja existência explicaria a obtenção apenas dos clusters do tipo $\mathrm{Ru}_{2} \mathrm{M}$ (e não do tipo $\mathrm{RuM}_{2}$ ) quando da síntese dos derivados heteronucleares.

Os compostos $\left[\mathrm{Ru}_{2} \mathrm{RhO}(\mathrm{OAc})_{6}(\mathrm{~L})_{3}\right] \mathrm{ClO}_{4}\left(\mathrm{OAc}=\right.$ íon acetato, $\mathrm{L}=\mathrm{H}_{2} \mathrm{O}$ ou py) foram os primeiros clusters heteronucleares a serem sintetizados ${ }^{41}$, tendo sido propostas três rotas para a sua obtenção, todas envolvendo o refluxo de soluções de $\mathrm{RuCl}_{3}, \mathrm{RhCl}_{3}, \mathrm{Na}(\mathrm{OAc}), \mathrm{HOAc}$ e $\mathrm{H}_{2} \mathrm{O}$. A preparação dos demais clusters heteronucleares envolve inicialmente a reação entre $\mathrm{RuCl}_{3}, \mathrm{HOAc}, \mathrm{C}_{2} \mathrm{H}_{5} \mathrm{OH}$ e $\mathrm{H}_{2} \mathrm{O}$, seguindo-se posterior adição de $\mathrm{M}(\mathrm{OAC})_{2}(\mathrm{M}=\mathrm{Mg}, \mathrm{Mn}, \mathrm{Co}, \mathrm{Ni}, \mathrm{Zn})^{34} . \mathrm{Em}$ alguns casos,

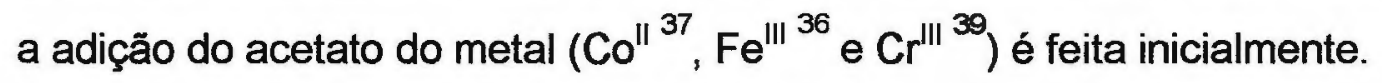

Em clusters do tipo $\left[\mathrm{Ru}_{3} \mathrm{O}\left(\mathrm{RCO}_{2}\right)_{6}(\mathrm{~S})_{3}\right]^{+}$as moléculas de solvente (S) são lábeis, podendo ser facilmente deslocadas por uma variedade de ligantes $L$. Isso permite a preparação de clusters simétricos, $\left[\mathrm{Ru}_{3} \mathrm{O}\left(\mathrm{RCO}_{2}\right)_{6}(\mathrm{~L})_{3}\right]^{\mathrm{n}}{ }^{26-28,40,48,50-55}$. Uma rota alternativa para a obtenção dos clusters simétricos foi descrita por Zhilyaev et al ${ }^{29}$, consistindo no aquecimento sob refluxo de $\left[\mathrm{Ru}_{2}\left(\mathrm{SO}_{4}\right)_{2}(\mathrm{OH})_{2}(\mathrm{~L})_{4}\right]$ em $\mathrm{RCO}_{2} \mathrm{H}$.

A preparação dos clusters assimétricos, $\left[R u_{3} O(O A c)_{6}(L)_{2}\left(L^{\prime}\right)\right]^{n}\left(L \neq L^{\prime}\right)$ envolve a redução de $\left[\mathrm{Ru}_{3} \mathrm{O}\left(\mathrm{RCO}_{2}\right)_{6}(\mathrm{~S})_{3}\right]^{+}$a $\left[\mathrm{Ru}_{3} \mathrm{O}\left(\mathrm{RCO}_{2}\right)_{6}(\mathrm{~S})_{3}\right]$, seguida de reação com $\mathrm{CO}$, conduzindo à obtenção de $\left[\mathrm{Ru}_{3} \mathrm{O}\left(\mathrm{RCO}_{2}\right)_{6}(\mathrm{~S})_{2}(\mathrm{CO})\right]$. A reação deste com $\mathrm{L}$ forma $\left[\mathrm{Ru}_{3} \mathrm{O}\left(\mathrm{RCO}_{2}\right)_{6}(\mathrm{~L})_{2}(\mathrm{CO})\right]$ que, quando reoxidado com $\mathrm{Br}_{2}$, perde o ligante cO disponibilizando um sítio para a coordenação de $L^{, 50,56-58}$. Alternativamente, parte-se do cluster $\left[\mathrm{Ru}_{3} \mathrm{O}\left(\mathrm{RCO}_{2}\right)_{6}(\mathrm{py})_{3}\right]^{+}$, e, após sua redução com hidrazina seguida de reação 
com CO, obtém-se $\left[\mathrm{Ru}_{3} \mathrm{O}\left(\mathrm{RCO}_{2}\right)_{6}(\mathrm{py})_{2}(\mathrm{CO})\right]$. Novamente, a reoxidação com $\mathrm{Br}_{2}$ conduz à saída de $\mathrm{CO}$, permitindo a coordenação de $\mathrm{L}^{\prime 27,55,59-61}$.

A síntese do cluster totalmente assimétrico $\left[R u_{3} O(O A c)_{6}(L)\left(L^{\prime}\right)\left(L^{\prime \prime}\right)\right]^{n}$ é realizada a partir da reação entre $\left[\mathrm{Ru}_{3} \mathrm{O}\left(\mathrm{RCO}_{2}\right)_{6}(\mathrm{~S})_{2}(\mathrm{CO})\right]$ e $\mathrm{L}$ (em quantidade menor que a estequiométrica), seguida de cromatografia. No produto $\left[\mathrm{Ru}_{3} \mathrm{O}\left(\mathrm{RCO}_{2}\right)_{6}(\mathrm{~S})(\mathrm{L})(\mathrm{CO})\right]$, $\mathrm{S}$ pode ser facilmente deslocado por L', enquanto a reoxidação labiliza o $\mathrm{CO}$, produzindo um sítio para a coordenação de $L^{\text {"57,62,63 }}$.

\subsubsection{Aspectos estruturais.}

$\mathrm{Na}$ Tabela 1.1 encontram-se algumas distâncias de ligação observadas em clusters que tiveram sua estrutura determinada por análises de difração de raios-X. Os dados obtidos são consistentes com a estrutura esquematizada na figura 1.5. Todos os compostos apresentam os átomos de rutênio nos vértices de um triângulo equilátero quase perfeito, exceto os clusters $\left[\mathrm{Ru}_{3} \mathrm{O}(\mathrm{OAc})_{6}\left(\mathrm{mbpy}^{+}\right)_{2}(\mathrm{CO})\right]\left(\mathrm{ClO}_{4}\right)_{2} .2 \mathrm{DMF}\left(\mathrm{mbpy}^{+}=\mathrm{N}-\right.$ metil-4,4'-bipiridínio, DMF= N,N'-dimetil-formamida) e $\left[\mathrm{Ru}_{3} \mathrm{O}(\mathrm{OAc})_{6}(\mathrm{py})_{2}(\mathrm{CNXy})\right] \cdot 2 \mathrm{HCCl}_{3}$ ( $\mathrm{CNXy}=2,6$-dimetil-isocianobenzeno) cujos arranjos são melhor descritos como triângulos isósceles. $O$ átomo de oxigênio encontra-se no centro do triângulo, situandose no plano dos três átomos de rutênio. Completando a esfera de coordenação do metal, encontram-se os grupos carboxilato em ponte e os ligantes terminais $\mathrm{L}$.

Analisando a tabela, observa-se que não há variações significativas nas distâncias de ligação Ru-Ru e Ru-O $\mathrm{O}_{\text {central }}$ com a alteração dos estados formais de oxidação dos átomos de rutênio, sugerindo que os elétrons são removidos ou adicionados em um orbital não-ligante e que a valência é deslocalizada ${ }^{25,64}$. O caráter isoestrutural das espécies oxidada e reduzida já havia sido evidenciado por Meyer et $a^{65}$ antes mesmo dos estudos de difração de raios- $X$ : ao investigarem a reação de auto-troca eletrônica entre os clusters $\left[\mathrm{Ru}_{3} \mathrm{O}(\mathrm{OAc})_{6}(\mathrm{py})_{3}\right]^{+}$e $\left[\mathrm{Ru}_{3} \mathrm{O}(\mathrm{OAc})_{6}(\mathrm{py})_{3}\right]$ por RMN, determinaram uma alta constante de velocidade $\left(1,1 \times 10^{8} \mathrm{~mol}^{-1} \mathrm{dm}^{3} \mathrm{~s}^{-1} \mathrm{em}\right.$ diclorometano). No caso cluster $\left[\mathrm{Ru}_{3} \mathrm{O}(\mathrm{OAc})_{6}\left(\mathrm{mbpy}^{+}\right)_{2}(\mathrm{CO})\right]\left(\mathrm{ClO}_{4}\right)_{2} .2 \mathrm{DMF}$, admite-se que o CO estabilize o estado de oxidação II no átomo de rutênio ao qual se coordena, enquanto os ligantes mbpy ${ }^{+}$coordenam-se aos íons de rutênio III, caracterizando uma espécie de valência localizada ${ }^{58}$. 0 mesmo ocorre com 0 cluster $\left[\mathrm{Ru}_{3} \mathrm{O}(\mathrm{OAc})_{6}(\mathrm{py})_{2}(\mathrm{CNXy})\right] .2 \mathrm{HCCl}_{3}$, cujo ligante $\mathrm{CNXy}$ apresenta comportamento similar ao do $\mathrm{CO}^{66}$. 
Tabela 1.1 - Distâncias de ligação em clusters do tipo $\mathrm{Ru}_{3} \mathrm{O}$ e $\mathrm{Ru}_{2} \mathrm{MO}$.

\begin{tabular}{|c|c|c|c|c|}
\hline Composto & Ru-O $\mathrm{O}_{\text {central }}$ & Ru-Ru & Ru-L & $\mathrm{Ru}-\mathrm{O}_{\text {acelato }}$ \\
\hline \multicolumn{5}{|c|}{ Estados formais de oxidação III,III,II } \\
\hline$\left[\mathrm{Ru}_{3} \mathrm{O}(\mathrm{OAc})_{6}\left(\mathrm{PPh}_{3}\right)_{3}\right]^{67}$ & $\begin{array}{l}1,95(2) \\
1,94(1) \\
1,87(2)\end{array}$ & $\begin{array}{l}3,316(3) \\
3,329(3) \\
3,342(3)\end{array}$ & $\begin{array}{l}2,425(7) \\
2,416(7) \\
2,400(8)\end{array}$ & $2,06(2)$ \\
\hline$\left[\mathrm{Ru}_{2} \mathrm{NiO}(\mathrm{OAc})_{6}(\mathrm{py})_{3}\right] \cdot \mathrm{py}^{34}$ & $1,9318(7)$ & $3,346(1)$ & $2,136(6)$ & $2,054(4)$ \\
\hline$\left[\mathrm{Ru}_{2} \mathrm{CoO}(\mathrm{OAC})_{6}(\mathrm{py})_{3}\right] . \mathrm{py}^{34}$ & $1,9394(8)$ & $3,359(1)$ & $2,174(5)$ & $2,061(3)$ \\
\hline$\left[\mathrm{Ru}_{3} \mathrm{O}(\mathrm{OAc})_{6}(\mathrm{py})_{2}(\mathrm{CNXy})\right] \cdot 2 \mathrm{HCCl}_{3} 66$ & $\begin{array}{l}2,035(3) \\
1,888(1)\end{array}$ & $\begin{array}{l}3,3909(4) \\
3,2840(7)\end{array}$ & $\begin{array}{l}1,880(5) \\
2,139(3)\end{array}$ & $\begin{array}{l}2,073(3) \\
2,043(3)\end{array}$ \\
\hline$\left[\mathrm{Ru}_{3} \mathrm{O}(\mathrm{OAc})_{6}\left(\mathrm{mbpy}^{+}\right)_{2}(\mathrm{CO})\right]\left(\mathrm{ClO}_{4}\right)_{2} .2 \mathrm{DMF}^{58}$ & $\begin{array}{l}2,039(11) \\
1,894(6)\end{array}$ & $\begin{array}{l}3,410(2) \\
3,276(2)\end{array}$ & $\begin{array}{l}1,839(20) \\
2,126(10)\end{array}$ & $2,044(5)$ \\
\hline \multicolumn{5}{|c|}{ Estados formais de oxidação III,III,III } \\
\hline$\left[\mathrm{Ru}_{3} \mathrm{O}(\mathrm{HCOO})_{6}\left(\mathrm{H}_{2} \mathrm{O}\right)_{3}\right] \mathrm{BF}_{4 \cdot 3 \mathrm{H}_{2} \mathrm{O}^{25}}$ & $1,93(2)$ & $3,33(1)$ & $2,09(2)$ & $2,035(2)$ \\
\hline$\left[\mathrm{Ru}_{3} \mathrm{O}(\mathrm{OAc})_{6}\left(\mathrm{H}_{2} \mathrm{O}\right)_{3}\right] \mathrm{BF}_{4} \cdot 2 \mathrm{H}_{2} \mathrm{O}^{25}$ & $\begin{array}{l}1,890(1) \\
1,910(1) \\
1,916(9)\end{array}$ & $\begin{array}{l}3,322(2) \\
3,294(2) \\
3,288(2)\end{array}$ & $\begin{array}{l}2,120(1) \\
2,130(1) \\
2,140(1)\end{array}$ & $2,03(1)$ \\
\hline$\left[\mathrm{Ru}_{3} \mathrm{O}(\mathrm{OAC})_{6}\left(\mathrm{H}_{2} \mathrm{O}\right)_{3}\right] \mathrm{ClO}_{4} \cdot 2 \mathrm{H}_{2} \mathrm{O}^{64}$ & $\begin{array}{l}1,906(6) \\
1,912(7) \\
1,904(6)\end{array}$ & $\begin{array}{l}3,305(1) \\
3,296(1) \\
3,310(1)\end{array}$ & $\begin{array}{l}2,121(7) \\
2,107(8) \\
2,089(8)\end{array}$ & $1,999(2)$ \\
\hline$\left[\mathrm{Ru}_{3} \mathrm{O}\left(\mathrm{H}_{5} \mathrm{C}_{2} \mathrm{COO}\right)_{6}(\mathrm{py})_{3}\right] \mathrm{PF}_{6} 29$ & $\begin{array}{l}1,921(8) \\
1,94 \text { (2) }\end{array}$ & $3,340(3)$ & $\begin{array}{l}2,10(2) \\
2,13(2)\end{array}$ & 2,022 \\
\hline$\left[\mathrm{Ru}_{3} \mathrm{O}\left(\mathrm{H}_{5} \mathrm{C}_{6} \mathrm{COO}\right)_{6}(\mathrm{py})_{3}\right] \mathrm{PF}_{6} 31$ & $1,935(2)$ & $3,350(2)$ & $2,134(8)$ & $2,019(6)$ \\
\hline \multicolumn{5}{|c|}{ Estados formais de oxidação IV,III,III } \\
\hline$\left[\mathrm{Ru}_{3} \mathrm{O}(\mathrm{OAC})_{6}\left(\mathrm{H}_{2} \mathrm{O}\right)_{3}\right]\left(\mathrm{ClO}_{4}\right)_{2} \cdot \mathrm{H}_{2} \mathrm{O}^{25}$ & $\begin{array}{l}1,939(25) \\
1,976(25) \\
1,801(40)\end{array}$ & $\begin{array}{l}3,299(5) \\
3,299(6) \\
3,295(6)\end{array}$ & $\begin{array}{l}2,130(21) \\
2,134(20) \\
2,008(43)\end{array}$ & 2,02 \\
\hline
\end{tabular}

$\mathrm{Na}$ ausência de dados de difração de raios- $\mathrm{X}$, a técnica de $\mathrm{RMN}$ tem sido muito utilizada na caracterização deste tipo de composto $\left({ }^{1} H^{26,27,31,37,40,41,50,57,58,61,62,67-71}\right.$, ${ }^{13} \mathrm{C}^{31,41,43,61,70},{ }^{19} \mathrm{~F}^{30,72}$ ). Na tabela 1.2 encontram-se valores de deslocamento químico de ${ }^{1} \mathrm{H}$ para os grupos acetato e piridina observados em clusters que têm em comum o ligante piridina. Pode-se observar que para os clusters simétricos os grupos metila são equivalentes, produzindo um único sinal. Essa equivalência é quebrada nos clusters assimétricos e nos heteronucleares, gerando mais de um sinal e permitindo uma diferenciação entre estes e os simétricos. Observa-se também que os paramagnéticos (compostos 1 a 6 ) apresentam os sinais dos grupos metila em frequências maiores que os diamagnéticos (compostos 7,9 a 12). Um deslocamento anômalo de sinais é observado para o cluster heteronuclear de rutênio e cobalto (compostos 8 e 13). Estudos mostraram que os sinais dos grupos metila variam também em função do $\mathrm{pKa}$ do ligante terminal ${ }^{61}$ (compostos 2 a 5). 
Tabela 1.2 - Valores de deslocamento químico $(\delta \mathrm{em} \mathrm{ppm})$ de ${ }^{1} \mathrm{H}$ para clusters de acetato de rutênio em : a) $\mathrm{CD}_{3} \mathrm{CN}$; b) $\mathrm{CD}_{2} \mathrm{Cl}_{2}$; c) $\mathrm{D}_{2} \mathrm{O}$.

\begin{tabular}{|c|c|c|c|c|c|}
\hline Composto & $\delta\left(\mathrm{CH}_{3}\right)$ & $\delta\left(\mathrm{H}_{\alpha} \mathrm{py}\right)$ & $\delta\left(\mathrm{H}_{\beta} \mathrm{py}\right)$ & $\delta\left(\mathrm{H}_{\gamma} \mathrm{py}\right)$ & Ref \\
\hline \multicolumn{6}{|c|}{ Estados formais de oxidação III, III, III } \\
\hline (1) $\left[\mathrm{Ru}_{3} \mathrm{O}(\mathrm{OAc})_{6}(\mathrm{py})_{3}\right] \mathrm{PF}_{6}{ }^{\mathrm{a}}$ & 4.82 & 0.25 & 5.82 & 6.57 & 61 \\
\hline \multirow[t]{2}{*}{ (2) $\left[\mathrm{Ru}_{3} \mathrm{O}(\mathrm{OAc})_{6}(\mathrm{py})_{2}(\mathrm{pz})\right] \mathrm{PF}_{6}^{\mathrm{a}}$} & 5.48 & 0.20 & 5.67 & 6.68 & 69 \\
\hline & 5.14 & & & & \\
\hline \multirow[t]{2}{*}{ (3) $\left[\mathrm{Ru}_{3} \mathrm{O}(\mathrm{OAc})_{6}(\mathrm{py})_{2}(\mathrm{acpy})\right] \mathrm{PF}_{6}{ }^{a}$} & 5.07 & 0.28 & 5.77 & 6.60 & 61 \\
\hline & 4.92 & & & & \\
\hline \multirow[t]{2}{*}{ (4) $\left[\mathrm{Ru}_{3} \mathrm{O}(\mathrm{OAc})_{6}(\mathrm{py})_{2}(\right.$ bipy $\left.)\right] \mathrm{PF}_{6}{ }^{\mathrm{a}}$} & 5.00 & 0.13 & 5.75 & 6.57 & 61 \\
\hline & 4.89 & & & & \\
\hline \multirow[t]{2}{*}{ (5) $\left[\mathrm{Ru}_{3} \mathrm{O}(\mathrm{OAc})_{6}(\mathrm{py})_{2}(\mathrm{vpy}) \mathrm{PF}_{6}^{\mathrm{a}}\right.$} & 4.83 & 0.17 & 5.81 & 6.50 & 61 \\
\hline & 4.79 & & & & \\
\hline \multirow[t]{2}{*}{ (6) $\left[\mathrm{Ru}_{3} \mathrm{O}(\mathrm{OAc})_{6}\left(\mathrm{mbpy}^{+}\right)_{2}(\mathrm{py})\right]\left(\mathrm{ClO}_{4}\right)_{3}{ }^{a}$} & 5.04 & 0.15 & 5.65 & 6.61 & 58 \\
\hline & 5.29 & & & & \\
\hline \multirow[t]{2}{*}{ (7) $\left[\mathrm{Ru}_{2} \mathrm{RhO}(\mathrm{OAc})_{6}(\mathrm{py})_{3}\right] \mathrm{ClO}_{4}{ }^{\mathrm{b}}$} & 1.96 & 8.91 & 7.74 & 8.14 & 41 \\
\hline & 2.42 & 8.60 & 7.96 & 8.11 & \\
\hline \multirow[t]{2}{*}{ (8) $\left.\left[\mathrm{Ru}_{2} \mathrm{CoO}(\mathrm{OAc})_{6}(\mathrm{py})_{3}\right]\right]_{3}^{\mathrm{b}}$} & 0.10 & 9.79 & 17.6 & 3.80 & 37 \\
\hline & 12.55 & 6.30 & 7.88 & 7.30 & \\
\hline \multicolumn{6}{|c|}{ Estados formais de oxidação III, III, II } \\
\hline$(9)\left[\mathrm{Ru}_{3} \mathrm{O}(\mathrm{OAc})_{6}(\mathrm{py})_{3}\right]^{0}$ & 2.14 & 9.02 & 7.69 & 7.99 & 27 \\
\hline \multirow[t]{2}{*}{ (10) $\left[\mathrm{Ru}_{3} \mathrm{O}(\mathrm{OAc})_{6}(\mathrm{py})_{2}(\mathrm{CO})\right]^{\mathrm{a}}$} & 2.10 & 9.14 & 8.13 & 8.31 & 70 \\
\hline & 2.16 & & & & \\
\hline \multirow[t]{2}{*}{ (11) $\left[\mathrm{Ru}_{3} \mathrm{O}(\mathrm{OAc})_{6}(\mathrm{py})_{2}(\mathrm{pz})\right]^{\mathrm{b}}$} & 2.04 & 9.30 & 7.79 & 8.03 & 27 \\
\hline & 2.09 & & & & \\
\hline \multirow[t]{3}{*}{ (12) $\left[\mathrm{Ru}_{3} \mathrm{O}(\mathrm{OAc})_{6}\left(\mathrm{H}_{2} \mathrm{O}\right)(\mathrm{py})(\mathrm{CO})\right]^{\mathrm{c}}$} & 1.99 & 9.62 & 8.27 & 8.61 & 62 \\
\hline & 1.97 & & & & \\
\hline & 1.76 & & & & \\
\hline \multirow[t]{2}{*}{ (13) $\left[\mathrm{Ru}_{2} \mathrm{CoO}(\mathrm{OAc})_{6}(\mathrm{py})_{3}\right]^{\mathrm{b}}$} & -5.42 & 12.65 & 10.40 & 9.01 & 37 \\
\hline & 29.27 & & & & \\
\hline
\end{tabular}

Os sinais das piridinas dos clusters paramagnéticos apresentam-se deslocados para menores frequências em relação ao ligante livre $\left(8,51\left(\mathrm{H}_{\text {orto }}\right), 7,14\left(\mathrm{H}_{\text {meta }}\right)\right.$ e 7,55 $\left(H_{\text {para }}\right)$ ), enquanto o oposto é observado nos compostos diamagnéticos. Tal fato foi interpretado em termos da anisotropia paramagnética da unidade $\mathrm{Ru}_{3} \mathrm{O}^{68,69}$.

Apesar do número de trabalhos utilizando espectros $\mathrm{RMN}-{ }^{13} \mathrm{C}$ na caracterização dos compostos ser pequeno, pôde-se observar que o pKa do ligante terminal também exerce influência nos sinais ${ }^{61}$. A atribuição dos sinais do espectro não é direta e interpretações errôneas podem ocorrer se técnicas bidimensionais (como ${ }^{1} \mathrm{H} \times{ }^{13} \mathrm{C}$ 
HETCOR e HMBC) não forem utilizadas, visto que nem todos os efeitos observados para o hidrogênio são notados no espectro de carbono ${ }^{73}$.

\subsubsection{Espectro eletrônico.}

Cotton e Norman ${ }^{67}$ propuseram um diagrama de orbitais moleculares qualitativo para o sistema eletrônico $\pi$ do cluster $\left[\mathrm{Ru}_{3} \mathrm{O}(\mathrm{OAc})_{6}\left(\mathrm{PPh}_{3}\right)_{3}\right]$ quando da elucidação de sua estrutura por difração de raios- $\mathrm{X}$. Consideraram o sistema $\mathrm{Ru}_{3} \mathrm{O}$ como uma unidade no grupo de ponto $D_{3 h}$, com o eixo $C_{3}$ coincidente com o eixo $z-$ um orbital $\sigma$ de simetria apropriada sobre cada metal poderia combinar-se com um orbital $\mathrm{sp}^{2}$ do oxigênio formando a estrutura $\sigma ; 5$ orbitais sobre cada metal seriam usados também em ligações $\sigma$ com os oxigênios dos acetatos em ponte e com o fósforo dos ligantes terminais. Restariam, então, 3 orbitais d sobre cada metal: um destes seria capaz de formar uma combinação linear com um mesmo tipo de orbital d sobre cada um dos outros dois íons de rutênio; esta combinação teria simetria apropriada para interação com o orbital $p$ não hibridizado do oxigênio, conduzindo a dois orbitais moleculares, um ligante e um anti-ligante. As outras oito combinações dos orbitais d seriam não-ligantes com respeito à interaçăo metal-oxigênio. Assim, o diagrama resultante para o sistema $\pi$ da unidade $\mathrm{Ru}_{3} \mathrm{O}$ apresentaria um orbital fortemente ligante, um fortemente anti-ligante e oito essencialmente não-ligantes. Os 16 elétrons dos 3 íns de rutênio e os 2 elétrons do oxigênio central preencheriam todos estes orbitais, exceto o antiligante, o que justificaria o diamagnetismo observado para o composto e sua particular estabilidade. Posteriormente, Meyer et $a f^{27}$ apresentaram um diagrama mais detalhado para o sistema $\pi$ dos clusters simétricos $\left[R u_{3} \mathrm{O}(\mathrm{OAc})_{6}(\mathrm{~L})_{3}\right]^{\mathrm{n}}\left(\mathrm{L}=\mathrm{py}, \mathrm{pz}, 4,4^{\prime}\right.$-bipy, trans1,2-bis(4-piridil)etileno e 1,2-bis(4-piridil)etano, admitindo que as suas estruturas fossem análogas à de $\left.\left[\mathrm{Ru}_{3} \mathrm{O}(\mathrm{OAc})_{6}\right)\left(\mathrm{PPh}_{3}\right)_{3}\right]$.

Cunha $^{74}$, que sintetizou vários outros clusters simétricos de acetato de rutênio, utilizou o mesmo diagrama qualitativo na interpretação dos espectros eletrônicos, incluindo a participação dos orbitais $\pi^{*}$ dos ligantes $\mathrm{N}$-heterocíclicos. Alexiou ${ }^{75}$ também utilizou este diagrama e seu desdobramento para a simetria $C_{2 v}$ na interpretação dos espectros eletrônicos dos clusters assimétricos $\left[\mathrm{Ru}_{3} \mathrm{O}(\mathrm{OAc})_{6}(\mathrm{~L})_{2}\left(\mathrm{~L}^{\prime}\right)\right]^{\mathrm{n}}$. A figura 1.6 apresenta estes diagramas bem como o sistema de coordenadas utilizado para obtêlos. O sistema de eixos e orbitais foi escolhido de maneira a enfatizar a importância da mistura Ru-O-Ru. 


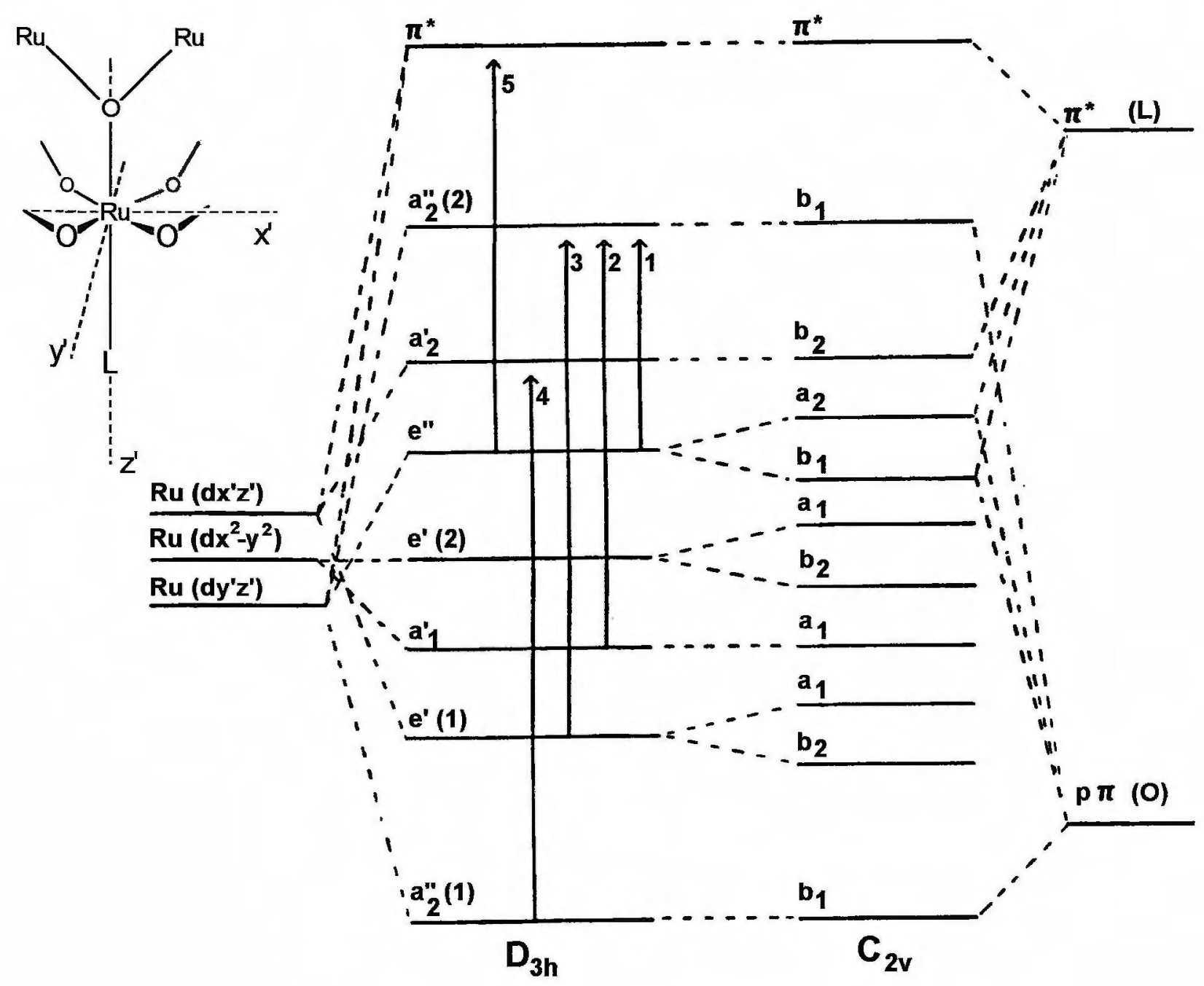

Figura 1.6 - Diagrama qualitativo de orbitais moleculares para o sistema $\pi$ de clusters trinucleares de rutênio em simetria $\mathrm{D}_{3 \mathrm{~h}}$ e $\mathrm{C}_{2 \mathrm{v}}$, com o sistema de coordenadas utilizado.

A respeito deste diagrama:

a) Em simetria $D_{3 h}$ as combinações entre orbitais $\mathrm{d}_{z^{\prime} y^{\prime}}$ (metal) e $\mathrm{p}_{z}$ (oxigênio) (esquema 1.2) dão origem a dois orbitais $a_{2}{ }^{n}$, enquanto combinações $d_{z^{\prime} y^{\prime}}-d_{z^{\prime} y^{\prime}}$ originam orbitais $e^{\prime \prime} ; a_{2}{ }^{\prime \prime}$ (1) de mais baixa energia (ligante) tem maior caráter de oxigênio, $\circ$ par de orbitais degenerados $e^{\prime \prime}$ é não-ligante, e $a_{2}{ }^{\prime \prime}$ (2) de energia mais elevada (antiligante) tem maior caráter de Ru.

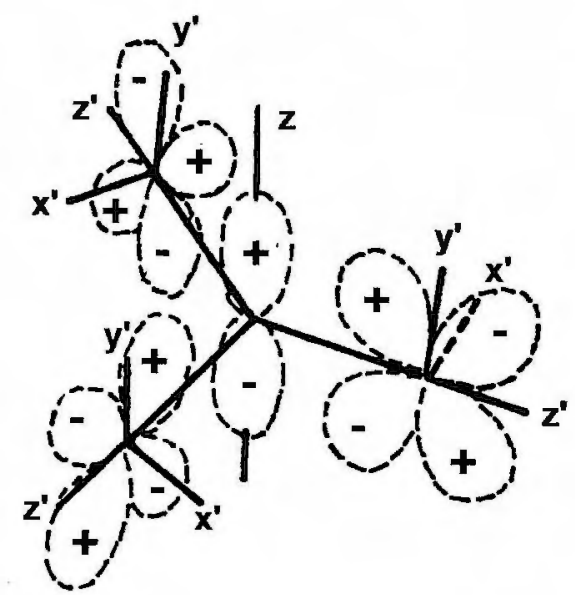

Esquema 1.2 
b) As combinações Ru-Ru podem ser construídas combinando-se orbitais $d_{x z^{\prime}}-d_{x^{\prime} z^{\prime}}$ localizados nos três sítios Ru (esquema 1.3). Os orbitais são direcionados um ao outro e sua combinação em simetria $D_{3 h}$ origina os degenerados e' (1) (ligação metal-metal) e o antiligante $a_{2}^{\prime}$, localizados no mesmo plano dos híbridos $\mathrm{sp}^{2}$ do oxigênio; assume-se, porém, que estes participam apenas do sistema $\sigma$. A colocação de $a_{2}^{\prime}$ em maior energia em relação a e" é arbitrária, tendo sido justificada por dados espectrais $^{27,74}$.

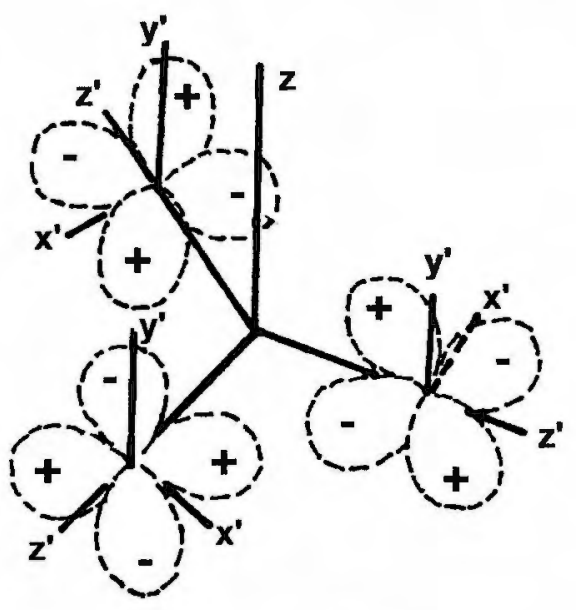

Esquema 1.3

c) Os orbitais restantes $\left(d_{x^{2}}{ }^{2}-y^{2}\right)$ são de simetria apropriada para interagir, mas estão separados consideravelmente (esquema 1.4). Estes mesmos orbitais podem também interagir por simetria com os orbitais $p$ localizados sobre os átomos de oxigênio dos acetatos em ponte, o que proporcionaria um mecanismo adicional para a interação Ru-Ru. Dadas as distâncias relativas envolvidas, assume-se que este último mecanismo tem pouca importância quando comparado às interações Ru-O-Ru e Ru-Ru, sendo suficiente, no entanto, para remover a degenerescência dos três orbitais $d_{x^{2}}{ }^{2} y^{2}$, o que origina o par degenerado $e^{\prime}$ (2) e o $a_{1}{ }^{\prime}$. A combinação dos orbitais $d_{x^{\prime} z^{\prime}}$ e $d_{z^{\prime} y^{\prime}}$ com os orbitais $p$ dos oxigênios dos acetatos em ponte também pode ocorrer, mas o efeito é considerado pequeno, sendo negligenciado na construção do diagrama.

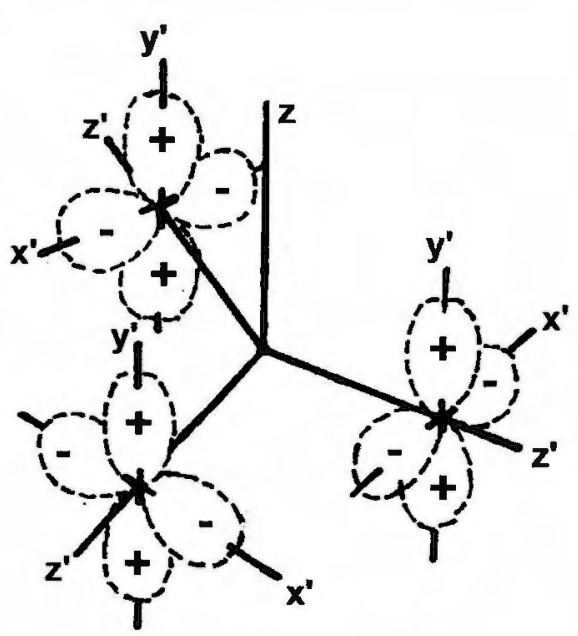

Esquema 1.4

d) Os ligantes $\mathrm{N}$-heterocíclicos tem orbitais $\pi$ e $\pi^{*}$ de simetria apropriada para que ocorra sobreposição com orbitais d dos íons de Ru. Se o plano do ligante é paralelo ao plano da unidade $\mathrm{Ru}_{3} \mathrm{O}$, interações ocorrem com os orbitais $\mathrm{a}_{2}$ " e e". Se o plano do ligante é perpendicular, interações ocorrem com $a_{2}^{\prime}$ ou e'. Uma vez que os ligantes têm provavelmente rotação livre em solução à temperatura ambiente, todos os quatro orbitais devem ser de alguma forma afetados. 
Como exemplo, a figura 1.7 apresenta o espectro eletrônico de $\left[\mathrm{Ru}_{3} \mathrm{O}(\mathrm{OAc})_{6}(\mathrm{py})_{3}\right]^{+}$em $\mathrm{CH}_{3} \mathrm{CN}^{74}$, com a decomposição em cinco bandas (a numeração refere-se às transições indicadas no diagrama da figura 1.6). A banda 1 foi atribuída à transição $A_{2}{ }^{\prime} \rightarrow E^{\prime}$, orbitalmente permitida $(x, y)$ em $D_{3 h}$; a banda 2 foi atribuída à

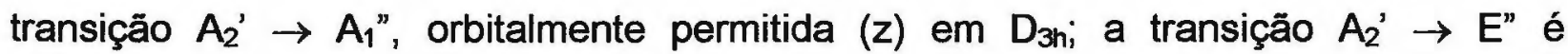
orbitalmente proibida em $D_{3 h}$, mas a transição $B_{2} \rightarrow A_{2}$ é permitida $(x)$ em $C_{2 v}$ o que levou Meyer et $a F^{27}$ a sugerirem que a origem da intensidade da banda 3 poderia advir de pequenas distorções. $A$ banda 4 , de menor intensidade, foi atribuída à transição $A_{2}{ }^{\prime}$ $\rightarrow A_{2}$ ", orbitalmente proibida em $D_{3 h}$ e $C_{2 v}$. $A$ banda 5 foi relacionada a uma transição de transferência de carga metal-ligante (TCML). No que diz respeito aos clusters heteronucleares, diagramas de orbitais moleculares similares são utilizados na interpretação dos espectros eletrônicos $37,40,41$.

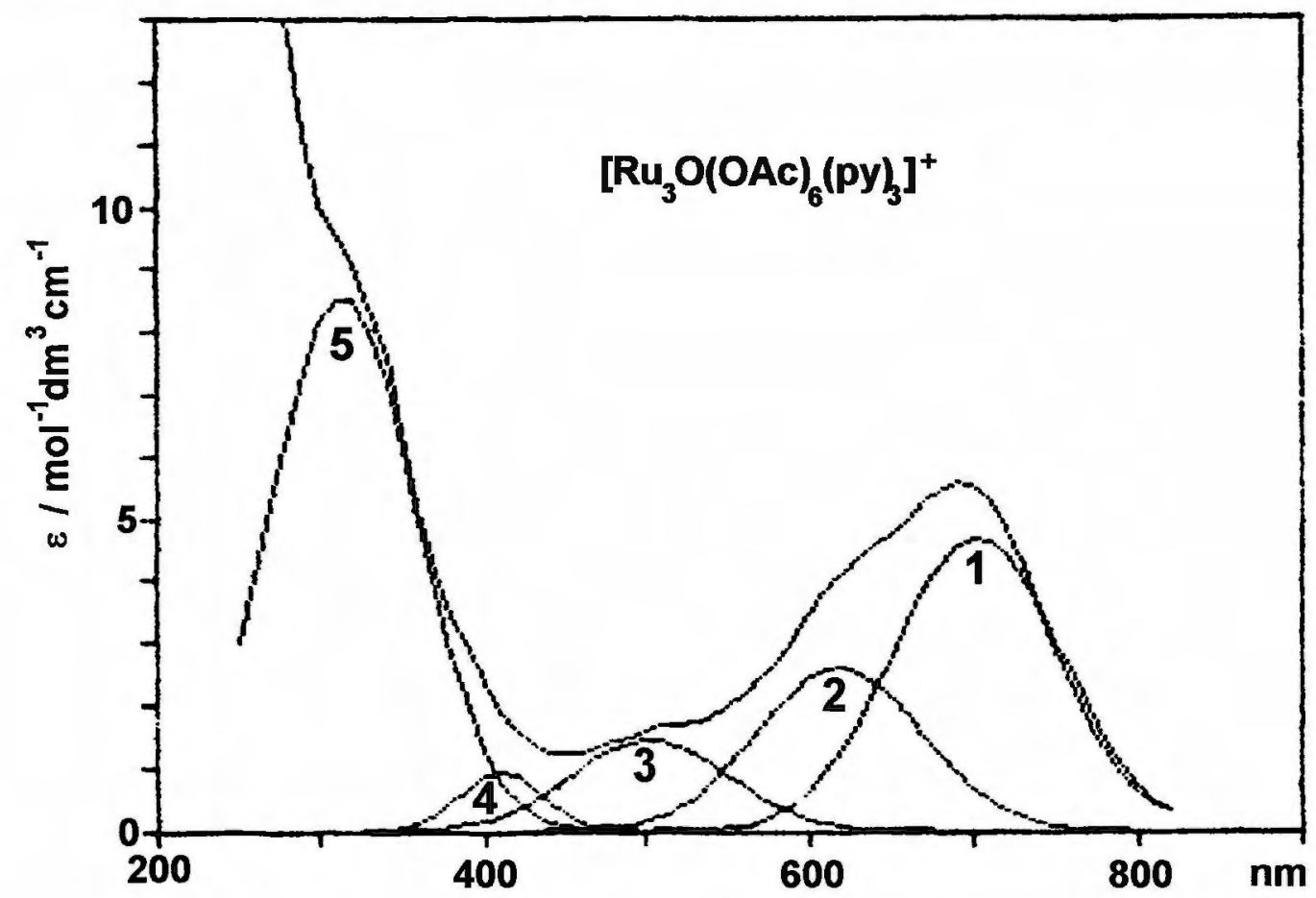

Figura 1.7 - Espectro eletrônico de $\left[\mathrm{Ru}_{3} \mathrm{O}(\mathrm{OAc})_{6}(\mathrm{py})_{3}\right]^{+}$em $\mathrm{CH}_{3} \mathrm{CN}^{74}$. Os números sob as bandas resultantes da decomposição referem-se às transições indicadas no diagrama da figura 1.6 .

Medidas de momento magnético efetivo foram feitas na década de $70^{26,50,76,77} \mathrm{e}$ mostraram que os compostos de valência mista (III,III,II) são diamagnéticos, enquanto os homovalentes (III,III,III) são paramagnéticos. Esta constatação contribuiu para a construção do diagrama de orbitais moleculares descrito acima. Nos últimos anos as 
propriedades magnéticas voltaram a ser estudadas, tanto de clusters homonucleares como de clusters heteronucleares, com o objetivo de se compreender melhor as interações $M-M$ nestes compostos ${ }^{3439,78}$. Verificou-se que os átomos de rutênio apresentam fortes interações de troca antiferromagnéticas via ponte $\mu_{3}-\mathrm{O}$, sendo a interação via $\mu_{2}-\mathrm{CH}_{3} \mathrm{CO}_{2}^{-}$fraca; em clusters do tipo $\mathrm{Ru}_{2} \mathrm{M}$ envolvendo íons da primeira série de transição, observou-se que $\mathrm{M}$ comporta-se como um íon magneticamente isolado, tendo uma interação fraca com os íons de rutênio.

\subsubsection{Comportamento eletroquímico.}

Os clusters trinucleares de rutênio possuem vários estados de oxidação acessiveis química e eletroquimicamente ${ }^{26-28,40,51-53,55,58-60,68,76,79-82}$. Os voltamogramas cíclicos apresentam uma série de ondas monoeletrônicas reversíveis atribuídas a pares redox sucessivos, de Ru", Ru", Ru" a Ru' ${ }^{\prime \prime}, R^{\prime \prime}$, Ru" (figura 1.8). Essas ondas exibem uma separação de aproximadamente $1 \mathrm{~V}$, caracterizando um sistema deslocalizado com forte interação entre os íons metálicos. O potencial associado a cada par redox

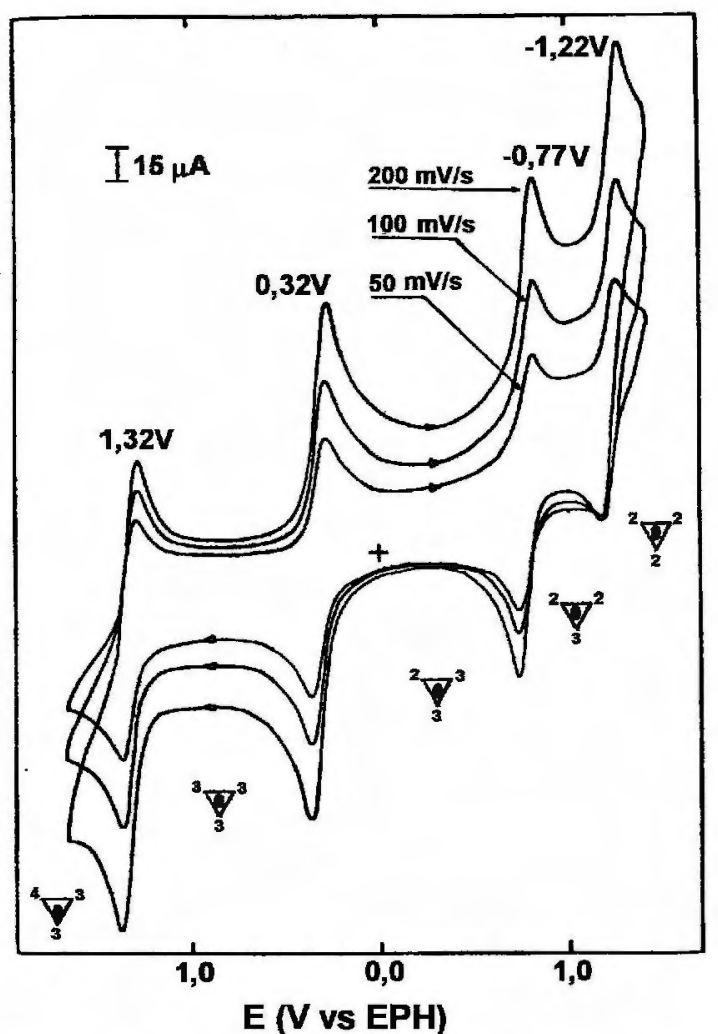
depende do caráter doador do ligante $\mathbf{N}$ heterocíclico $^{28,55}$ e do substituinte do íon carboxilato $^{31,40}$, permitindo sua modulação. Um número maior de ondas é obtido quando - ligante $\mathrm{L}$ apresenta isomeria de ligação (como no caso do dimetilsulfóxido ${ }^{59}$ ), ou é eletroquimicamente ativo (como no caso do cluster contendo ligantes $\mathrm{mbpy}^{+}$, em que observou-se um desdobramento nos pares redox correspondentes a estes ligantes, devido ao seu acoplamento eletrônico via orbitais $\left.\mathrm{Ru}(\mathrm{d} \pi)-\left(\mu_{3}-\mathrm{O}\right)(\mathrm{p} \pi)-\mathrm{Ru}(\mathrm{d} \pi)^{40,58}\right)$.

Figura 1.8 - Voltamogramas cíclicos do cluster $\left[\mathrm{Ru}_{3} \mathrm{O}(\mathrm{OAc})_{6}(\mathrm{pz})_{3}\right]^{\mathrm{n}}$ em $\mathrm{CH}_{3} \mathrm{CN}$ (perclorato de tetra-etilamônio, $\mathrm{TEACIO}_{4}, 0,1 \mathrm{~mol} \mathrm{dm}^{-3}$ como eletrólito suporte) a diferentes velocidades de varredura ${ }^{28}$. 
A partir dos valores de potenciais redox, foi possível calcular constantes de comproporcionamento $\left(\mathrm{K}_{\mathrm{com}}\right)$ para os clusters $\left[\mathrm{Ru}_{3} \mathrm{O}(\mathrm{OAc})_{6}(\mathrm{py})_{3}\right]$ e $\left[\mathrm{R} \mathrm{u}_{3} \mathrm{O}(\mathrm{OAc})_{6}(\mathrm{py})_{3}\right]^{2+}$ através da equação $K_{\text {com }}=\exp (F \Delta E / R T)$, onde $\Delta E$ representa, para $\left[R u_{3} O(O A c)_{6}(p y)_{3}\right]$, a separação entre os potenciais redox dos pares $\mathrm{Ru}^{\mathrm{III}}, \mathrm{Ru}^{\mathrm{III}}, \mathrm{Ru}^{\mathrm{III}} / \mathrm{Ru^{ \prime \prime \prime }}, \mathrm{Ru^{ \prime \prime \prime }}, \mathrm{Ru^{ \prime \prime }}$ e $\mathrm{Ru}^{\mathrm{III}}$, $\mathrm{Ru}^{\prime \prime \prime}, \mathrm{Ru}^{\prime \prime} / \mathrm{Ru}^{\prime \prime \prime}, \mathrm{Ru} u^{\prime \prime}, \mathrm{Ru}$ ", enquanto para $\left[\mathrm{Ru}_{3} \mathrm{O}(\mathrm{OAc})_{6}(\mathrm{py})_{3}\right]^{2+} \Delta \mathrm{E}$ refere-se à diferença

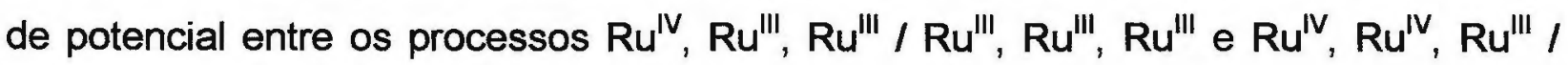

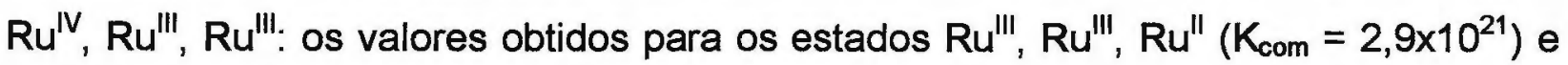
$\mathrm{Ru}^{\mathrm{IV}}, \mathrm{Ru}^{\mathrm{III}}, \mathrm{Ru}^{\mathrm{II \prime}}\left(\mathrm{K}_{\mathrm{com}}=7,7 \times 10^{15}\right)$ refletiram a grande estabilidade destes estados de valência mista ${ }^{79}$.

Em meio aquoso, observou-se que o potencial relacionado ao par redox $\mathrm{Ru}^{\mathrm{III}}$, Ru", Ru" / Ru", Ru", Ru" varia em função do $\mathrm{pH}$, ocorrendo a saída do oxigênio central em meio ácido ${ }^{40,52,81}$ em um processo reversível que pode também ser observado

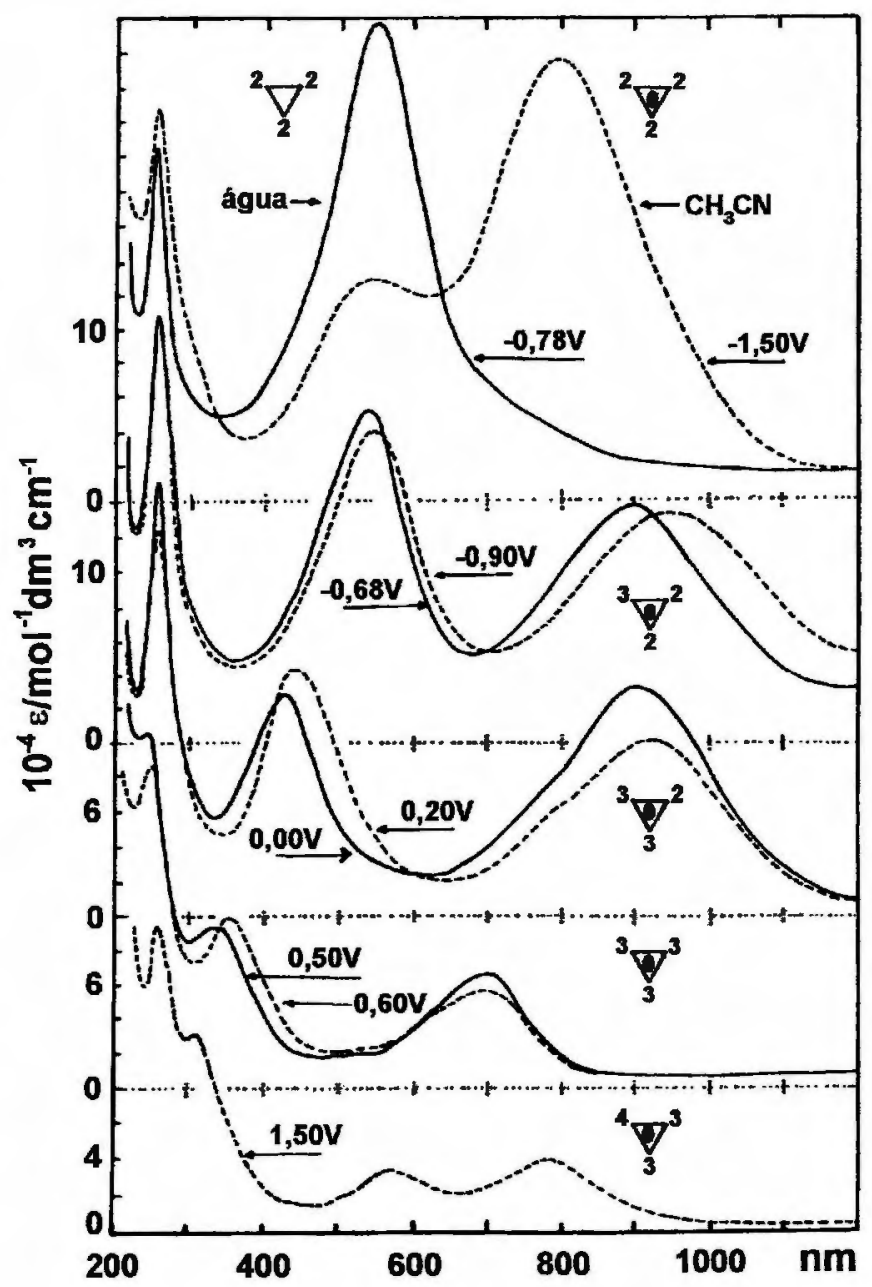
quimicamente $^{26,50}$. Esta saída do oxigênio está relacionada ao seu papel na estabilização dos orbitais dos íons de rutênio. Quando o cluster é oxidado, ocorre doação de elétrons dos orbitais $p \pi$ do oxigênio para os orbitais $\mathrm{d} \pi$ vazios do metal; com a redução do cluster, este tipo de interação não é mais possível.

$\mathrm{Na}$ figura 1.9 podemos observar que para cada estado de oxidação existe um padrão espectral diferente. De modo geral, as bandas dos clusters trinucleares de rutênio deslocam-se para comprimentos de onda maiores a medida que seu conteúdo eletrônico aumenta.

Figura 1.9 - Espectroeletroquímica do cluster $\left[\mathrm{Ru}_{3} \mathrm{O}(\mathrm{OAc})_{6}(\mathrm{pz})_{3}\right]^{\mathrm{n}}$ em água $(\mathrm{KCl} 0,1$ mol dm ${ }^{-3}$ como eletrólito suporte) e em $\mathrm{CH}_{3} \mathrm{CN}\left(\mathrm{TEAClO}_{4} 0,1 \mathrm{~mol} \mathrm{dm}^{-3}\right)^{81}$. 
O número de elétrons nos orbitais $\pi$ influi no número de bandas inter-metálicas: enquanto no estado reduzido $\mathrm{Ru}^{\prime \prime}, \mathrm{Ru}$ ", $\mathrm{Ru}^{\prime \prime}$ elas não podem mais ser observadas (segundo o diagrama da figura 1.6, este estado apresenta todos os orbitais $\pi$ preenchidos), no estado oxidado $\mathrm{Ru}^{\mathrm{IV}}$, Ru ${ }^{\mathrm{III}}, \mathrm{Ru} \mathrm{u}^{\text {III }}$ ocorre uma banda adicional (segundo o mesmo diagrama, este estado exibe dois níveis vacantes, podendo ser observada uma segunda transição metal-metal)

As propriedades espectrais e redox dos clusters trinucleares de rutênio imobilizados em matrizes poliméricas são mantidas, tais como sílica-gel ${ }^{60}$, e em eletrodos modificados com polipirrol ${ }^{53}$, poli(4-vinilpiridina) ${ }^{82}$ e penta-cianoferratos ${ }^{83}$.

\subsubsection{Supermoléculas: clusters trinucleares de rutênio como unidades estruturais.}

A auto-estruturação ("self-assembly") via ligantes em ponte representa a forma mais simples de obtenção de sistemas organizados ${ }^{10}$. Desta forma, utilizando principalmente pirazina e $4,4^{\prime}$-bipiridina, foram obtidos dímeros ${ }^{56,63,66,84,85}$ (esquema 1.5), trímeros ${ }^{86}$ (esquema 1.6) e tetrâmeros ${ }^{68,69}$ (esquema 1.7) de clusters.

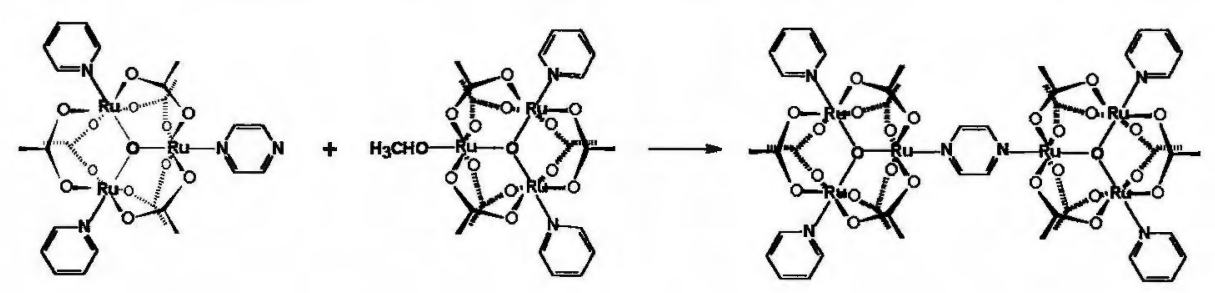

Esquema 1.5

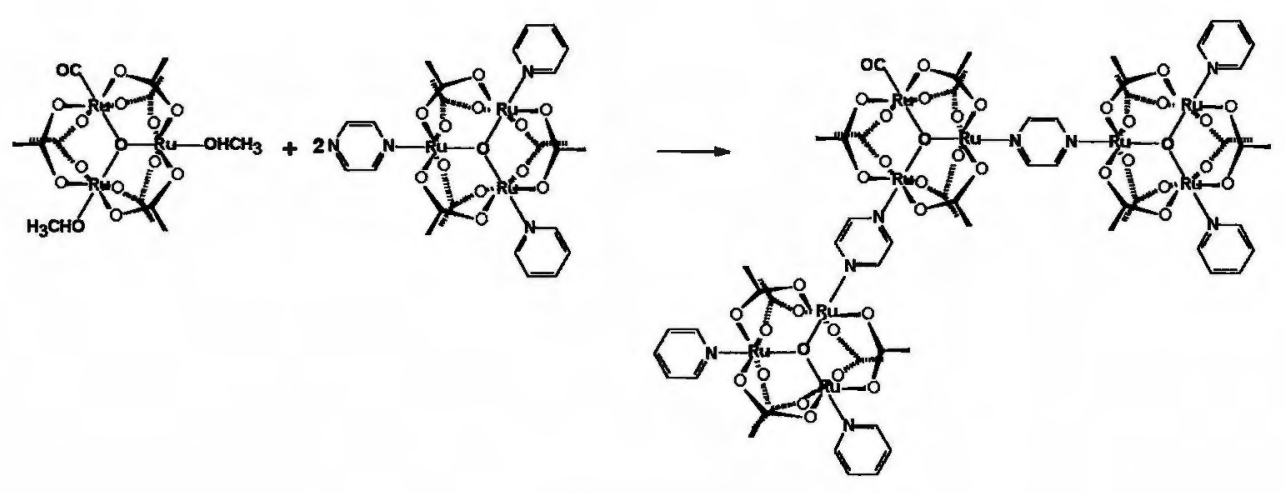

Esquema 1.6 


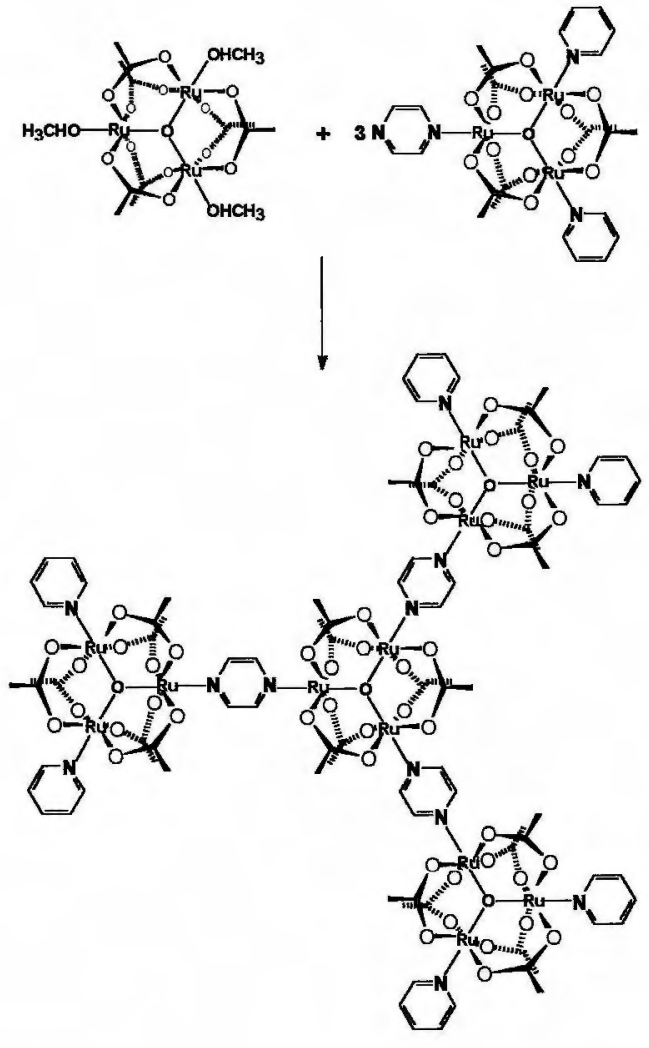

Esquema 1.7

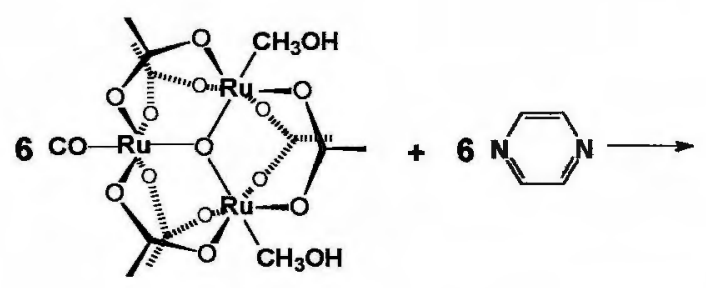

Esquema 1.9

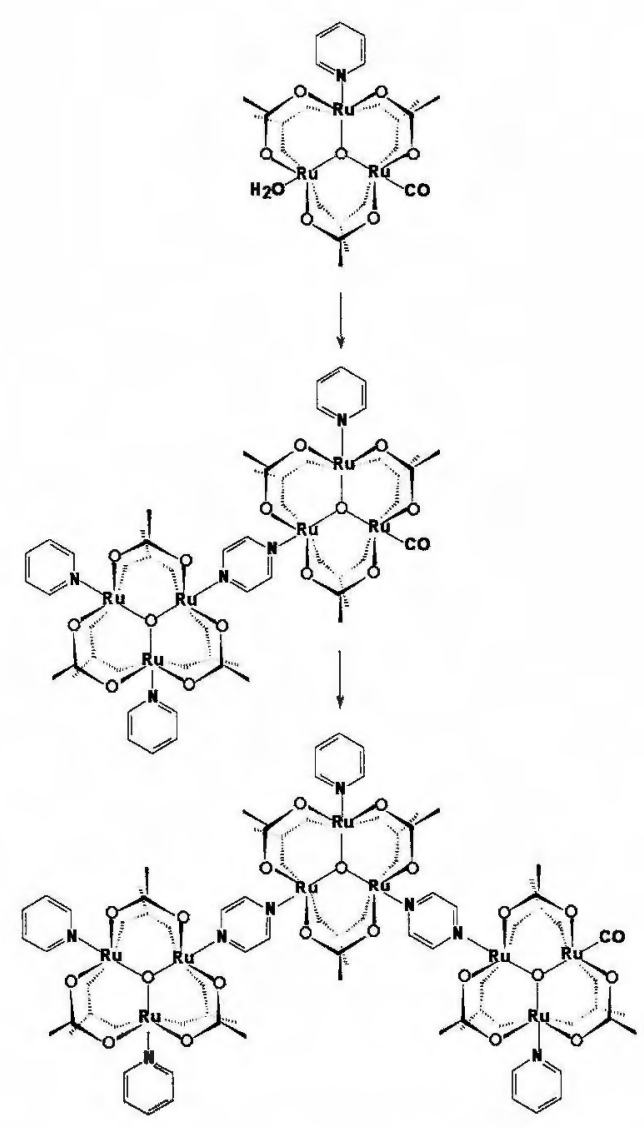

Esquema 1.8

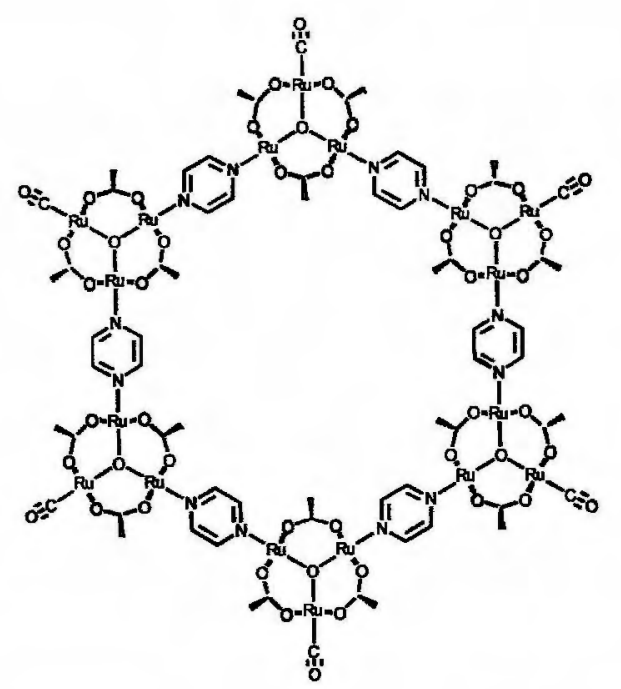

A estratégia de síntese destes compostos envolve a reação de um cluster contendo um sítio lábil e outro com um ligante de ponte. Alternativamente, pode-se utilizar um cluster totalmente assimétrico possuindo um sítio inerte, um lábil e um fotodissociável, como em $\left[\mathrm{Ru}_{3} \mathrm{O}(\mathrm{OAc})_{6}\left(\mathrm{H}_{2} \mathrm{O}\right)(\mathrm{CO})(\mathrm{py})\right]$, de modo a permitir a construção de oligômeros ${ }^{62}$ (esquema 1.8). Recentemente foi relatada a síntese e caracterização de um hexâmero cíclico, a partir de um cluster assimétrico com 2 ligantes lábeis e pirazina $^{87}$ (esquema 1.9). 
No caso dos dímeros, as formas oxidada e reduzida, incluindo as espécies de valência mista, podem ser obtidas química ou eletroquimicamente. Além da química redox tipicamente reversível das unidades individuais, o comportamento eletroquímico reflete também a extensão da interação entre os clusters através do ligante em ponte, interação essa que depende do próprio ligante-ponte como da densidade eletrônica nos centros $\mathrm{Ru}_{3} \mathrm{O}$. Ela é particularmente forte no caso do dímero da ponte de pirazina, devido à sobreposição favorável entre os orbitais d dos centros $\mathrm{Ru}_{3} \mathrm{O}$ e os orbitais $\pi^{*}$ da pirazina. Por outro lado, o acoplamento eletrônico aumenta a medida que o dímero é reduzido. Para outros ligantes em ponte (4,4'-bipiridina, trans-1,2-bis(4-piridil)eteno e 1,2-bis(4piridil)etano), a interação eletrônica entre os clusters é muito menos intensa: as correspondentes espécies de valência mista comportam-se como se fossem independentes (sistemas de valência localizada) ${ }^{56}$. 0 tetrâmero indicado no esquema 1.7 apresentou um comportamento análogo: forte interação eletrônica entre as subunidades via pontes de pirazina, que aumenta a medida que cresce o conteúdo eletrônico dos centros $\mathrm{Ru}_{3} \mathrm{O}$.

O trímero indicado no esquema 1.6 foi considerado uma "esponja" de elétrons em virtude da extensão de seu comportamento eletroquímico: dez processos redox foram detectados por voltametria cíclica na faixa de potencial entre -1,47 e 2,44V.

Dos exemplos apresentados no item 1.1, referente à química supramolecular, conclui-se que a combinação de espécies moleculares exibindo propriedades complementares é de grande interesse na obtenção de modelos de catalisadores biológicos e dispositivos moleculares, e em estudos de transferência eletrônica e fotossíntese artificial ${ }^{88}$. Neste sentido, foi sintetizada a supermolécula $\left.\left[\mathrm{Ru}_{3} \mathrm{O}(\mathrm{OAC}) \propto(\mathrm{pz}) \mathrm{Ru}\left(\mathrm{NH}_{3}\right)_{5}\right\}_{3}\right]\left(\mathrm{PF}_{6}\right)_{6}$,
incorporando duas unidades distintas: o cluster central

Figura 1.10 - Estrutura de $\left[\mathrm{Ru}_{3} \mathrm{O}(\mathrm{OAc})\left\{(\mathrm{pz}) \mathrm{Fe}(\mathrm{CN}\}_{5}\right\}_{3}\right]^{9-}$. 


\subsection{Porfirinas e metaloporfirinas}

Escrever um texto genérico sobre porfirinas e metaloporfirinas não é tarefa fácil tal a grande quantidade de informações disponíveis na literatura, seja na forma de livros texto, seja na forma de artigos científicos. Assim, o texto que se segue não tem a pretensão de se constituir em uma revisão das propriedades e aplicações destes compostos, mas sim apenas um pequeno resumo de alguns tópicos, alguns gerais, outros específicos, que têm estreita relação com a presente Tese.

\subsubsection{Aspectos gerais.}

O anel básico de uma porfirina é mostrado na figura 1.11. As porfirinas

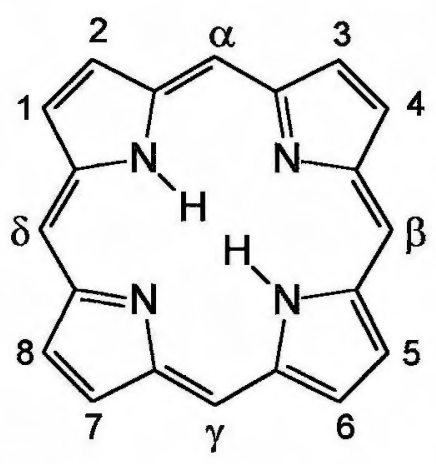
propriamente ditas são obtidas por substituição dos hidrogênios pirrólicos externos (posições 1 a 8 na figura 1.11) ou dos hidrogênios dos grupos metino $(\alpha, \beta, \delta$ e $\gamma$ ). Usa-se o termo porfina para designar 0 anel não substituído. Já a substituição dos hidrogênios ligados aos átomos de nitrogênio da porfirina denominada "porfirina base-livre", por íons de metais, conduz à obtenção das metaloporfirinas.

Figura 1.11 - Porfina.

As porfirinas agem como cofatores em uma grande variedade de processos biológicos. A metaloporfirina de maior ocorrência natural é a ferro-protoporfirina IX, também conhecida como heme (figura 1.12), o grupo prostético de um grande número de heme-proteínas que apresentam diversas funções bioquímicas: hemoglobina (transporte de $\mathrm{O}_{2}$ ), mioglobina (armazenamento de $\mathrm{O}_{2}$ ), citocromos (mediação de transferências de elétrons), catalase (decomposição de $\mathrm{H}_{2} \mathrm{O}_{2}$ ), citocromos $\mathrm{P}-450$ (hidroxilações e epoxidações, entre outras reações), etc ${ }^{90}$.

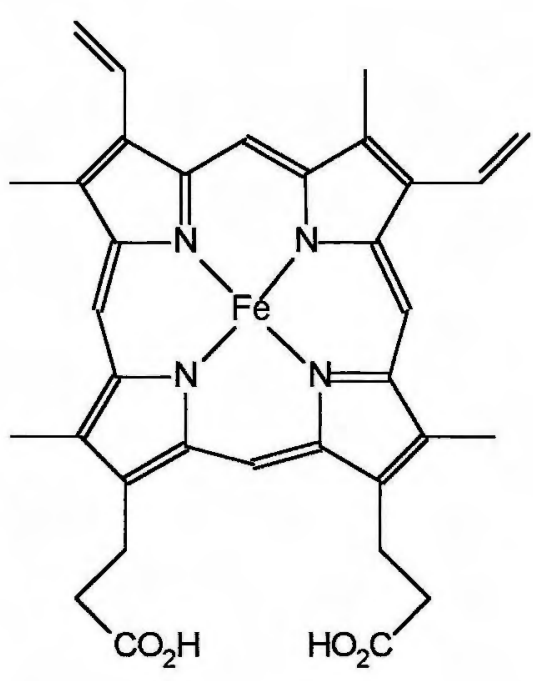

Figura 1.12 - Heme. 
A maioria das porfirinas naturais são substituídas por oito resíduos alquil ou alcenil nas posições 1 a 8 (figura 1.11), de modo semelhante ao heme. A síntese de tais compostos frequentemente consome um tempo demasiado longo, enquanto a extração de fontes naturais envolve uma laboriosa purificação. Frente a tais dificuldades, porfirinas substituídas nas posições meso por grupos aril (que são relativamente fáceis de serem sintetizadas, como a meso-tetra-fenilporfirina, TPP, figura 1.13), tem sido comumente utilizadas em estudos biomiméticos ou mesmo no desenvolvimento de novos catalisadores. Tais porfirinas foram primeiramente preparadas, em baixos rendimentos, por Rothemund a partir de pirrol e benzaldeído ${ }^{91}$. Adler et $a^{92}$ e Lindsey et $a^{93}$ aperfeiçoaram as rotas sintéticas, de modo que quantidades relativamente grandes podem ser facilmente obtidas (figura 1.14).

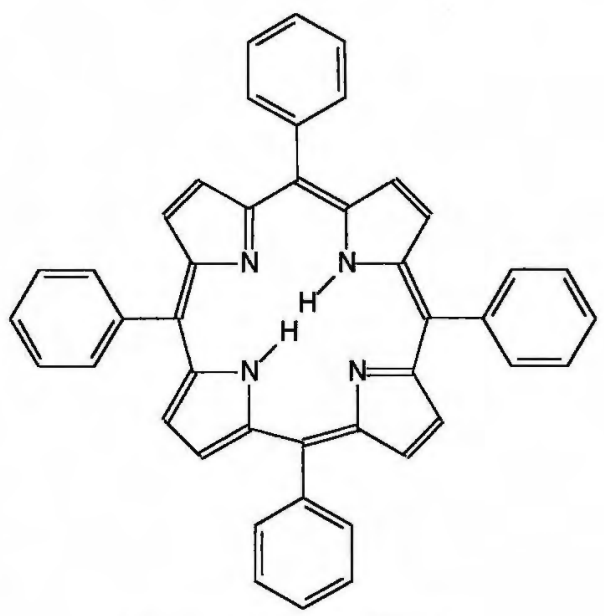

Figura 1.13 - TPP.
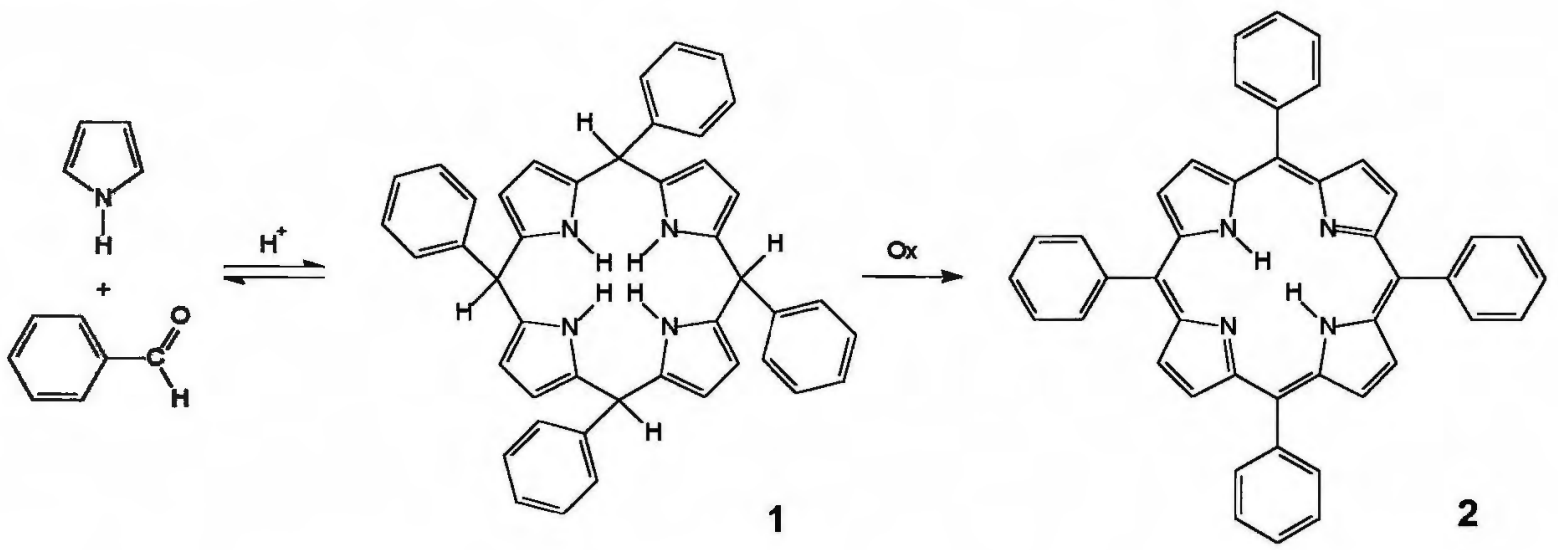

Figura 1.14 - Síntese de TPP pelo método de Lindsey ${ }^{93}$ : pirrol e benzaldeído reagem reversivelmente a temperatura ambiente, formando uma distribuição de tetra(fenil)porfirinogênio (1) e polipirrilmetanos (não mostrados); a adição de um oxidante (por exemplo 2,3,5,6-tetraclorobenzoquinona) converte irreversivelmente o porfirinogênio (1) na porfirina aromática (2).

Enquanto as meso-tetra-arilporfirinas são eletronicamente similares aos derivados 1 a 8 alquil-substituídos, estericamente são muito diferentes, uma vez que os quatro grupos aril são praticamente ortogonais ao plano do anel, característica que pode ser usada para proteger ambas as faces do anel (e o metal central com os ligantes axiais) ${ }^{94}$. 
1.4.2 Espectro eletrônico: o modelo dos quatro orbitais de fronteira.

Apesar de proposto no final da década de 50 e início dos anos $60^{96-97}$, o modelo dos quatro orbitais de fronteira ainda continua sendo um bom ponto de partida na abordagem das estruturas eletrônicas de porfirinas e metaloporfirinas ${ }^{98,99}$. Assim, uma breve recapitulação sobre a concepção deste modelo, baseada em publicações da década de $70^{100,101}$, torna-se aqui necessária.

O "coração eletrônico" de uma porfirina ${ }^{101}$ é considerado como sendo um anel com 16 átomos e 18 elétrons $\pi$, possuindo um eixo perpendicular $C_{2}$ no caso da porfirina base-livre, ou um eixo perpendicular $\mathrm{C}_{4}$ no caso da metaloporfirina, sendo responsável pelos tipos de espectros observados, perturbados em maior ou menor extensão pelas diversas modificações possiveis na estrutura básica. As modificações promovidas pela substituição dos hidrogênios pirrólicos ou dos hidrogênios dos grupos metino causam efeitos pequenos sobre os espectros eletrônicos se não ocorrem interações entre os substituintes e a conjugação do anel. Se os substituintes interferem com a conjugação, a perturbação torna-se considerável, como no caso das tetra(benzo)porfirinas, porfirazinas e ftalocianinas (figura 1.15).

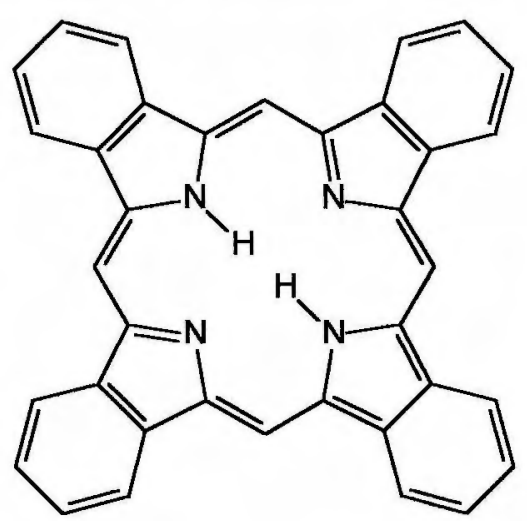

tetrabenzoporfirina

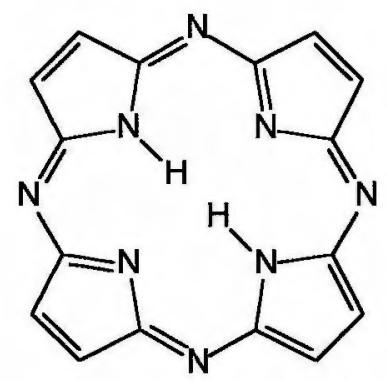

porfirazina

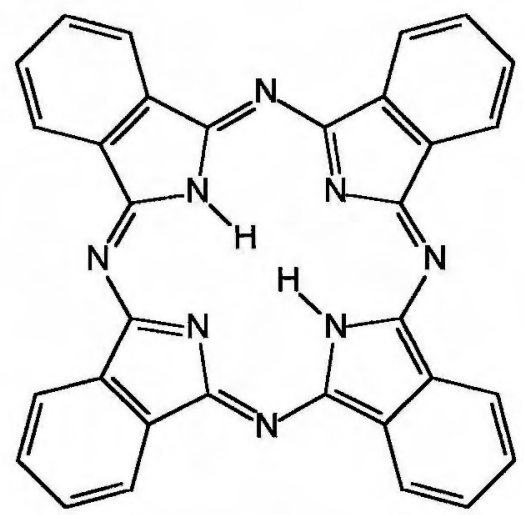

ftalocianina

Figura 1.15 - Compostos correlatos à porfirina.

Mudanças consideráveis nas propriedades eletrônicas também podem ser observadas com a variação do substituinte central, isto é, o átomo ou grupo de átomos que ocupam o centro do anel porfirínico. Segundo Gouterman ${ }^{101}$, dentro da classe das metaloporfirinas é possível uma classificação em metaloporfirinas regulares e metaloporfirinas irregulares, de acordo com os espectros de absorção e emissão que apresentem. As regulares possuem metais com camadas eletrônicas totalmente 
preenchidas que produzem apenas um pequeno efeito sobre os espectros de absorção e emissão, o que pode ser compreendido como uma pequena perturbação sobre os elétrons $\pi$ do anel porfirínico. Já as irregulares apresentam metais com camadas parcialmente preenchidas, tendo os orbitais do metal um efeito muito maior sobre a absorção e a emissão, ou através da mistura com os orbitais do anel, ou através da introdução de novas transições.

Tomemos como exemplo os espectros eletrônicos da octa(etil)porfirina base-livre $\left(\mathrm{H}_{2} \mathrm{OEP}\right)$ e da octa(etil)porfirinato de zinco ( $\mathrm{ZnOEP}$ ), uma metaloporfirina regular segundo Gouterman ${ }^{101}$ (figura 1.16). Observa-se que o espectro eletrônico de $\mathrm{H}_{2} \mathrm{OEP}$ apresenta quatro bandas no visível, comumente denominadas bandas $Q$, uma intensa em torno de $400 \mathrm{~nm}$ (denominada banda B ou Soret) e outras bandas de menor intensidade em maior energia (bandas $M$ e $N$ da região UV na figura 1.16; frequentemente entre estas duas bandas ocorre uma terceira, denominada banda $L$ ). $O$ espectro de ZnOEP é similar, com exceção das bandas no visivel, que ocorrem em número de duas.
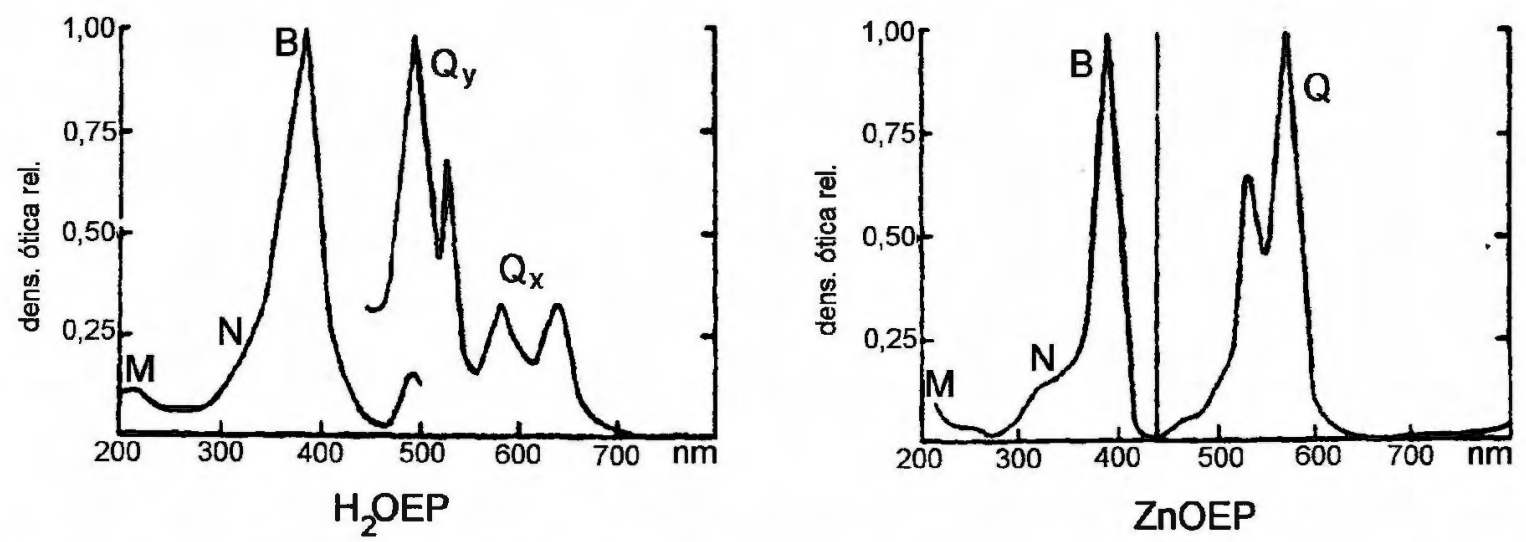

Figura 1.16 - Espectros eletrônicos na fase vapor de octa-etilporfirina base-livre $\left(\mathrm{H}_{2} \mathrm{OEP}\right)$ e de octa(etil)porfirinato de zinco (ZnOEP) ${ }^{100}$. As intensidades das bandas nas regiōes UV e visível foram separadamente normalizadas para a unidade.

$\mathrm{Na}$ interpretação dos espectros eletrônicos, uma vez que os anéis centrais das porfirinas são planares e conjugados, o tratamento de orbitais moleculares por métodos baseados apenas em elétrons $\pi$ foi inicialmente utilizado. Em tais tratamentos, considera-se que os elétrons $\pi$ são livres para moverem-se sobre o "esqueleto" molecular independentemente dos elétrons $\sigma$ : o espectro eletrônico e outras propriedades são principalmente determinadas pelos elétrons $\pi$. Assim, o método FEMO (Free Electron Molecular Orbital) foi o primeiro método de orbitais moleculares 
aplicado a porfirinas. Em sua forma mais simples, este método é apenas uma extensão do problema unidimensional da partícula em uma caixa: sistemas cíclicos como as porfirinas são tratados usando o modelo da partícula em um anel - os elétrons $\pi$ são considerados como confinados a um anel de energia potencial negativa constante, com energia potencial igual a zero fora do anel, sendo posicionados em orbitais moleculares com energias iguais a $E=q^{2} h^{2} / 2 m C^{2}$, onde q é um número quântico $(0,1,2,3 \ldots)$ e $C$ é a circunferência do anel. As energias das transições eletrônicas são calculadas como diferenças de $\mathrm{E}$.

Esta simples versão foi aplicada por Kuhn ${ }^{102}$ e Simpson ${ }^{103}$ em 1949. A diferença entre os átomos de carbono e nitrogênio foi ignorada, assim como ramificações no esqueleto porfirínico. Das possíveis escolhas de perímetro molecular, ambos usaram um anel de 18 membros incluindo dois dos quatro átomos de nitrogênio, envolvendo 18 elétrons $\pi$. Kuhn reportou concordância do modelo com a região das bandas observadas, mas não com a complexidade: a teoria prevê quatro transições degeneradas entre os orbitais caracterizados por $q= \pm 4$ e $q= \pm 5$. Simpson apontou $q$ como essencialmente um momento angular; assim, os estados excitados teriam momentos angulares de $\pm 1 \mathrm{e} \pm 9$, não degenerados: transições permitidas para \pm 1 (Soret) e proibidas para \pm 9 (bandas $Q$ ). Vários refinamentos foram aplicados a esta primeira abordagem $^{100}$. No entanto, embora forneça resultados rapidamente, a teoria permite obter apenas energias de transição, sem especificar simetrias ou multiplicidades de estados.

Posteriormente, em um modelo muito similar ao FEMO, tratou-se a porfirina como um polieno cíclico: a metaloporfirina foi considerada um anel contendo 16 grupos $\mathrm{CH}$ e a porfirina base-livre um anel de 18 grupos, ambos possuindo 18 elétrons $\pi$, gerando-se estados excitados também similares àqueles gerados pelo FEMO $(q= \pm$ $4 \rightarrow q= \pm 5$ ). No entanto, o modelo do polieno cíclico forneceu uma explicação simples para 0 desdobramento das bandas $Q$ da metaloporfirina para a porfirina base-livre: Moffitt $^{104,105}$ demonstrou que em um anel com $(4 n+2)$ membros a degenerescência é perdida no estado singlete de menor energia por interação eletrônica. Portanto, uma mudança de metaloporfirina para porfirina base-livre poderia ser encarada como uma mudança análoga à de um polieno cíclico de 16 para 18 membros, ambos possuindo 18 elétrons $\pi$.

A primeira aplicação do modelo de Hückel foi realizada por Longet-Higgins et al ${ }^{106}$. Neste modelo, os orbitais moleculares são expressos como combinações lineares 
de orbitais atômicos, podendo ser prontamente visualizados e interpretados em termos químicos, sendo manipuláveis pela teoria de grupo; além disso, fornece grandezas importantes como ordens de ligação e densidades de carga. A aplicação do modelo conduziu à obtenção de 2 orbitais ocupados de maior energia (HOMO's), 3a $a_{2 u}$ e $1 a_{1 u}$ e 2 orbitais degenerados não ocupados de menor energia (LUMO's), 4e.g. Os cálculos colocaram a transição $3 a_{2 u} \rightarrow 4 e_{g}$ (identificada com as bandas $Q$ ) em menor energia do que a transição $1 a_{1 u} \rightarrow 4 e_{g}$ (identificada com a Soret). Contudo, os mesmos cálculos mostravam que as duas transições não deveriam possuir dipolos de transição muito diferentes, o que está em desacordo com a baixíssima intensidade das bandas $Q$ em relação à Soret: enquanto as bandas $Q$ apresentam normalmente uma absortividade por mol $(\varepsilon)$ entre $1,0 \times 10^{4}$ e $2 \times 10^{4} \mathrm{~mol}^{-1} \mathrm{dm}^{3} \mathrm{~cm}^{-1}$, a banda Soret tem seu $\varepsilon$ variando entre $2 \times 10^{5}$ e $4 \times 10^{5} \mathrm{~mol}^{-1} \mathrm{dm}^{3} \mathrm{~cm}^{-1}$ 99,101 . Várias outras aplicações se seguiram, com variações na magnitude assumida para a integral de sobreposição $S$ e nas integrais de ressonância envolvendo nitrogênio, $\alpha_{N}$ e $\beta_{C N}$. Embora se obtivessem energias de transição em boa concordância com os dados experimentais, nenhuma destas aplicações explicou a grande diferença entre as intensidades das bandas $Q$ e Soret ${ }^{100}$.

O modelo dos quatro orbitais de fronteira foi desenvolvido por Gouterman et $a^{95-}$ 97,101 na tentativa de unir o modelo de Hückel, que permitia a consideração de variações no esqueleto porfirínico, com os modelos FEMO e do polieno cíclico, que pareciam incluir corretamente os principais efeitos de interação eletrônica. Os quatro orbitais moleculares envolvidos são os ocupados de maior energia $a_{1 u}$ e $a_{2 u}$ (HOMO's), e os degenerados $e_{g}$, vazios de menor energia (LUMO's), como indicado na figura 1.17, tendo sido proposto que $a_{1 u}$ e $a_{2 u}$ fossem "quase" degenerados.

As configurações no estado excitado resultantes de transições mono-eletrônicas para os orbitais $e_{\mathrm{g}}$ seriam "quase" degeneradas também, ocorrendo então combinaçōes para produzir estados que assemelhavam-se aos preditos pelos métodos FEMO e do polieno cíclico. Gouterman et $a^{97}$ fizeram um tratamento quantitativo deste modelo. Foi "forçada" a "quase" degenerescência antre $a_{1 u}$ e $a_{2 u}$ pela parametrização $\alpha_{N}=\alpha_{C}+2 \beta_{C C}$ e $\alpha_{C N}=0,5 \beta_{C C}$.

A combinação das configurações de estado "quase" degeneradas foi tratada por interação de configuração, isto é, construíram-se as funções de onda de estado excitado como combinações lineares das quatro configurações resultantes das transições eletrônicas entre os quatro orbitais. Encontrou-se que uma forte interação entre as configurações $\left(a_{1 u} e_{g}\right)$ e $\left(a_{2 u} e_{g}\right)$ causaria um aumento de intensidade da banda 
Soret às expensas da banda $Q$. As energias de transição e as intensidades calculadas mostraram-se em boa concordância com os dados experimentais. No entanto, a parametrização escolhida produziu uma ordem de ligação $\mathrm{C}-\mathrm{N}$ igual a 0,218 , o que corresponde a uma ligação muito longa. Retornando aos nossos exemplos (espectros eletrônicos de $\mathrm{H}_{2} \mathrm{OEP}$ e ZnOEP, figura 1.16) e tendo em mente o modelo dos quatro orbitais de fronteira (figura 1.17):

a) a banda de menor energia de ZnOEP, denominada agora $Q_{(0,0)}$, é de origem eletrônica para o estado singlete de menor energia;

b) a outra banda de ZnOEP no visível $\left(Q_{(1,0)}\right)$ foi originariamente identificada como uma componente vibrônica com base no intervalo de energia relativamente constante entre $Q_{(0,0)}$ e $Q_{(1,0)}$ (cerca de $\left.1250 \mathrm{~cm}^{-1}\right)^{101}$; é atribuída a uma transição envolvendo o estado vibracional $v_{0}$ do estado fundamental e o estado vibracional $v_{1}$ do estado excitado ${ }^{99}$;

c) a banda Soret $\left(B_{(0,0)}\right)$ é de origem eletrônica para o segundo estado singlete; em espectros de alta resolução, foi possível observar outra banda na região, deslocada cerca de $1250 \mathrm{~cm}^{-1}$ para maiores energias, tendo sido denominada $B_{(1,0)}$ e atribuída a uma transição envolvendo o estado vibracional $v_{0}$ do estado fundamental e o estado vibracional $v_{1}$ do estado excitado $^{101}$.

d) no caso da porfirina base-livre $\left(\mathrm{H}_{2} \mathrm{OEP}\right)$, o abaixamento de simetria para $\mathrm{D}_{2 \mathrm{~h}}$ conduz ao desdobramento de $E_{u}$ em $B_{2 u}$ e $B_{3 u}$, originando quatro bandas no visível.

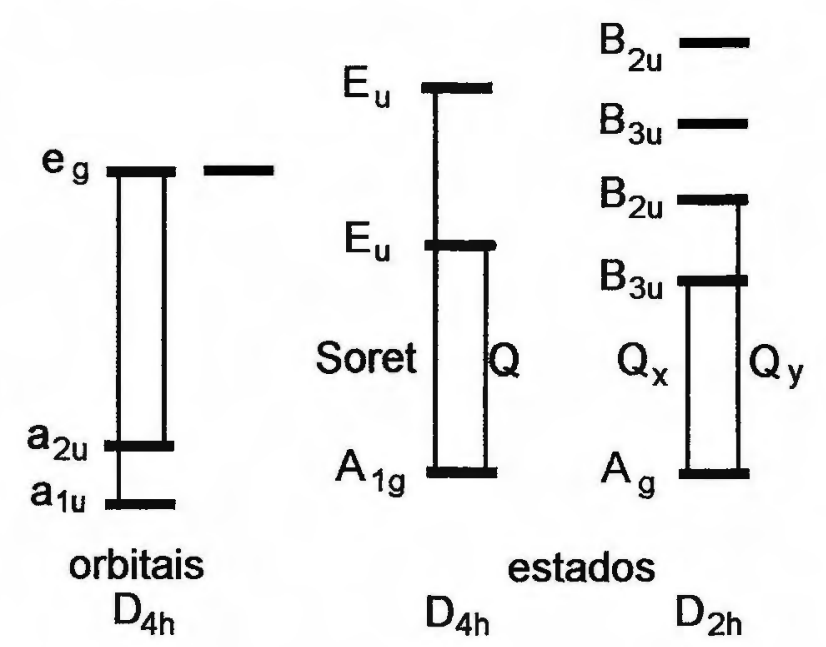

Figura 1.17 - Transições eletrônicas no modelo dos quatro orbitais de fronteira.

Apesar de suas limitações quanto a aplicações quantitativas, o modelo dos quatro orbitais de fronteira é um bom ponto de partida em abordagens qualitativas e semi-quantitativas dos espectros de absorção e emissão de metaloporfirinas regulares. 
No caso das irregulares, dada a perturbação dos elétrons $\pi$ do anel porfírínico causada pelos elétrons do íon metálico central, a situação é mais complicada. Já em 1979, Gouterman $^{101}$ relacionava exemplos de cálculos efetuados em tais sistemas: IEH (Iterative Extended Hückel), CNDO (Complete Neglet of Differential Overlap) e cálculos $a b$ initio, entre outros. Como afirmado anteriormente, as metaloporfirinas irregulares diferem das regulares em propriedades de emissão e, em muitos casos, de absorção também. Ainda segundo Gouterman ${ }^{101}$, pode-se classificar os tipos não usuais de absorção em:

a) espectros de absorção hipso: são semelhantes aos espectros das metaloporfirinas regulares, porém deslocados para maiores energias, característicos das porfirinas dos metais de transição com configuração eletrônica $d^{6} a d^{9}$. Um exemplo é o espectro eletrônico da Co"OEP (figura 1.18). O deslocamento observado pode ser interpretado como resultante da combinação entre os orbitais vazios $e_{g}(\pi)$ (anel) e os orbitais preenchidos $d \pi$ (metal), combinação que aumenta o intervalo de energia entre os orbitais $e_{g}\left(\pi^{*}\right)$ e os HOMO's $a_{2 u}(\pi)$ e $a_{1 u}(\pi)$ (figura 1.18).

b) espectros de absorção hiper: apresentam bandas adicionais de absorção (além de $\mathrm{Q}, \mathrm{B}, \mathrm{N})$ na região $\lambda>320 \mathrm{~nm}$. Dentro desta classe, ainda é possível a subdivisão em:

1) tipo p: são espectros apresentados pelas metaloporfirinas dos metais do grupo principal, em baixos estados de oxidação ( $\left.\mathrm{Sn}^{\prime \prime}, \mathrm{Pb}^{\prime \prime}, \mathrm{As}^{\prime \prime \prime}, \mathrm{Sb}^{\prime \prime \prime}, \mathrm{Bi}^{\mathrm{III}}\right)$; as bandas adicionais são atribuídas a transições de transferência de carga $\mathrm{a}_{2 \mathrm{u}}\left(\mathrm{np}_{\mathrm{z}}\right)($ metal $) \rightarrow \mathrm{e}_{\mathrm{g}}\left(\pi^{*}\right)(\text { anel })^{101}$.

2) tipo d: são espectros apresentados pelas metaloporfirinas dos metais de transição com configurações $d^{1}$ a $d^{6}$ como, por exemplo, o espectro eletrônico da [MnTPP(CI)( $\left.\left.\mathrm{H}_{2} \mathrm{O}\right)\right]$ exibido na figura 1.19, onde pode-se notar 7 bandas assinaladas conforme designação proposta por Boucher ${ }^{107}$. As bandas adicionais podem ser atribuídas a transições de transferência de carga $a_{1 u}(\pi), a_{2 u}(\pi)($ anel $) \rightarrow e_{g}(d \pi)(\text { metal })^{101,108}$. 


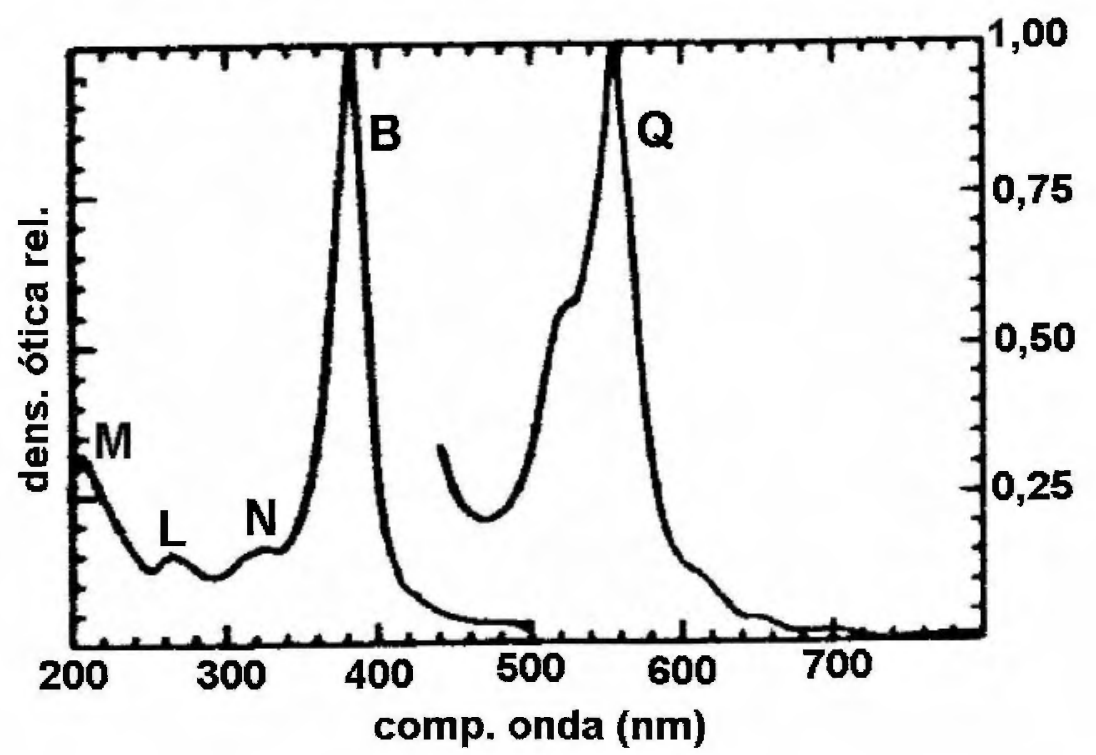

$$
b_{1 g}\left(d_{x-y^{2}}^{2}\right)-\quad b_{1 g}\left(d_{x-y}^{2} y^{2}\right)-
$$

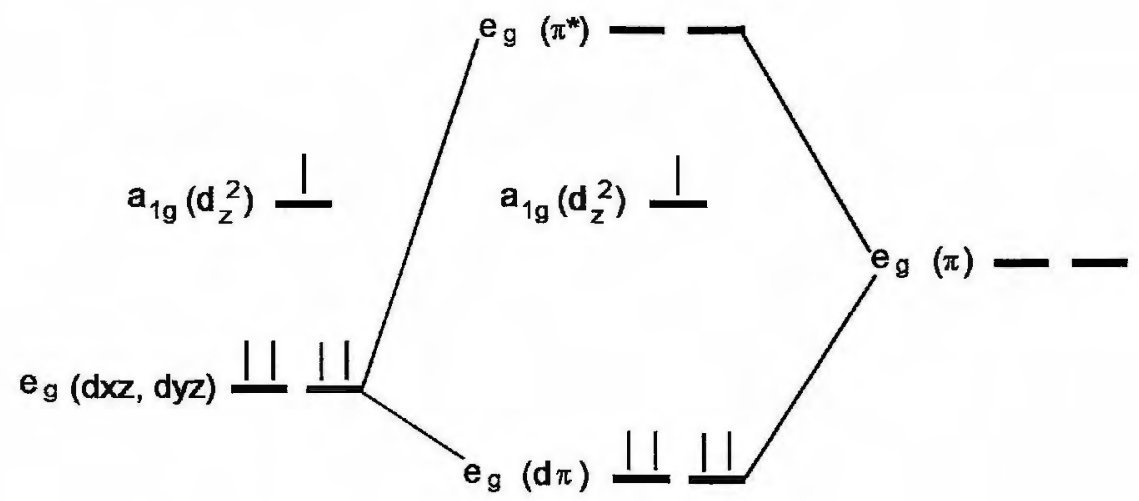

$$
\begin{aligned}
& b_{2 g}(d x y) \perp \mid \quad b_{2 g}(d x y) \frac{||}{a_{2 u}(\pi) \frac{||}{11}} \\
& a_{1 u}(\pi) \Perp
\end{aligned}
$$$$
a_{2 u}(\pi) \perp
$$$$
a_{14}(\pi) \perp
$$

Co(II) porfirina

Figura 1.18 - Acima, espectro eletrônico na fase vapor de CoOEP ${ }^{101}$ (as intensidades das bandas nas regiões UV e visivel foram separadamente normalizadas para a unidade). Abaixo, um diagrama qualitativo de orbitais moleculares mostrando os orbitais de fronteira de porfirina de $\mathrm{Co}^{11}{ }^{101}$. 


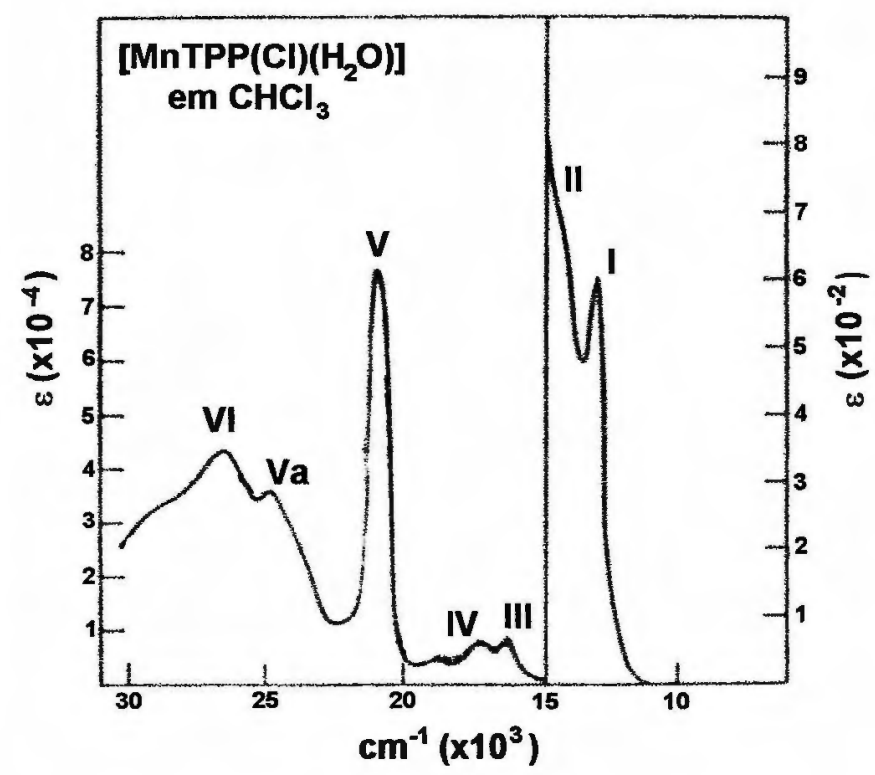

$b_{1 g}\left(d_{x-y}^{2}{ }^{2}\right)-\quad b_{1 g}\left(d_{x}^{2}-y^{2}\right)-$

Banda I

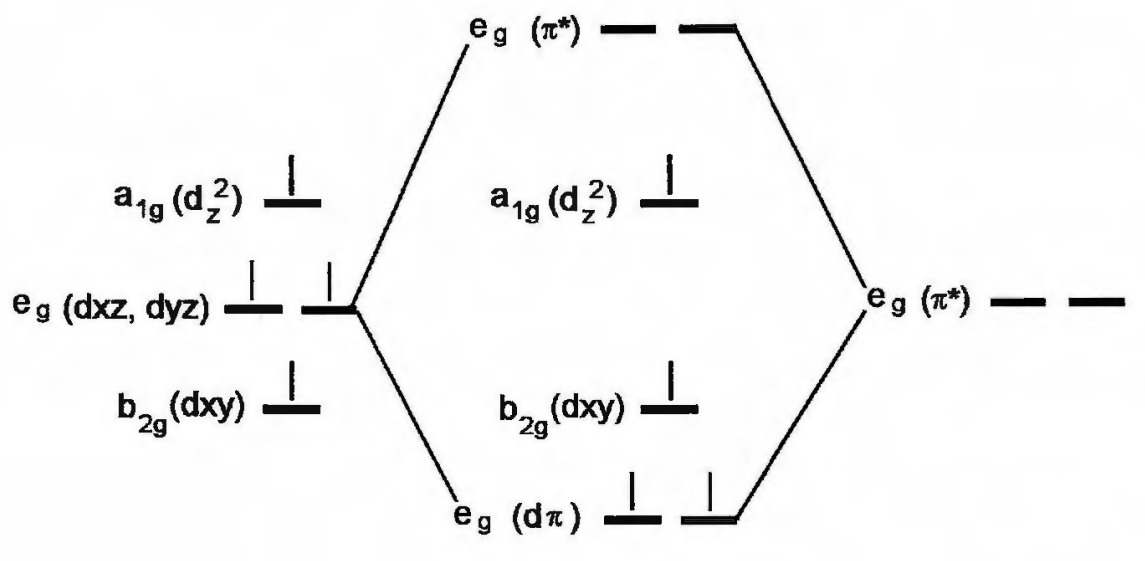

$a_{2 u}, a_{1 u} \rightarrow e_{g}$

Banda II

$a_{2 u} \rightarrow a_{1 g}$

Banda III

$a_{2 u}, a_{1 u} \rightarrow e_{g}$

Banda IV

$a_{2 u}, a_{1 u} \rightarrow e_{g}{ }^{*}$

$$
\begin{array}{ll}
a_{2 u}(\pi) \frac{||}{\mid !} & a_{2 u}(\pi) \frac{||}{a_{1 u}(\pi) \frac{\mid}{a_{1 u}(\pi)}} \\
b_{2 u}(\pi) \frac{||}{\mid 1} & b_{2 u}(\pi) \frac{||}{a_{2 u}^{\prime}(\pi) !}
\end{array}
$$

Banda V

porfirina $b_{2 u}, a_{2 u} \rightarrow e_{g}$

Banda $\mathrm{V}_{\mathrm{a}}$

$a_{2 u}^{\prime} \rightarrow a_{1 g}$

Banda VI

$a_{2 u}, a_{1 u} \rightarrow e_{g}^{*}$

$b_{2 u}, a^{\prime}{ }_{2 u} \rightarrow e_{g}$

Figura 1.19 - Acima, espectro eletrônico de $\left[\mathrm{MnTPP}(\mathrm{Cl})\left(\mathrm{H}_{2} \mathrm{O}\right)\right.$ em $\mathrm{CHCl}_{3}{ }^{101}$. Abaixo, um diagrama qualitativo de orbitais moleculares mostrando os orbitais de fronteira de uma porfirina de $\mathrm{Mn}^{\mathrm{III}}{ }^{101,108-110}$ com atribuição (tentativa) de bandas ${ }^{108,110}$. 


\subsubsection{Metaloporfirinas como catalisadores em oxidações de substratos orgânicos.}

Existe uma crescente demanda por catalisadores mais eficientes e seletivos para a oxidação de substratos orgânicos ${ }^{111-113}$. O problema da ativação das ligações CH sob condições brandas permanece como um problema tanto em química fina como na indústria química: as reações catalíticas de oxidação são frequentemente acompanhadas pela formação de radicais livres, o que faz diminuir a seletividade ${ }^{114}$.

Uma estratégia para se obter novos catalisadores constitui-se em tentar mimetizar sistemas enzimáticos que tenham sido selecionados pelos organismos vivos em sua evolução. Neste sentido, as mono-oxigenases que utilizam as heme-proteínas citocromos P-450 têm motivado um intenso estudo cujo interesse volta-se não só para a obtenção de catalisadores eficientes e seletivos para a síntese orgânica, como também para a elucidação do metabolismo de drogas, agroquímicos e outros xenobióticos, e para a preparação de grandes quantidades de metabólitos oxidados de compostos de interesse biológico ${ }^{17}$.

As mono-oxigenases catalisam reações nas quais apenas um dos dois átomos do $\mathrm{O}_{2}$ é incorporado ao substrato, o outro sendo reduzido a água; esta redução é possivel pela ação de co-substratos, doadores de elétrons e de átomos de hidrogênio, como as formas reduzidas da nicotinamida adenina dinucleotídeo (NADH) ou da nicotinamida adenina dinucleotídeo fosfato (NADPH), por exemplo. As reações de mono-oxigenação mais numerosas e complexas são as que empregam o citocromo P-450, uma família de heme-proteínas muito semelhantes entre si; várias centenas de membros desta família já são conhecidos, cada um com uma diferente especificidade a um determinado substrato ${ }^{115}$. A figura 1.20 (em que se salienta a coordenação axial Feresíduo de cisteína, a ligação da porfirina de ferro com a parte proteica da enzima) procura representar de maneira simplificada o ciclo catalítico proposto para estas enzimas $^{15}$ : em estado de repouso, a P-450 está em equilíbrio entre um complexo $\mathrm{Fe}$ (III) baixo spin hexa-coordenado e um complexo Fe(III) alto spin penta-coordenado; com a ligação do substrato, o equilíbrio desloca-se em favor do complexo alto spin pentacoordenado - a mudança de spin facilita o ganho de um elétron e a subsequente ligação de $\mathrm{O}_{2}$ forma um intermediário baixo spin hexacoordenado, estável; este, então, recebe um segundo elétron e a clivagem heterolítica libera água para formar o intermediário reativo que acredita-se um complexo ferro-oxo de alta valência, capaz de introduzir seu átomo de oxigênio em muitos substratos, realizando a hidroxilação de 
alcanos, a epoxidação de alcenos e de anéis aromáticos e a oxidação do enxofre de tioéteres, entre outras reaçöes ${ }^{15}$. As citocromos P-450 são capazes de realizar oxidações utilizando doadores de átomos de oxigênio tais como perácidos, hidroperóxidos ou iodosilarenos (espécies AO da figura 1.20).

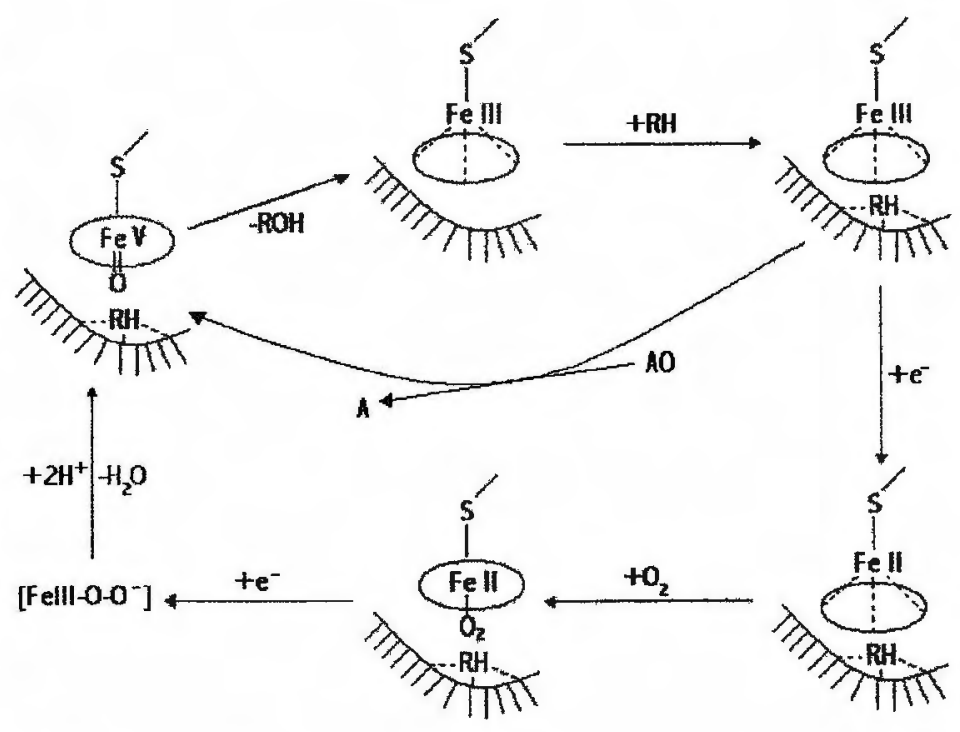

Figura 1.20 - Citocromo P-450: ciclo catalítico ${ }^{15}$.

Uma vez que as citocromos P-450 são capazes de catalisar seletivamente diversas reações de oxidação, naturalmente a mimetização de seu sítio ativo constituise em atraente estratégia para a obtenção de novos catalisadores. Nesta direção, duas abordagens são seguidas; na primeira, complexos porfirínicos são utilizados em catálise homogênea, sendo distinguíveis três gerações de catalisadores ${ }^{114,116}$ a partir do final dos anos 70 :

1a. geração: iniciada com o trabalho de Groves et $a l^{117}$ que mostraram que um sistema simples, envolvendo iodosilbenzeno ( $\mathrm{PhlO}$ ) como doador de oxigênio e $\mathrm{Fe}(\mathrm{TPP}) \mathrm{Cl}$ (figura 1.21) como catalisador, era capaz de reproduzir algumas das reações promovidas pelas citocromos P-450, pelo menos de um ponto de vista qualitativo. Seguiu-se, então, o estudo de diferentes metais de transição incorporados à porfirina, avaliando-se a capacidade catalítica de cada sistema na oxidação de diversos substratos utilizando-se vários oxidantes $^{15}$. Contudo, estas simples meso-tetrafenilporfirinas mostraram-se susceptíveis à desativação por oxidação dos átomos de carbono das posições meso ${ }^{114}$ : esta reduzida estabilidade tornou inviável o seu uso em química preparativa.

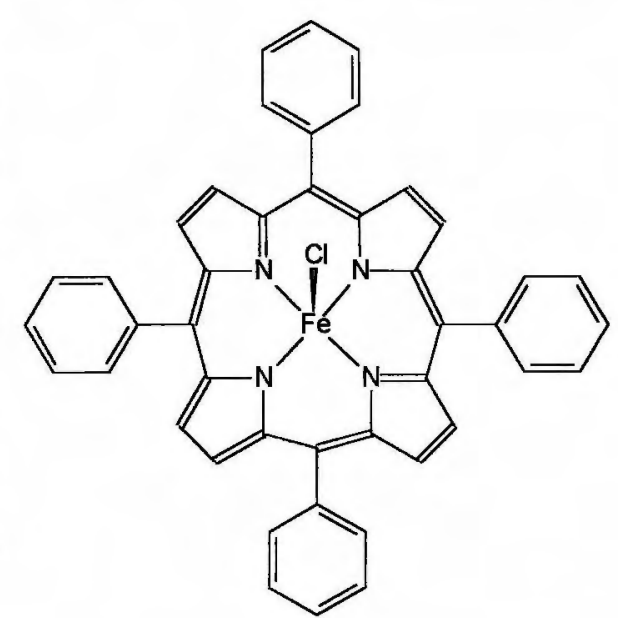

Figura $1.21-\mathrm{Fe}(\mathrm{TPP}) \mathrm{Cl}$. 
2a. geracão: melhores resultados foram obtidos, em termos de estabilidade e atividade, com porfirinas de manganês e de ferro contendo substituintes receptores de elétrons nos grupos fenil das posições meso. Este é o caso da tetra-(2,6-di-clorofenil)porfirina de manganês (MnTDCPP, figura 1.22); ao lado do efeito eletrônico receptor sobre o anel porfirínico, diminuindo sua densidade eletrônica e, portanto, aumentando o seu potencial de oxidação, os átomos de cloro nas posições orto promovem alguma proteção estérica à espécie ativa manganês-oxo de alta valência, prevenindo uma rápida destruição oxidativa da porfirina $^{114,116}$.

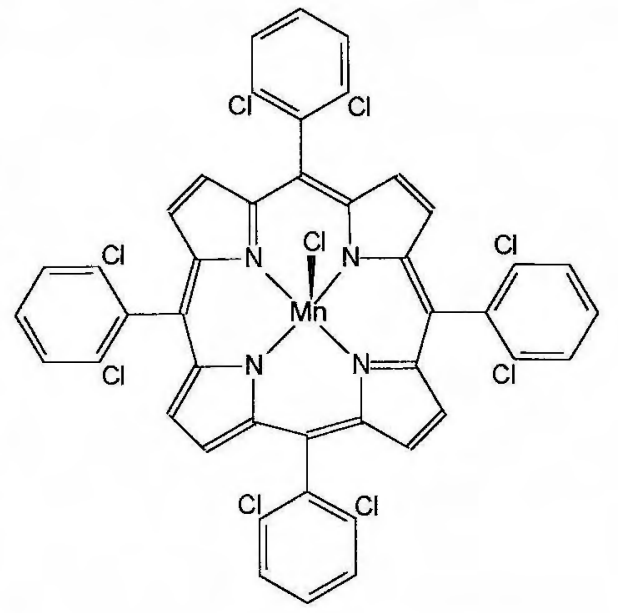

Figura $1.22-[\mathrm{MnTDCPP}] \mathrm{Cl}$.

3a. geração: os melhores resultados obtidos com os catalisadores de 2a. geração conduziram à síntese de porfirinas contendo halogêneos diretamente ligados ao núcleo porfirínico, através dos átomos de carbono pirrólicos, como no caso da $\beta$-octa-cloromeso-tetra-(2,6-di-clorofenil)porfirina de manganês $(\beta-\mathrm{Cl}-\mathrm{MnTDCPP}, \quad$ figura 1.23). Em diversas publicações $^{94,116,118,119}$ afirmou-se que estas porfirinas são muito mais ativas como catalisadores e muito mais resistentes à degradação oxidativa do que os seus análogos não substituídos em $\beta$, o que é consistente com a expectativa de que a presença destes $\beta$-substituintes eletronegativos deveria aumentar significativamente o potencial de oxidação do macrociclo.

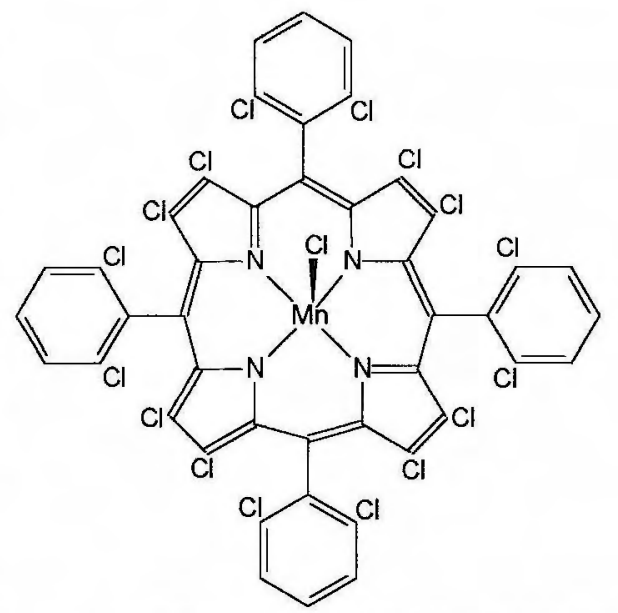

Figura $1.23-[\beta-8 \mathrm{Cl}-\mathrm{MnTDCPP}] \mathrm{Cl}$.

No entanto, alguns pesquisadores verificaram, por exemplo, que a $\beta$-ClMnTDCPP era, na realidade, menos estável que o seu análogo de $2 a$ geração (MnTDCPP), o mesmo fato sendo observado entre porfirinas $\beta$-bromo substituídas e seus análogos não substituídos; com $\beta$-flúorporfirinas a situação tenderia realmente a uma maior estabilidade e eficiência ${ }^{111}$. Torna-se importante considerar aqui que a determinação da estrutura por difração de raios-X de $\beta$-octa-bromoporfirinas ${ }^{120}$ e cálculos de mecânica molecular e quânticos semi-empíricos de $\beta$-octa-bromo- e $\beta$-octa- 
cloroporfirinas ${ }^{121}$ mostraram que estes compostos adotam uma estrutura em forma de sela para o núcleo porfirínico, estando cada anel de pirrol inclinado por mais de $30^{\circ}$; cada grupo meso-aril também encontra-se inclinado de maneira a minimizar as fortes interações estéricas com os $\beta$-halogêneos. Adicionalmente, os potenciais de primeira ionização calculados não diferiram muito entre as $\beta$-octa-bromo- e $\beta$-octacloroporfirinas e os análogos não halogenados em $\beta$. Esta diferente estrutura (as porfirinas da 1a. ou 2a. gerações exibem um anel porfirínico planar com os quatro grupos meso-aril quase perpendiculares), além de presumivelmente expor o macrociclo à oxidação, contribuiria também para as diferentes seletividades observadas entre análogos da 2a. e da 3a. gerações, devido às diferentes acessibilidades dos substratos aos intermediários ativos metal-oxo ${ }^{116}$.

Além destas três gerações de catalisadores homogêneos, pode-se ainda citar modelos porfirínicos com elaborado ambiente estérico, como o mostrado na figura 1.24, onde o enfoque principal está voltado para a regio e a estereoseletividade, além naturalmente da eficiência e estabilidade ${ }^{18}$. Contudo, o uso destas metaloporfirinas em reaçōes envolvendo grandes quantidades apresenta muitas limitações: 0 uso de oxidantes diferentes do iodosilbenzeno, por exemplo, conduz a baixos rendimentos $e$ baixas estereoseletividades ${ }^{111}$.

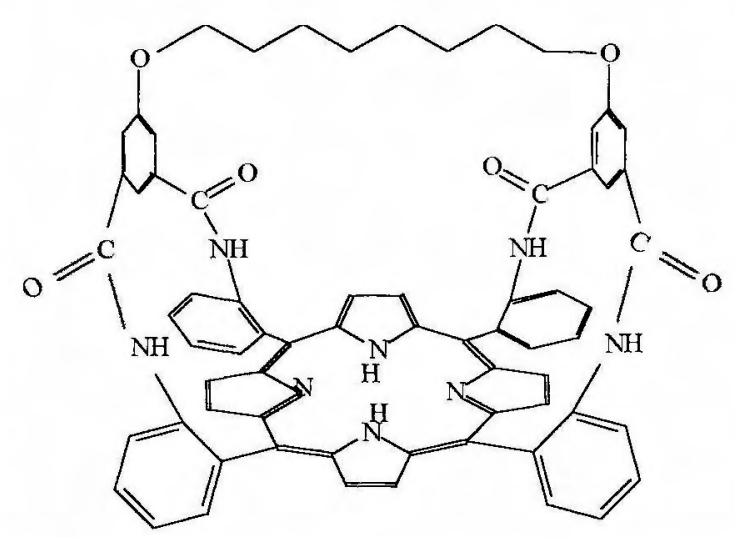

Figura 1.24 - Porfirina "picnic basket".

A outra abordagem na procura por sistemas miméticos das citocromos P-450 consiste em utilizar complexos porfirínicos como catalisadores heterogêneos. Existem diversas estratégias possíveis para a imobilização de metaloporfirinas: polimerização ${ }^{122}$, adsorção ou intercalação em diferentes matrizes minerais como sílica, alumina, argilas e zeólitas ${ }^{123-125}$, ligação covalente em diversos suportes funcionalizados como, por exemplo, sílica com função ácido carboxílico e montmorilonita com função amina ${ }^{126-128}$. Esta imobilização tem, como objetivos principais, facilitar a recuperação do catalisador ao final da reação, melhorar a regioseletividade e prevenir a auto-oxidação do modelo enzimático, pontos críticos da catálise homogênea. Nas citocromos P-450 estes pontos críticos são superados devido à atuação do envelope proteico que permite uma fácil separação do catalisador dos 
produtos oxidados, sendo responsável pelo reconhecimento do substrato e pela sua oxidação seletiva. Portanto, a utilização de matrizes minerais ou orgânicas pode ser encarada como mimetizações do envelope proteico da enzima. Finalmente, a imobilização de metaloporfirinas também tem sido efetuada através da eletropolimerização sobre a superfície de eletrodos, resultando em filmes eletrocatalíticos $^{129,130}$.

\subsubsection{Porfirinas de cobalto: catalisadores para a redução de $\mathrm{O}_{2}$.}

A importância do estudo de catalisadores para a redução tetra-eletrônica de $\mathrm{O}_{2}$ pode ser avaliada considerando-se, por exemplo:

a) o ponto de vista biológico - todos os organismos aeróbios realizam esta reação exotérmica, catalisada pelo complexo enzimático multimetálico citocromo c oxidase durante a fosforilação oxidativa, processo que armazena energia na forma de adenosina-trifosfato (ATP), além de

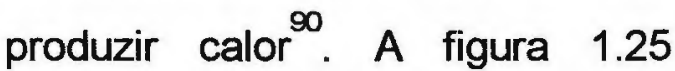
mostra a ocorrência da fosforilação oxidativa no contexto do metabolismo, ilustrado de uma maneira geral $^{131}$, em que se observa a utilização, pelo complexo enzimático, de prótons e elétrons oriundos do metabolismo degradativo dos alimentos.
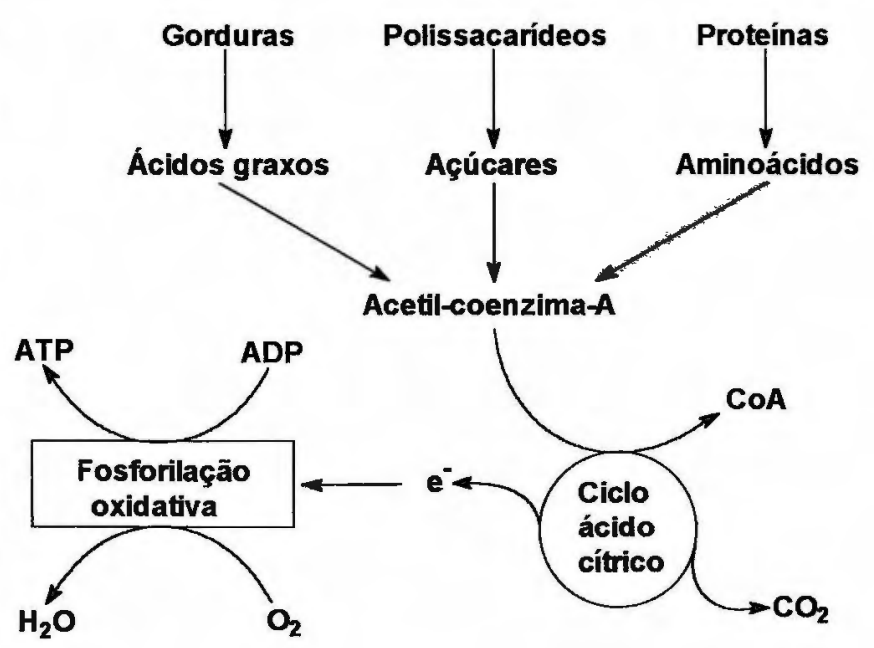

Figura 1.25 - Visão geral do metabolismo ${ }^{131}$.

b) o ponto de vista tecnológico - trata-se de uma "reação-chave" no desenvolvimento de células de combustível mais eficientes e de menor custo ${ }^{132}$. Nas células de combustivel, platina finamente dividida, suportada em carbono de grande área superficial, é o catalisador mais frequentemente empregado para realizar a redução de $\mathrm{O}_{2}$ a $\mathrm{H}_{2} \mathrm{O}$. No entanto, este tipo de catalisador apresenta as desvantagens de alto custo e gradual perda na atividade catalítica, a medida que diminui a área superficial das partículas ativas de platina devido à sinterização, dissolução, desalojamento ou adsorção de impurezas ${ }^{133}$. 
A redução de $\mathrm{O}_{2}$ pode ocorrer por mecanismos bi- ou tetraeletrônicos, sendo o primeiro o mais comum. Geralmente, porfirinas de cobalto catalisam esta redução produzindo $\mathrm{H}_{2} \mathrm{O}_{2}$ (redução bieletrônica) ao invés de $\mathrm{H}_{2} \mathrm{O}$ (redução tetraeletrônica) ${ }^{133}$. $\mathrm{O}$ fato de apenas algumas porfirinas de cobalto serem efetivamente catalisadores tetraeletrônicos conduziu ao questionamento de quais fatores controlavam a ativação do intermediário metal- $\mathrm{O}_{2}$ para o processo envolvendo quatro elétrons. Neste sentido, duas diferentes abordagens têm sido empregadas, ambas utilizando eletrodos de grafite pirolítico modificados por filmes das porfirinas de cobalto (a adsorção sobre eletrodos oferece vantagens sobre catalisadores em solução: menor quantidade de catalisador é empregada - menos de $10^{-9} \mathrm{~mol} \mathrm{~cm}^{-2}$ - e a transferência de elétrons para as espécies confinadas ao eletrodo é rápida). Na primeira, em que se destaca o trabalho de Collman et al ${ }^{131,134138}$, bi-metaloporfirinas cofaciais têm sido investigadas. A figura 1.26 apresenta um exemplo deste tipo de sistema em que o mecanismo proposto para a reação envolve duas etapas: (i) redução de $\mathrm{O}_{2} a_{2} \mathrm{H}_{2} \mathrm{O}_{2}$ e (ii) redução de $\mathrm{H}_{2} \mathrm{O}_{2}$ a $\mathrm{H}_{2} \mathrm{O}$.
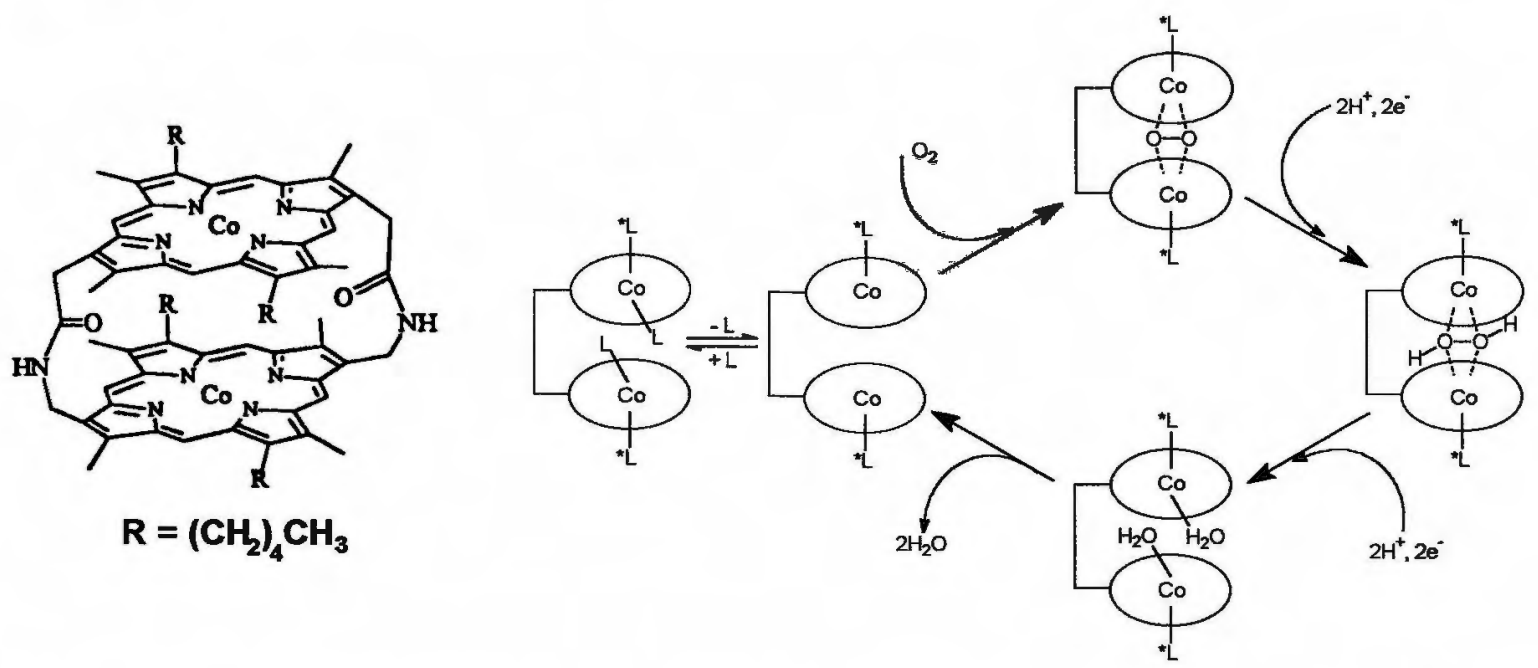

Figura 1.26 - À esquerda, estrutura de uma bi-metaloporfirina cofacial. À direita, esquema simplificado de um possivel mecanismo para a redução tetraeletrônica de $\mathrm{O}_{2}$ em duas etapas, catalisada por bi-metaloporfirina cofacial ${ }^{136}$.

Com relação ao mecanismo, presume-se inicialmente que o oxigênio coordenase simultaneamente aos dois íns de Co em dois diferentes estados de oxidação, $\mathrm{Co}$ (II) e Co(III), havendo evidências de que este último comporta-se como um ácido de Lewis. Aparentemente, este ácido é necessário para manter dentro da cavidade o substrato parcialmente reduzido de modo a não permitir a sua dissociação antes da completa redução, uma vez que observou-se que apenas um sítio redox é suficiente 
para a redução tetraeletrônica. A eficiência da catálise neste tipo de sistema (em outras palavras, redução tetraeletrônica versus redução bieletrônica) é controlada principalmente pela escolha dos metais do núcleo porfirínico (por exemplo, Co-Co, Co$\mathrm{Al}, \mathrm{Co}-\mathrm{Cu}$, etc) e pela distância entre os mesmos.

Numa outra abordagem, em que Anson et al ${ }^{139-146}$ têm publicado resultados muito significativos, ligantes foram colocados na periferia do anel porfirínico de modo a permitir a coordenação de complexos metálicos que poderiam agir como doadores de elétrons (utilizaram-se, principalmente, complexos penta-aminrutênio coordenados aos resíduos piridínicos nas posições meso, como o indicado na figura 1.27). A estratégia baseava-se na idéia de que cada complexo metálico poderia suprir um elétron para o sítio catalítico através de transferências intramoleculares, de maneira a se obter os quatro elétrons necessários para a redução do $\mathrm{O}_{2}$ a água; os complexos metálicos oxidados que resultariam deste processo poderiam ser novamente reduzidos eletroquimicamente e o ciclo catalítico repetido. No entanto, apesar de alguns dos catalisadores preparados mostrarem-se realmente efetivos na redução tetraeletrônica, verificou-se posteriormente que 0 mecanismo catalítico não envolvia transferências eletrônicas intramoleculares, mas era mais adequadamente descrito se interações de retrodoação dos doadores de elétrons periféricos com o núcleo porfirínico fossem consideradas. Um mecanismo proposto para a redução tetraeletrônica de $\mathrm{O}_{2}$ promovida pelo filme de CoTPyP $\left[\mathrm{Ru}\left(\mathrm{NH}_{3}\right)_{5}\right]_{4}^{12+}$ é mostrado abaixo $^{133}$.

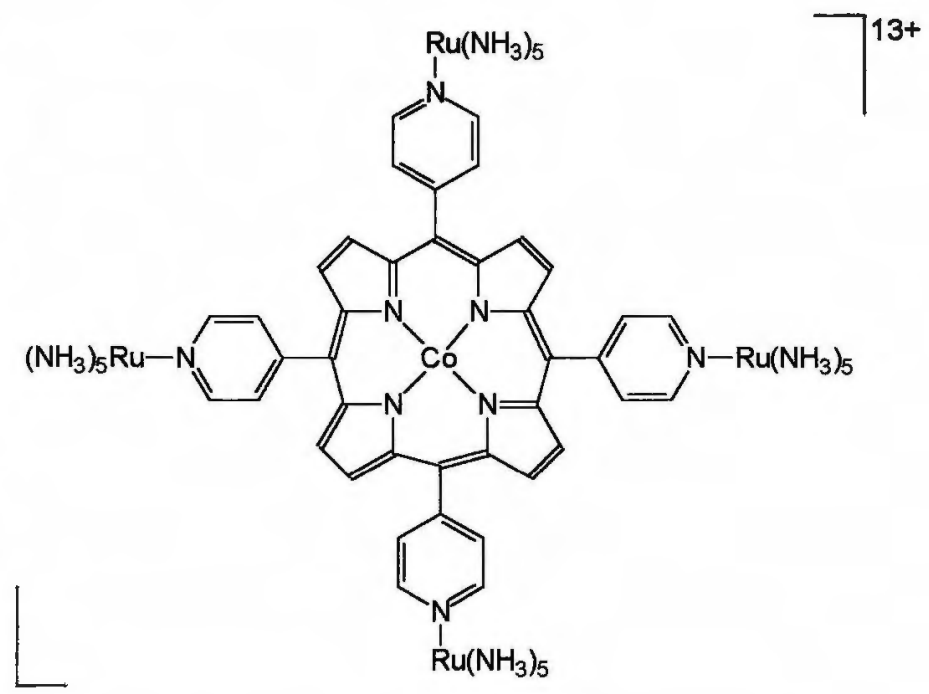

Figura $1.27-$ CoTPyP[Ru( $\left.\left(\mathrm{NH}_{3}\right)_{5}\right]_{4}{ }^{12+}$.

$$
\begin{aligned}
& \text { Co'IPPyP[Ru" } \left.\left.\left(\mathrm{NH}_{3}\right)_{5}\right]_{4}{ }^{13+}+e^{-} \leftrightarrow \text { CollTPyP[Ru'" }\left(\mathrm{NH}_{3}\right)_{5}\right]_{4}{ }^{12+} \\
& \text { Co"TPyP[Ru" } \left.\left(\mathrm{NH}_{3}\right)_{5}\right]_{4}{ }^{12+}+\mathrm{O}_{2} \leftrightarrow \mathrm{O}_{2} \mathrm{Co}^{\prime \prime T P y P}\left[\mathrm{Ru}^{\prime \prime \prime}\left(\mathrm{NH}_{3}\right)_{5}\right]_{4}{ }^{12+} \\
& \left.\mathrm{O}_{2} \mathrm{Co} \text { "TPyP[Ru" }\left(\mathrm{NH}_{3}\right)_{5}\right]_{4}{ }^{12+}+4 \mathrm{e}^{-} \leftrightarrow \mathrm{O}_{2} \mathrm{Co}^{\prime \prime} \mathrm{TPyP}\left[\mathrm{Ru}^{\prime \prime}\left(\mathrm{NH}_{3}\right)_{5}\right]_{4}{ }^{8+} \\
& \mathrm{O}_{2} \mathrm{Co}^{\prime \prime} T P y P\left[\mathrm{Ru}^{\prime \prime}\left(\mathrm{NH}_{3}\right)_{5}\right]_{4}^{8+}+4 \mathrm{e}^{-}+4 \mathrm{H}^{+} \rightarrow \rightarrow \rightarrow \mathrm{Co}^{\prime \prime} T P y P\left[\mathrm{Ru}^{\prime \prime}\left(\mathrm{NH}_{3}\right)_{5}\right]_{4}^{8+}+2 \mathrm{H}_{2} \mathrm{O} \\
& \text { Co"TPyP[Ru" } \left.\left(\mathrm{NH}_{3}\right)_{5}\right]_{4}^{8+}+\mathrm{O}_{2} \leftrightarrow \mathrm{O}_{2} \mathrm{Co}{ }^{\prime \prime} T P y P\left[R u^{\prime \prime}\left(\mathrm{NH}_{3}\right)_{5}\right]_{4}^{8+}
\end{aligned}
$$


1.4.5 A utilização de porfirinas e metaloporfirinas em quimica supramolecular.

Se a combinação de espécies moleculares exibindo propriedades complementares é, como visto anteriormente, de grande interesse em química supramolecular, a utilização de porfirinas e metaloporfirinas como subunidades de sistemas supramoleculares tem sido extensivamente investigada uma vez que podem introduzir propriedades redox, catalíticas ou fotoquímicas em tais sistemas ${ }^{19,20,99,147,148}$, como no segundo exemplo descrito no item 1.2.

Nos últimos anos, a atenção tem se voltado também para o desenvolvimento de oligômeros de porfirinas e metaloporfirinas sempre que um arranjo ordenado destas presume-se como crucial para uma determinada função; inicialmente, as unidades porfirínicas foram conectadas via ligação covalente envolvendo espaçadores ou não ${ }^{149-}$ 152 (figura 1.28).
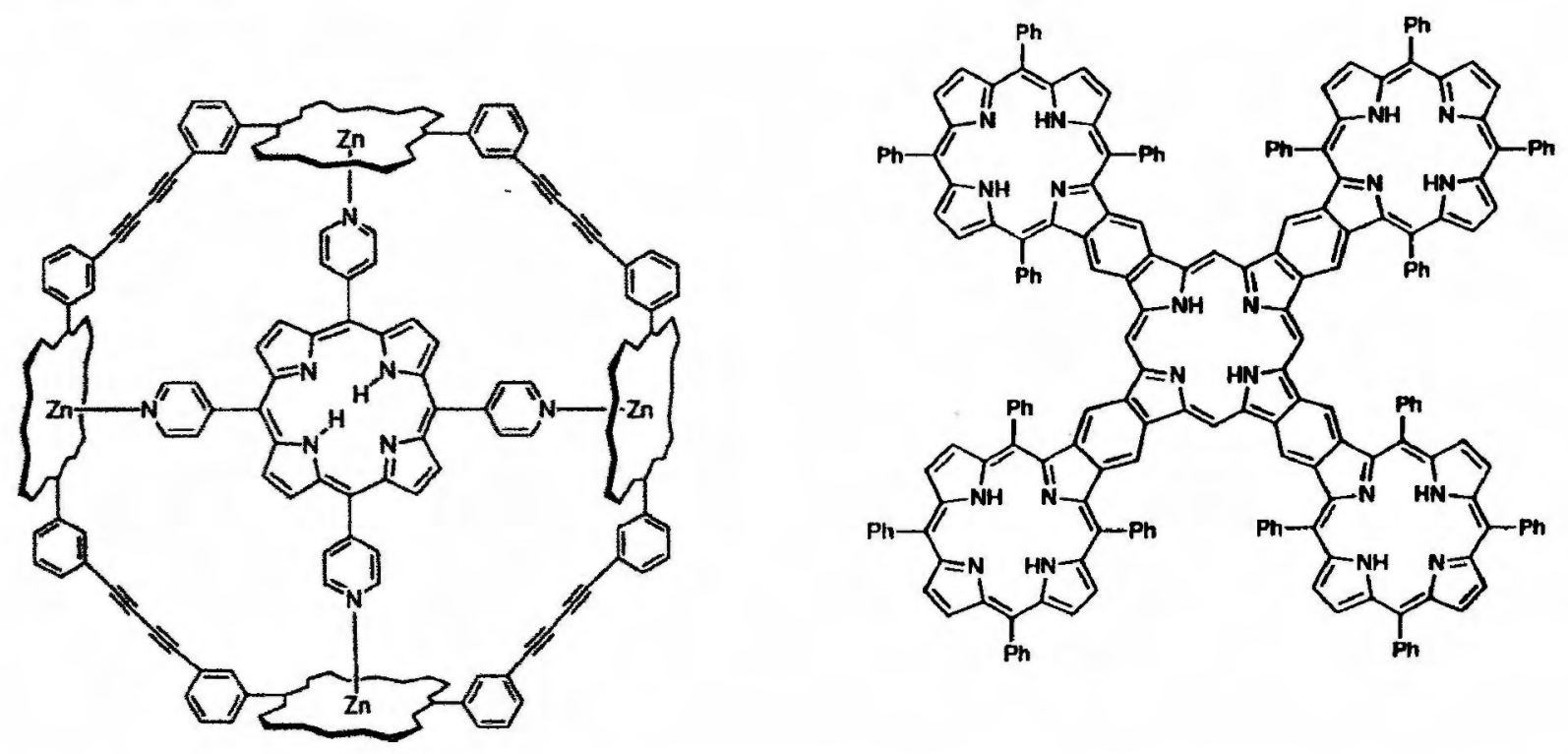

Figura 1.28 - Tetrâmero de porfirina de zinco com porfirina base-livre em seu interior (à esquerda) ${ }^{149}$ e pentâmero de porfirina base-livre sem espaçador (à direita, $\mathrm{Ph}=$ fenil) $^{151}$.

Posteriormente foi desenvolvida uma metodologia alternativa de obtençäo destes arranjos ordenados, com caráter tipicamente supramolecular, baseada no uso do reconhecimento molecular através de ligações de hidrogênio e interações eletrostáticas ou na química de coordenação de íons metálicos ${ }^{153,154}$ (figura 1.29). 

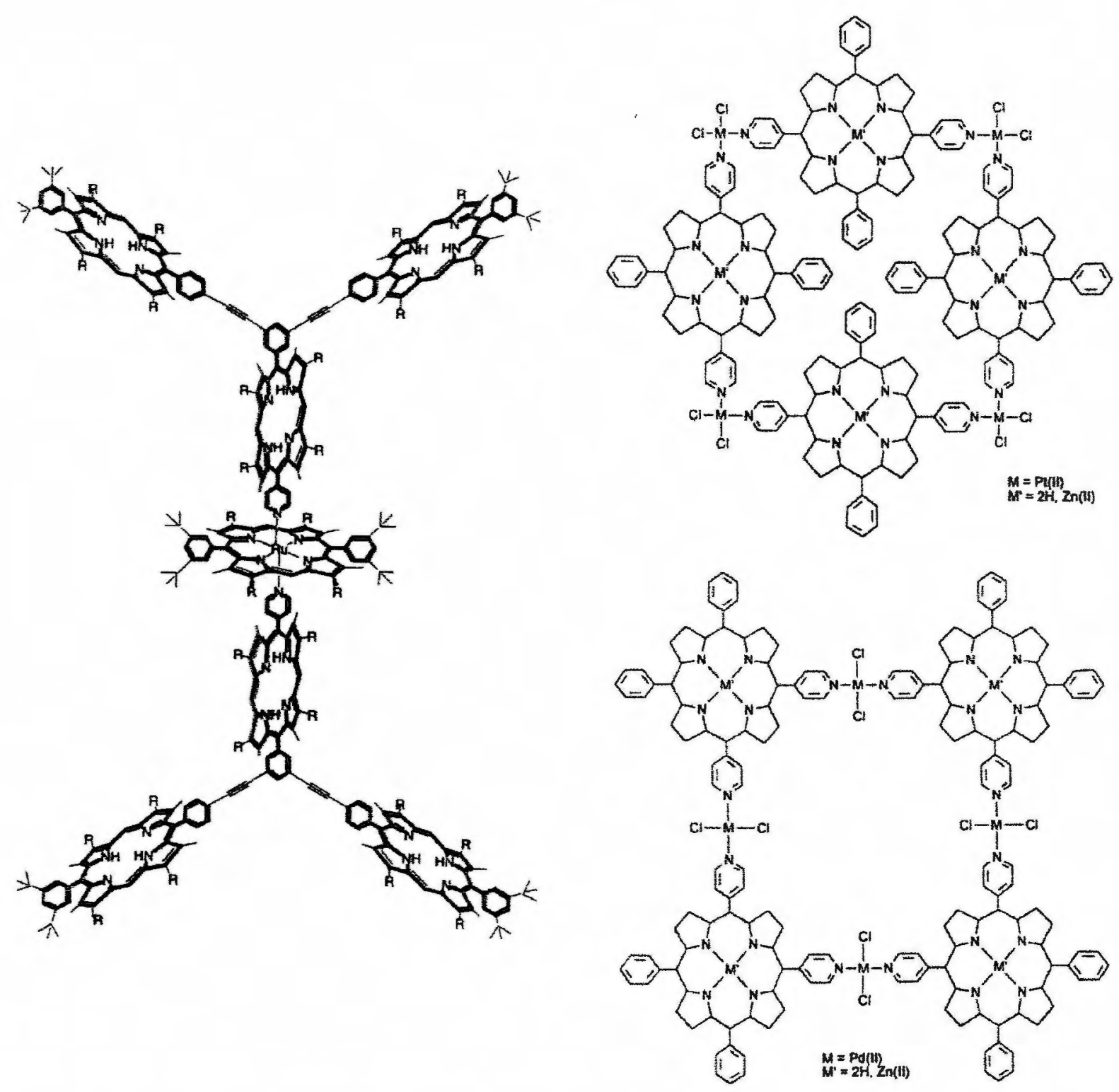

Figura 1.29 - Trímeros de porfirinas base-livre axialmente coordenados a uma porfirina de rutênio (à esquerda, $\mathrm{R}=\mathrm{n}$-hexil) ${ }^{154}$, e tetrâmeros de porfirinas/metaloporfirinas ligados por complexos metálicos(à direita) ${ }^{153}$.

Assim, devido a (i) síntese relativamente fácil, (ii) estabilidade, (iii) diversidade de propriedades e (iv) possibilidade de modificações, seja no centro, seja na periferia, as porfirinas/metaloporfirinas constituem-se em uma classe de unidades estruturais ("building blocks") extremamente atraente para fins supramoleculares. 


\subsection{Objetivos}

As metaloporfirinas modificadas por clusters trinucleares de acetato de rutênio $\left(\mathrm{MTCP}^{n+}\right)$ a que se refere o título do presente trabalho estão mostradas na figura 1.30. Tais compostos são o resultado da continuação do estudo iniciado por Toma et $a l^{88}$, envolvendo a síntese, caracterização e comportamento eletroquímico da mesotetra(cluster)porfirina base-livre $\left(\mathrm{H}_{2} \mathrm{TCP}^{4+}\right)$.

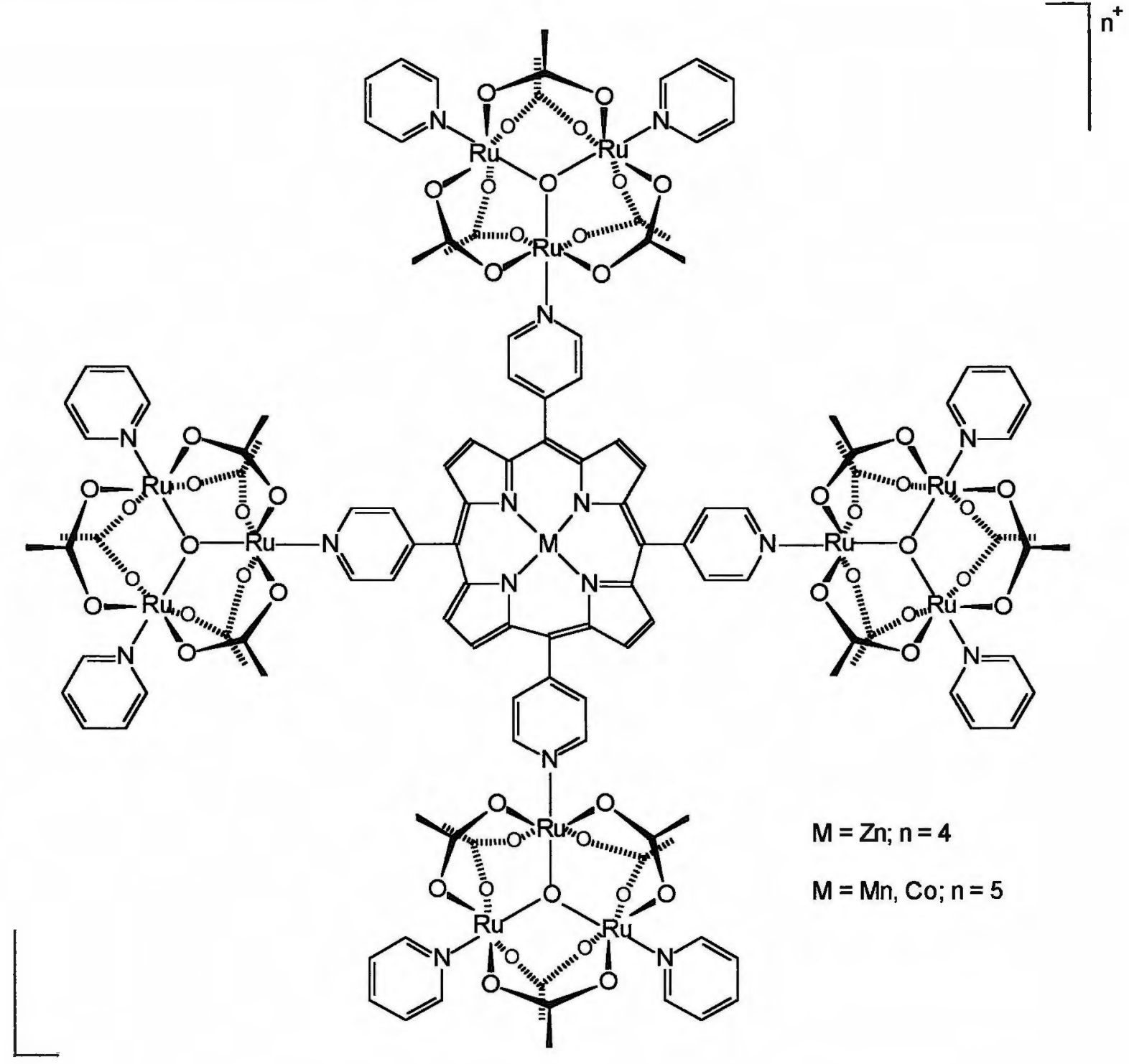

Figura 1.30 - Estrutura de $M T C P^{n+}$.

Dentro de uma concepção de química supramolecular, o projeto de pesquisa, iniciado em março de 1997, apresentava como objetivo a união de um componente de reconhecido potencial catalítico (metaloporfirina) com outro de extensa química de óxido-redução reversível (cluster trinuclear de acetato de rutênio). Presumivelmente, a 
combinação destes dois tipos de unidades em uma supermolécula poderia resultar em uma espécie com reatividade inédita, uma vez que os clusters periféricos poderiam atuar como fonte ou sorvedouro de elétrons em processos catalíticos mediados pelo núcleo porfirínico.

Portanto, o objetivo desta Tese é relatar os resultados obtidos na condução do projeto. Para tanto, são descritas detalhadamente as rotas sintéticas que conduziram à obtenção de três diferentes supermoléculas: três metaloporfirinas (meso-tetra(4piridil)porfirinato de zinco, de manganês, e de cobalto), cada uma delas contendo quatro acetatos trinucleares de rutênio coordenados aos quatro resíduos piridínicos do núcleo porfirínico, como mostrado na figura 1.30, caracterizadas por ressonância magnética nuclear, espectroscopia eletrônica e pelo comportamento eletroquímico.

Finalmente, procurar-se-á demonstrar que a reatividade do núcleo porfirínico foi alterada de forma muito significativa nas supermoléculas, fazendo o uso de algumas das reações usualmente descritas na literatura envolvendo porfirinas de zinco, de manganês e de cobalto: equilíbrios de coordenação axial, oxidações de substratos orgânicos em fase homogênea e redução de dioxigênio por eletrodos quimicamente modificados, respectivamente. 


\section{CAPÍTULO 2}

\section{EXPERIMENTAL}

BIBLIOTECA INSTITUTO DE QUIMICA 


\subsection{Reagentes}

Os reagentes e solventes utilizados sem purificação prévia, todos de grau analítico, e as respectivas procedências, são indicados abaixo.

\begin{tabular}{|c|c|}
\hline $\mathrm{RuCl}_{3} \cdot \mathrm{nH}_{2} \mathrm{O}$ & Aldrich \\
\hline $\mathrm{Na}\left(\mathrm{H}_{3} \mathrm{CCOO}\right) \cdot 3 \mathrm{H}_{2} \mathrm{O}$ & Carlo Erba \\
\hline $\mathrm{C}_{2} \mathrm{H}_{5} \mathrm{OH}$ (absoluto) & Merck \\
\hline $\mathrm{H}_{3} \mathrm{CCOOH}$ (glacial) & Merck \\
\hline $\mathrm{H}_{3} \mathrm{COH}$ & Merck \\
\hline Acetona & Merck \\
\hline Éter etílico & Carlo Erba \\
\hline Piridina & Aldrich \\
\hline Hidrazina & Riedel de Haen \\
\hline Benzeno & Cromato \\
\hline $\mathrm{H}_{2} \mathrm{SO}_{4}$ & Merck \\
\hline $\mathrm{HCOOH}$ & Merck \\
\hline $\mathrm{H}_{2} \mathrm{CCl}_{2}$ & Merck \\
\hline $\mathrm{Br}_{2}$ & Merck \\
\hline $\mathrm{H}_{2} \mathrm{TPyP}$ (97\% pureza) & Aldrich \\
\hline $\mathrm{Mn}\left(\mathrm{H}_{3} \mathrm{CCOO}\right)_{2 .} 4 \mathrm{H}_{2} \mathrm{O}$ & Carlo Erba \\
\hline $\mathrm{Zn}\left(\mathrm{H}_{3} \mathrm{CCOO}\right)_{2 .} 2 \mathrm{H}_{2} \mathrm{O}$ & Quimibrás \\
\hline $\mathrm{Co}\left(\mathrm{H}_{3} \mathrm{CCOO}\right)_{2} \cdot 4 \mathrm{H}_{2} \mathrm{O}$ & Baker \\
\hline 2,2,2-tri-fluoretanol & Aldrich \\
\hline $\mathrm{CH}_{3} \mathrm{CN}$ & Carlo Erba \\
\hline $\mathrm{CD}_{3} \mathrm{CN}$ & Merck \\
\hline Dimetilsulfóxido- $d_{6}\left(\mathrm{DMSO}-d_{6}\right)$ & Aldrich \\
\hline $\mathrm{CuSO}_{4} \cdot 5 \mathrm{H}_{2} \mathrm{O}$ & Carlo Erba \\
\hline 1,2-Dicloroetano (DCE) & Merck \\
\hline Ciclohexano & Carlo Erba \\
\hline Ciclohexanona & Aldrich \\
\hline 1-octanol & Aldrich \\
\hline Imidazol & Sigma \\
\hline Hexafluorfosfato de tetrabutilamônio $\left(\mathrm{TBAPF}_{6}\right)$ & Aldrich \\
\hline $\mathrm{K}_{3}\left[\mathrm{Fe}(\mathrm{CN})_{6}\right]$ & Merck \\
\hline
\end{tabular}


$\mathrm{HClO}_{4}$

Hidróxido de tetrabutilamônio

$\mathrm{KNO}_{3}$

$\mathrm{KCl}$

$\mathrm{AgNO}_{3}$
Merck

Aldrich

Qeel

Carlo Erba

Carlo Erba

N,N'-dimetilformamida (DMF, procedência: Sigma) foi purificado através de secagem por $\mathrm{CuSO}_{4}$, seguida de destilação a pressão reduzida ${ }^{155}$. Iodosilbenzeno (PhIO) foi fornecido pela Prof. Dra. Yassuko lamamoto, do Departamento de Química da Faculdade de Filosofia, Ciências e Letras da Universidade de São Paulo (Ribeirão Preto) bem como cicloocteno (Aldrich); este último foi cromatografado em coluna de alumina imediatamente antes de sua utilização nas reações de oxidação. Perclorato de tetraetilamônio $\left(\mathrm{TEAClO}_{4}\right)$ foi preparado através da reação entre o hidróxido correspondente e ácido perclórico, sendo purificado por recristalização ${ }^{156}$. 


\subsection{Equipamentos e procedimentos}

\subsubsection{Ressonância magnética nuclear $(R M N)$ e espectroscopia eletrônica.}

Todos os espectros de RMN foram obtidos a temperatura ambiente, utilizandose três espectrômetros: Bruker DPX-300 (300 MHz), Bruker DRX-500 (500 MHz) e Varian UNITYINOVA $300 \mathrm{MHz})$. Os valores de deslocamento químico $(\delta, \mathrm{ppm})$ foram reportados em função dos sinais dos prótons residuais dos solventes utilizados.

Os espectros de absorção UV-visível foram obtidos em espectrofotômetro Hewlett Packard modelo 8453.

\subsubsection{Voltametria cíclica e espectroeletroquímica.}

Os voltamogramas cíclicos foram obtidos utilizando-se um potenciostatogalvanostato da EG\&G Instruments (Princeton Applied Research) modelo 283, acoplado a microcomputador $100 \mathrm{Mhz}$ (programa: Model 270/250 Research Electrochemistry Software 4.30). A cela eletroquímica utilizada foi a convencional, de três eletrodos ${ }^{157}$ : eletrodo de trabalho (disco de platina), eletrodo de referência (fio de prata imerso em solução de $\mathrm{AgNO}_{3} 0,01 \mathrm{~mol} \mathrm{dm}^{-3} / \mathrm{TEACIO}_{4} 0,10 \mathrm{~mol} \mathrm{dm}^{-3} \mathrm{em} \mathrm{CH} \mathrm{CH}_{3} \mathrm{CN}$, com potencial igual a $0,503 \mathrm{~V}$ versus o eletrodo padrão de hidrogênio, $\mathrm{EPH}^{158-160}$ ), e eletrodo auxiliar (fio de platina). Todos os valores de potencial foram convertidos para - EPH pela adição de $0,503 \mathrm{~V}$ aos potenciais obtidos experimentalmente. Recentemente, Pavlishchuk e Addison ${ }^{161}$ propuseram novas constantes de conversão para potenciais redox medidos em soluções de acetonitrila a $25^{\circ} \mathrm{C}$ contendo $\mathrm{TEAClO}_{4}$ ou TEAPF $6,1 \mathrm{~mol} \mathrm{dm}^{-3}$ versus diferentes eletrodos de referência, entre os quais o acima descrito, para o qual foi sugerido o valor de $+0,542 \mathrm{~V}$ como fator de conversão para ० EPH; este fator de conversão foi baseado no potencial medido para o par ferrocino / ferroceno, enquanto Kratochvil et al ${ }^{158}$ utilizaram o par $\mathrm{Rb}^{\mathrm{l}} / \mathrm{Rb}$ como base

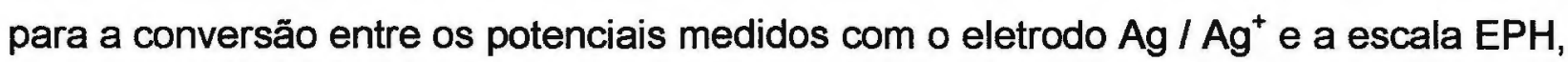
sugerindo, então, o valor $+0,503 \mathrm{~V}^{100,161}$; verificada a diferença significativa entre as duas conversões, resolveu-se manter a conversão de Kratochvil et al, utilizada frequentemente pelo grupo de pesquisa do Prof. Dr. Henrique E. Toma, reservando-se para um período posterior uma investigação mais profunda sobre a proposta de 
Pavlishchuk e Addison. De qualquer forma, os potenciais experimentais podem ser facilmente acessados através da subtração de $0,503 \mathrm{~V}$ dos potenciais reportados.

A espectroeletroquímica foi realizada utilizando-se uma cela de caminho ótico igual a $0,025 \mathrm{~cm}$ dispondo de um minigrid de ouro como eletrodo de trabalho e eletrodos de referência ( $\mathrm{Ag} / \mathrm{Ag}^{+}, 0,503 \mathrm{~V}$ vs EPH) e auxiliar (fio de platina). A aplicação de potenciais foi feita com um potenciostato-galvanostato da EG\&G Instruments (Princeton Applied Research) modelo 173.

2.2.3 Determinação de constante de equilíbrio de coordenação axial por titulação espectrofotométrica.

Para a determinação das constantes de equilibrio de formação dos adutos $\mathrm{ZnTCP}(\mathrm{L})^{4+}$, onde $\mathrm{L}=\mathrm{CH}_{3} \mathrm{CN}$, piridina ou imidazol, foram realizadas titulações espectrofotométricas, monitorando-se a formação pelas alterações na banda Soret. Em um ensaio típico, à uma cela espectrofotométrica de vidro, dispondo em sua parte superior de um bulbo com tampa de vidro esmerilhado, contendo uma solução de $\mathrm{ZnTCP}\left(\mathrm{PF}_{6}\right)_{4}$ em $\mathrm{CH}_{2} \mathrm{Cl}_{2}\left(\left[\mathrm{ZnTCP}\left(\mathrm{PF}_{6}\right)_{4}\right]=(1\right.$ a 2,3$) \times 10^{-6} \mathrm{~mol} \mathrm{dm}^{-3}$, volume $=15$ a 20 $\mathrm{mL}$ ), foram sucessivamente adicionadas pequenas alíquotas (5 a $50 \mu \mathrm{L}$ ) de solução do ligante $\mathrm{L}$ em $\mathrm{CH}_{2} \mathrm{Cl}_{2}$, exceto no caso da titulação com $\mathrm{CH}_{3} \mathrm{CN}$ que foi adicionada sem prévia diluição. Após cada adição e homogeneização, o espectro eletrônico era registrado. Cada titulação foi realizada por duas vezes, no mínimo.

\subsubsection{Oxidações de substratos orgânicos: cromatografia.}

As reações de oxidação foram realizadas em colaboração com Dra. Hérica Cristina Sacco e Profa. Dra. Yassuko lamamoto, no Departamento de Química da Faculdade de Filosofia, Ciências e Letras da Universidade de São Paulo (Ribeirão Preto), tendo sido efetuadas em sistema fechado (frascos de $5 \mathrm{~mL}$ com tampa rosqueada), a temperatura ambiente, sob agitação magnética. Em uma reação típica, soluções do substrato e do catalisador (porfirinas de $\mathrm{Mn}^{\text {III) }}$ ) em $\mathrm{CH}_{3} \mathrm{CN}$ ou 1,2dicloroetano foram transferidas para o frasco de reação, seguindo-se a adição de padrão interno (ciclohexanona para a reação de oxidação do cicloocteno e 1-octanol para a reação de oxidação do ciclohexano) e de PhIO. Os rendimentos reportados nas reações são baseados na quantidade deste oxidante. 
A análise dos produtos das reações de oxidação foi conduzida por cromatografia gasosa pelo método de adição de padrão interno ${ }^{162}$. Cromatógrafo utilizado: Varian, modelo STAR $3400 \mathrm{cx}$ acoplado à Workstation Varian, com detector de ionização de chama. Usou-se nitrogênio ( $30 \mathrm{~mL} \mathrm{~min}^{-1}$ ) como gás de arraste e mistura hidrogênio (40 $\mathrm{mL} \mathrm{min}^{-1}$ ) / ar comprimido (300 $\mathrm{mL} \mathrm{min}^{-1}$ ) para manutenção da chama. Coluna: Megabore ( $30 \mathrm{~m}$ de comprimento por $0,538 \mathrm{~mm}$ de diâmetro interno, contendo como fase líquida um filme de espessura de DB-WAX).

2.2.5 Redução de dioxigênio por eletrodos modificados por filmes de CoTCP: voltametria cíclica, espectroeletroquímica, voltametria de eletrodo de disco rotatório e voltametria de eletrodo de anel e disco rotatórios.

Os filmes de CoTCP ${ }^{5+}$ foram obtidos pela transferência de pequenas alíquotas de solução metanólica $6 \times 10^{-4} \mathrm{~mol} \mathrm{dm}^{-3}$ de $\left[\mathrm{CoTCP}(\mathrm{Cl})\left(\mathrm{H}_{2} \mathrm{O}\right)\right] \mathrm{Cl}_{4}$ para a superfície do eletrodo de carbono vítreo (área $=0,20 \mathrm{~cm}^{2}$ ), permitindo-se a secagem ao ar.

No estudo eletroquímico (voltametria cíclica e espectroeletroquímica) do eletrodo modificado pelo filme de $\mathrm{CoTCP}^{5+}$ em meio aquoso, foi utilizada uma cela eletroquímica de quartzo, com um eletrodo $\mathrm{Ag} / \mathrm{AgCl}\left(\mathrm{KCl} 1,0 \mathrm{~mol} \mathrm{dm}^{-3}\right)$ como referência (potenciais convertidos para o EPH pela adição de $0,222 \mathrm{~V}$ aos valores experimentais de potencial), e um fio de platina como eletrodo auxiliar. $\mathrm{KNO}_{3} 0,5 \mathrm{~mol}$ $\mathrm{dm}^{-3} \mathrm{em}$ tampão acetato $0,05 \mathrm{~mol} \mathrm{dm}^{-3}(\mathrm{pH}=4,7)$ foi usado como eletrólito suporte. $\mathrm{Na}$ espectroeletroquímica, este mesmo arranjo foi utilizado no registro dos espectros a diferentes potenciais, com $\circ$ auxílio de um espectrofotômetro de fibra ótica (Guided Wave, modelo 260).

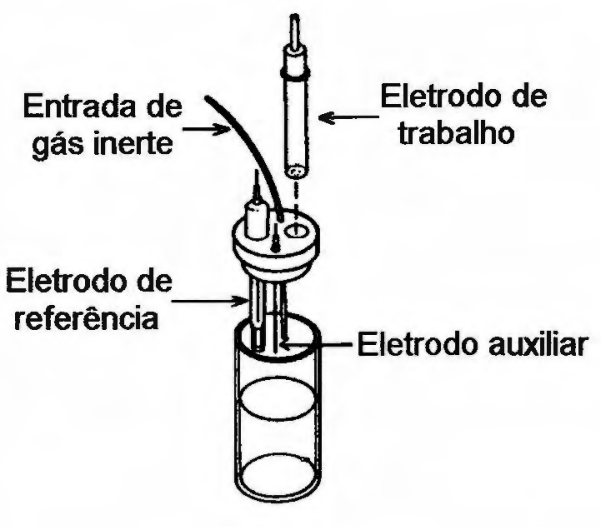

Figura 2.1 - Cela eletroquimica.

No estudo da redução catalítica de dioxigênio pelo filme de CoTCP $^{5+}$ em meio aquoso $\left(\mathrm{KNO}_{3} 0,5 \mathrm{~mol} \mathrm{dm}^{-3}\right.$; tampão acetato $0,05 \mathrm{~mol} \mathrm{dm}^{-3}, \mathrm{pH}=4,7$ ), foram feitos experimentos de voltametria cíclica, voltametria de eletrodo de disco rotatório e voltametria de anel e disco rotatórios, tendo sido utilizados: potenciostato-galvanostato da EG\&G Instruments (Princeton Applied Research, modelo 283); bipotenciostato (EG\&G / PAR, modelo 366); registrador gráfico Hewlett Packard (modelo 7090A); 
sistema de eletrodos anel-disco (EG\&G / PAR, modelo 636); eletrodo de anel de platina e disco de carbono vítreo (EG\&G / PAR, modelo AFMT 28T GC/Pt 0030, área do disco $\left.=0,16 \mathrm{~cm}^{2}\right)$. Os eletrodos de referência e auxiliar utilizados foram, respectivamente, $\mathrm{Ag} / \mathrm{AgCl}\left(\mathrm{KCl} 1,0 \mathrm{~mol} \mathrm{dm}^{-3}\right)$ e fio de platina. 


\subsection{Sínteses}

\subsubsection{Síntese de $\left[R u_{3} \mathrm{O}(\mathrm{OAc})_{6}(p y)_{2}\left(\mathrm{CH}_{3} \mathrm{OH}\right)\right] P F_{6}$.}

A síntese deste cluster assimétrico, baseada em modificaçōes do procedimento desenvolvido por Meyer et $a f^{27}$ a partir do descrito por Spencer e Wilkinson ${ }^{26,50}$ (conforme discutido no item 1.3.1), envolve quatro etapas. $O$ cluster obtido inicialmente, $\left[\mathrm{Ru}_{3} \mathrm{O}(\mathrm{OAc})_{6}\left(\mathrm{CH}_{3} \mathrm{OH}\right)_{3}\right] \mathrm{H}_{3} \mathrm{CCOO}$, apesar de conter acetato de sódio como impureza, é considerado adequado para a utilização nas etapas subsequentes ${ }^{26,27,74,75,163,164}$; em vista disso, não foram incluídos cálculos de rendimento nas descrições das etapas, mas citaram-se apenas as massas obtidas dos produtos.

a) Primeira etapa: obtenção de $\left[\mathrm{Ru}_{3} \mathrm{O}(\mathrm{OAc})_{6}\left(\mathrm{CH}_{3} \mathrm{OH}\right)_{3}\right] \mathrm{H}_{3} \mathrm{CCOO}$.

Em um balão de fundo redondo de $500 \mathrm{~mL}$ adicionou-se $5 \mathrm{~g}$ de $\mathrm{RuCl}_{3} \cdot \mathrm{nH}_{2} \mathrm{O}, 10 \mathrm{~g}$ de $\mathrm{NaOAc} .3 \mathrm{H}_{2} \mathrm{O}, 125 \mathrm{~mL}$ de álcool etílico absoluto e $125 \mathrm{~mL}$ de ácido acético glacial. Após manter a mistura reacional em refluxo por 4 horas, seguido de repouso durante a noite, filtrou-se a solução. O filtrado foi evaporado (em rotoevaporador) até a formação de óleo. Adicionou-se, então, $100 \mathrm{~mL}$ de metanol, evaporando-se a solução novamente. Esta última operação (adição de metanol seguida de evaporação) foi repetida outras duas vezes. Finalmente, após adicionar $200 \mathrm{~mL}$ de acetona ao resíduo, filtrou-se a solução, lavando-se o sólido obtido (cor verde) com éter etílico. $O$ produto foi seco ao ar, posteriormente à vacuo em dessecador contendo sílica gel, obtendo-se $5,2 \mathrm{~g}$.

b) Segunda etapa: obtenção de $\left[R u_{3} O(O A c)_{6}(p y)_{3}\right]$.

A uma solução contendo $6 \mathrm{~g}$ de $\left[\mathrm{Ru}_{3} \mathrm{O}(\mathrm{OAc})_{6}\left(\mathrm{CH}_{3} \mathrm{OH}\right)_{3}\right] \mathrm{OAc}$ em $360 \mathrm{~mL}$ de metanol adicionou-se $24 \mathrm{~mL}$ de piridina, aquecendo-se sob refluxo por 5 minutos. Resfriou-se a solução em banho de gelo, seguindo-se a adição de $26 \mathrm{~mL}$ de solução aquosa de hidrazina a 65\%, lentamente e sob agitação. Após a adição, manteve-se a agitação por mais quinze minutos, seguindo-se filtração e lavagem do sólido obtido (cor verde) com água, metanol e, por fim, com éter etílico. $O$ produto foi seco ao ar, posteriormente à vácuo em dessecador contendo sílica gel, obtendo-se $4 \mathrm{~g}$. 
c) Terceira etapa: obtenção de $\left[\mathrm{Ru}_{3} \mathrm{O}\left(\mathrm{H}_{3} \mathrm{CCOO}\right)_{6}(\mathrm{py})_{2}(\mathrm{CO})\right] \mathrm{C}_{6} \mathrm{H}_{6}$.

Adicionou-se $4 \mathrm{~g}$ de $\left[\mathrm{Ru}_{3} \mathrm{O}(\mathrm{OAc})_{6}(\mathrm{py})_{3}\right]$ a uma solução contendo $300 \mathrm{~mL}$ de benzeno e $100 \mathrm{~mL}$ de metanol, deaerada com argônio. Mantendo-se a solução em refluxo, borbulhou-se $\mathrm{CO}$ (gerado pelo gotejamento de ácido fórmico sobre $\mathrm{H}_{2} \mathrm{SO}_{4} \mathrm{em}$ sistema separado) por 5 horas. Após resfriamento, filtrou-se a solução, lavando-se o sólido obtido (cor azul) com éter etílico, seguindo-se secagem ao ar, posteriormente à vácuo em dessecador contendo sílica gel. Obteve-se $2,8 \mathrm{~g}$ de produto.

d) Quarta etapa: obtenção de $\left[\mathrm{Ru}_{3} \mathrm{O}\left(\mathrm{H}_{3} \mathrm{CCOO}\right)_{6}(\mathrm{py})_{2}\left(\mathrm{CH}_{3} \mathrm{OH}\right)\right] \mathrm{PF}$.

Dissolveu-se $2,8 \mathrm{~g}$ de $\left[\mathrm{Ru}_{3} \mathrm{O}\left(\mathrm{H}_{3} \mathrm{CCOO}\right)_{6}(\mathrm{py})_{2}(\mathrm{CO})\right] \mathrm{C}_{6} \mathrm{H}_{6}$ em $280 \mathrm{~mL}$ de $\mathrm{CH}_{2} \mathrm{Cl}_{2}$. Sob agitação, adicionou-se lentamente $56 \mathrm{~mL}$ de solução de $\mathrm{Br}_{2} 0,15 \mathrm{~mol} \mathrm{dm}^{-3} \mathrm{em} \mathrm{CH}_{2} \mathrm{Cl}_{2}$. Após a adição, manteve-se a agitação por 10 minutos. Em seguida, o solvente foi totalmente removido (rotoevaporador). Ao resíduo adicionou-se $220 \mathrm{~mL}$ de metanol, mantendo-se a solução sob refluxo por 30 minutos. Adicionou-se, então, uma solução contendo $2,7 \mathrm{~g}$ de $\mathrm{NH}_{4} \mathrm{PF}_{6}$ em $15 \mathrm{~mL}$ de metanol. Após resfriamento em banho de gelo, seguiu-se filtração, lavagem do sólido obtido (cor azul) com metanol e, por último, com éter etílico. $\mathrm{O}$ produto foi primeiramente seco ao ar, posteriormente à vácuo em dessecador contendo sílica gel, obtendo-se $2,8 \mathrm{~g}$. Análise (\%) calculada / experimental para $\mathrm{C}_{23} \mathrm{H}_{32} \mathrm{O}_{14} \mathrm{~N}_{2} \mathrm{PF}_{6} \mathrm{Ru}_{3}: \mathrm{C} 27,4 / 27,3 ; \mathrm{H} 3,20 / 3,01 ; \mathrm{N} 2,78 / 2,69$.

\subsubsection{Síntese das metaloporfirinas.}

Uma vez que se dispunha de $\mathrm{H}_{2}$ TPyP comercial (Aldrich, 97\% pureza), a síntese das metaloporfirinas consistituiu-se em apenas inserir os íons $\mathrm{Zn}^{\prime \prime}, \mathrm{Mn}^{\text {" e }} \mathrm{Co}$ " no núcleo porfirínico, o que foi feito pelo método do acetato ${ }^{165}$. Embora tenha se iniciado as reações com os metais no estado de oxidação +2 , trabalhando-se sob atmosfera inerte, foram observadas oxidações dos metais inseridos ( $\mathrm{Co}^{\prime \prime} \rightarrow \mathrm{Co}^{\prime \prime \prime}$ e $\mathrm{Mn}^{\prime \prime} \rightarrow \mathrm{Mn} n^{\text {III}}$ ) pela análise dos espectros eletrônicos dos produtos.

a) Síntese de $\left[\mathrm{ZnTPyP}\left(\mathrm{H}_{2} \mathrm{O}\right)\right] \cdot \mathrm{H}_{2} \mathrm{O}$.

Transferiu-se $0,5 \mathrm{~g}$ de $\mathrm{H}_{2}$ TPyP para balão de $500 \mathrm{~mL}, 3$ bocas, fundo redondo. Adicionou-se $250 \mathrm{~mL}$ de ácido acético glacial. Após borbulhamento de argônio por 15 
minutos, adicionou-se $0,54 \mathrm{~g}$ de $\mathrm{Zn}(\mathrm{OAc})_{2} .2 \mathrm{H}_{2} \mathrm{O}$, deixando-se em refluxo por duas horas sob atmosfera inerte (borbulhamento de argônio). Após resfriamento, evaporouse a solução (rotoevaporador) até formação de óleo, seguindo-se adição de $50 \mathrm{~mL}$ de água destilada e deionizada e nova evaporação. Adicionando-se mais $50 \mathrm{~mL}$ de água, seguiu-se filtração. $O$ sólido obtido (cor violeta escuro) foi lavado com água e, por último, com pequena quantidade de metanol, sendo seco à vacuo em dessecador contendo sílica gel. Rendimento: $83 \%$. Análise (\%) calc. / exp. para $\mathrm{C}_{40} \mathrm{H}_{28} \mathrm{O}_{2} \mathrm{~N}_{8} \mathrm{Zn}$ : C $66,9 / 65,7 ;$ H 3,93 / 3,98; N 15,6 / 15,4.

b) Síntese de $\left[\mathrm{MnTPyP}(\mathrm{OAc})\left(\mathrm{H}_{2} \mathrm{O}\right)\right] \cdot \mathrm{H}_{2} \mathrm{O}$.

O procedimento para esta síntese foi idêntico ao anterior. Neste caso, utilizou-se $0,8 \mathrm{~g}$ de $\mathrm{Mn}(\mathrm{OAC})_{2} .4 \mathrm{H}_{2} \mathrm{O}$ obtendo-se um rendimento de $76 \%$ (sólido de cor violeta escuro). Análise (\%) calc. I exp. para $\mathrm{C}_{42} \mathrm{H}_{31} \mathrm{O}_{4} \mathrm{~N}_{8} \mathrm{Mn}$ : C 65,8 / 65,5; H 4,08 / 4,16; N 14,6 / 14,3.

c) Síntese de $\left[\mathrm{CoTPyP}(\mathrm{OAc})\left(\mathrm{H}_{2} \mathrm{O}\right)\right] \cdot \mathrm{H}_{2} \mathrm{O}$.

O procedimento para esta síntese foi idêntico aos anteriores. Neste caso, utilizou-se $0,8 \mathrm{~g}$ de $\mathrm{Co}(\mathrm{OAc})_{2} \cdot 4 \mathrm{H}_{2} \mathrm{O}$ obtendo-se um rendimento de $78 \%$ (sólido de cor violeta). Análise (\%) calc. / exp. para $\mathrm{C}_{42} \mathrm{H}_{31} \mathrm{O}_{4} \mathrm{~N}_{8} \mathrm{Co}$ : C 65,4 / 64,5; H 4,06 / 4,07; N 14,6 / 14,4.

\subsubsection{Síntese das supermoléculas $\mathrm{ZnTCP^{4+ }}, \mathrm{MnTCP}^{5+}$ e $\mathrm{CoTC} \mathrm{P}^{5+}$.}

O procedimento adotado para a síntese das três supermoléculas é baseado no descrito por Toma et a ${ }^{88}$ para a obtenção de $\mathrm{H}_{2}$ TCP: reação à temperatura ambiente, em 2,2,2-trifluoretanol (TFE), entre o cluster assimétrico $\left[\mathrm{Ru}_{3} \mathrm{O}\left(\mathrm{H}_{3} \mathrm{CCOO}\right)_{6}(\mathrm{py})_{2}\left(\mathrm{CH}_{3} \mathrm{OH}\right)\right] \mathrm{PF}_{6}$ e as correspondentes metaloporfirinas, na proporção molar $1 / 4$ (cluster / metaloporfirina). A estratégia procura utilizar o sítio no cluster contendo o ligante lábil $\left(\mathrm{CH}_{3} \mathrm{OH}\right)$ para promover a coordenação deste com o nitrogênio do resíduo de piridina da posição meso da metaloporfirina.

a) Sintese de $\mathrm{ZnTCP}\left(\mathrm{PF}_{6}\right)_{4}$.

Dissolveu-se $0,056 \mathrm{~g}$ de $\left[\mathrm{ZnTPyP}\left(\mathrm{H}_{2} \mathrm{O}\right)\right] \cdot \mathrm{H}_{2} \mathrm{O}$ em $20 \mathrm{~mL}$ de TFE. Sob agitação, adicionou-se $0,320 \mathrm{~g}$ de $\left[\mathrm{Ru}_{3} \mathrm{O}\left(\mathrm{H}_{3} \mathrm{CCOO}\right)_{6}(\mathrm{py})_{2}\left(\mathrm{CH}_{3} \mathrm{OH}\right)\right] \mathrm{PF} \mathrm{F}_{6}$ dissolvidos em $15 \mathrm{~mL}$ de 
TFE. Manteve-se a agitação por 20 horas, a temperatura ambiente. Após evaporação a $1 / 3$ do volume inicial (rotoevaporador), o produto foi precipitado com éter etílico, filtrando-se em seguida. O sólido obtido (cor verde) foi lavado com água e, por último, com éter etílico. A secagem foi efetuada primeiramente ao ar, posteriormente à vácuo em dessecador contendo sílica gel. Rendimento: 69\%. Análise (\%) calc. / exp. para $\mathrm{C}_{128} \mathrm{H}_{136} \mathrm{O}_{52} \mathrm{~N}_{16} \mathrm{P}_{4} \mathrm{~F}_{24} \mathrm{ZnRu}_{12}$ : C 33,5/34,5; H 2,96/3,13; N 4,88 / 5, 17.

b) Síntese de $\left[\mathrm{MnTCP}(\mathrm{OAc})\left(\mathrm{H}_{2} \mathrm{O}\right)\right]\left(\mathrm{PF}_{6}\right)_{4}$.

O procedimento para esta síntese foi idêntico ao anterior. Neste caso, foram utilizadas $0,068 \mathrm{~g}$ de $\left[\mathrm{MnTPyP}(\mathrm{OAc})\left(\mathrm{H}_{2} \mathrm{O}\right)\right] \cdot \mathrm{H}_{2} \mathrm{O}$ e $0,373 \mathrm{~g}$ de $\left[\mathrm{Ru}_{3} \mathrm{O}\left(\mathrm{H}_{3} \mathrm{CCOO}\right)_{6}(\mathrm{py})_{2}\left(\mathrm{CH}_{3} \mathrm{OH}\right)\right] \mathrm{PF}$. Rendimento: $75 \%$ (sólido de cor verde). Análise (\%) calc. $/$ exp. para $\mathrm{C}_{130} \mathrm{H}_{141} \mathrm{O}_{55} \mathrm{~N}_{16} \mathrm{P}_{4} \mathrm{~F}_{24} \mathrm{MnRu}_{12}$ : C 33,5 / 33,5; H 3,05/3,03; N 4,82 / 5, 14.

c) Síntese de $\left[\mathrm{CoTCP}(\mathrm{OAC})\left(\mathrm{H}_{2} \mathrm{O}\right)\right]\left(\mathrm{PF}_{6}\right)_{4}$.

Neste caso, o procedimento adotado foi ligeiramente diferente: dissolveu-se $0,074 \mathrm{~g}$ de [CoTPyP(OAc) $\left.\left(\mathrm{H}_{2} \mathrm{O}\right)\right] \cdot \mathrm{H}_{2} \mathrm{O}$ em $250 \mathrm{~mL}$ de TFE. Sob agitação, adicionou-se $0,426 \mathrm{~g}$ de $\left[\mathrm{Ru}_{3} \mathrm{O}\left(\mathrm{H}_{3} \mathrm{CCOO}\right)_{6}(\mathrm{py})_{2}\left(\mathrm{CH}_{3} \mathrm{OH}\right)\right] \mathrm{PF}_{6}$, mantendo-se a agitação por 20 horas. $\mathrm{O}$ solvente foi, então, totalmente removido (rotoevaporador). O resíduo foi lavado com metanol, exaustivamente com água $\mathrm{e}$, por último, com éter etílico. A secagem do sólido (cor verde) foi feita primeiramente ao ar, posteriormente à vácuo em dessecador contendo sílica gel. Rendimento: $52 \%$. Análise (\%) calc. / exp. para $\mathrm{C}_{130} \mathrm{H}_{141} \mathrm{O}_{55} \mathrm{~N}_{16} \mathrm{P}_{4} \mathrm{~F}_{24} \mathrm{CoRu}_{12}$ : C 33,5 / 32,6; H 3,03 / 3,03; N 4,81 / 4,89.

Troca do contra-ion e do ligante axial de [CoTCP $\left.(\mathrm{OAC})\left(\mathrm{H}_{2} \mathrm{O}\right)\right]\left(\mathrm{PF}_{6}\right)_{4}$ : adicionou-se 300 $\mathrm{mg}$ de $\mathrm{LiCl}$ a $25 \mathrm{~mL}$ de $\mathrm{CH}_{3} \mathrm{CN}$; o sobrenadante foi sendo lentamente transferido para um balão de $125 \mathrm{~mL}$ (fundo redondo) contendo $50 \mathrm{mg}$ de [CoTCP(OAC)( $\left.\left.\mathrm{H}_{2} \mathrm{O}\right)\right]\left(\mathrm{PF}_{6}\right)_{4}$ dissolvidos em $10 \mathrm{~mL}$ de $\mathrm{CH}_{3} \mathrm{CN}$, sob agitação. Ao final da adição, o $\mathrm{LiCl}$ residual foi dissolvido em $1 \mathrm{~mL}$ de água destilada e deionizada, e a solução resultante foi transferida para o balão contendo a solução de CoTCP, mantendo-se a agitação durante 1 hora. $O$ produto foi precipitado com éter etílico, filtrando-se a seguir. A secagem foi efetuada à vácuo em dessecador contendo sílica gel. Rendimento: $80 \%$ de $\left[\mathrm{CoTCP}(\mathrm{Cl})\left(\mathrm{H}_{2} \mathrm{O}\right)\right](\mathrm{Cl})_{4}$ (sólido de cor verde). 
CAPÍTULO 3

RESSONÂNCIA MAGNÉTICA NUCLEAR 


\subsection{ZnTCP $\left(\mathrm{PF}_{6}\right)_{4}$}

Os sinais nos espectros de RMN- ${ }^{1} \mathrm{H}$ e RMN $-{ }^{13} \mathrm{C}$ de $\mathrm{ZnTCP}\left(\mathrm{PF}_{6}\right)_{4}$ em $\mathrm{CD}_{3} \mathrm{CN}$ foram atribuídos com base nos experimentos DEPT 135 (espectro RMN unidimensional de correlação ${ }^{1} \mathrm{H}-{ }^{13} \mathrm{C}$ com intensificação de sinal por transferência de polarização), COSY (espectro RMN bidimensional de correlação homonuclear ${ }^{1} \mathrm{H}-{ }^{1} \mathrm{H}$ ) e HETCOR (espectro RMN bidimensional de correlação heteronuclear ${ }^{1} \mathrm{H}-{ }^{13} \mathrm{C}$ ), tendo sido confirmados por comparação com os espectros de clusters trinucleares de acetato de rutênio (discutidos no Capítulo 1 , item 1.3.2), assim como de porfirinas mesosubstituídas $^{166-168}$ e do análogo $\mathrm{H}_{2} \mathrm{TCP}\left(\mathrm{PF}_{6}\right)_{4}{ }^{88}$.

Os espectros RMN- ${ }^{1} \mathrm{H}$ e COSY de solução $2 \times 10^{-3} \mathrm{~mol} \mathrm{dm}^{-3}$ de $\mathrm{ZnTCP}\left(\mathrm{PF}_{6}\right)_{4} \mathrm{em}$ $\mathrm{CD}_{3} \mathrm{CN}$ são mostrados na figura 3.1. Como pode ser observado, o sinal em $7,85 \mathrm{ppm}$ $(8 \mathrm{H})$ não é acoplado com qualquer outro sinal, sendo sua posição consistente com a posição de sinais de 8 prótons pirrólicos de porfirinas diamagnéticas ${ }^{166-168}$. Este singlete, que informa uma espécie simétrica, foi atribuído aos 8 prótons pirrólicos $\mathrm{H}_{m}$ de $\mathrm{ZnTCP}\left(\mathrm{PF}_{6}\right)_{4}$ ( fig. 3.1). De modo semelhante, os dois sinais intensos (singletes) em 5,02 e $5,11 \mathrm{ppm}$ (total $=72 \mathrm{H}$ ) não mostram-se acoplados com quaisquer outros sinais, sendo característicos de prótons metílicos dos acetatos em ponte de clusters trinucleares de rutênio (Capítulo 1, item 1.3.2); tais sinais foram atribuídos aos prótons $\mathrm{H}_{\mathrm{c}}$ e $\mathrm{H}_{\mathrm{a}}$ de $\mathrm{ZnTCP}\left(\mathrm{PF}_{6}\right)_{4}$, respectivamente.

No Capítulo 1 , item 1.3.2, foi visto que as propriedades paramagnéticas do núcleo $\mathrm{Ru}_{3} \mathrm{O}$ podem induzir grandes deslocamentos para menores frequências dos sinais dos prótons das piridinas coordenadas em relação aos respectivos sinais das piridinas livres, um efeito que decresce rapidamente em função da distância. Assim, o sinal em $0,34 \mathrm{ppm}(16 \mathrm{H})$ foi atribuído aos prótons nas posiçōes orto das piridinas terminais, enquanto os sinais em 5,92 (16H) e 6,69 (8H) foram atribuídos aos prótons nas posições meta e para, respectivamente. Por outro lado, o núcleo porfirínico induz um efeito de corrente de anel sobre os prótons das piridinas em ponte, deslocando os sinais em sentido oposto (maiores frequências). Portanto, os sinais em 6,52 ppm (8H) e $1,00 \mathrm{ppm}(8 \mathrm{H})$ puderam ser atribuídos aos prótons $\mathrm{H}_{\mathrm{i}}$ e $\mathrm{H}_{\mathrm{h}}$ das piridinas em ponte. Tais atribuições são suportadas pelo espectro COSY (fig. 3.1).

$\mathrm{Na}$ figura 3.2 observa-se que, no caso do espectro $\mathrm{RMN}-{ }^{13} \mathrm{C}$, a atribuição dos carbonos não-quaternários foi efetuada pelo espectro HETCOR, enquanto os sinais dos carbonos quaternários foram assinalados com auxílio do espectro DEPT 135 e por 
comparação $^{169}$, principalmente com o espectro de $\mathrm{H}_{2} \mathrm{TCP}\left(\mathrm{PF}_{6}\right)_{4}{ }_{4}^{88}$. O sinal correspondente ao carbono $C_{j}$ não pôde ser observado, provavelmente devido a sua baixa intensidade ${ }^{88}$.
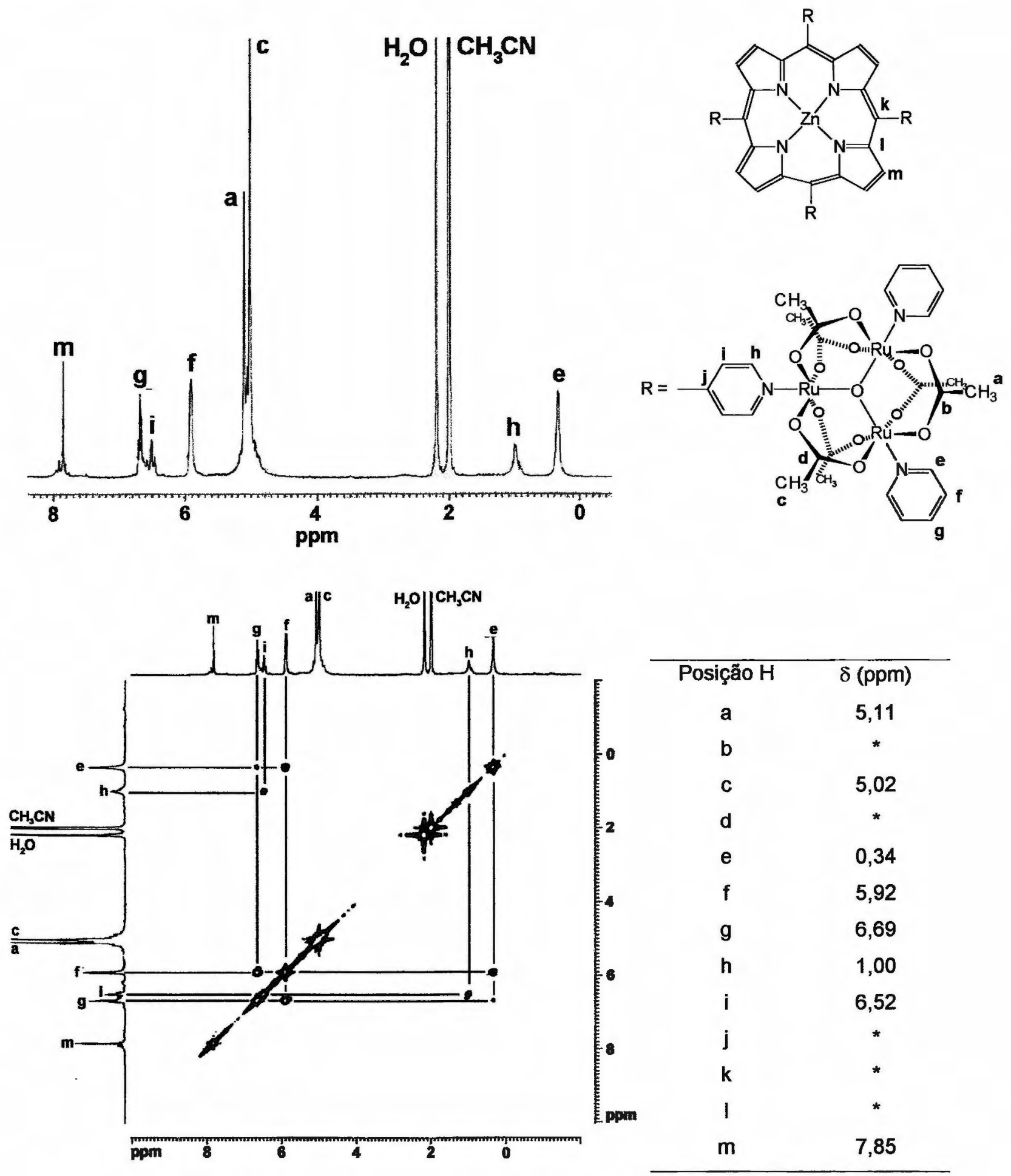

Figura 3.1 - Espectro RMN- ${ }^{1} \mathrm{H}$ (à esquerda, acima) e espectro COSY (à esquerda, abaixo) de $\mathrm{ZnTCP}\left(\mathrm{PF}_{6}\right)_{4} 2 \times 10^{-3} \mathrm{~mol} \mathrm{dm}^{-3} \mathrm{em} \mathrm{CD}_{3} \mathrm{CN}$. As letras referem-se às posições dos prótons na estrutura (à direita, acima), cujos deslocamentos químicos $(\delta, \mathrm{ppm})$ estão indicados à direita, abaixo. Equipamento: Espectrômetro Bruker DPX-300. 


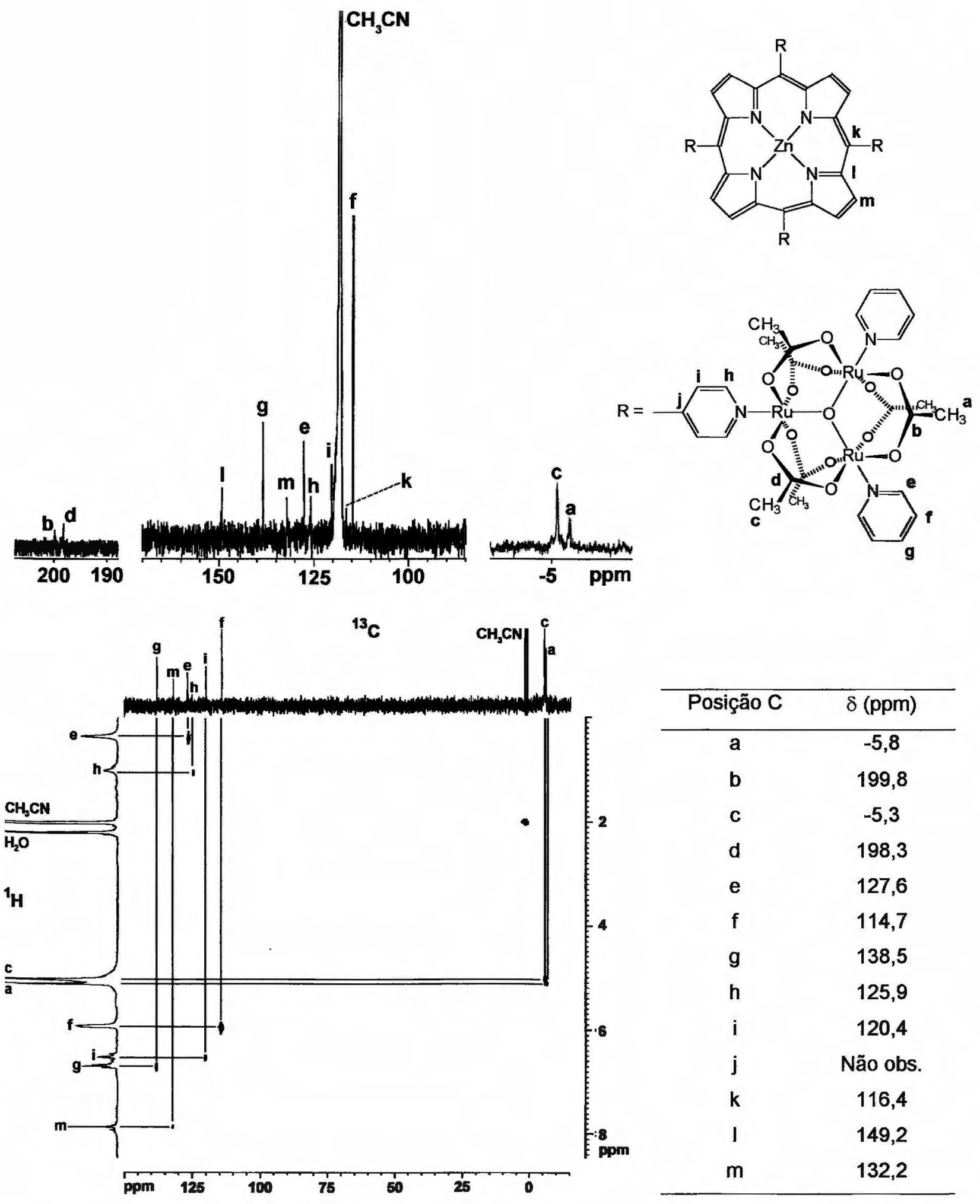

Figura 3.2 - Espectro RMN $-{ }^{13} \mathrm{C}$ (à esquerda, acima) e espectro HETCOR (à esquerda, abaixo, com correlação de prótons efetuada com os sinais dos átomos de carbono no espectro DEPT-135) de $\mathrm{ZnTCP}\left(\mathrm{PF}_{6}\right)_{4} 2 \times 10^{-3} \mathrm{~mol} \mathrm{dm}^{-3} \mathrm{em} \mathrm{CD}_{3} \mathrm{CN}$. As letras referem-se às posições dos carbonos na estrutura (à direita, acima), cujos deslocamentos químicos $(\delta, \mathrm{ppm})$ estão indicados à direita, abaixo. Equipamento: Espectrômetro Bruker DPX-300. 


\section{2 $\left[\mathrm{MnTCP}(\mathrm{OAC})\left(\mathrm{H}_{2} \mathrm{O}\right)\right]\left(\mathrm{PF}_{6}\right)_{4}$}

A figura 3.3 apresenta o espectro $\mathrm{RMN}-{ }^{1} \mathrm{H}$ de $\left[\mathrm{MnTCP}(\mathrm{OAc})\left(\mathrm{H}_{2} \mathrm{O}\right)\right]\left(\mathrm{PF}_{6}\right)_{4}$ em DMSO- $d_{6}$, com a respectiva atribuição dos sinais.

\begin{tabular}{cc}
\hline Posição H & $\delta$ (ppm) \\
\hline a & 4,57 \\
b & 4,43 \\
c & $-0,18$ \\
d & 6,01 \\
e & 6,46 \\
f & $\sim 0,4$ (largo) \\
g & $\sim 8,5$ (largo) \\
h & $\sim-28$ (largo) \\
\hline
\end{tabular}
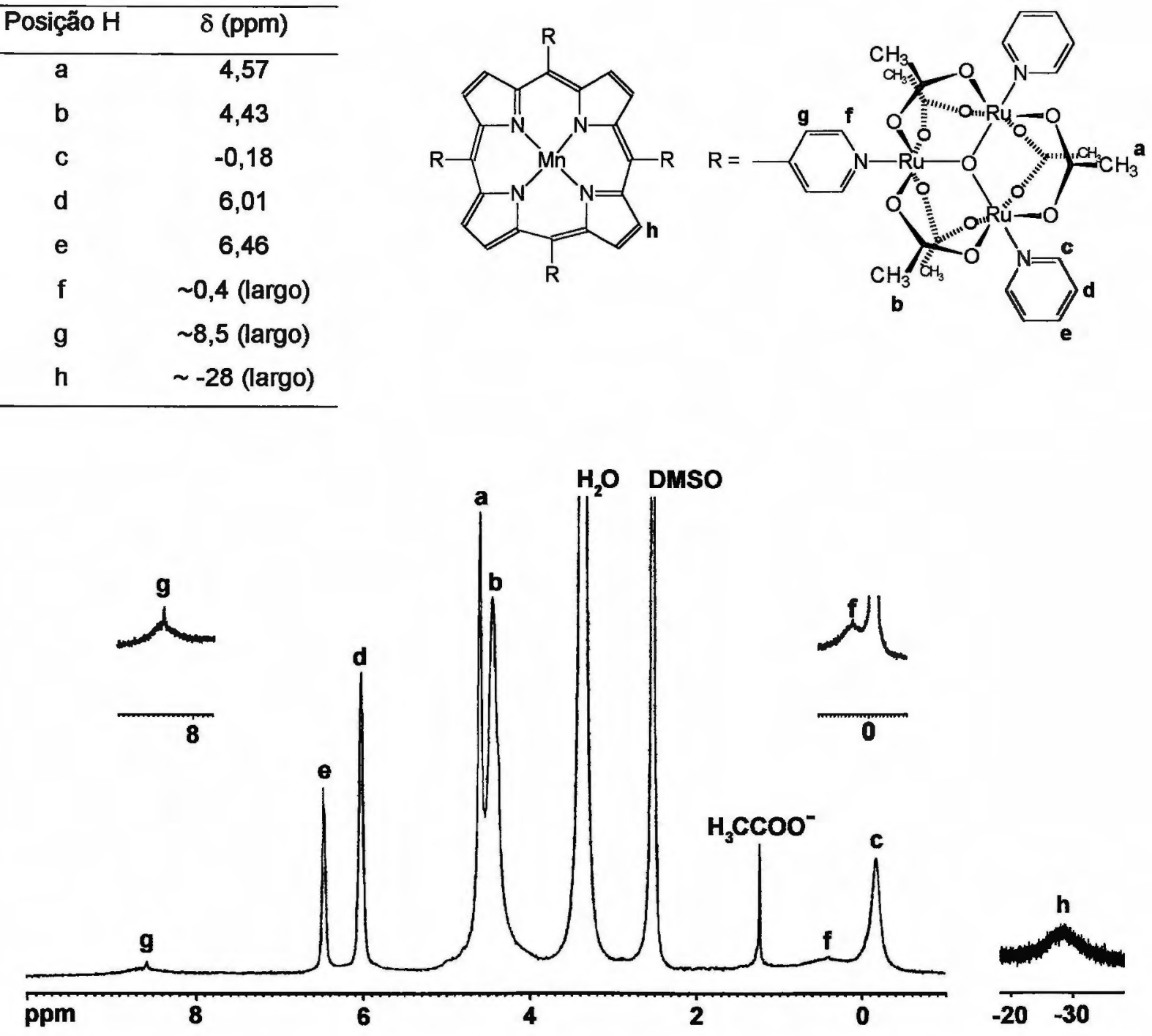

Figura 3.3 - Espectro RMN- ${ }^{-1} \mathrm{H}$ de $\left[\mathrm{MnTCP}(\mathrm{OAc})\left(\mathrm{H}_{2} \mathrm{O}\right)\right]\left(\mathrm{PF}_{6}\right)_{4} 2 \times 10^{-3} \mathrm{~mol} \mathrm{dm}^{-3} \mathrm{em}$ DMSO- $d_{6}$. As letras referem-se às posições dos prótons na estrutura (à direita, acima), cujos deslocamentos químicos $(\delta, \mathrm{ppm})$ estão indicados à esquerda, acima.

Equipamento: Espectrômetro Bruker DRX-500.

Esta supermolécula possui um sítio paramagnético adicional, em relação a $\mathrm{ZnTCP}^{4+}$ : o ín $\mathrm{Mn}^{\text {III }}$ no núcleo porfirínico. Em consequência, os sinais mostram-se alargados e deslocados. Uma comparação dos espectros do cluster $\left[\mathrm{Ru}_{3} \mathrm{O}(\mathrm{OAc})_{6}(\mathrm{py})_{3}\right]^{+}$ (Capítulo 1, item 1.3.2) e de [Mn ${ }^{\text {IIITPP] }}{ }^{+166}$ mostra que o efeito do paramagnetismo do núcleo $\mathrm{Ru}_{3} \mathrm{O}$ sobre os sinais de $\mathrm{RMN}$ não é tão pronunciado quanto o provocado pelo 
ion $\mathrm{Mn}^{\mathrm{III}}$ do núcleo porfirínico. Por exemplo, os sinais dos prótons pirrólicos de [Mn ${ }^{\text {IIITPP] }}{ }^{+}$localizam-se entre $-19,7$ e $-36,4$ enquanto os sinais dos prótons nas posições orto dos grupos fenil ou não são observados, ou apresentam-se como sinais alargados na região onde normalmente ocorrem em tetra(fenil)porfirinas diamagnéticas $^{166,170}$. Este efeito do íon $\mathrm{Mn}^{\text {"II }}$ torna-se menos pronunciado a medida que a distância do íon aumenta, de modo que os sinais de $\left[\mathrm{MnTCP}(\mathrm{OAC})\left(\mathrm{H}_{2} \mathrm{O}\right)\right]\left(\mathrm{PF}_{6}\right)_{4} \mathrm{em}$ 4,$57 ; 4,43 ;-0,18 ; 6,01 ;$ e 6,46 foram atribuídos aos prótons mais afastados deste íon, por comparação com os espectros de $\mathrm{H}_{2} \mathrm{TCP}\left(\mathrm{PF}_{6}\right)_{4}{ }_{4}^{88}$ e $\mathrm{ZnTCP}\left(\mathrm{PF}_{6}\right)_{4}$. Os sinais alargados em 8,5 e 0,4 foram atribuídos aos prótons das piridinas em ponte, e o sinal em -28 ppm aos prótons pirrólicos do núcleo porfirínico.

Também observa-se no espectro da figura 3.3 que o sinal bem definido em 1,22 ppm reflete uma influência negligenciável tanto do ín paramagnético $\mathrm{Mn}^{\text {III }}$ como dos clusters periféricos. Tal sinal foi atribuído aos prótons do grupo acetato, proposto inicialmente como um dos dois ligantes axiais de $\mathrm{MnTCP}^{5+}$, por comparação com o respectivo sinal de acetato de sódio em $\mathrm{D}_{2} \mathrm{O}(1,90 \mathrm{ppm})^{171}$. Este resultado indica que este ligante não está axialmente coordenado ao íon $\mathrm{Mn}^{\text {III }}$ em solução de DMSO, como já observado por Kelly e Kadish ${ }^{172}$ para haletos e pseudo-haletos. 


\section{$3.3\left[\mathrm{CoTCP}(\mathrm{Cl})\left(\mathrm{H}_{2} \mathrm{O}\right)\right] \mathrm{Cl}_{4}$}

O espectro de RMN- ${ }^{1} \mathrm{H}$ de $\left[\mathrm{CoTCP}(\mathrm{Cl})\left(\mathrm{H}_{2} \mathrm{O}\right)\right] \mathrm{Cl}_{4}$ em DMSO-d (figura 3.4) apresenta sinais muito alargados, fato incomum para uma porfirina de $\mathrm{Co}^{\text {III. }}$. Geralmente, estes complexos são diamagnéticos, exibindo espectros bem definidos na presença de ligantes axiais ou em solventes coordenantes (espécies hexacoordenadas com relação ao íon central $\left.\mathrm{Co}^{\prime \prime \prime}\right)^{173,174}$. Em alguns casos, particularmente em solventes não-coordenantes como $\mathrm{CDCl}_{3}$, o espectro pode apresentar-se com sinais alargados $^{175}$. Tal alargamento tem sido atribuído à presença de espécies paramagnéticas pentacoordenadas ( $\pi$-cátion radical ou porfirina de Co"); alternativamente, o alargamento tem sido associado a porfirinas de Coll' spin alto ou a um equilíbrio de spin $^{173}$.

\begin{tabular}{cc}
\hline Posição H & $\delta$ (ppm) \\
\hline a, b & 4,47 \\
c & 0,13 \\
d & 6,15 \\
e & 6,53 \\
f & 0,85 \\
g & $\sim 8,0$ (largo) \\
h & $\sim 9,0$ (largo) \\
\hline
\end{tabular}
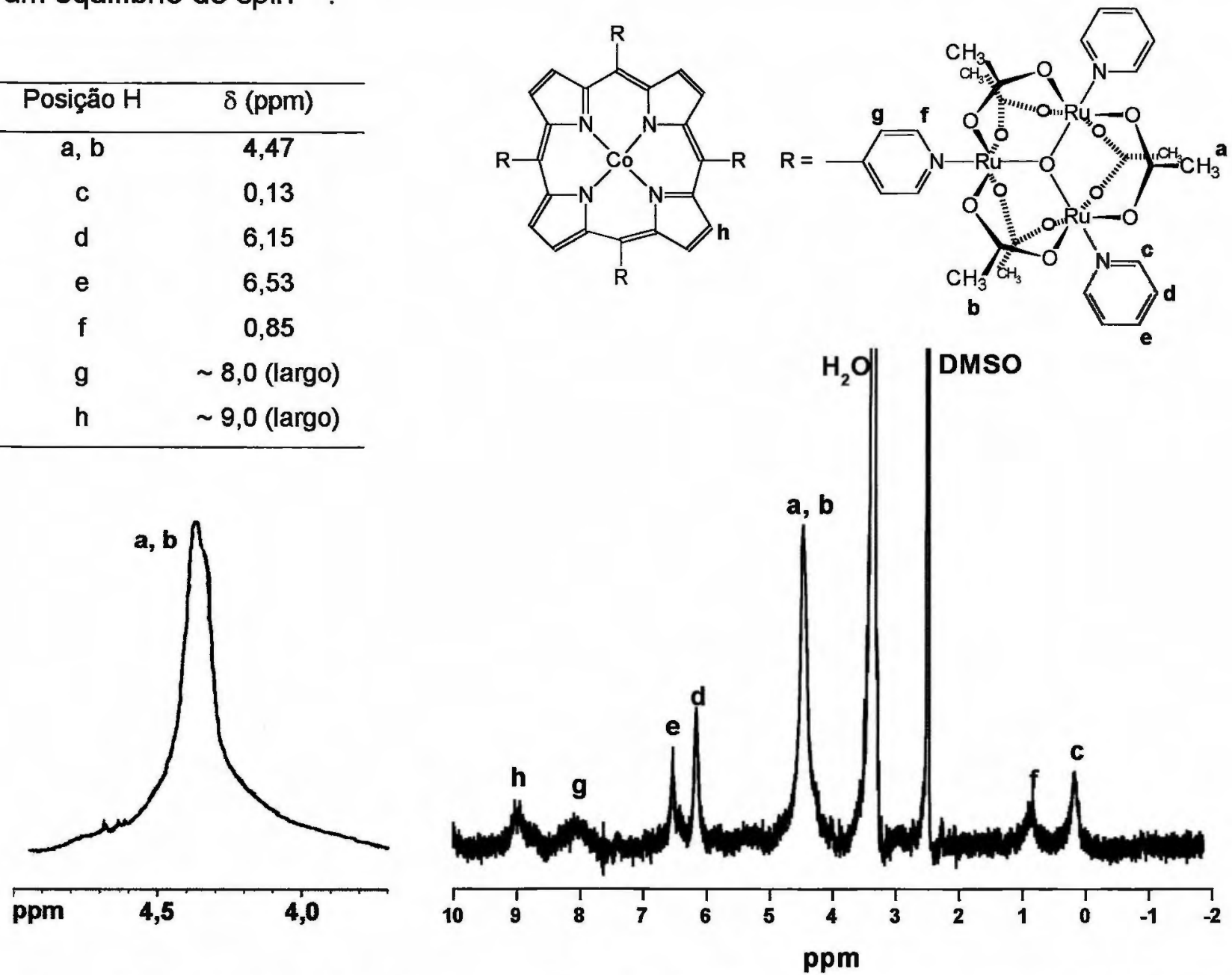

Figura 3.4 - Abaixo e à direita, espectro RMN- ${ }^{1} \mathrm{H}$ de $\left[\mathrm{CoTCP}(\mathrm{Cl})\left(\mathrm{H}_{2} \mathrm{O}\right)\right](\mathrm{Cl})_{4} 2 \times 10^{-3} \mathrm{~mol}$ $\mathrm{dm}^{-3}$ em DMSO- $d_{6}$ (equipamento: Varian UNITY INOVA, $300 \mathrm{MHz}$ ). As letras referem-se às posições dos prótons na estrutura (à direita, acima), cujos deslocamentos químicos $(\delta, \mathrm{ppm})$ estão indicados à esquerda, acima. Abaixo e à esquerda, ampliação de região dos sinais dos acetatos obtidos em espectrômetro Bruker DRX-500 (500 MHz). 
Lin e Marzilli ${ }^{173}$, ao estudarem a coordenação axial em porfirinas de cobalto por $\mathrm{RMN}$, observaram que a adição de DMSO à soluções de $\operatorname{CoTPP}(\mathrm{Cl})$ ou $\mathrm{CoTCF}_{3} \mathrm{PP}(\mathrm{Cl})$ em $\mathrm{CDCl}_{3}$ ( $\mathrm{TCF}_{3} \mathrm{PP}=$ tetra(4-trifluormetilfenil)porfirinato) resultava em uma melhor definição dos sinais de ressonância, sugerindo que a água, fracamente coordenada ao

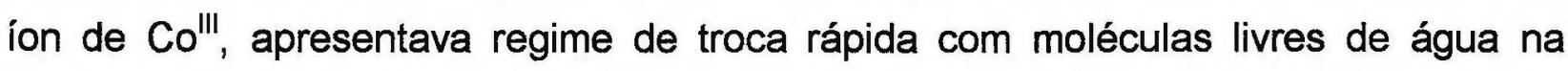
solução. Portanto, CoTPP $(\mathrm{Cl})$ ou $\mathrm{CoTCF}_{3} \mathrm{PP}(\mathrm{Cl})$ em $\mathrm{CDCl}_{3}$ seriam misturas das formas penta- e hexacoordenadas. Com relação ao DMSO, sugeriram que este coordena-se ao íon de Co ${ }^{\text {III }}$ pelo átomo de oxigênio e que a velocidade de troca (DMSO coordenado I DMSO livre) dependia do ligante trans, sendo mais lenta quando este coordena-se por oxigênio (DMSO ou $\mathrm{H}_{2} \mathrm{O}$ ) do que quando é um íon $\mathrm{Cl}^{-}$.

No caso de $\left[\mathrm{CoTCP}(\mathrm{Cl})\left(\mathrm{H}_{2} \mathrm{O}\right)\right] \mathrm{Cl}_{4}$, as propriedades paramagnéticas das unidades $\mathrm{Ru}_{3} \mathrm{O}$ podem induzir grandes deslocamentos para menores frequências apenas dos sinais de prótons mais próximos, como discutido anteriormente, mas não um alargamento pronunciado. Por outro lado, a presença de $\mathrm{Co}^{11} \mathrm{TCP}^{4+}$ ou CoTCP ${ }^{5+}-\pi$ cátion radical em concentrações significativas pode ser usualmente detectada por espectroscopia UV-Visivel (como veremos mais adiante, no Capítulo 5), presença esta que não foi confirmada pela análise do espectro eletrônico da solução utilizada no estudo por RMN- ${ }^{1} \mathrm{H}$. Do exposto, pode-se inferir ou a existência de um grau significativo de paramagnetismo no núcleo porfirínico de $\left[\mathrm{CoTCP}(\mathrm{Cl})\left(\mathrm{H}_{2} \mathrm{O}\right)\right] \mathrm{Cl}_{4}$ envolvendo um equilíbrio de spin, ou a ocorrência de mecanismos de coordenação I dissociação axial com velocidades comparáveis às do tempo de escala do experimento de $\mathrm{RMN}^{-1} \mathrm{H}$ (ms).

Deste modo, os sinais de ressonância foram tentativamente atribuídos como segue (figura 3.4). $\mathrm{O}$ sinal mais intenso em $4,47 \mathrm{ppm}$ foi associado aos prótons dos acetatos; como vimos, em clusters assimétricos e nos análogos $\mathrm{H}_{2} \mathrm{TCP}^{4+}, \mathrm{ZnTCP}^{4+}$ e $\mathrm{MnTCP}^{5+}$, os respectivos prótons originam dois sinais bem definidos, embora com razoável sobreposição - no caso de $\left[\mathrm{CoTCP}(\mathrm{Cl})\left(\mathrm{H}_{2} \mathrm{O}\right)\right] \mathrm{Cl}_{4}$ as frequências de ressonância são muito próximas. Contudo, utilizando-se um equipamento de $500 \mathrm{MHz}$, é possivel identificar um ombro em menor frequência (figura 3.4). Ainda por comparação com os clusters assimétricos e com os derivados análogos, os sinais em 0,$13 ; 6,15$ e 6,53 ppm foram associados aos prótons das piridinas terminais, enquanto os sinais em 0,85 e $8 \mathrm{ppm}$ foram atribuídos aos prótons das piridinas em ponte, que sofrem o efeito de corrente do anel porfirínico, em oposição ao efeito paramagnético das unidades $\mathrm{Ru}_{3} \mathrm{O}$ periféricas. $O$ remanescente sinal em torno de $9 \mathrm{ppm}$ foi relacionado aos prótons pirrólicos. 
CAPÍTULO 4

\section{ESPECTROSCOPIA ELETRÔNICA}


A discussão que se segue a respeito dos espectros eletrônicos das supermoléculas $\mathrm{ZnTCP}^{4+}$, MnTCP ${ }^{5+}$ e $\mathrm{CoTCP}^{5+}$ está baseada no que foi apresentado anteriormente, no Capítulo 1, itens 1.3.3 (espectros eletrônicos dos clusters trinucleares de acetato de rutênio) e 1.4 .2 (espectros eletrônicos de porfirinas e metaloporfirinas).

\section{1 $\mathrm{ZnTCP}\left(\mathrm{PF}_{6}\right)_{4}$}

$\mathrm{O}$ espectro de absorção UV-Visivel em $\mathrm{CH}_{3} \mathrm{CN}$ de $\mathrm{ZnTCP}\left(\mathrm{PF}_{6}\right)_{4}$ caracteriza-se por uma contínua sobreposição de bandas (figura 4.1): as características do núcleo porfirínico, Soret, $Q_{(1,0)}$ e $Q_{(0,0)}$, podem ser localizadas com máximos em 436, 572 e 619 $\mathrm{nm}$, respectivamente; a banda relacionada à transiçöes internas nas unidades $\mathrm{Ru}_{3} \mathrm{O}$ tem seu máximo em $685 \mathrm{~nm}$. A banda em $324 \mathrm{~nm}$ pode ser descrita como a sobreposição entre a banda $\mathbf{N}$ do núcleo porfirínico e a banda de transferência de carga metal-ligante dos clusters periféricos.

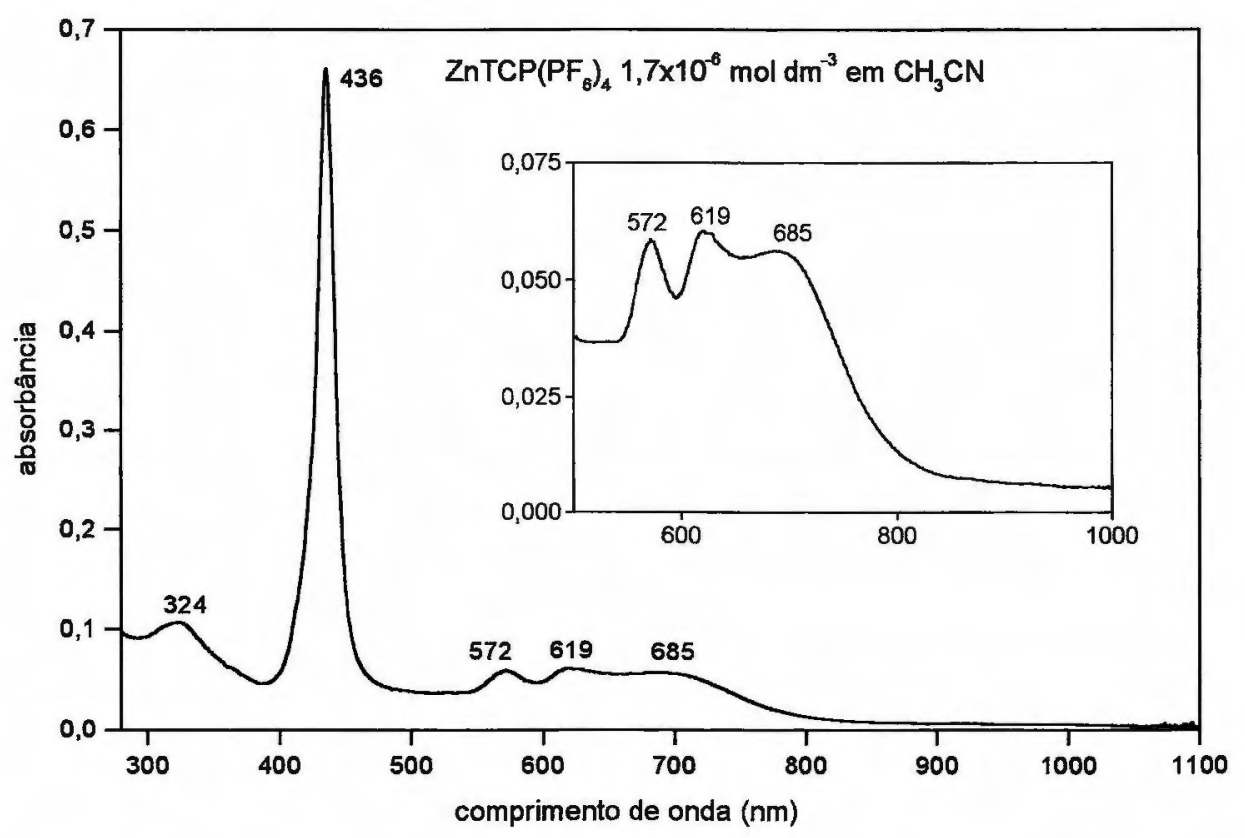

\begin{tabular}{cccccc}
\hline$\lambda(\mathrm{nm})$ & 324 & 436 & 572 & 619 & 685 \\
$\log \varepsilon$ & 4,81 & 5,59 & 4,55 & 4,56 & 4,52 \\
\hline
\end{tabular}

Figura 4.1 -Espectro eletrônico de solução de $\mathrm{ZnTCP}\left(\mathrm{PF}_{6}\right)_{4} 1,7 \times 10^{-6} \mathrm{~mol} \mathrm{dm}^{-3} \mathrm{em}$ $\mathrm{CH}_{3} \mathrm{CN}$.

Uma importante consequência da coordenação dos clusters aos resíduos piridínicos de ZnTPyP é a completa supressão da luminescência desta última. Estudos 
de Wall et $a l^{176}$ de um análogo mais simples (uma mono(4-piridil)tri(fenil)porfirina de zinco modificada por um cluster ou dímeros de cluster, figura 4.2) mostraram que a supressão ocorre via transferência de elétrons intramolecular.
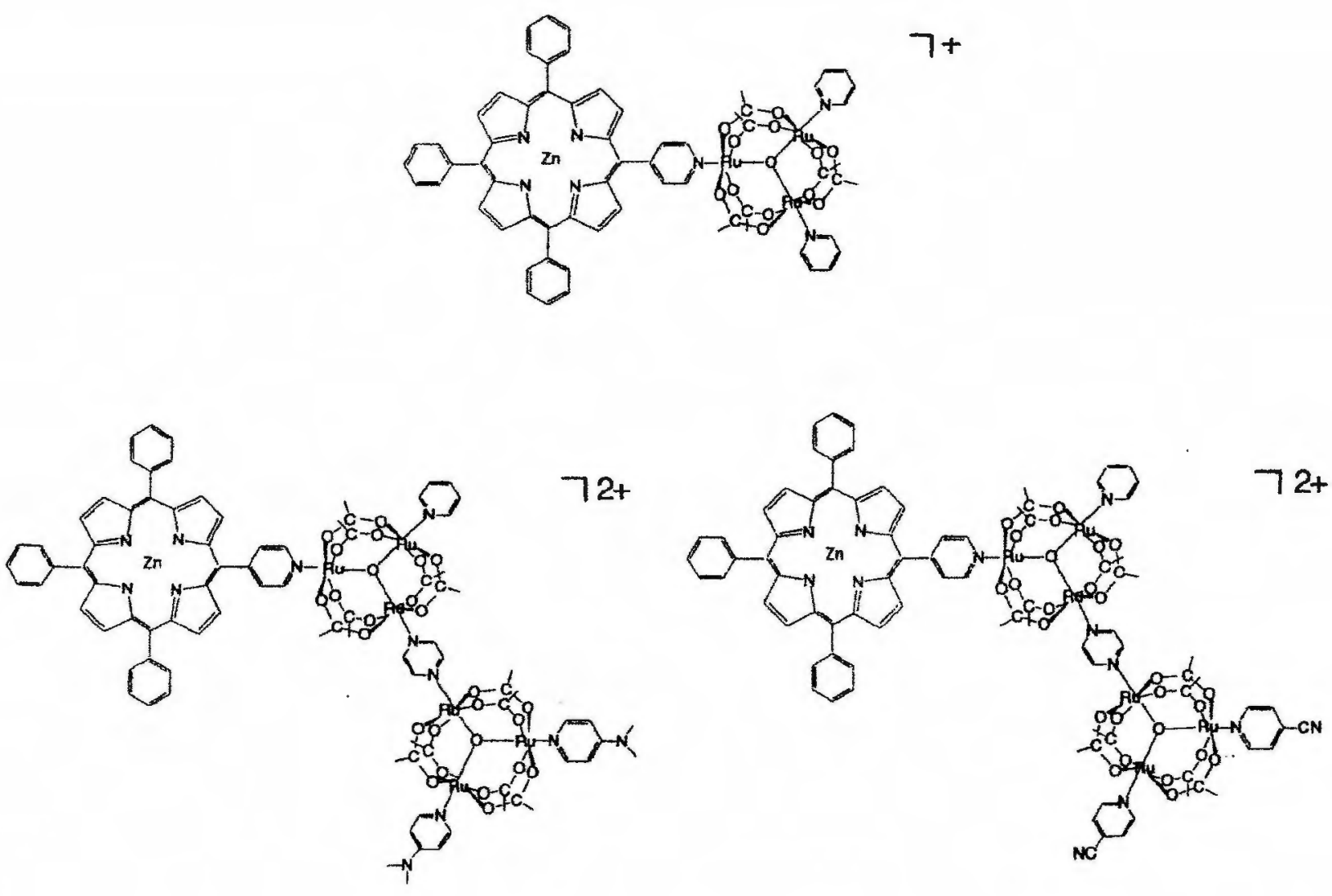

Figura 4.2 - Fórmulas estruturais dos complexos estudados por Wall et al ${ }^{176}$. 


\section{2 [MnTCP(OAC)( $\left.\left.\mathrm{H}_{2} \mathrm{O}\right)\right]\left(\mathrm{PF}_{6}\right)_{4}$}

À semelhança dos análogos $\mathrm{H}_{2} \mathrm{TCP}^{4+}$ e $\mathrm{ZnTCP}^{4+}$, o espectro eletrônico de [MnTCP(OAC) $\left.\left(\mathrm{H}_{2} \mathrm{O}\right)\right]\left(\mathrm{PF}_{6}\right)_{4}$ em $\mathrm{CH}_{3} \mathrm{CN}$ apresenta uma extensa sobreposição entre as bandas do núcleo porfirínico e as bandas dos clusters trinucleares de acetato de rutênio (figura 4.3). Assim, as bandas III, IV, V e VI, características de porfirinas de $\mathrm{Mn}^{\mathrm{III}}$, apresentam seus máximos de absorção em 621, 584, 475 e $370 \mathrm{~nm}$, respectivamente. A banda larga, com máximo em $691 \mathrm{~nm}$, é característica de transições internas nas unidades $\mathrm{Ru}_{3} \mathrm{O}$. A banda de transferência de carga metalligante dos clusters periféricos sobrepōe-se às bandas da porfirina de $\mathrm{Mn}^{\text {III }}$ na região UV, contribuindo para que a banda $V_{a}$ apresente-se como um ombro, em menor energia, da banda VI.

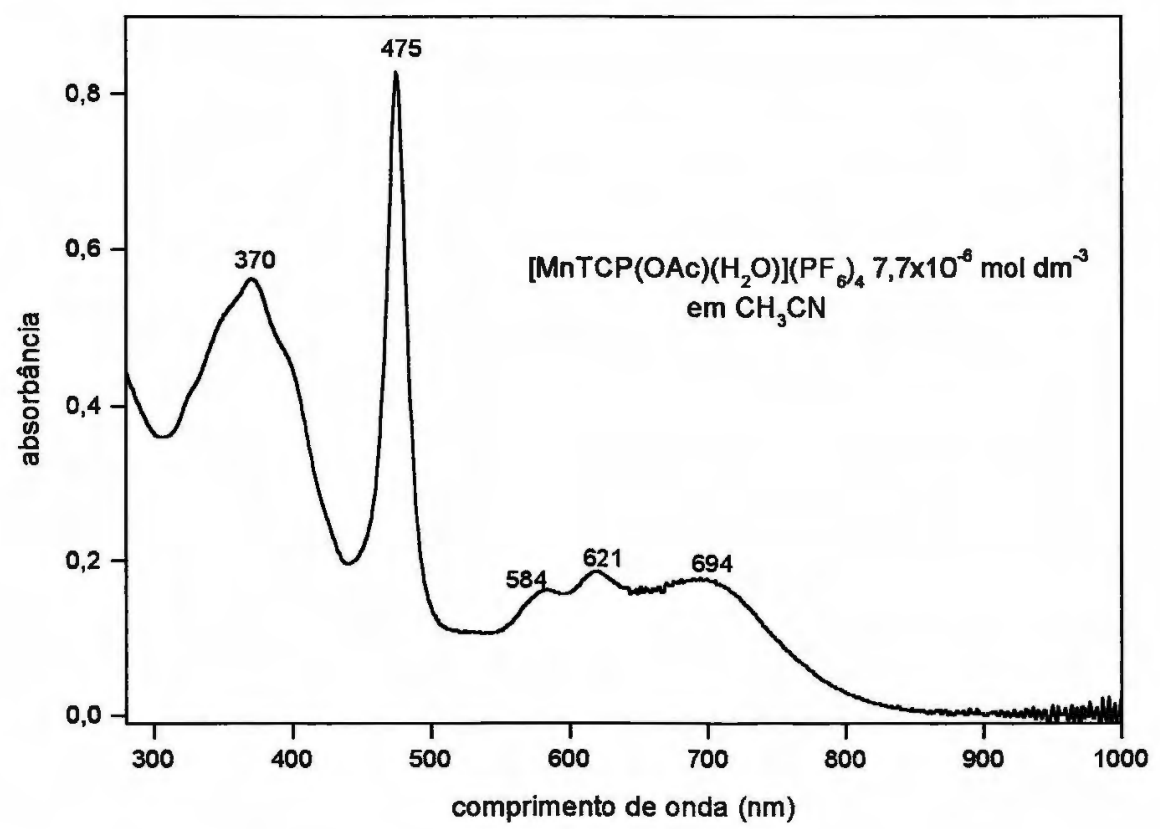

\begin{tabular}{cccccc}
\hline$\lambda(\mathrm{nm})$ & 370 & 475 & 584 & 621 & 694 \\
$\log \varepsilon$ & 4,86 & 5,01 & 4,30 & 4,36 & 4,34 \\
\hline
\end{tabular}

Figura 4.3 - Espectro eletrônico de solução de $\left[\mathrm{MnTCP}(\mathrm{OAc})\left(\mathrm{H}_{2} \mathrm{O}\right)\right]\left(\mathrm{PF}_{6}\right)_{4} 7,7 \times 10^{-6} \mathrm{~mol}$ $\mathrm{dm}^{-3} \mathrm{em} \mathrm{CH}_{3} \mathrm{CN}$. 


\section{$4.3\left[\mathrm{CoTCP}(\mathrm{OAc})\left(\mathrm{H}_{2} \mathrm{O}\right)\right]\left(\mathrm{PF}_{6}\right)_{4}$}

$\mathrm{O}$ espectro eletrônico de [CoTCP $\left.(\mathrm{OAc})\left(\mathrm{H}_{2} \mathrm{O}\right)\right]\left(\mathrm{PF}_{6}\right)_{4}$ em $\mathrm{CH}_{3} \mathrm{CN}$ (figura 4.4), como já observado para os análogos $\mathrm{H}_{2} \mathrm{TCP}, \mathrm{ZnTCP}$ e MnTCP, caracteriza-se pela contínua sobreposição de bandas. No entanto, é possível localizar as bandas características de porfirina de $\mathrm{Co}^{\mathrm{III}}$ em 435, 557 e $611 \mathrm{~nm}$, que correspondem às bandas Soret (ou $B$ ), $Q_{(1,0)}$ e $Q_{(0,0)}$, respectivamente. A banda atribuída a transições internas nas unidades $\mathrm{Ru}_{3} \mathrm{O}$ tem seu máximo em $693 \mathrm{~nm}$. Finalmente, uma banda em maior energia (em torno de $318 \mathrm{~nm}$ ) provavelmente envolve a sobreposição da banda $\mathrm{N}$ do núcleo porfirínico com a banda de transferência de carga metal-ligante dos clusters periféricos.

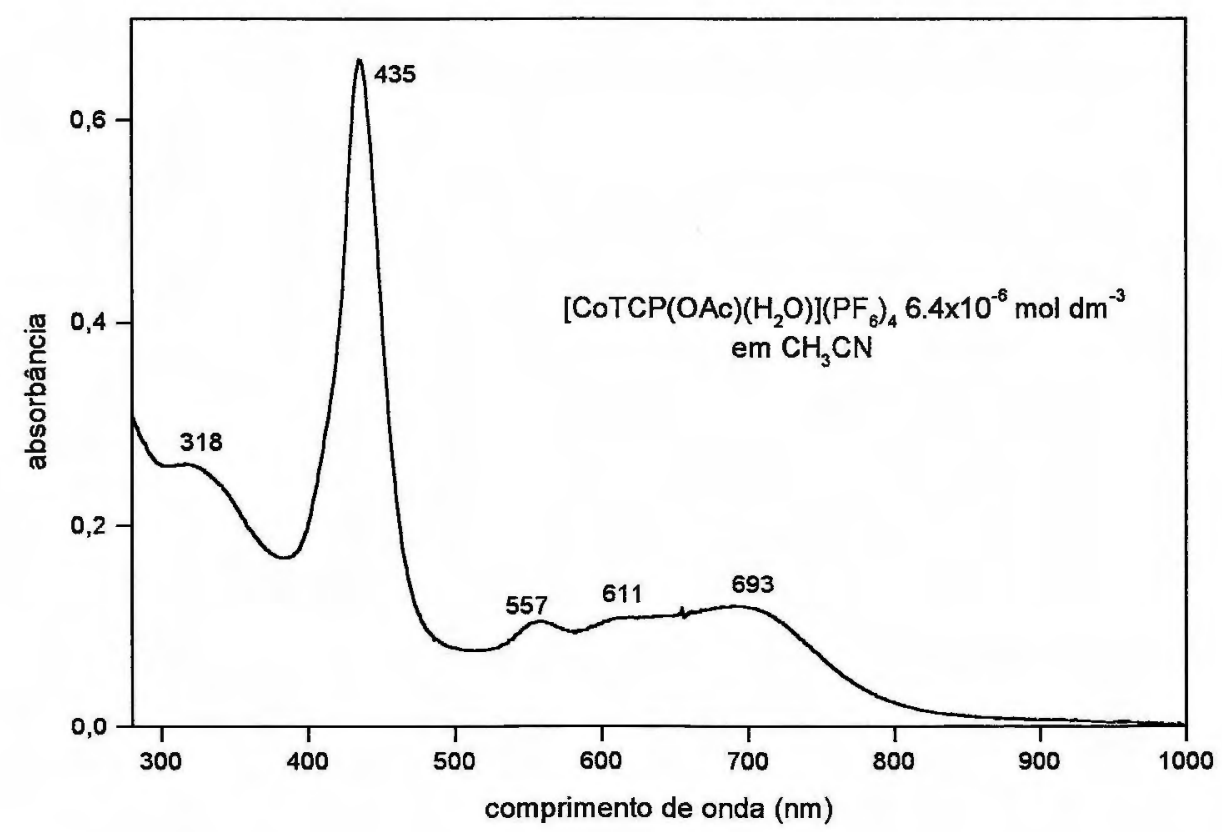

\begin{tabular}{cccccc}
\hline$\lambda(\mathrm{nm})$ & 318 & 435 & 557 & 611 & 693 \\
$\log \varepsilon$ & 4,61 & 5,01 & 4,22 & 4,23 & 4,28 \\
\hline
\end{tabular}

Figura 4.4 - Espectro eletrônico de solução de $\left[\mathrm{CoTCP}(\mathrm{OAc})\left(\mathrm{H}_{2} \mathrm{O}\right)\right]\left(\mathrm{PF}_{6}\right)_{4} 6,4 \times 10^{-6} \mathrm{~mol}$

$$
\mathrm{dm}^{-3} \mathrm{em} \mathrm{CH} \mathrm{CH}_{3} \mathrm{CN} \text {. }
$$


CAPÍTULO 5

\section{COMPORTAMENTO ELETROQUÍMICO: VOLTAMETRIA CÍCLICA E ESPECTROELETROQUÍMICA}




\subsection{Sobre a voltametria cíclica}

A voltametria cíclica tornou-se uma técnica comumente empregada em estudos eletroquímicos iniciais de novos compostos em solução, bem como de filmes e interfaces, embora tenha também se mostrado muito útil na obtenção de informações sobre complicadas reações na interface solução / eletrodo ${ }^{177}$. Uma abordagem detalhada sobre a técnica está fora do contexto desta Tese, uma vez que a mesma pode ser facilmente encontrada em livros texto, como o de Gosser ${ }^{177}$ ou o de Bard e Faulkner ${ }^{157}$; de forma bastante suscinta e didática, artigos lidando com o assunto foram publicados no Journal of Chemical Education, já no início da década de oitenta ${ }^{178-181}$. No entanto, algumas breves considerações a respeito da técnica parecem ser aqui adequadas.

Basicamente, um experimento de voltametria cíclica consiste em variar (crescente ou decrescentemente), em função do tempo, o potencial de um eletrodo imerso em uma solução em repouso, até se atingir um determinado valor a partir do qual o sentido da variação (varredura) é invertido. O potencial deste eletrodo de trabalho é controlado através de um eletrodo de referência, podendo ser considerado como um sinal de excitação cujo gráfico potencial versus tempo exibe um formato triangular (figura 5.1).
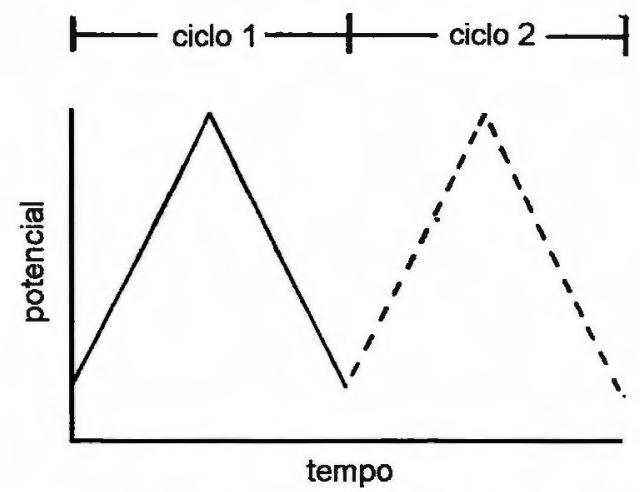

Figura 5.1 - Sinal de excitação para voltametria cíclica.

A esperada resposta a este sinal constitui-se em corrente elétrica ou, em outras palavras, em transferência de elétrons na interface eletrodo / solução: na presença de uma espécie eletroativa, quando o potencial aplicado ao eletrodo $(E)$ aproximar-se do potencial formal de redução da espécie $\left(E^{0^{3}}\right)$, haverá transferência de elétrons na interface, originando corrente elétrica. A magnitude desta corrente dependerá da reação de transferência eletrônica e do movimento de material eletroativo em direção à interface (difusão). Um gráfico corrente versus potencial (voltamograma) é apresentado na figura 5.2 . 


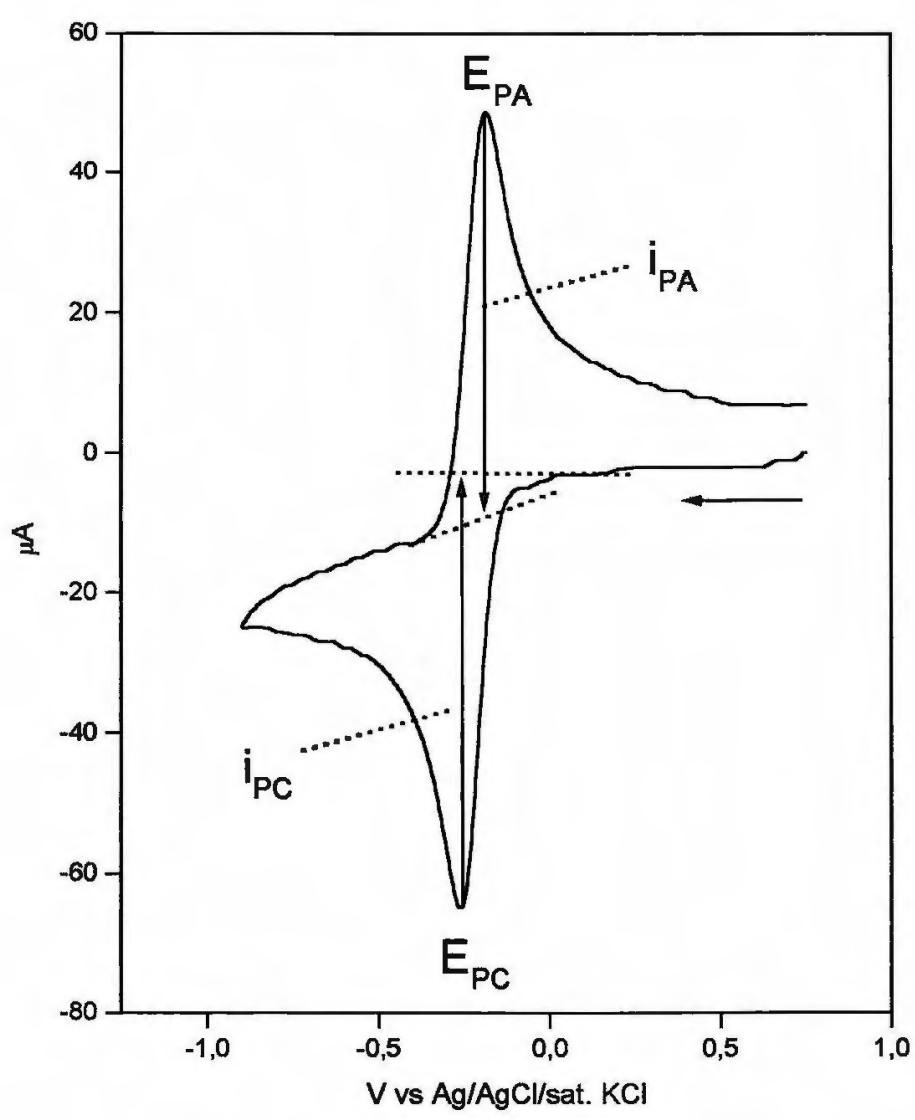

Figura 5.2 - Voltamograma cíclico a $50 \mathrm{mV} \mathrm{s}^{-1}$ de solução aquosa de [Ru(EDTA) $\left.\left(\mathrm{H}_{2} \mathrm{O}\right)\right]^{-} 3 \times 10^{-3} \mathrm{~mol} \mathrm{dm}^{-3}$ (trifluoracetato de sódio $0,25 \mathrm{~mol}$ $\mathrm{dm}^{-3}$ como eletrólito suporte), em pH 4,5 (tampão acetato $0,05 \mathrm{~mol}$ $\mathrm{dm}^{-3}$ ), a $25^{\circ} \mathrm{C}$. Eletrodo de trabalho: carbono vitreo; eletrodo de referência: $\mathrm{Ag} / \mathrm{AgCl}(\mathrm{KCl} \quad 1,0$ $\mathrm{mol} \mathrm{dm}^{-3}$ ); eletrodo auxiliar; fio de platina $^{182}$.

Em termos cinéticos, é possível demonstrar que, para o caso geral

$$
0+n e^{-} \frac{k_{f}}{k_{b}}=R
$$

as constantes de velocidade de transferência de elétrons $k_{f}$ e $k_{b}$ são dadas por ${ }^{157}$ :

$$
\begin{gathered}
k_{f}=k^{0} \exp \left[-\alpha n F\left(E-E^{0}\right) / R T\right] \\
e \\
k_{b}=k^{0} \exp \left[(1-\alpha) n F\left(E-E^{0}\right) / R T\right]
\end{gathered}
$$

onde $\mathrm{k}^{0}$ é a constante de velocidade padrão de transferência eletrônica heterogênea (seu valor é uma propriedade da reação entre um composto particular e o eletrodo utilizado); o termo $\alpha$ é denominado coeficiente de transferência, possuindo um valor que varia de 0 a 1 (sua origem está relacionada ao fato de que apenas uma fração da energia que é introduzida no sistema - na forma de potencial aplicado - é utilizada no abaixamento da barreira da energia de ativação), F é a constante de Faraday, R é a constante universal dos gases e $\mathrm{T}$ a temperatura absoluta.

A dependência exponencial de $k_{f}$ e $k_{b}$ com relação ao potencial aplicado faz com que inicialmente ocorra um aumento abrupto na corrente (figura 5.2). Contudo, a eletrólise da espécie em solução diminui sua concentração na região próxima à 
superfície do eletrodo; uma vez que o experimento é realizado utilizando-se um eletrodo estacionário em uma solução sem agitação, a difusão, um processo relativamente lento, é o principal modo de transporte da espécie à superfície do eletrodo, e o volume com deficiência de espécies não eletrolisadas aumenta - em outras palavras, cresce o caminho médio que a espécie deverá percorrer até atingir o eletrodo. Como resultado, obtém-se um perfil de curva corrente versus potencial com formato de onda. Se o sistema é reversível, é possivel regenerar as espécies inicialmente eletrolisadas pela inversão do sentido de varredura, gerando uma onda de mesma intensidade de corrente mas oposta à primeira e defasada com relação ao potencial, em virtude do compromisso entre os potenciais aplicados e o processo de difusão. Os parâmetros importantes em um voltamograma cíclico são as magnitudes das correntes de pico anódica ( $\mathrm{i}_{\mathrm{PA}}$ ) e catódica (i $\mathrm{i}_{\mathrm{PC}}$ ), e os potenciais de pico anódico $\left(E_{P A}\right)$ e catódico $\left(E_{P C}\right)$ (figura 5.2).

Um par redox em que as espécies trocam elétrons rapidamente com o eletrodo de trabalho é denominado como eletroquimicamente reversível. Nesta situação, a corrente de pico ip para a varredura direta do primeiro ciclo é descrita pela equação 5.3, conhecida como equação de Randles-Sevcik:

$$
i_{p}=2,69 \times 10^{5} n^{3 / 2} A D^{1 / 2} v^{1 / 2} C
$$

onde $\quad n=$ número de elétrons envolvidos no processo

$\mathrm{A}=$ área do eletrodo, $\mathrm{cm}^{2}$

$\mathrm{D}=$ coeficiente de difusão, $\mathrm{cm}^{2} \mathrm{~s}^{-1}$

$v=$ velocidade de varredura, volt $s^{-1}$

$\mathrm{C}=$ concentração da espécie eletroativa, $\mathrm{em} \mathrm{mol} \mathrm{cm}^{-3}$

Ainda com relação a um sistema reversível, é possível demonstrar que:

$$
\begin{gathered}
\Delta E_{P}=E_{P A}-E_{P C}=0,059 / n \\
\left.i_{P A} / i_{P C}=1 \quad \text { (eq. } 5.5\right)
\end{gathered}
$$

Em analogia com a polarografia, na voltametria cíclica também se usa a notação de potencial de meia onda, $E_{1 / 2}$, cujo valor é diretamente extraído dos voltamogramas de sistemas reversíveis (eq. 5.6). 


$$
\left.E_{1 / 2}=\left(E_{P A}+E_{P C}\right) / 2 \quad \text { (eq. } 5.6\right)
$$

$\mathrm{Se}$ as constantes de difusão das espécies oxidada e reduzida não diferem significativamente, o valor de $E_{1 / 2}$ pode ser considerado também como o potencial formal de redução, $E^{0}$. A figura 5.3 exibe os voltamogramas cíclicos de uma espécie tipicamente reversível eletroquimicamente.
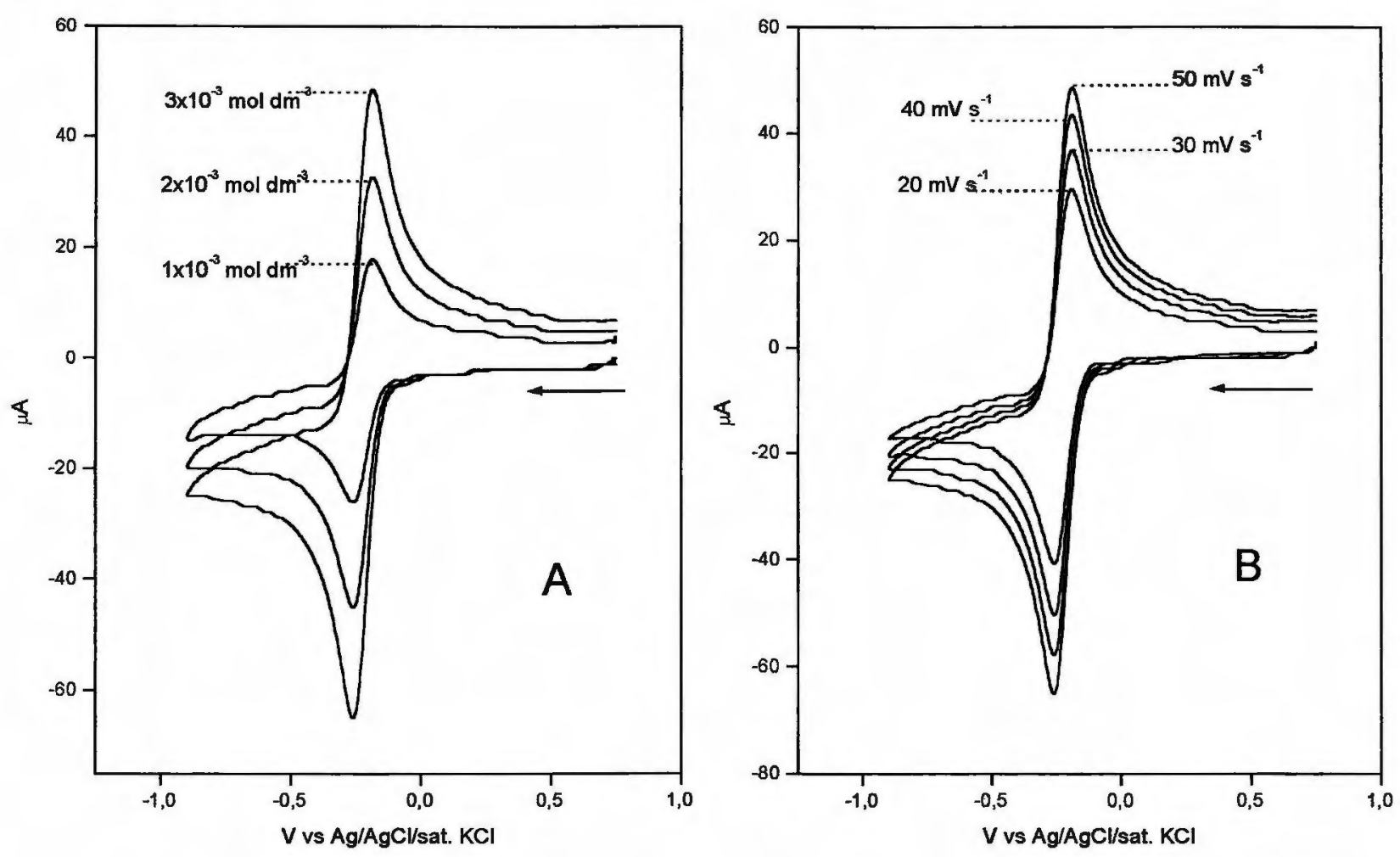

Figura 5.3 - Voltamogramas cíclicos de solução aquosa de $\left[\mathrm{Ru}(\mathrm{EDTA})\left(\mathrm{H}_{2} \mathrm{O}\right)\right]^{-182}$ : A) em diferentes concentrações; $B$ ) a diferentes velocidades de varredura. Demais condições: similares às descritas na figura 5.2 .

Pares redox cujos picos nos voltamogramas afastam-se à medida que aumenta a velocidade de varredura são classificados como quase-reversíveis. Nos casos em que a separação dos picos é muito grande, os sistemas são geralmente denominados totalmente irreversiveis; os sistemas que envolvem reações originando produtos que não podem ser revertidos eletroquimicamente ao reagente inicial (por exemplo, reações que envolvem quebra extensiva de ligações e/ou perda de substituintes), são ditos quimicamente irreversíveis. A irreversibilidade eletroquímica tem sua origem na menor velocidade de troca de elétrons entre a espécie em solução e o eletrodo de trabalho; nesta situação, as equações 5.3 a 5.6 não são aplicáveis. 


\subsection{Sobre a espectroeletroquímica}

A espectroeletroquímica é uma técnica analítica híbrida, resultado da combinação entre espectroscopia e eletroquímica. Em resumo, os estados de oxidação das espécies são eletroquimicamente alterados pela adição ou remoção de elétrons na superfície de um eletrodo, enquanto medidas espectroscópicas sobre a solução adjacente são feitas simultaneamente, permitindo obter espectros e potenciais de redução, além de possibilitar a observação de reações químicas subsequentes das espécies eletroquimicamente geradas.

Embora várias técnicas espectroscópicas possam ser associadas à eletroquímica $^{183}$, descrever-se-á aqui, suscintamente, apenas a amplamente utilizada neste trabalho: espectroeletroquímica UV-vísivel de camada fina, que envolve a observação de uma fina camada de solução confinada próxima a um eletrodo transparente - o feixe de luz do espectrofotômetro atravessa ambos, a solução e o eletrodo transparente; no presente trabalho utilizou-se um "mini-grid" de ouro como eletrodo, cuja transparência é devida a um número elevado de pequeníssimos orifícios (figura 5.4).

A espectroeletroquímica de camada fina oferece um meio simples de controlar o estado de oxidação das espécies em um pequeno volume de solução para a observação do espectro resultante: o potencial redox da fina camada de solução é precisamente ajustado pelo potencial aplicado, como o determinado para um sistema reversível

$$
\mathrm{O}+\mathrm{ne} \rightleftharpoons \mathrm{R}
$$

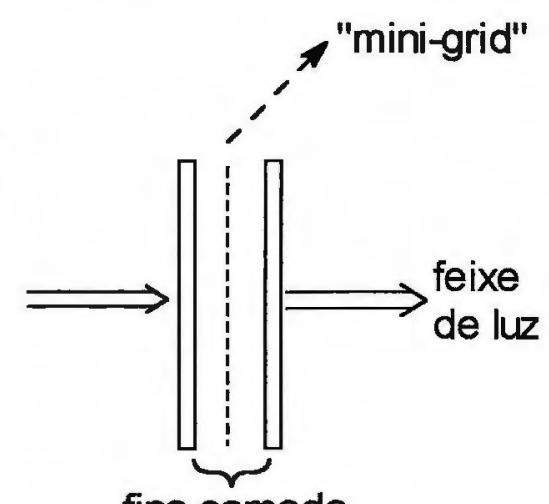

fina camada

Figura 5.4

pela equação de Nernst,

$$
E=E^{01}+\frac{0,059}{n} \log \frac{[O]}{[R]}
$$

Embora o potencial aplicado $E$ controle a razão [O] / [R] na superfície do eletrodo, a razão na fina camada de solução ajusta-se rapidamente ao mesmo valor por eletrólise. Assim, para um sistema reversível é possível obter potenciais formais de redução e valores de $n$, através de um gráfico de Nernst. 


\section{$5.3 \quad \mathrm{ZnTCP}\left(\mathrm{PF}_{6}\right)_{4}$}

Nos voltamogramas cíclicos de $\mathrm{ZnTCP}\left(\mathrm{PF}_{6}\right)_{4}$ em $\mathrm{CH}_{3} \mathrm{CN}$ quatro conjuntos de ondas podem ser observados entre -1,35 e 2,40 V , designados na discussão que se segue como "ondas das regiões I, II, III e IV" (figura 5.5) . O perfil dos voltamogramas é similar aos obtidos com os clusters trinucleares de rutênio com ligantes $\mathrm{N}$ heterocíclicos (Capítulo 1, item 1.3.4), com pequenas distorções apresentadas nas ondas das regiões II e III: a espectroeletroquímica, discutida a seguir, indicou a ocorrência adicional de processos redox centrados no núcleo porfirínico. A onda na região $\mathrm{I}$, com $E_{1 / 2}=0,15 \mathrm{~V}$, é tipicamente reversível, enquanto a onda IV $\left(E_{P A}=2,19 \mathrm{~V}\right)$ é irreversível.

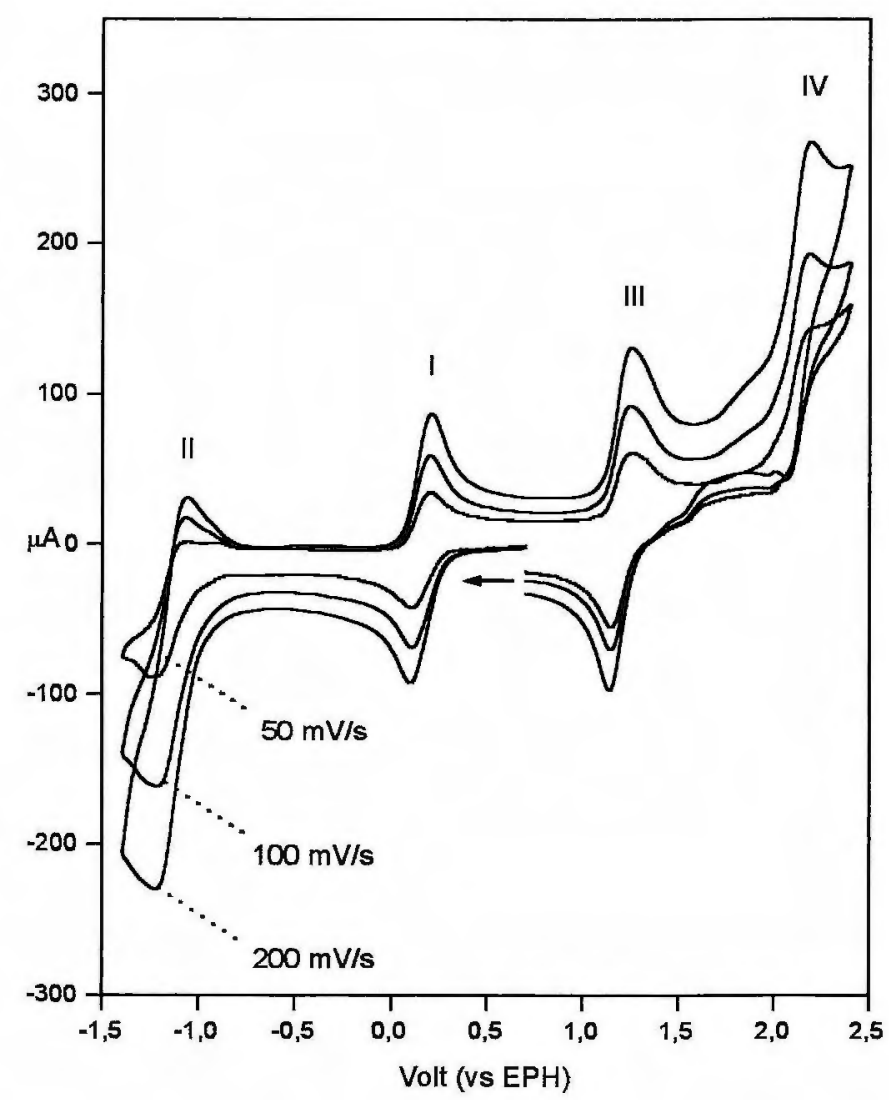

Figura 5.5 - Voltamogramas cíclicos a 50,100 e $200 \mathrm{mV} \mathrm{s}^{-1}$ de solução de $\mathrm{ZnTCP}\left(\mathrm{PF}_{6}\right)_{4} \quad 3 \times 10^{-3}$ mol $\mathrm{dm}^{-3}$ em $\mathrm{CH}_{3} \mathrm{CN}$ (eletrólito suporte: $\mathrm{TEACIO}_{4} 0,1 \mathrm{~mol} \mathrm{dm}^{-3}$ ), a $25^{\circ} \mathrm{C}$.

A espectroeletroquímica na região I (figura 5.6) exibiu, na redução de 0,303 a $0,003 \mathrm{~V}$, o decréscimo de intensidade das bandas de absorção dos clusters periféricos em 689 e $318 \mathrm{~nm}$, simultaneamente ao surgimento de bandas largas em 920 e em torno de $400 \mathrm{~nm}$. Estas mudanças são consistentes com a redução dos clusters do estado $\mathrm{Ru}^{\prime \prime \prime}, \mathrm{Ru}^{\mathrm{III}}, \mathrm{Ru}$ 'II para o estado $\mathrm{Ru}^{\mathrm{III}}, \mathrm{Ru}^{\mathrm{III}}, \mathrm{Ru}^{\prime \prime}$, como discutido anteriormente (Capítulo 1, item 1.3.4). Paralelamente, a banda Soret teve seu máximo deslocado de 426 para $428 \mathrm{~nm}$, além de sua intensidade aumentada, sugerindo interação eletrônica 
entre as unidades; no entanto, a não ocorrência de um par de ondas para cada um dos clusters periféricos indica que o acoplamento eletrônico entre estes, através da porfirina em ponte, é negligenciável ${ }^{184}$. O valor de $E_{1 / 2}$ determinado pelo tratamento dos dados espectroeletroquímicos, monitorando-se a banda em $920 \mathrm{~nm}$ (gráfico de Nernst, figura 5.6), coincidiu com o obtido pela voltametria cíclica, dentro do erro experimental.
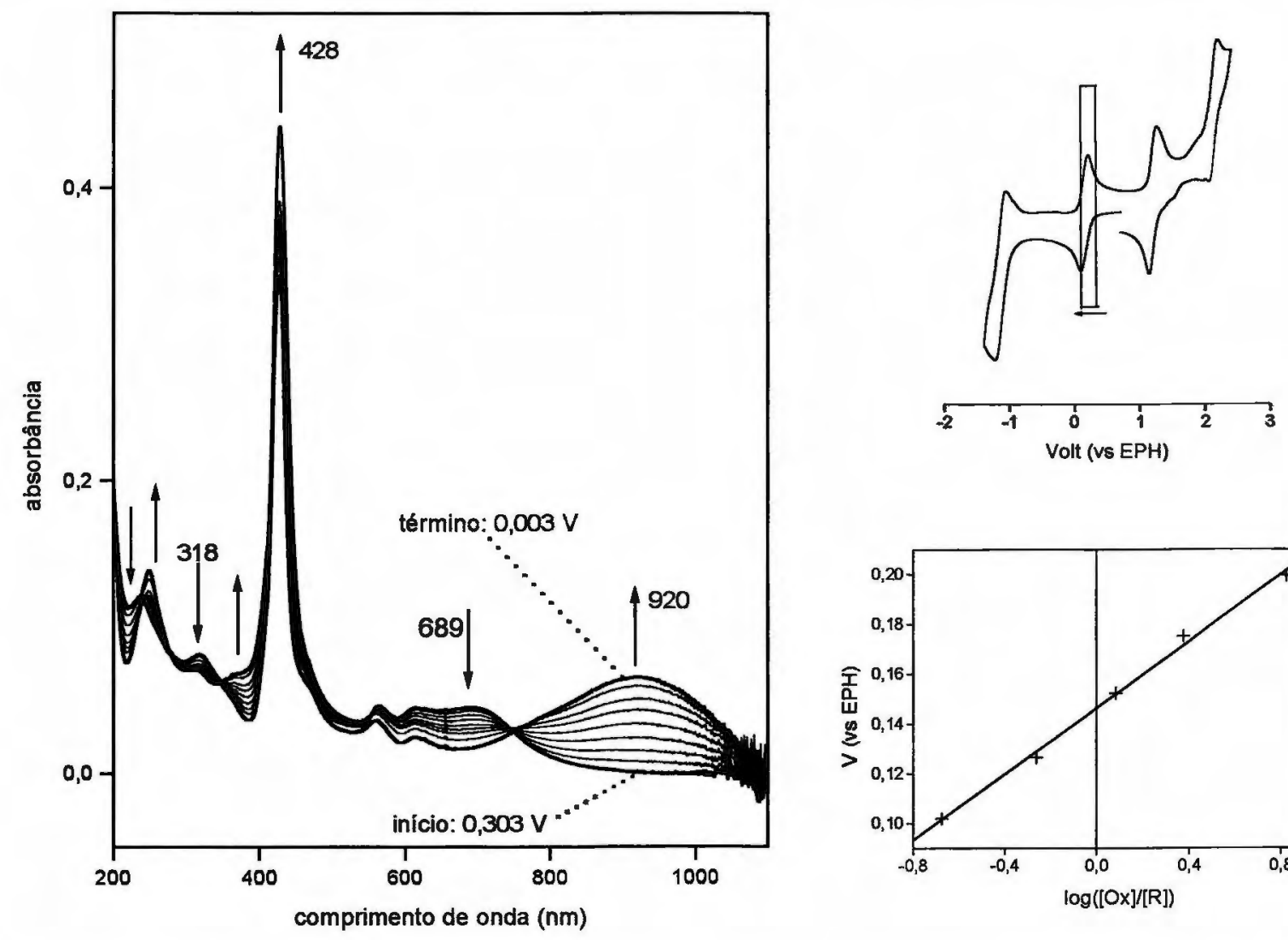

Figura 5.6 - À esquerda, espectroeletroquímica de solução de $\mathrm{ZnTCP}\left(\mathrm{PF}_{6}\right)_{4} 8 \times 10^{-5} \mathrm{~mol}$ $\mathrm{dm}^{-3}$ em $\mathrm{CH}_{3} \mathrm{CN}$ (eletrólito suporte: $\mathrm{TEAClO}_{4} 0,1 \mathrm{~mol} \mathrm{dm}^{-3}$ ); os sucessivos espectros referem-se aos potenciais 0,303 (início); 0,203; 0,$178 ; 0,153 ; 0,128 ; 0,103 ; 0,078$; 0,053; e 0,003 V (término). À direita, acima: indicação no voltamograma cíclico da região de potencial investigada; abaixo: gráfico Nernst, de 0,203 a 0,103 V.

A forma e intensidade relativa da onda na região II, segundo a voltametria cíclica (figura 5.5), sugere a presença de mais de um par redox. Ao se variar o potencial de 0,947 a $-1,197 \mathrm{~V}$ a banda Soret deslocou-se para $467 \mathrm{~nm}$, enquanto ocorreu o surgimento de uma banda larga em torno de $700 \mathrm{~nm}$ (figura $5.7-A$ ), alterações consistentes com a formação de porfirina radical $\pi$-ânion ${ }^{185}$. Concomitantemente, a banda em $920 \mathrm{~nm}$ (clusters) deslocou-se para $942 \mathrm{~nm}$, enquanto a absorção em torno de $400 \mathrm{~nm}$ diminui, fatos que podem ser atribuídos à redução dos clusters, de Ru', 
$\mathrm{Ru}^{\prime \prime \prime}, \mathrm{Ru}$ "l para Ru", $\mathrm{Ru}$ ", $\mathrm{Ru}^{\text {II }}$ (Capítulo 1, item 1.3.4). Portanto, estes dois processos

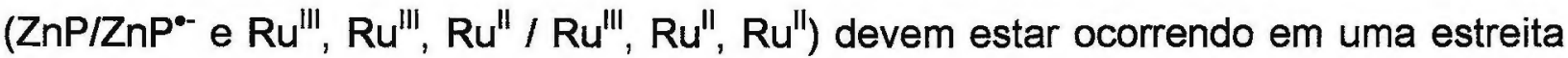
faixa de potencial.

Ao se aplicar potenciais mais negativos, de $-1,197$ a $-1,347 \mathrm{~V}$ (figura 5.7-B), ocorreu o aparecimento de uma banda em torno de $825 \mathrm{~nm}$ simultaneamente ao desaparecimento da banda característica de porfirina radical $\pi$-ânion (em torno de 700 $\mathrm{nm}$ ), enquanto a banda Soret teve sua intensidade diminuída, comportamento típico da redução de porfirina radical $\pi$-ânion para porfirina radical $\pi$-diânion ${ }^{185,186}$. Devido à proximidade do potencial redox deste par em relação ao do par $\mathrm{ZnP} / \mathrm{ZnP}{ }^{\circ-}$, tornou-se possivel acompanhar o decaimento da banda Soret remanescente de ZnP (em torno de $433 \mathrm{~nm})$.
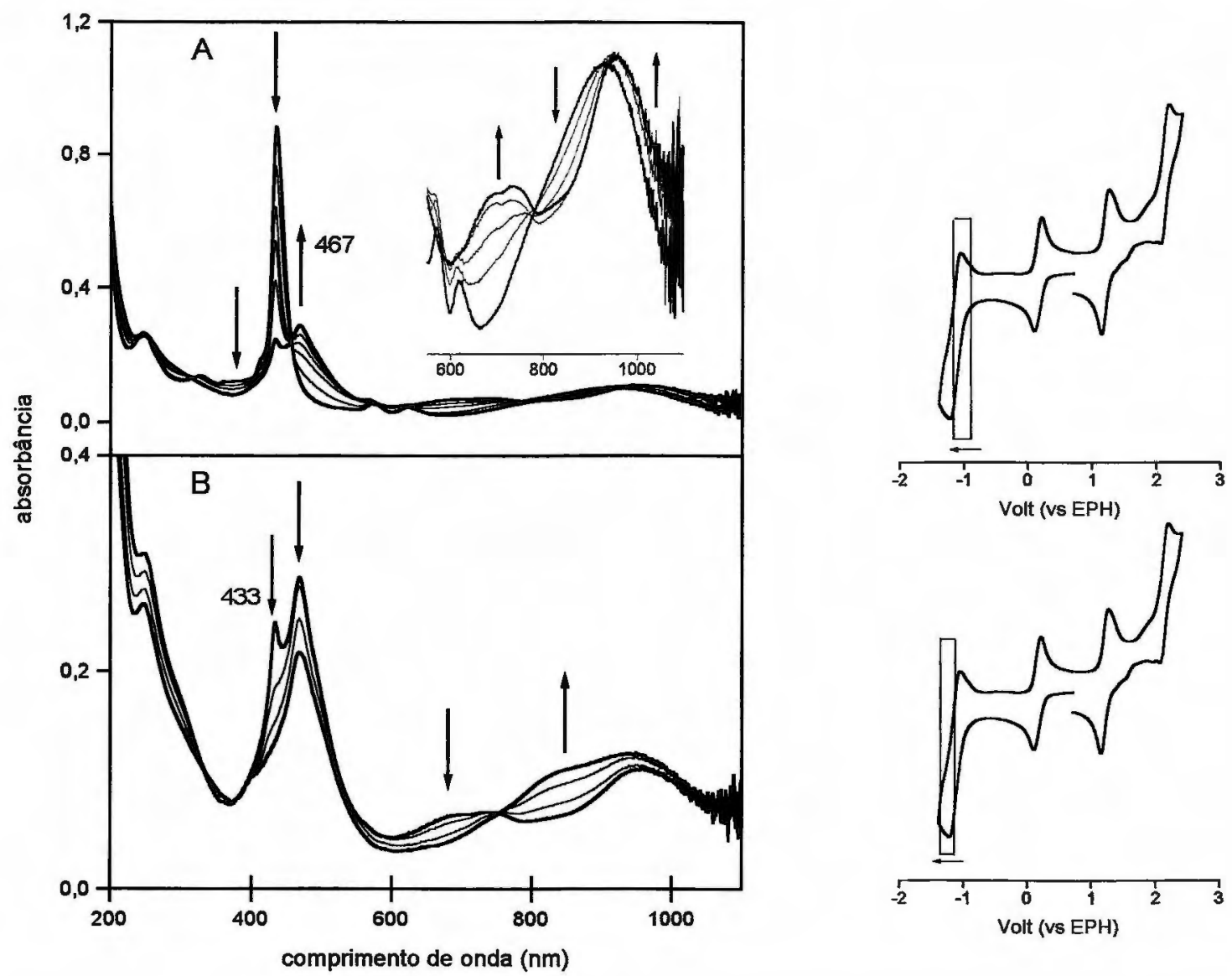

Figura 5.7 - À esquerda, espectroeletroquímica de solução de $\mathrm{ZnTCP}\left(\mathrm{PF}_{6}\right)_{4} 1 \times 10^{-4} \mathrm{~mol}$

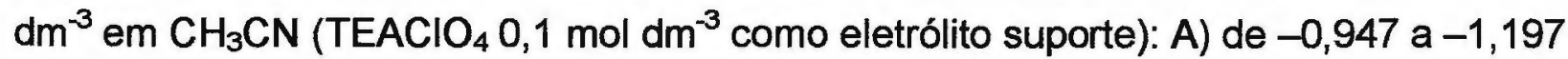
V; B) de -1,197 a -1,347 V. À direita, indicação nos voltamogramas cíclicos das regiões de potencial investigadas.

As ondas anódicas na região III dos voltamogramas cíclicos da figura 5.5 exibem uma maior corrente que as correspondentes ondas na região I, além de apresentarem- 
se alargadas, o que indica a existência de, no mínimo, dois pares redox envolvidos. Através da espectroeletroquímica, acompanhando-se a variação de potencial de 1,003 a 1,253 V (figura 5.8-A), foi possível identificar o primeiro par: a oxidação provoca queda na intensidade na banda larga com máximo em $689 \mathrm{~nm}$, simultaneamente ao aparecimento de duas bandas, uma com máximo em $796 \mathrm{~nm}$ e outra que se sobrepōe às bandas $Q$ do núcleo porfirínico, resultando em um máximo de absorção localizado em $559 \mathrm{~nm}$ - tais mudanças são consistentes com a oxidação dos clusters do estado

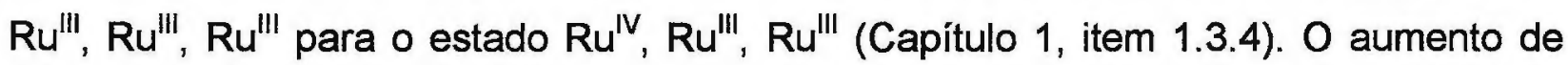
intensidade da banda Soret que, além disso, tem seu máximo deslocado de 426 para $429 \mathrm{~nm}$, reflete um grau de acoplamento eletrônico que não deve ser pronunciado, uma vez que os voltamogramas cíclicos não indicam um potencial redox diferente para cada um dos quatro clusters periféricos, à semelhança do observado para as reduções.
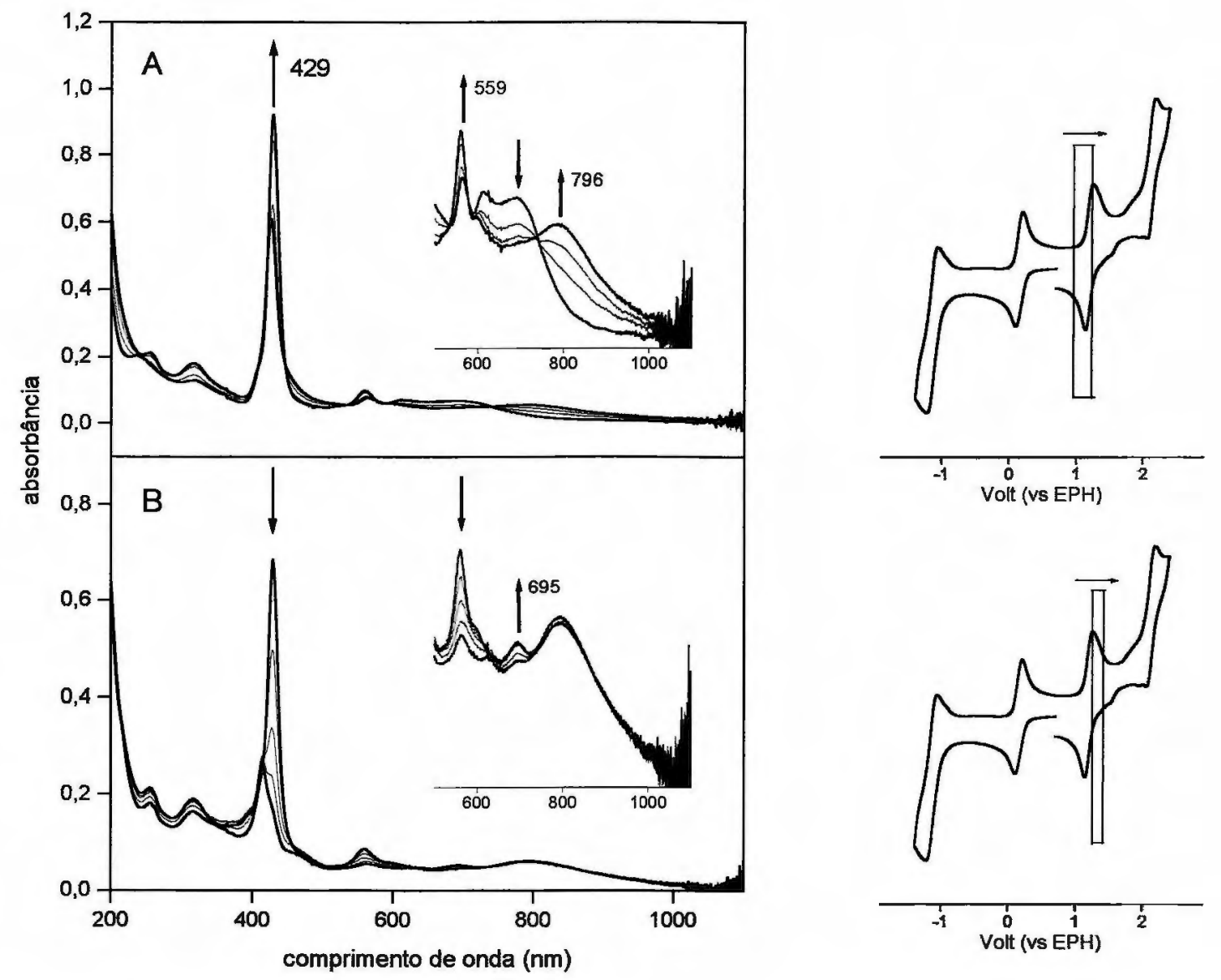

Figura 5.8 - À esquerda, espectroeletroquímica de solução de $\mathrm{ZnTCP}\left(\mathrm{PF}_{6}\right)_{4} 1 \times 10^{-4} \mathrm{~mol}$ $\mathrm{dm}^{-3} \mathrm{em} \mathrm{CH} \mathrm{CH}_{3} \mathrm{CN}\left(\mathrm{TEAClO}_{4}\right.$ 0,1 mol dm $\mathrm{m}^{-3}$ como eletrólito suporte): A) de 1,003 a 1,253 V; B) de 1,253 a 1,403 V. À direita, indicação nos voltamogramas cíclicos das respectivas regiões de potencial investigadas. 
Prosseguindo na oxidação até $1,403 \mathrm{~V}$ (figura 5.8-B), notou-se o decaimento nas intensidades das bandas Soret e $Q$, enquanto forma-se uma banda com máximo em $695 \mathrm{~nm}$; as bandas relacionadas aos clusters aparentemente não são afetadas pelo processo observado. Este comportamento é consistente com a oxidação do núcleo porfirínico ao seu radical $\pi$-cátion ${ }^{185,187}$.

Finalmente, em potenciais mais positivos (correspondentes à região IV na figura 5.5), a onda irreversível com $E_{P A}=2,19 \mathrm{~V}$ foi atribuída ao par redox $\mathrm{Ru}^{\mathrm{IV}}$, $\mathrm{Ru}^{\mathrm{IV}}$, $\mathrm{Ru}^{\mathrm{II}}$ / $\mathrm{Ru}^{\mathrm{IV}}, \mathrm{Ru}^{\mathrm{III}}, \mathrm{Ru^{ \prime \prime \prime }}, \mathrm{em}$ analogia aos clusters trinucleares de acetato de rutênio possuindo ligantes $\mathrm{N}$-heterocíclicos (Capítulo 1, item 1.3.4).

Em resumo, a voltametria cíclica e a espectroeletroquímica de $\mathrm{ZnTCP}^{4+}$ em $\mathrm{CH}_{3} \mathrm{CN}$ revelaram a existência de sete processos redox na faixa de potencial compreendida entre $-1,35$ e 2,4 V: quatro atribuídos aos clusters periféricos e três centrados no núcleo porfirínico. 


\section{$5.4\left[\mathrm{MnTCP}(\mathrm{OAC})\left(\mathrm{H}_{2} \mathrm{O}\right)\right]\left(\mathrm{PF}_{6}\right)_{4}$}

Os voltamogramas cíclicos de $\left[\mathrm{MnTCP}(\mathrm{OAc})\left(\mathrm{H}_{2} \mathrm{O}\right)\right]\left(\mathrm{PF}_{6}\right)_{4}$ em N,N'dimetilformamida (DMF) entre $-1,50$ e 1,50V apresentam quatro conjuntos de ondas (figura 5.9). Novamente, de modo a facilitar a discussão, os voltamogramas foram divididos em quatro regiões de potencial, designadas como I, II, III e IV. As ondas nas regiões I, III e IV podem ser prontamente relacionadas como oriundas de processos redox sofridos pelos clusters periféricos (Capítulo 1.3.4), embora as ondas catódicas da

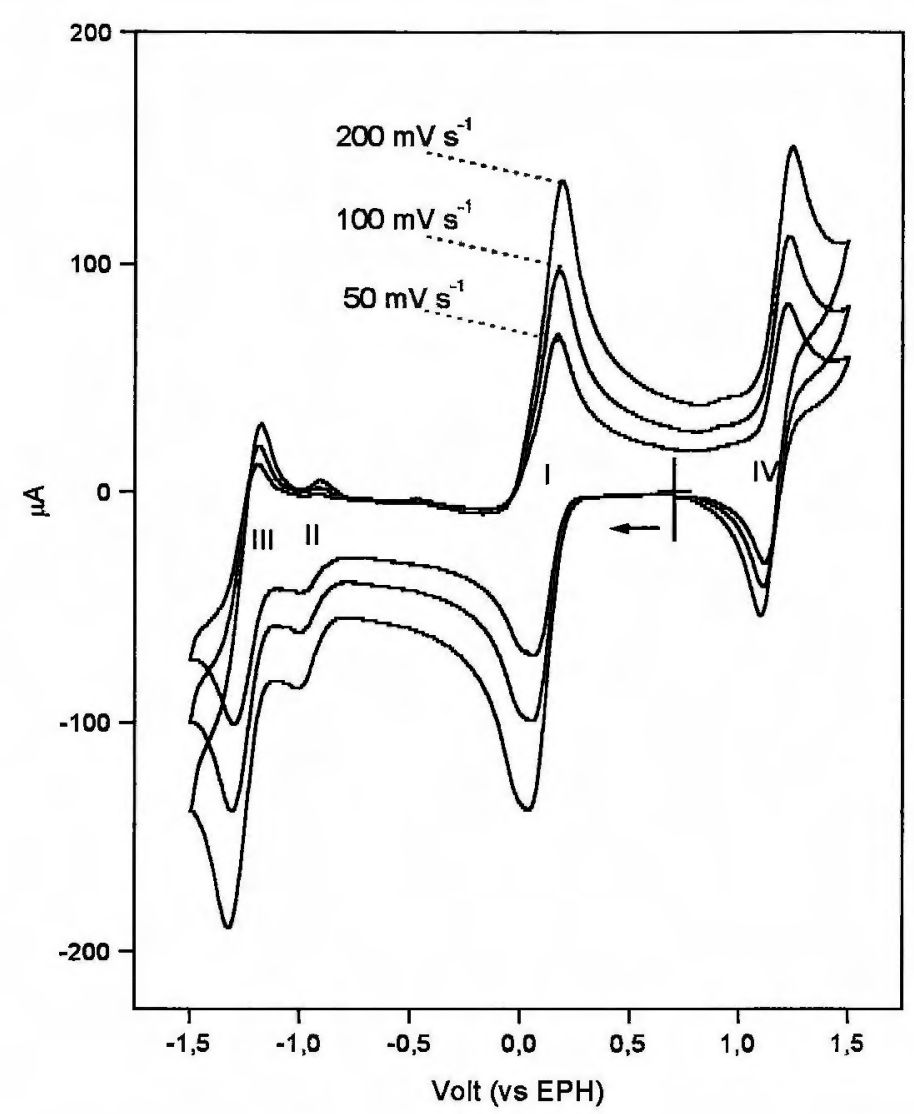

região I apresentem-se distorcidas, o que sugere 0 envolvimento de outro par redox; as menores correntes das ondas na região II indicam processos centrados no núcleo porfirínico.

Figura 5.9 - Voltamogramas cíclicos a 50,100 e $200 \mathrm{mV} \mathrm{s}^{-1}$ de uma solução de $\left[\mathrm{MnTCP}(\mathrm{OAC})\left(\mathrm{H}_{2} \mathrm{O}\right)\right]\left(\mathrm{PF}_{6}\right)_{4} \quad 2 \times 10^{-3}$ $\mathrm{mol} \mathrm{dm}{ }^{-3}$ em DMF $\left(\mathrm{TEAClO}_{4} 0,1 \mathrm{~mol}\right.$ $\mathrm{dm}^{-3}$ como eletrólito suporte), a $25^{\circ} \mathrm{C}$.

Na região $\mathrm{I}$, além das ondas apresentarem-se com uma corrente de pico maior em comparação com a região $\mathrm{IV}$, as ondas catódicas apresentam-se alargadas, sugerindo a existência de, no mínimo, dois pares redox. Uma vez que o número total de elétrons envolvidos na redução dos clusters é quatro e na redução do metal do núcleo porfirínico é um, a onda mais intensa em potenciais mais positivos pode ser

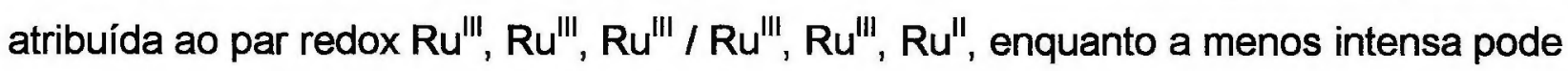

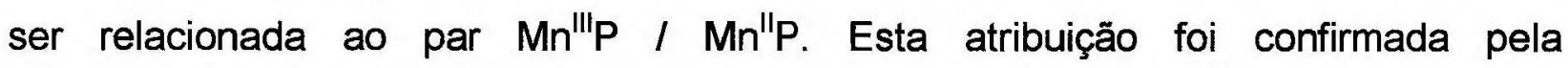
espectroeletroquímica: ao se variar o potencial de 0,303 a 0,153 V, a banda devida a transições internas nas unidades $\mathrm{Ru}_{3} \mathrm{O}$, com máximo em $694 \mathrm{~nm}$, teve sua intensidade diminuída à medida que ocorreu o surgimento de outra banda em torno de $900 \mathrm{~nm}$, 
enquanto as bandas associadas ao núcleo porfirínico permaneceram inalteradas, evidenciando o processo de redução dos clusters periféricos (figura 5.10-A); a existência de uma diminuição de absorção próximo a $330 \mathrm{~nm}$, paralela a um aumento na região de $400 \mathrm{~nm}$, pode ser entendida como resultado do deslocamento da banda TCML.
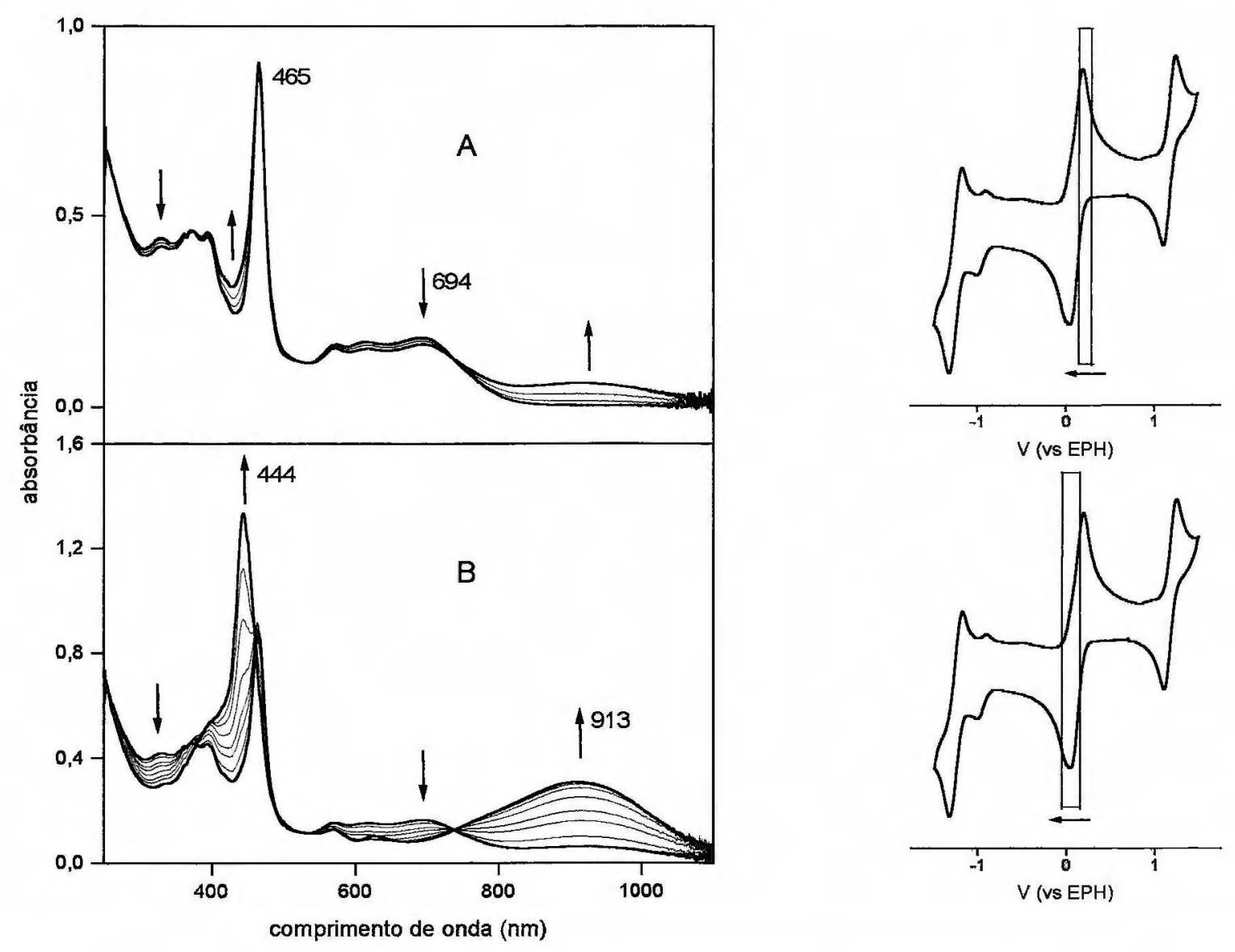

Figura 5.10 - À esquerda, espectroeletroquímica de solução de [MnTCP(OAc) $\left.\left(\mathrm{H}_{2} \mathrm{O}\right)\right]\left(\mathrm{PF}_{6}\right)_{4} 3,4 \times 10^{-4} \mathrm{~mol} \mathrm{dm}^{-3} \mathrm{em} \mathrm{DMF}$ (eletrólito suporte: TEAClO 4 0,1 $\mathrm{mol} \mathrm{dm^{-3 }}$ ): A) de 0,303 a 0,$153 ; B$ ) de 0,153 a $-0,047 \mathrm{~V}$. À direita, indicação nos voltamogramas cíclicos das respectivas regiōes de potencial investigadas.

Prosseguindo na redução até $-0,047 \mathrm{~V}$ (figura 5.10-B), ao lado da continuação da redução dos clusters periféricos evidenciada pela formação da banda larga com máximo em $913 \mathrm{~nm}$, ocorreu o desaparecimento das bandas $\mathrm{V}, \mathrm{V}_{\mathrm{a}}$ e $\mathrm{VI}$ do núcleo porfirínico com o surgimento de uma banda intensa com máximo em $444 \mathrm{~nm}$,

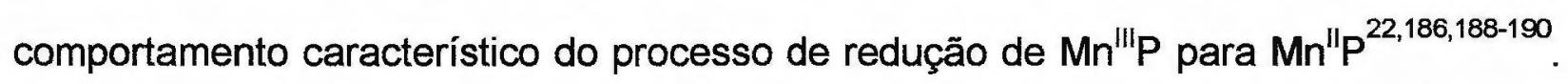
A estimativa do potencial para o par $\mathrm{Ru}^{\prime \prime \prime}, \mathrm{Ru}^{\prime \prime \prime}, \mathrm{Ru}^{\mathrm{II \prime}} / \mathrm{Ru}^{\prime \prime \prime}, \mathrm{Ru}^{\prime \prime \prime}, \mathrm{Ru}^{\prime \prime}$ utilizando-se os dados espectroeletroquímicos através de um gráfico de Nernst convencional pela monitoração da banda em $913 \mathrm{~nm}$, resultou em um valor igual a $0,11 \mathrm{~V}$, mas o 
correspondente cálculo para o par $\mathrm{Mn}$ "IIP / $\mathrm{Mn}$ "I foi dificultado pela extensa sobreposição entre as bandas dos clusters (em transformação, devido à continuidade do processo redox) e as bandas do núcleo porfirínico.

Um interessante resultado foi obtido quando a voltametria cíclica e a espectroeletroquímica foram conduzidas em 1,2-dicloroetano (TBAPF 6 0,1 mol dm como eletrólito suporte). Neste caso, o potencial redox do par $\mathrm{Mn}{ }^{\mathrm{III}} \mathrm{P} / \mathrm{Mn}$ "I é deslocado para potenciais mais positivos em relação ao potencial do par $\mathrm{Ru}^{\mathrm{II \prime}}$, $\mathrm{Ru}^{\mathrm{III}}$, $\mathrm{Ru}^{\text {III } / \mathrm{Ru}} \mathrm{u}^{\mathrm{III}}, \mathrm{Ru} \mathrm{u}^{\mathrm{III}}, \mathrm{Ru} \mathrm{u}^{\text {II }}$ (figura 5.11), invertendo a ocorrência das alterações no espectro eletrônico: ao se variar o potencial de 0,303 a 0,153 V (figura 5.11-A), a intensidade da banda $V$ do núcleo porfirínico $(\lambda=478 \mathrm{~nm})$ tem sua intensidade diminuída paralelamente à formação da banda Soret, característica de porfirinas de manganês(II), com máximo em $453 \mathrm{~nm}$.
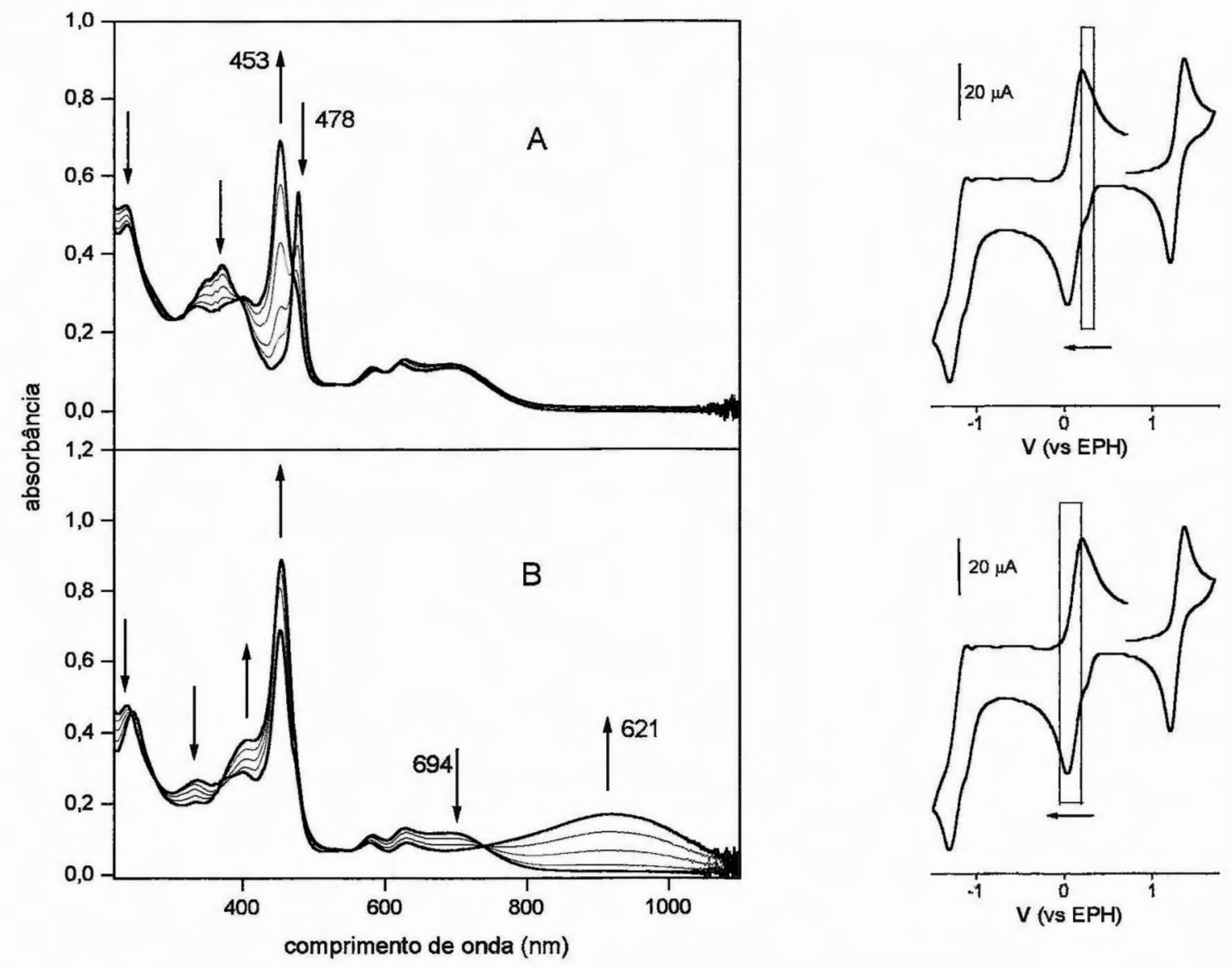

Figura 5.11 - À esquerda, espectroeletroquímica de solução de [MnTCP(OAC) $\left.\left(\mathrm{H}_{2} \mathrm{O}\right)\right]\left(\mathrm{PF}_{6}\right)_{4} 2 \times 10^{-4} \mathrm{~mol} \mathrm{dm}^{-3} \mathrm{em}$ 1,2-dicloroetano (eletrólito suporte: TBAPF $_{6} 0,1 \mathrm{~mol} \mathrm{dm}^{-3}$ ): A) de 0,303 a 0,153 V; B) de 0,153 a -0,047 V. À direita, indicação nos voltamogramas cíclicos das respectivas regiões de potencial investigadas $\left(\mathrm{v}=200 \mathrm{mV} \mathrm{s}^{-1},\left[\mathrm{MnTCP}(\mathrm{OAc})\left(\mathrm{H}_{2} \mathrm{O}\right)\right]\left(\mathrm{PF}_{6}\right)_{4} 2 \times 10^{-3} \mathrm{~mol} \mathrm{dm}^{-3} \mathrm{em} \mathrm{1,2-}\right.$ dicloroetano $/ \operatorname{TBAPF}_{6} 0,1 \mathrm{~mol} \mathrm{dm}^{-3}$, a $25^{\circ} \mathrm{C}$ ). 
Continuando a redução até -0,047 V (figura 5.11-B), observou-se a formação da banda larga com máximo em $921 \mathrm{~nm}$, característica de clusters nos estados Ru', Ru ${ }^{\prime \prime \prime}$, Ru". Os valores de $E_{1 / 2}$ estimados por gráficos de Nernst para os pares Mn"'P / Mn"P e

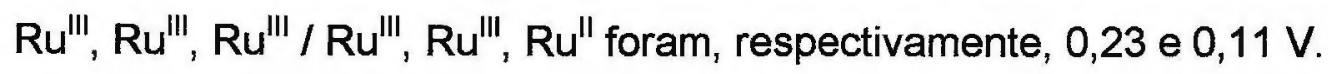

Os estudos na reação de redução de $\mathrm{Mn}{ }^{\text {IIIP }}$ a Mn"P têm mostrado que o valor de $E_{1 / 2}$ para o par redox envolvido depende da basicidade do anel porfirínico, do solvente e dos ligantes axiais coordenados ao ín de $\mathrm{Mn}^{\mathrm{III}}{ }^{191}$. Além disso, Kelly e Kadish ${ }^{172}$ observaram que os potenciais redox de Mn"'TPP em solventes coordenantes (como DMF, por exemplo) são independentes do contra-íon / ligante axial, enquanto em solventes não-coordenantes (como 1,2-dicloroetano) a dependência é resultado da estabilização do estado $\mathrm{Mn}$ (III) sobre o estado $\mathrm{Mn}$ (II) à medida que aumenta a força de ligação $\mathrm{Mn}(\mathrm{III})$ - contraíon / ligante axial. Este fato sugere que em DMF as posições axiais de Mn'llTPP são ocupadas pelas moléculas do solvente. Por analogia, pode-se então assumir que as espécies em solução durante a redução consistiam de $\left[\mathrm{Mn}^{\mathrm{III}} \mathrm{TCP}(\mathrm{DMF})_{2}\right]^{5+}$ e $\left[\mathrm{Mn}^{\mathrm{II}} \mathrm{TCP}(\mathrm{DMF})_{2}\right]^{4+}$ ou $\left[\mathrm{Mn}^{\mathrm{II}} \mathrm{TCP}(\mathrm{DMF})\right]^{4+}$. Esta última espécie é possivelmente $\circ$ produto final da redução uma vez que $\mathrm{Mn}$ "I $\mathrm{P}$ apresentam forte preferência pela pentacoordenação ${ }^{192,193}$. Por outro lado, em 1,2-dicloroetano as principais espécies em solução devem envolver o íon acetato como ligante axial.

Portanto, considerando a coordenação do acetato quando o solvente utilizado foi 1,2-dicloroetano, pode-se presumir que a sua influência seria a de deslocar o potencial de redução da supermolécula para valores mais negativos, pela estabilização do estado $\mathrm{Mn}$ (III) sobre o estado $\mathrm{Mn}$ (II). Não obstante, o valor de 0,23 V determinado para - $E_{1 / 2}$ é significativamente deslocado para potenciais mais positivos em comparação com os respectivos valores de outras porfirinas de manganês(III), observados em torno de $0,0 \mathrm{~V}^{172}$. Tal fato pode ser interpretado como resultado do pronunciado caráter elétron-aceitador assumido pelos clusters periféricos coordenados na periferia do núcleo porfirínico, caráter este que será também evidenciado mais adiante, no Capítulo 6, item 6.1.2, no estudo do equilíbrio de coordenação axial de $\mathrm{ZnTCP}^{4+}$.

Retornando à discussão dos voltamogramas cíclicos obtidos em DMF (figura 5.9), observa-se na região II ondas de menor corrente que as observadas na região I, cujas reversibilidades aumentam à medida que aumenta a velocidade de varredura, sugerindo um processo eletroquímico reversível seguido por reação química ${ }^{157}$. As menores intensidades de corrente sugerem uma reação redox envolvendo o núcleo porfirínico. De fato, ao se variar o potencial de $-0,70$ a $-1,097 \mathrm{~V}$ (figura 5.12) as bandas 
Soret e Q gradualmente desaparecem enquanto aumenta a absorção acima de 700 $\mathrm{nm}$, fatos consistentes com a formação de porfirina radical $\pi$-diânion ${ }^{185,186}$. A formação de porfirina radical $\pi$-ânion não pôde ser detectada devido à ausência da banda larga característica em torno de $700 \mathrm{~nm}$. Assim, a redução na região II pode ser entendida como dois processos monoeletrônicos sucessivos ( $\mathrm{Mn}^{\text {II }} \mathrm{P} / \mathrm{Mn}^{\| \prime} \mathrm{P}^{\circ-} / \mathrm{Mn}^{\| \prime} \mathrm{P}^{\circ 2-}$ ) com valores de potenciais redox muito próximos.
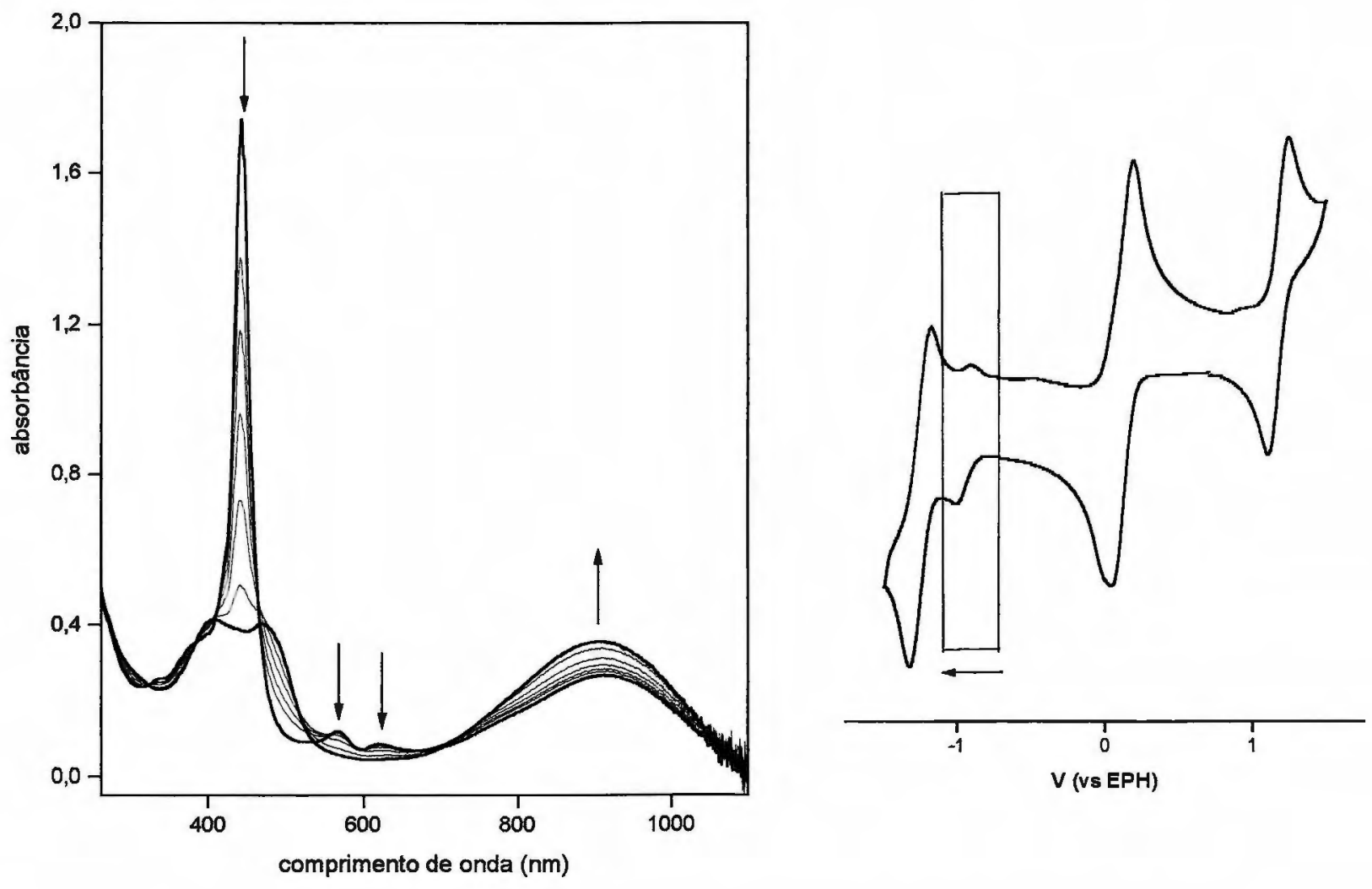

Figura 5.12 - À esquerda, espectroeletroquímica de solução de [MnTCP(OAc) $\left.\left(\mathrm{H}_{2} \mathrm{O}\right)\right]\left(\mathrm{PF}_{6}\right)_{4} 3,4 \times 10^{-4} \mathrm{~mol} \mathrm{dm}^{-3}$ em DMF (eletrólito suporte: TEACIO ${ }_{4}$ 0,1 $\left.\mathrm{mol} \mathrm{dm}^{-3}\right)$, de $-0,70$ a $-1,097 \mathrm{~V}$. À direita, indicação no voltamograma cíclico da região de potencial investigada.

As ondas voltamétricas na região III dos voltamogramas cíclicos (figura 5.9) indicam o envolvimento de um par redox reversivel ( $E_{1 / 2}$ estimado em $-1,25 \mathrm{~V}$ ). Durante a espectroeletroquímica, variando-se o potencial de $-1,097$ a -1,497 V (figura 5.13), observou-se o deslocamento para menores energias das bandas relacionadas aos clusters periféricos, comportamento característico da redução $\mathrm{Ru}^{\prime \prime \prime}, \mathrm{Ru}^{\mathrm{III}}, \mathrm{Ru}^{\prime \prime}$ / $\mathrm{Ru}^{\mathrm{III}}$, $R u^{\prime \prime}, R u^{\text {Il }}$ (Capítulo 1, item 1.3.4). 


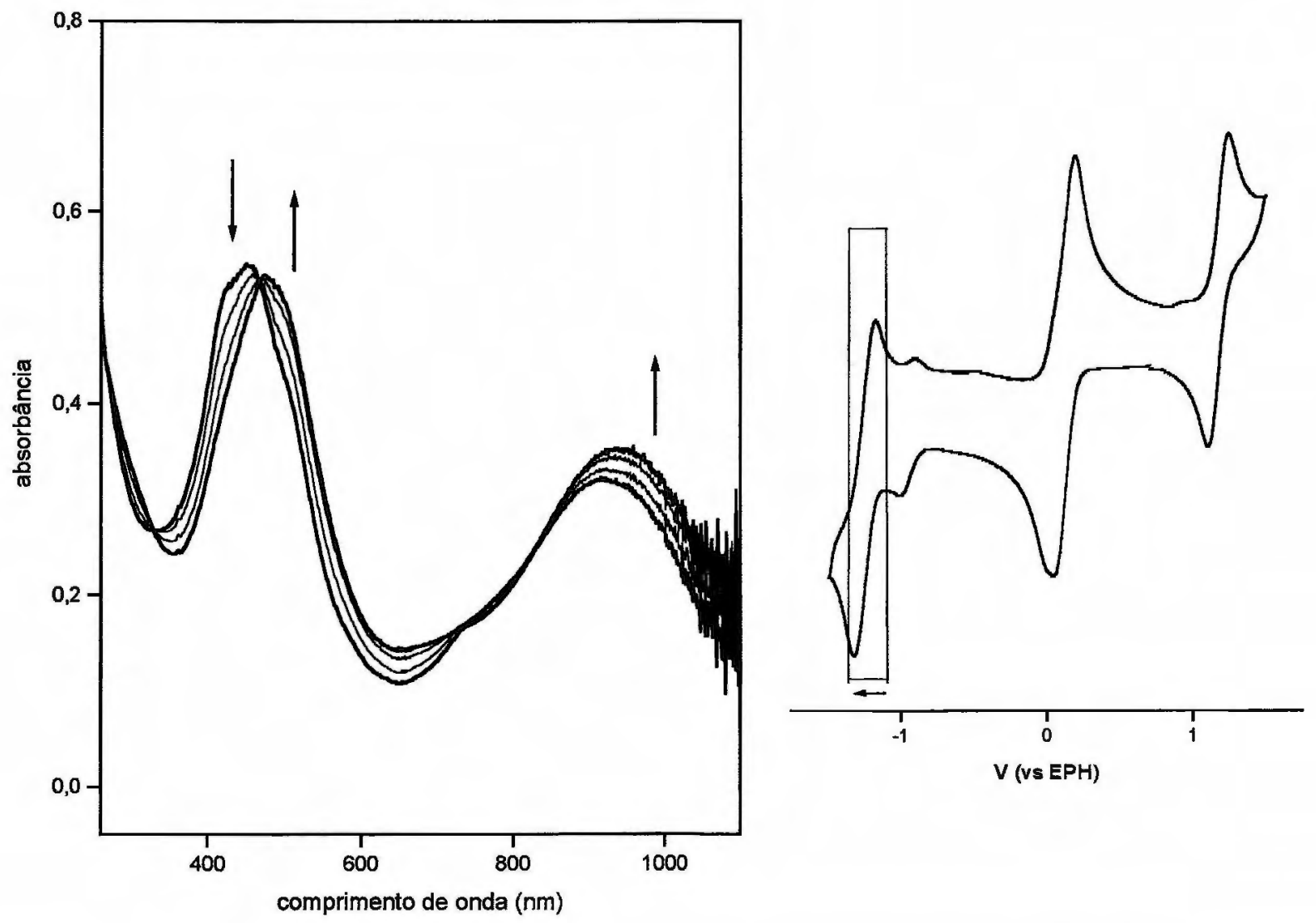

Figura 5.13 - À esquerda, espectroeletroquímica de solução de [MnTCP(OAc) $\left.\left(\mathrm{H}_{2} \mathrm{O}\right)\right]\left(\mathrm{PF}_{6}\right)_{4} 3,4 \times 10^{-4} \mathrm{~mol} \mathrm{dm}^{-3} \mathrm{em} \mathrm{DMF}$ (eletrólito suporte: $\mathrm{TEACIO}_{4} 0,1$ $\mathrm{mol} \mathrm{dm}^{-3}$ ), de $-1,097 \mathrm{a}-1,497 \mathrm{~V}$. À direita, indicação no voltamograma cíclico da região de potencial investigada.

Finalmente, a região IV dos voltamogramas cíclicos (figura 5.9) exibe ondas similares às observadas na região III, com um valor de $E_{1 / 2}$ estimado em 1,17 V. Acompanhando por espectroscopia UV-visivel a oxidação de 1,003 a 1,303 V (figura 5.14), observou-se o decréscimo de intensidade da banda larga devida a transições internas nas unidades $\mathrm{Ru}_{3} \mathrm{O}$ (com máximo em $693 \mathrm{~nm}$ ) paralelamente ao surgimento de outra banda larga com máximo em $775 \mathrm{~nm}$, indicando a oxidação dos clusters

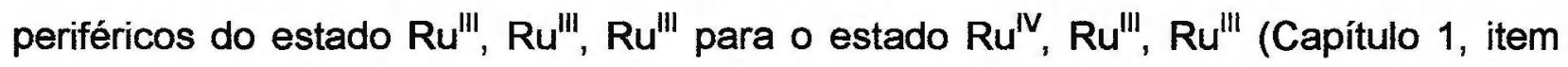
1.3.4). Esta atribuição é reforçada pelo deslocamento da banda TCML para maiores energias (resultando em um máximo em $320 \mathrm{~nm}$ ) e pela observação da segunda banda oriunda de transições internas nos clusters (Capítulo 1, item 1.3.4), que se sobrepõe à banda IV do núcleo porfirínico (resultando em um máximo em $564 \mathrm{~nm}$ ). Novamente observa-se interação eletrônica entre as subunidades através do aumento de intensidade da banda $V$ da porfirina de manganês(III); no entanto, como anteriormente, 
a não observação de uma onda voltamétrica para cada um dos quatro clusters periféricos indica que esta interação é pequena.
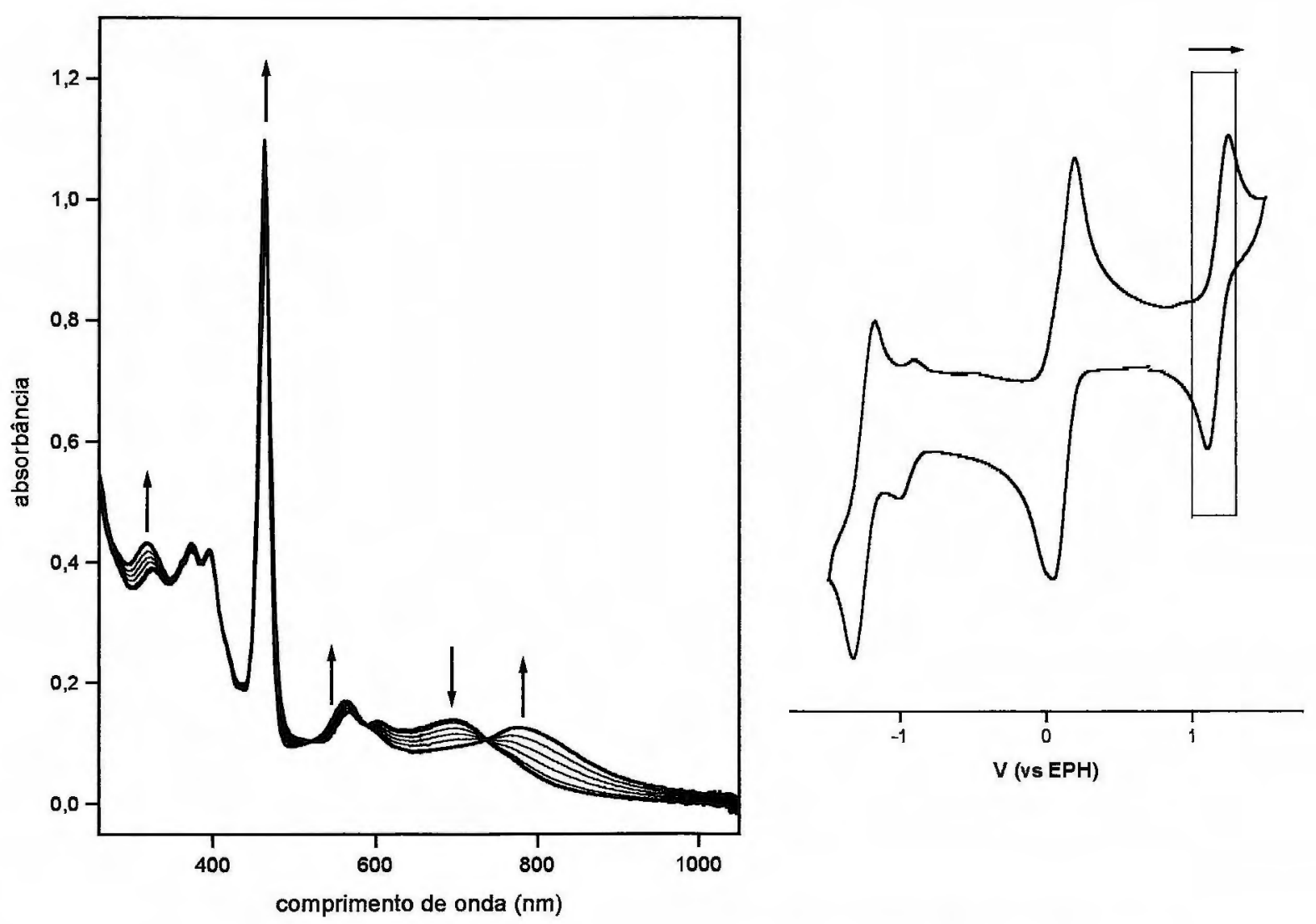

Figura 5.14 - À esquerda, espectroeletroquímica de solução de

[MnTCP(OAc) $\left.\left(\mathrm{H}_{2} \mathrm{O}\right)\right]\left(\mathrm{PF}_{6}\right)_{4} 3,4 \times 10^{-4} \mathrm{~mol} \mathrm{dm}^{-3} \mathrm{em} \mathrm{DMF}$ (eletrólito suporte: TEACIO ${ }_{4} 0,1$ $\mathrm{mol} \mathrm{dm}^{-3}$ ), de 1,003 a 1,303 V. À direita, indicação no voltamograma cíclico da região de potencial investigada. 


\section{$5.5\left[\mathrm{CoTCP}(\mathrm{OAC})\left(\mathrm{H}_{2} \mathrm{O}\right)\right]\left(\mathrm{PF}_{6}\right)_{4}$}

A figura 5.15 exibe os voltamogramas cíclicos de $\left[\mathrm{CoTCP}(\mathrm{OAc})\left(\mathrm{H}_{2} \mathrm{O}\right)\right]\left(\mathrm{PF}_{6}\right)_{4} \mathrm{em}$ $\mathrm{CH}_{3} \mathrm{CN}$ (TBAPF $0,1 \mathrm{~mol} \mathrm{dm}^{-3}$ como eletrólito suporte) a várias velocidades de varredura, com a indicação de cinco processos redox ocorrendo em regiões de potencial denominadas regiões I, II, III, IV e V. Em analogia aos análogos $\mathrm{ZnTCP}^{4+} \mathrm{e}$ $\mathrm{MnTCP}^{5+}$, os processos nas regiões I, II, III e V podem ser associados ao envolvimento dos pares redox $\mathrm{Ru}^{\mathrm{IV}}, \mathrm{Ru}^{\mathrm{III}}, \mathrm{Ru}^{\mathrm{III}} / \mathrm{Ru}^{\mathrm{III}}, \mathrm{Ru}^{\mathrm{III}}, \mathrm{Ru}^{\mathrm{III}}\left(\mathrm{E}_{1 / 2}=1,25 \mathrm{~V}\right.$, reversível), Ru${ }^{\mathrm{IV}}, \mathrm{Ru}^{\mathrm{IV}}$,

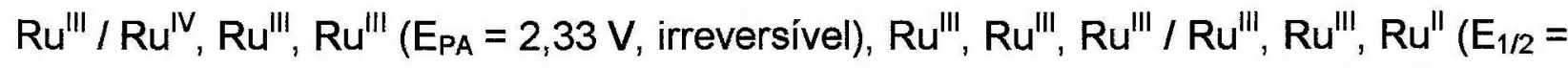
$0,19 \mathrm{~V}$, reversível) e $\mathrm{Ru}^{\prime \prime \prime}, \mathrm{Ru}^{\prime \prime \prime}, \mathrm{Ru} \mathrm{u}^{\prime \prime} / \mathrm{Ru}^{\prime \prime \prime}, \mathrm{Ru}^{\prime \prime}, \mathrm{Ru}^{\prime \prime}\left(\mathrm{E}_{1 / 2}=-1,05 \mathrm{~V}\right.$, reversível). A espectroeletroquímica (discutida a seguir) confirmou esta atribuição. Exceto pelo

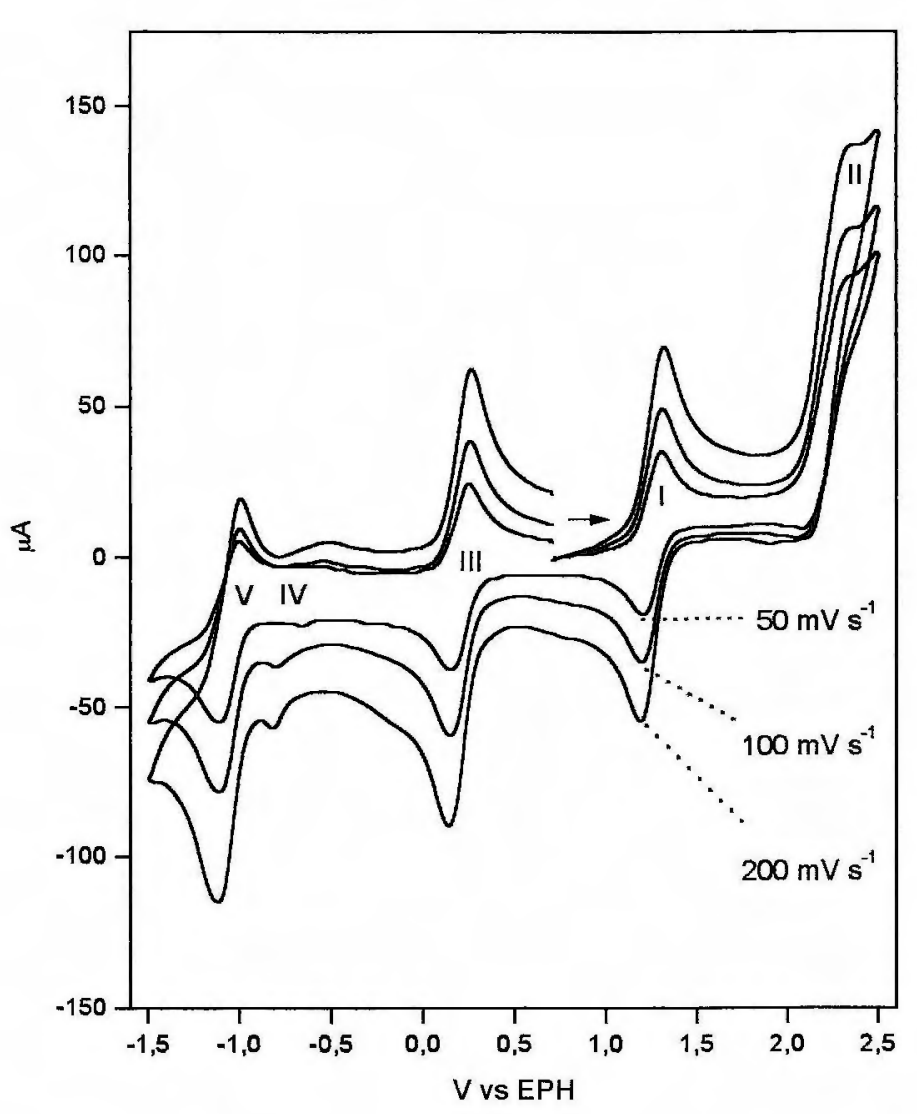
processo ocorrendo na região $\mathrm{IV}$, em que uma onda catódica $\left(E_{P C}=-0,80 \mathrm{~V}\right.$ ) apresenta-se associada a uma onda anódica larga em torno de $-0,5 \mathrm{~V}$, não é possível encontrar outras evidências notórias de processos redox centrados no núcleo porfirínico.

Figura 5.15 - Voltamogramas cíclicos a 50,100 e $200 \mathrm{mV} \mathrm{s}^{-1}$ de solução de [CoTCP $\left.(\mathrm{OAC})\left(\mathrm{H}_{2} \mathrm{O}\right)\right]\left(\mathrm{PF}_{6}\right)_{4} \quad 2 \times 10^{-3} \mathrm{~mol}$ $\mathrm{dm}^{-3}$ em $\mathrm{CH}_{3} \mathrm{CN}$ (eletrólito suporte: TBAPF $_{6} 0,1 \mathrm{~mol} \mathrm{dm}^{-3}$ ), a $25^{\circ} \mathrm{C}$.

Ao se variar o potencial de 0,703 a $1,403 \mathrm{~V}$, as alterações verificadas no espectro eletrônico permitiram confirmar a oxidação dos clusters do estado $\mathrm{Ru}^{\prime \prime \prime}, \mathrm{Ru}^{\mathrm{III}}, \mathrm{Ru}$ 'II' para $\mathrm{Ru}^{\mathrm{IV}}, \mathrm{Ru}^{\mathrm{III}}$, Ru"l: diminuição de intensidade da banda larga com máximo em $693 \mathrm{~nm}$, paralelamente ao surgimento de outras duas bandas atribuídas a transições internas nas unidades $\mathrm{Ru}_{3} \mathrm{O}$, uma com máximo em $795 \mathrm{~nm}$ e outra que, sobreposta às bandas $\mathrm{Q}$, resulta em um máximo em $559 \mathrm{~nm}$, enquanto a TCML torna-se bem definida em 316 $\mathrm{nm}$ (figura 5.16). Um aumento de intensidade na banda Soret pode ser associado à 
existência de um fraco acoplamento eletrônico entre as subunidades, em analogia aos análogos $\mathrm{ZnTCP}^{4+}$ e $\mathrm{MnTCP}^{5+}$.

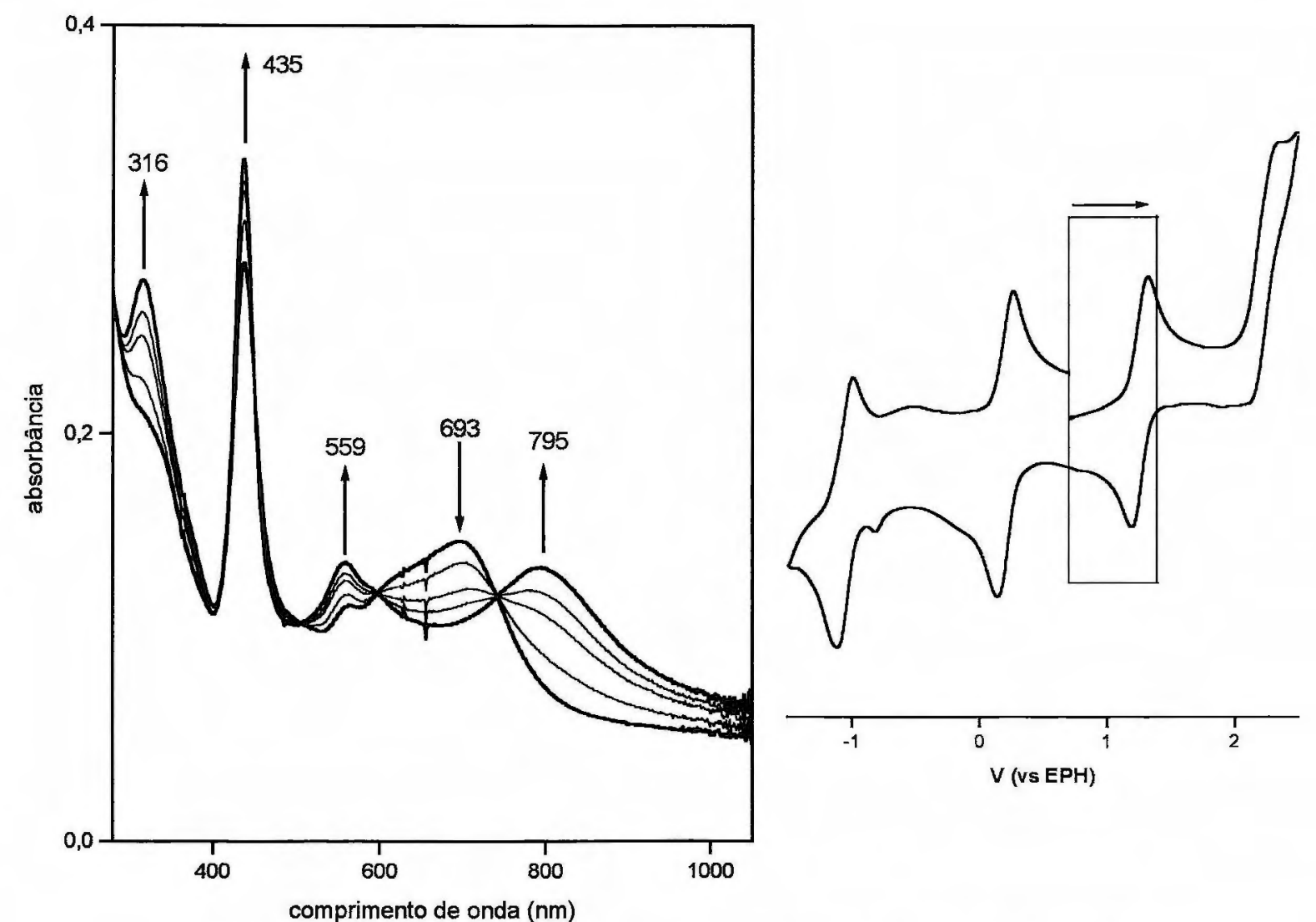

Figura 5.16 - À esquerda, espectroeletroquímica de solução de [CoTCP $\left.(\mathrm{OAC})\left(\mathrm{H}_{2} \mathrm{O}\right)\right]\left(\mathrm{PF}_{6}\right)_{4} 3 \times 10^{-4} \mathrm{~mol} \mathrm{dm}^{-3} \mathrm{em} \mathrm{CH}_{3} \mathrm{CN}$ (eletrólito suporte: TBAPF 6 0,1 $\mathrm{mol} \mathrm{dm}^{-3}$ ), de 0,703 a $1,403 \mathrm{~V}$. À direita, indicação no voltamograma cíclico da região de potencial investigada.

Contrariamente ao observado com o análogo $\mathrm{ZnTCP}^{4+}$, nenhuma alteração no espectro foi observada entre 1,40 e 2,00 V, fato que concorda com a ausência de ondas nos voltamogramas cíclicos nesta faixa de potencial (figura 5.15), sugerindo que a oxidação do anel porfirínico de $\mathrm{CoTCP}^{5+}$ ao seu radical $\pi$-cátion ocorra acima deste potencial (em CoTPP ${ }^{+}$esta oxidação se efetua em torno de 1,20V, em diclorometano ${ }^{191,194}$ ). Esta diferença de comportamento eletroquímico pode ser racionalizada em termos de um forte efeito elétron-aceitador dos clusters periféricos nos estados de oxidação $\mathrm{Ru}^{\mathrm{IV}}, \mathrm{Ru}^{\mathrm{III}}, \mathrm{Ru} \mathrm{u}^{\mathrm{III}}$ sobre o núcleo porfirinico, deslocando o $\mathrm{E}_{1 / 2}$ de oxidação do anel para potenciais mais positivos que os usualmente observados. Infelizmente, acima de $2,00 \mathrm{~V}$ a intensidade de corrente tornou-se maior que a permitida pelo potenciostato, inviabilizando os experimentos de espectroeletroquímica em potenciais mais positivos. 
A espectroeletroquímica de 0,703 a $0,003 \mathrm{~V}$ (região de potencial III dos voltamogramas cíclicos da figura 5.15) informou a ocorrência de dois processos: (i) redução de $\mathrm{Co}^{\text {III }} \mathrm{TCP}^{5+}$ a $\mathrm{Co}^{\prime \prime} \mathrm{TCP}^{4+}$, evidenciada pelo deslocamento da banda Soret para maior energia, de 435 para $413 \mathrm{~nm}$; este processo é perceptível a partir de 0,403 $\mathrm{V} e$, até $0,303 \mathrm{~V}$, nenhuma alteração significativa pôde ser observada nas bandas relacionadas aos clusters (figura 5.17-A); (ii) redução dos clusters, do estado Ru', $\mathrm{Ru}^{\mathrm{III}}$, $\mathrm{Ru}^{\prime \prime \prime}$ para o estado Ru', Ru', Ru"; esta atribuição é baseada nas discussões anteriores para os análogos $\mathrm{ZnTCP}^{4+}$ e $\mathrm{MnTCP}^{5+}$. Esta redução é perceptivel a partir de $0,253 \mathrm{~V}$, como mostra a figura 5.17-B, em que também pode ser observada a continuação simultânea da redução do íon de $\mathrm{Co}(\mathrm{III})$.
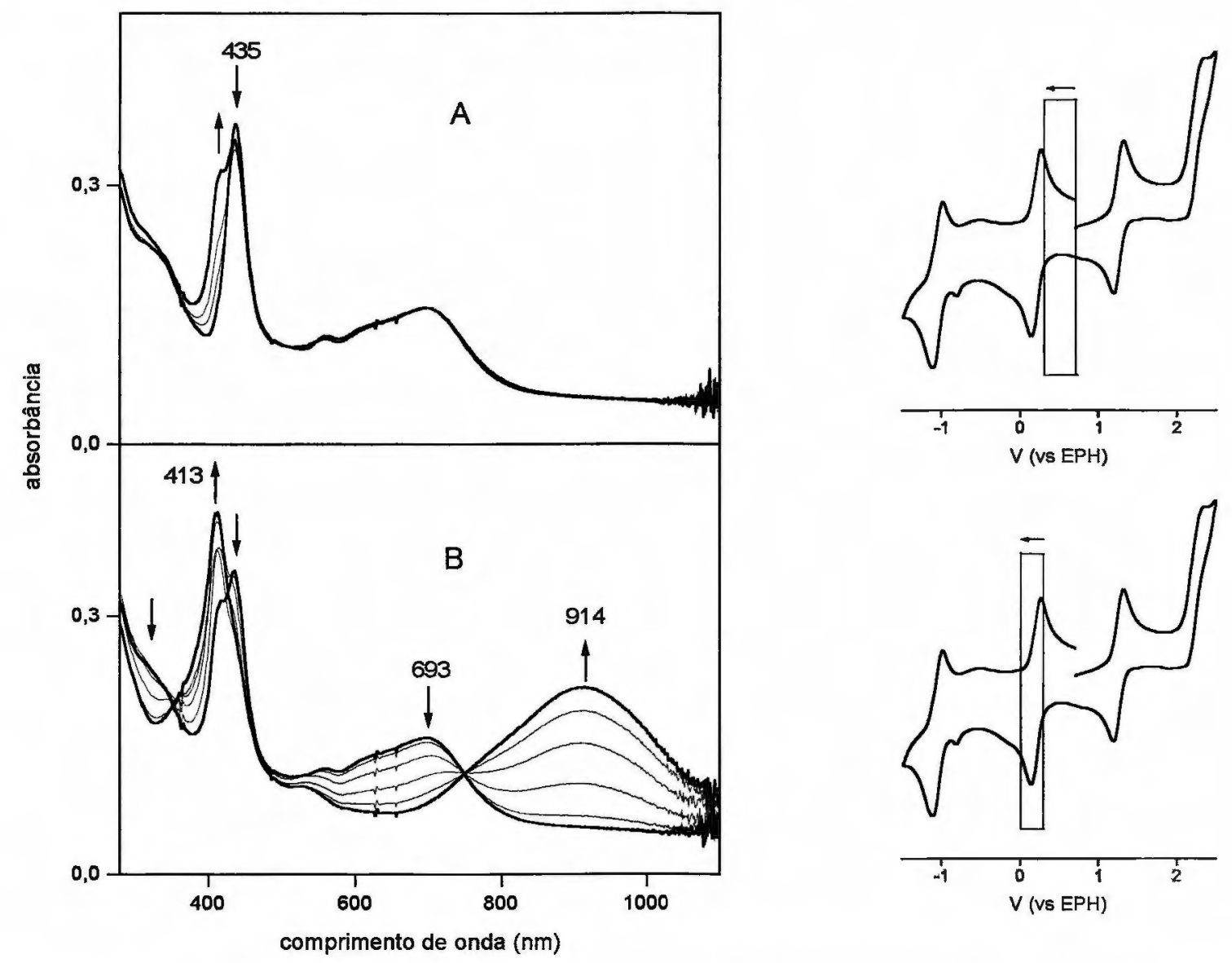

Figura 5.17 - À esquerda, espectroeletroquímica de solução de [CoTCP $\left.(\mathrm{OAC})\left(\mathrm{H}_{2} \mathrm{O}\right)\right]\left(\mathrm{PF}_{6}\right)_{4} 3 \times 10^{-4} \mathrm{~mol} \mathrm{dm}^{-3} \mathrm{em} \mathrm{CH}_{3} \mathrm{CN}$ (eletrólito suporte: TBAPF 6,1 mol dm ${ }^{-3}$ ): A) de 0,703 a 0,303 V; B) de 0,303 a 0,003 V. À direita, indicação nos voltamogramas cíclicos das regiões de potencial investigadas.

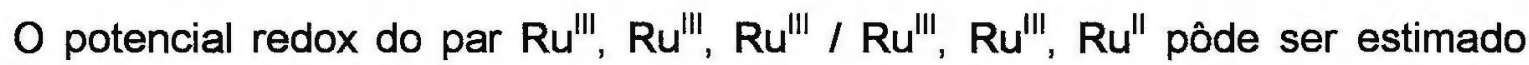
como anteriormente, através de um gráfico de Nernst monitorando-se a absorção em $914 \mathrm{~nm}$, onde bandas devido à transições no núcleo porfirínico estão ausentes; tal 
tratamento resultou em um valor de $E_{1 / 2}$ igual a $0,20 \mathrm{~V}$, valor este muito próximo ao determinado através dos voltamogramas $(0,19 \mathrm{~V})$. A determinação do potencial do par $\mathrm{Co}^{\text {IIITCP }}{ }^{5+} / \mathrm{Co}^{11} \mathrm{TCP}^{4+}$ é dificultada pela extensa sobreposição das bandas de absorção entre as subunidades, dificuldade aumentada pelo fato de que as bandas da porfirina podem ter suas absortividades alteradas em função dos processos redox sofridos pelos clusters, como visto anteriormente. No entanto, através da espectroeletroquímica indicada na figura 5.17, fica evidente que os potenciais redox dos dois pares são suficientemente próximos para que haja sobreposição dos processos eletroquímicos, o que resulta na observação de uma única onda de redução na região III dos voltamogramas cíclicos (figura 5.15).
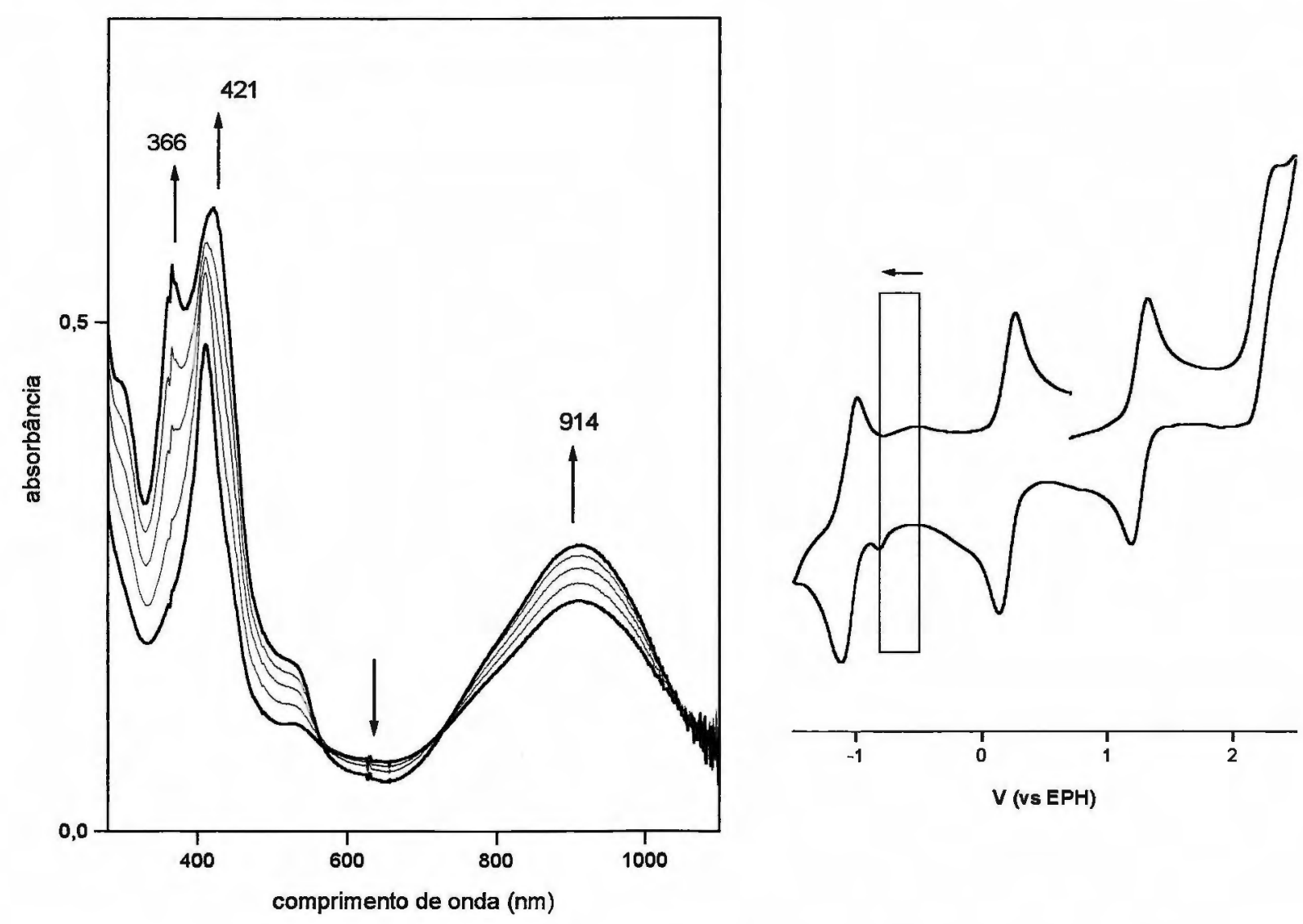

Figura 5.18 - À esquerda, espectroeletroquímica de solução de [CoTCP $\left.(\mathrm{OAC})\left(\mathrm{H}_{2} \mathrm{O}\right)\right]\left(\mathrm{PF}_{6}\right)_{4} 3 \times 10^{-4} \mathrm{~mol} \mathrm{dm}^{-3}$ em $\mathrm{CH}_{3} \mathrm{CN}$ (eletrólito suporte: TBAPF 6 0,1 $\left.\mathrm{mol} \mathrm{dm}^{-3}\right)$, de $-0,497$ a $-0,797 \mathrm{~V}$. À direita, indicação no voltamograma cíclico da região de potencial investigada.

Ao se variar o potencial de $-0,497$ a $-0,797 \mathrm{~V}$ (região IV), ocorreu um aumento na absorção em todos os comprimentos de onda, à exceção da faixa entre 560 e 730 $\mathrm{nm}$ (figura 5.18). Novas bandas surgiram em 366 e em torno de $300 \mathrm{~nm}$, enquanto a Soret teve seu máximo deslocado de 413 para $421 \mathrm{~nm}$. Especificamente com relação 
às bandas da porfirina, o espectro final é similar ao obtido por Kobayashi et al ${ }^{195}$ na redução de Co"TPP com sódio metálico em tetra(hidro)furano, e atribuído a Co'TPP. Corroborando esta atribuição, não são observadas as bandas características de porfirina radical $\pi$-ânion (em torno de $700 \mathrm{~nm}$ ) e de porfirina radical $\pi$-diânion (em torno de $800 \mathrm{~nm})^{185,186,196}$. O aumento de absorbância da banda associada aos clusters em 914 nm pode ser associado à interação eletrônica entre as subunidades.

Prosseguindo a redução, de $-0,797$ a $-1,197 \mathrm{~V}$ (região de potencial V), observou-se o deslocamento para menor energia tanto da banda TCML como a associada às transições internas nas unidades $\mathrm{Ru}_{3} \mathrm{O}$ dos clusters periféricos (figura 5.19). Com o deslocamento da banda $T C M L$, ocorreu uma diminuição significativa na absorbância da região em torno de $400 \mathrm{~nm}$, permitindo que as bandas de absorção relacionadas à porfirina de cobalto(I) se apresentassem melhor definidas. Como discutido anteriormente, tais mudanças são consistentes com a redução dos clusters

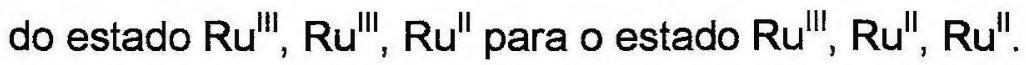
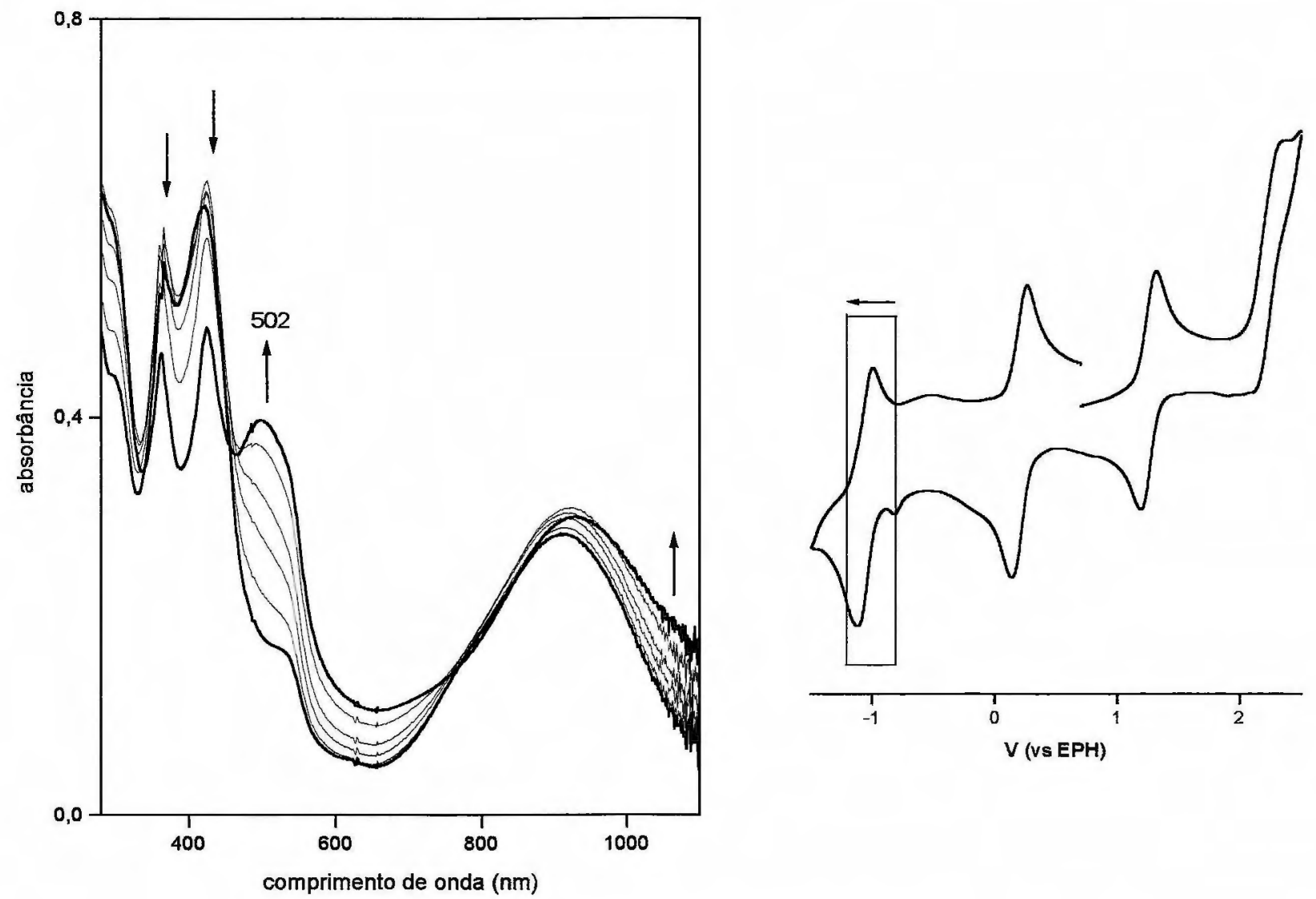

Figura 5.19 - À esquerda, espectroeletroquímica de solução de [CoTCP(OAc) $\left.\left(\mathrm{H}_{2} \mathrm{O}\right)\right]\left(\mathrm{PF}_{6}\right)_{4} 3 \times 10^{-4} \mathrm{~mol} \mathrm{dm}^{-3} \mathrm{em} \mathrm{CH}_{3} \mathrm{CN}$ (eletrólito suporte: TBAPF 6,1 $\mathrm{mol} \mathrm{dm}^{-3}$ ), de $-0,797 \mathrm{a}-1,197 \mathrm{~V}$. À direita, indicação no voltamograma cíclico da região de potencial investigada. 
O fato de não serem observadas reduções no anel porfirínico de $\operatorname{CoTCP}^{5+}$ não é incomum: algumas poucas caracterizações têm sido feitas para a redução de porfirinas de cobalto(I); isto se deve, em parte, ao potencial extremamente negativo necessário para tais processos que, frequentemente, ocorrem além do limite de potencial dos solventes ${ }^{191}$.

Por fim, com relação aos processos envolvendo o ín de cobalto: enquanto o potencial redox do par Co'IIP / CollP é influenciado pelo solvente, pelo eletrólito suporte $e$, principalmente, pelas magnitudes das constantes de formação na adição de ligantes axiais, o potencial do par Coll $\mathrm{P} / \mathrm{Co} \mathrm{P}$ é apenas ligeiramente afetado pelas condições de solvente e eletrólito suporte ${ }^{191}$. Além disso, torna-se necessário considerar também a variação na estereoquímica do íon de cobalto em função do seu estado de oxidação: em Co"l'P há preferência pela hexacoordenação; em Coll'P o íon central ocorre quase invariavelmente como pentacoordenado, enquanto na formação de Co'P sugere-se a saída do ligante, resultando em um íon tetracoordenado (sem ligantes axiais) ${ }^{191}$. Portanto, a maior dificuldade em se reoxidar Co'TCP' a Co"TCP (como indicam os voltamogramas da figura 5.15 , região IV) pode estar associada à ausência do ligante acetato, presumivelmente capaz de estabilizar o estado de oxidação maior. 
CAPÍTULO 6

\section{REATIVIDADE}




\subsection{Coordenação axial de $\mathrm{ZnTCP}^{4+}$}

6.1.1 Método de cálculo utilizado na determinação das constantes de equilíbrio de formação de complexos $\operatorname{ZnTCP}(L)^{4+}, L=$ ligante axial, e das constantes de equilibrio de substituição axial.

Para a determinação das constantes de equilíbrio de formação e de substituição de $\operatorname{ZnTCP}(L)^{4+}$, foram realizadas titulaçōes espectrofotométricas, monitorando-se as reações pelas alterações na banda Soret; por exemplo, ao se adicionar alíquotas de solução de piridina (py) em diclorometano (DCM) à solução de $\mathrm{ZnTCP}^{4+}$ em DCM, a formação de ZnTCP(py) ${ }^{4+}$ pôde ser acompanhada pelo deslocamento da Soret de 424 para $432 \mathrm{~nm}$ (figura 6.1), sendo utilizada nos cálculos posteriores a absorção neste comprimento de onda.

As reações de formação de complexos $\mathrm{ZnTCP}(L)^{4+}$ foram conduzidas em DCM, tendo sido determinadas as constantes de equilíbrio de formação das espécies $\mathrm{ZnTCP}\left(\mathrm{CH}_{3} \mathrm{CN}\right)^{4+}, \mathrm{ZnTCP}(\mathrm{py})^{4+}$ e $\mathrm{ZnTCP}(\mathrm{im})^{4+}$ (im = imidazol). As reações de substituição foram conduzidas em $\mathrm{CH}_{3} \mathrm{CN}$, assumindo-se $\mathrm{ZnTCP}\left(\mathrm{CH}_{3} \mathrm{CN}\right)^{4+}$ como complexo de partida, tendo sido estudadas as substituições de $\mathrm{CH}_{3} \mathrm{CN}$ por $\mathrm{H}_{2} \mathrm{O}$, piridina e imidazol. A figura 6.1 apresenta as transformações verificadas no espectro de $\mathrm{ZnTCP}^{4+}$ na região da banda Soret no decorrer destas titulações.

É geralmente aceito que as porfirinas de zinco apresentam-se tetracoordenadas em solventes não-coordenantes (DCM, benzeno ou tolueno, por exemplo), sendo possível a adição de apenas um ligante axial ${ }^{197-199}$. No caso particular de $\mathrm{ZnTCP}^{4+}$, este processo pode ser representado por

$$
\mathrm{ZnTCP}+\mathrm{L} \rightleftharpoons \mathrm{ZnTCP}(\mathrm{L})
$$

sendo definida a constante de equilíbrio de formação $K_{F}$ por

$$
K_{F}=\frac{[\mathrm{ZnTCP}(L)]}{[\mathrm{ZnTCP}][\mathrm{L}]}
$$


93
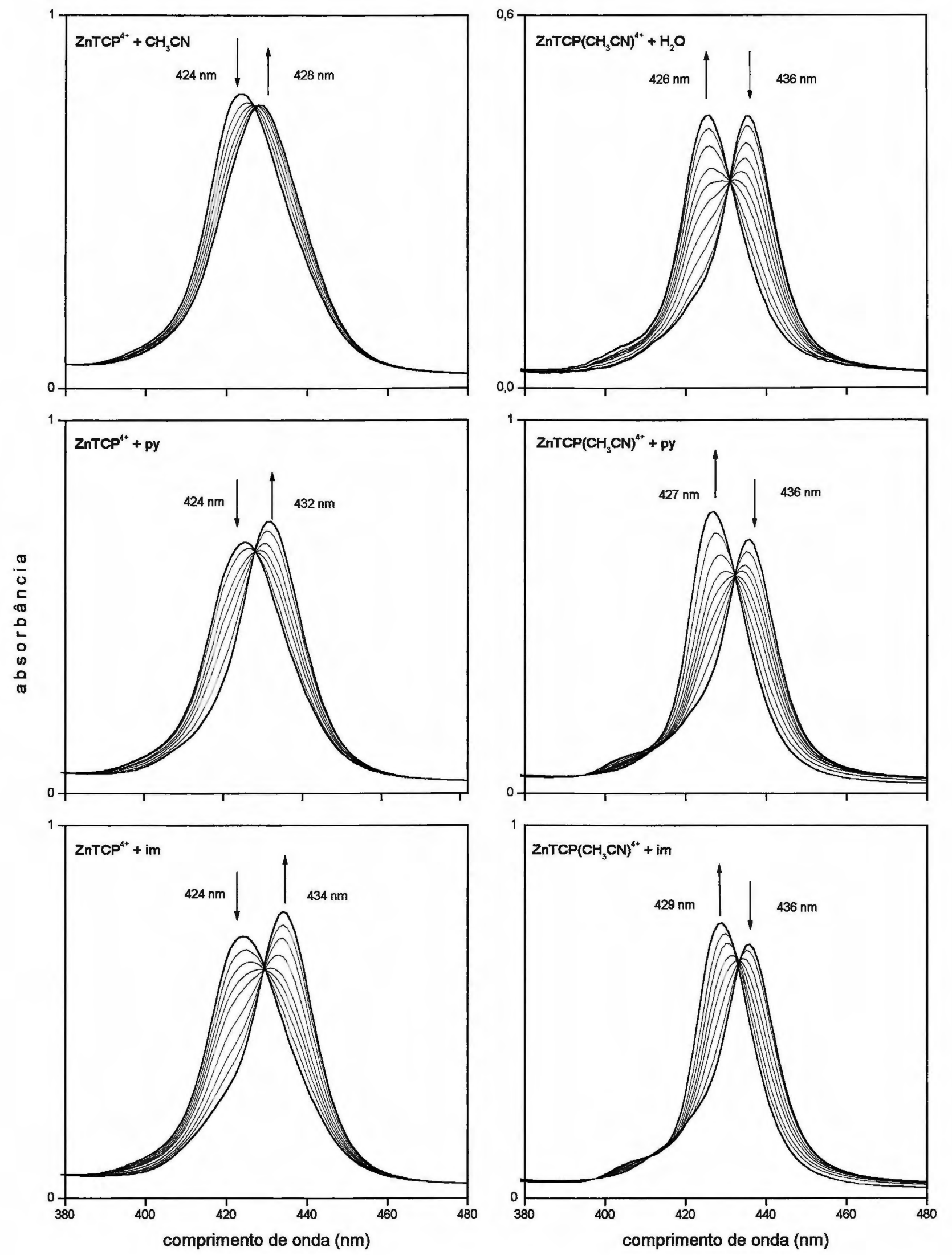

Figura 6.1 - Alterações observadas na banda Soret de $\mathrm{ZnTCP}\left(\mathrm{PF}_{6}\right)_{4}$ no transcorrer das reações de formação (em DCM, à esquerda) e de substituição (em $\mathrm{CH}_{3} \mathrm{CN}$, à direita), a $25^{\circ} \mathrm{C}$. 
Representando a concentração total de $\mathrm{ZnTCP}^{4+}$ e de $\mathrm{L}$ por, respectivamente, $[\mathrm{ZnTCP}]_{\mathrm{T}}$ e $[\mathrm{L}]_{\mathrm{T}}$, temos:

$$
[\mathrm{ZnTCP}]_{\mathrm{T}}=[\mathrm{ZnTCP}]+[\mathrm{ZnTCP}(\mathrm{L})] \quad e \quad[\mathrm{~L}]_{\mathrm{T}}=[\mathrm{L}]+[\mathrm{ZnTCP}(\mathrm{L})]
$$

Substituindo na equação 6.1 :

$$
\mathrm{K}_{\mathrm{F}}=\frac{[\mathrm{ZnTCP}(\mathrm{L})]}{\left.\left\{[\mathrm{ZnTCP}]_{\mathrm{T}}-[\mathrm{ZnTCP}(\mathrm{L})]\right\}[\mathrm{L}]_{\mathrm{T}}-[\mathrm{ZnTCP}(\mathrm{L})]\right\}}
$$

A absorção no comprimento de onda escolhido (banda Soret) para monitorar a formação de $\mathrm{ZnTCP}(\mathrm{L})$ por espectrofotometria UV-visível inclui também a absorção devida à espécie ZnTCP:

$$
A=\varepsilon_{Z n T C P}[Z n T C P]+\varepsilon_{Z n T C P(L)}[Z n T C P(L)] \quad(b=1 c m)
$$

ou

$$
A=\varepsilon_{Z n T C P}\left\{[Z n T C P]_{T}-[Z n T C P(L)]\right\}+\varepsilon_{Z n T C P(L)}[Z n T C P(L)]
$$

$\varepsilon_{Z n T C P}[Z n T C P]_{T}$ é a absorbância $\left(A_{0}\right)$ que a solução apresentaria sem a presença de L. Resolvendo a equação 6.3 para $\mathrm{ZnTCP}(\mathrm{L})$ :

$$
[\mathrm{ZnTCP}(\mathrm{L})]=\frac{\mathrm{A}-\mathrm{A}_{0}}{\varepsilon_{\mathrm{ZnTCP}(\mathrm{L})}-\varepsilon_{\mathrm{ZnTCP}}}
$$

A substituição desta expressão na equação 6.2 , seguida de rearranjo, conduz à equação básica do método gráfico de Rose-Drago ${ }^{200}$ (equação 6.4), com duas incógnitas, $\mathrm{K}_{\mathrm{F}}$ e $\varepsilon_{\mathrm{ZnTCP}(L)}$ :

$$
\frac{1}{K_{F}}=\frac{A-A_{0}}{\varepsilon_{\text {ZnTCP(L) }}-\varepsilon_{Z_{n T C P}}}-[Z n T C P]_{T}-[L]_{T}+\frac{[Z n T C P]_{T}[L]_{T}\left(\varepsilon_{Z_{n T C P(L)}}-\varepsilon_{\left.Z_{n T C P}\right)}\right.}{A-A_{0}}
$$

Neste método, o gráfico é construído a partir de uma solução cujos valores de $[Z n T C P]_{T},[L] T$ e A são conhecidos, calculando-se os valores $\mathrm{K}^{-1}$ a partir de diferentes 
valores de $\varepsilon_{\mathrm{ZnTCP}(L)}$ arbitrariamente atribuídos em torno do seu valor esperado. Os resultados são então plotados ( $\mathrm{K}^{-1}$ versus $\left.\varepsilon_{\mathrm{ZnTCP}(L)}\right)$, e o procedimento é repetido para outras soluções (diferentes $[Z n T C P]_{T},\left[L_{T}\right.$ e A). A intersecção de duas destas retas é uma representação gráfica da solução de duas equaçōes simultâneas. A intersecção de todas as retas calculadas deveria idealmente ocorrer em um único ponto, onde os valores de $\mathrm{K}^{-1}$ e EnTCP(L) $_{\mathrm{Z}}$ satisfazem todos os dados experimentais; no entanto, como resultado do erro experimental, geralmente as intersecções distribuem-se por uma pequena área, se há uma precisão aceitável (figura 6.2). Se são atribuídos pesos equivalentes a todas as intersecções, $\mathrm{K}^{-1}$ pode ser calculado pela média e o erro experimental pode ser expresso pelo desvio padrão.
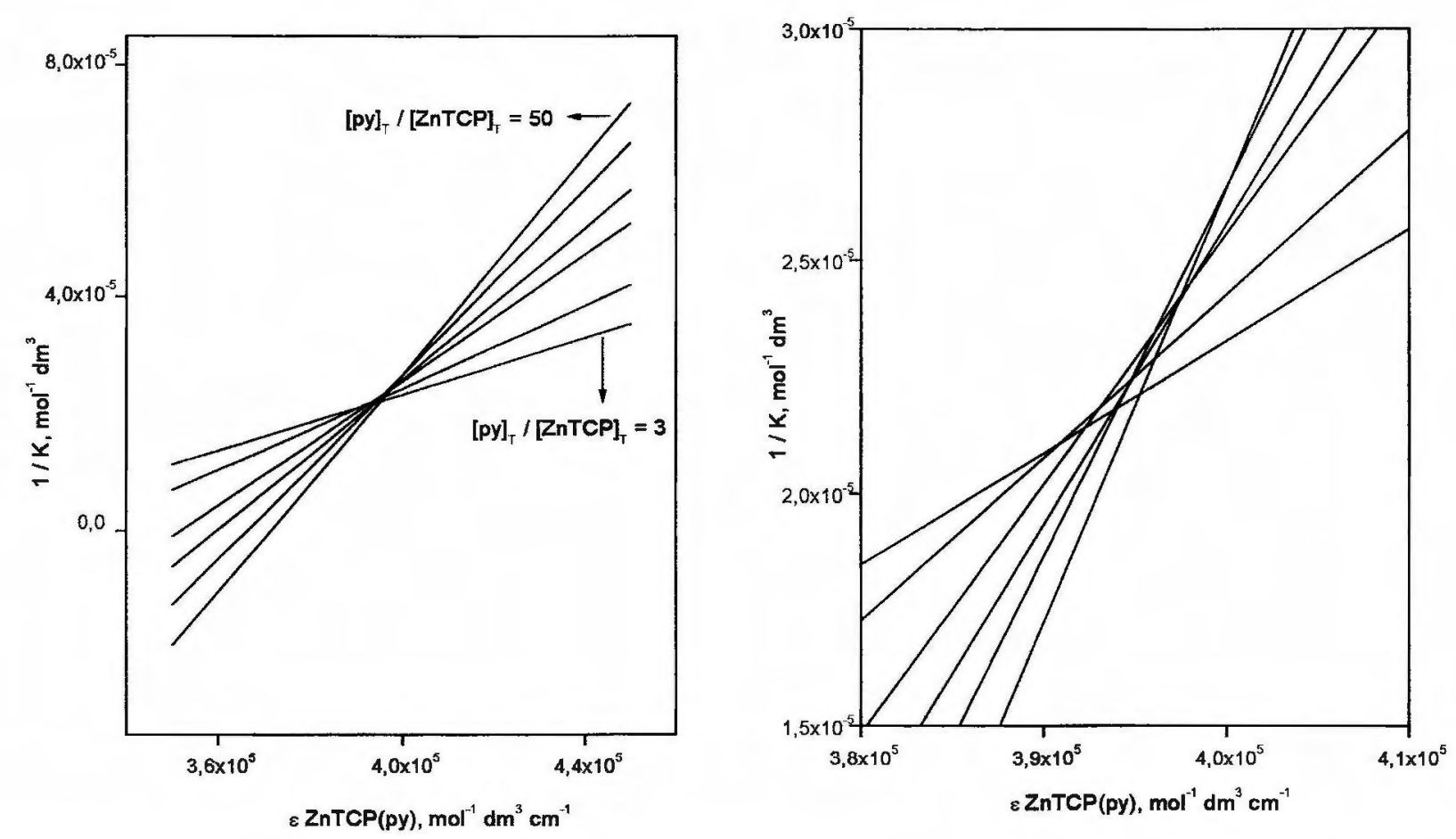

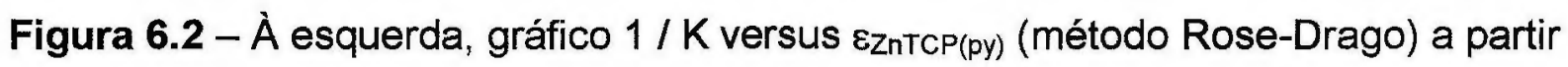
dos dados obtidos em uma das titulações de solução de $\mathrm{ZnTCP}\left(\mathrm{PF}_{6}\right)_{4}$ em DCM com solução de piridina (py) em DCM. À direita, ampliação da região das intersecções.

Rose e Drago apontam algumas vantagens na aplicação deste método:

- a única assunção envolvida na derivação da equação 6.4 é a existência de, no máximo, duas espécies absorvendo no comprimento de onda de monitoramento.

- uma solução trivial corresponderia a encontrar uma solução analítica para duas diferentes condições (por exemplo, duas soluções com diferentes concentrações de 
$\mathrm{L}$ e/ou $\mathrm{ZnTCP}^{4+}$ ): igualam-se as duas equações, determina-se $\varepsilon$ e, a seguir, $\mathrm{K}$; o método descrito possibilita a utilização de várias combinações de concentrações no cálculo da constante de equilíbrio, além de permitir a visualização de dados afetados de erros grosseiros e que, portanto, podem ser desprezados.

- o método permite calcular constantes de equilibrio mesmo para as reações em que K não é suficientemente grande para que se possa admitir reação completa; na extrapolação do método Benesi-Hildebrand ${ }^{201}$ (frequentemente referido como método B-H), por exemplo, existe a condição de reação completa, além de ser necessário que $[L]_{T} \gg\left[M L_{n}\right]$ para a reação $M+n L \leftrightarrow M L_{n}$ (equação 6.5).

$$
\log \frac{\left(A-A_{0}\right)}{\left(A_{F}-A\right)}=n \log [L]+\log K
$$

onde $\mathrm{A}$ : absorbância a uma determinada [L]

$A_{0}$ : absorbância em que $[L]=0$

$A_{F}$ : absorbância em que $[M]_{T}=\left[M L_{n}\right]$

- ainda em comparação com o método $\mathrm{B}-\mathrm{H}$, neste deve-se admitir que a absortividade molar do complexo é uma constante independente da concentração do ligante e, portanto, possíveis variações na constante dielétrica do solvente não são consideradas; tendências nos valores de $\varepsilon$ e K em função da concentração do ligante são prontamente visualizadas no método Rose-Drago, se existirem.

Este método foi utilizado no cálculo das constantes de equilíbrio de formação de $\mathrm{ZnTCP}(\mathrm{py})^{4+}$ e $\mathrm{ZnTCP}(\mathrm{im})^{4+}$ em DCM, a $25^{\circ} \mathrm{C}$. No caso da titulação com $\mathrm{CH}_{3} \mathrm{CN}$, $\left[\mathrm{CH}_{3} \mathrm{CN}\right]_{\mathrm{T}} \gg[\mathrm{ZnTCP}]_{\mathrm{T}}$ e os dois primeiros membros da equação 6.4 tornam-se negligenciáveis quando comparados aos dois últimos. Logo:

$$
\frac{1}{\mathrm{~K}_{\mathrm{F}}}=-\left[\mathrm{CH}_{3} \mathrm{CN}\right]_{\mathrm{T}}+\frac{[\mathrm{ZnTCP}]_{\mathrm{T}}\left[\mathrm{CH}_{3} \mathrm{CN}\right]_{\mathrm{T}}\left(\varepsilon_{\mathrm{ZnTCP}\left(\mathrm{CH} \mathrm{C}_{3} \mathrm{CN}\right)}-\varepsilon_{\mathrm{ZnTCP}}\right)}{\mathrm{A}-\mathrm{A}_{0}}
$$

Rearranjando:

$$
\frac{[\mathrm{ZnTCP}]_{\mathrm{T}}}{\mathrm{A}-\mathrm{A}_{0}}=\frac{1}{\mathrm{~K}_{\mathrm{F}}\left(\varepsilon_{\mathrm{ZnTCP}\left(\mathrm{CH}_{3} \mathrm{CN}\right)}-\varepsilon_{\mathrm{ZnTCP}}\right)\left[\mathrm{CH}_{3} \mathrm{CN}\right]_{T}}+\frac{1}{\left(\varepsilon_{\mathrm{ZnTCP}\left(\mathrm{CH} \mathrm{H}_{3} \mathrm{CN}\right)}-\varepsilon_{\mathrm{ZnTCP}}\right)}
$$


Um gráfico $[\mathrm{ZnTCP}]_{\mathrm{T}} /\left(\mathrm{A}-\mathrm{A}_{0}\right)$ versus $1 /\left[\mathrm{CH}_{3} \mathrm{CN}\right]_{\mathrm{T}}$ produziu uma reta cujo coeficiente linear foi identificado como $1 /\left(\varepsilon_{\mathrm{ZnTCP}(\mathrm{CH} 3 \mathrm{CN})}-\varepsilon_{\mathrm{ZnTCP}}\right)$. Consequentemente, $\mathrm{K}$ pode ser determinado pelo coeficiente angular (figura 6.3).

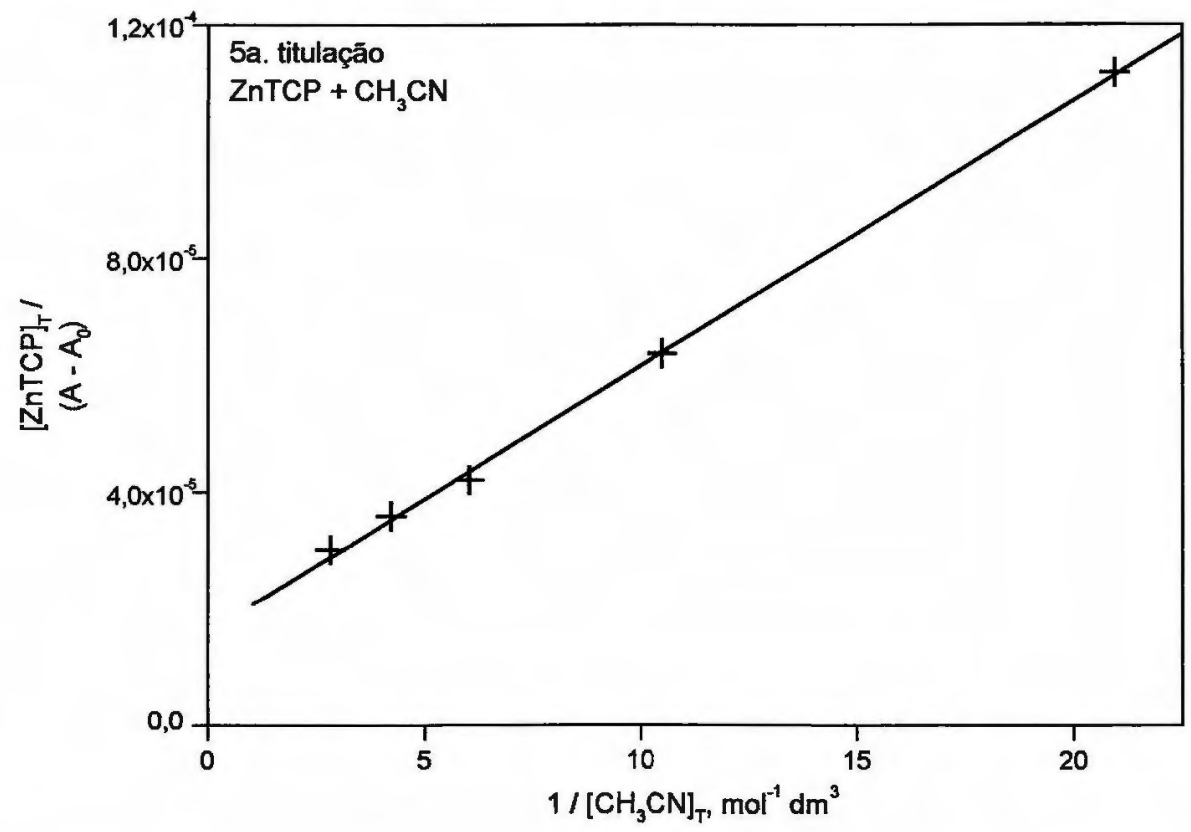

Figura 6.3 - Gráfico $[\mathrm{ZnTCP}]_{\mathrm{T}} /\left(\mathrm{A}-\mathrm{A}_{0}\right)$ versus $1 /\left[\mathrm{CH}_{3} \mathrm{CN}\right]_{\mathrm{T}}$ a partir dos dados obtidos em uma das titulações de solução de $\mathrm{ZnTCP}\left(\mathrm{PF}_{6}\right)_{4} \mathrm{Com} \mathrm{CH}_{3} \mathrm{CN}$, a $25^{\circ} \mathrm{C}$ (solvente: DCM).

Quanto às reações de substituição, efetuadas em $\mathrm{CH}_{3} \mathrm{CN}$ a $25^{\circ} \mathrm{C}$, pode-se representá-las por

$$
\mathrm{ZnTCP}\left(\mathrm{CH}_{3} \mathrm{CN}\right)+\mathrm{L} \rightleftharpoons \mathrm{ZnTCP}(\mathrm{L})+\mathrm{CH}_{3} \mathrm{CN}
$$

onde $\mathrm{L}=\mathrm{H}_{2} \mathrm{O}$, piridina ou imidazol, definindo-se a constante de equilíbrio de substituição $\mathrm{K}_{\mathrm{S}}$,

$$
\mathrm{K}_{\mathrm{S}}=\frac{[\mathrm{ZnTCP}(\mathrm{L})]\left[\mathrm{CH}_{3} \mathrm{CN}\right]}{\left[\mathrm{ZnTCP}\left(\mathrm{CH}_{3} \mathrm{CN}\right)\right][\mathrm{L}]}
$$

Se considerarmos $\left[\mathrm{CH}_{3} \mathrm{CN}\right]=$ constante, podemos definir uma constante $\mathrm{Ks}_{\mathrm{s}}$ tal que

$$
\mathrm{K}_{\mathrm{s}}^{\prime}=\frac{\mathrm{K}_{\mathrm{S}}}{\left[\mathrm{CH}_{3} \mathrm{CN}\right]}=\frac{[\mathrm{ZnTCP}(\mathrm{L})]}{\left[\mathrm{ZnTCP}\left(\mathrm{CH}_{3} \mathrm{CN}\right)\right][\mathrm{L}]}
$$


e o método Rose-Drago póde ser utilizado para calcular Ks':

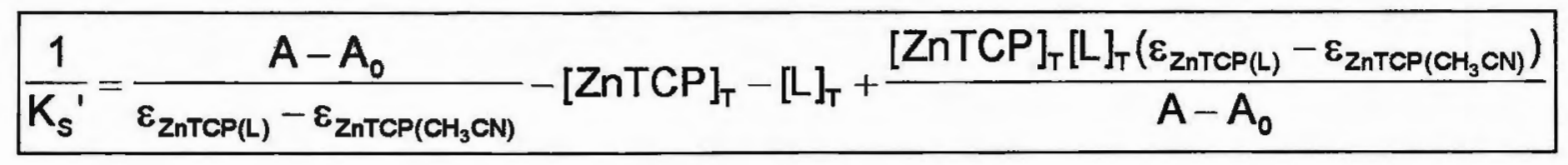

onde $[\mathrm{ZnTCP}]_{\mathrm{T}}=\left[\mathrm{ZnTCP}\left(\mathrm{CH}_{3} \mathrm{CN}\right)\right]+[\mathrm{ZnTCP}(\mathrm{L})]$

e

$$
[L]_{T}=[L]+[Z n T C P(L)]
$$

Este foi o procedimento adotado no caso do tratamento dos dados das reações de substituição de $\mathrm{CH}_{3} \mathrm{CN}$ em $\mathrm{ZnTCP}\left(\mathrm{CH}_{3} \mathrm{CN}\right)^{4+}$ quando $\mathrm{L}=$ piridina ou imidazol (figura 6.4-A). No caso de $L=\mathrm{H}_{2} \mathrm{O},\left[\mathrm{H}_{2} \mathrm{O}\right]_{T} \gg[\mathrm{ZnTCP}]_{T}$ e a equação 6.7 pôde ser aplicada na forma (figura 6.4-B):

$$
\frac{[\mathrm{ZnTCP}]_{\mathrm{T}}}{\mathrm{A}-\mathrm{A}_{\mathrm{O}}}=\frac{1}{\mathrm{~K}_{\mathrm{s}}^{\prime}\left[\varepsilon_{\mathrm{ZnTCP}\left(\mathrm{H}_{2} \mathrm{O}\right)}-\varepsilon_{\mathrm{ZnTCP}\left(\mathrm{CH} \mathrm{H}_{3} \mathrm{CN}\right)}\right]\left[\mathrm{H}_{2} \mathrm{O}\right]}+\frac{1}{\varepsilon_{\mathrm{ZnTCP}\left(\mathrm{H}_{2} \mathrm{O}\right)}-\varepsilon_{\mathrm{ZnTCP}\left(\mathrm{CH} \mathrm{H}_{3} \mathrm{CN}\right)}}
$$
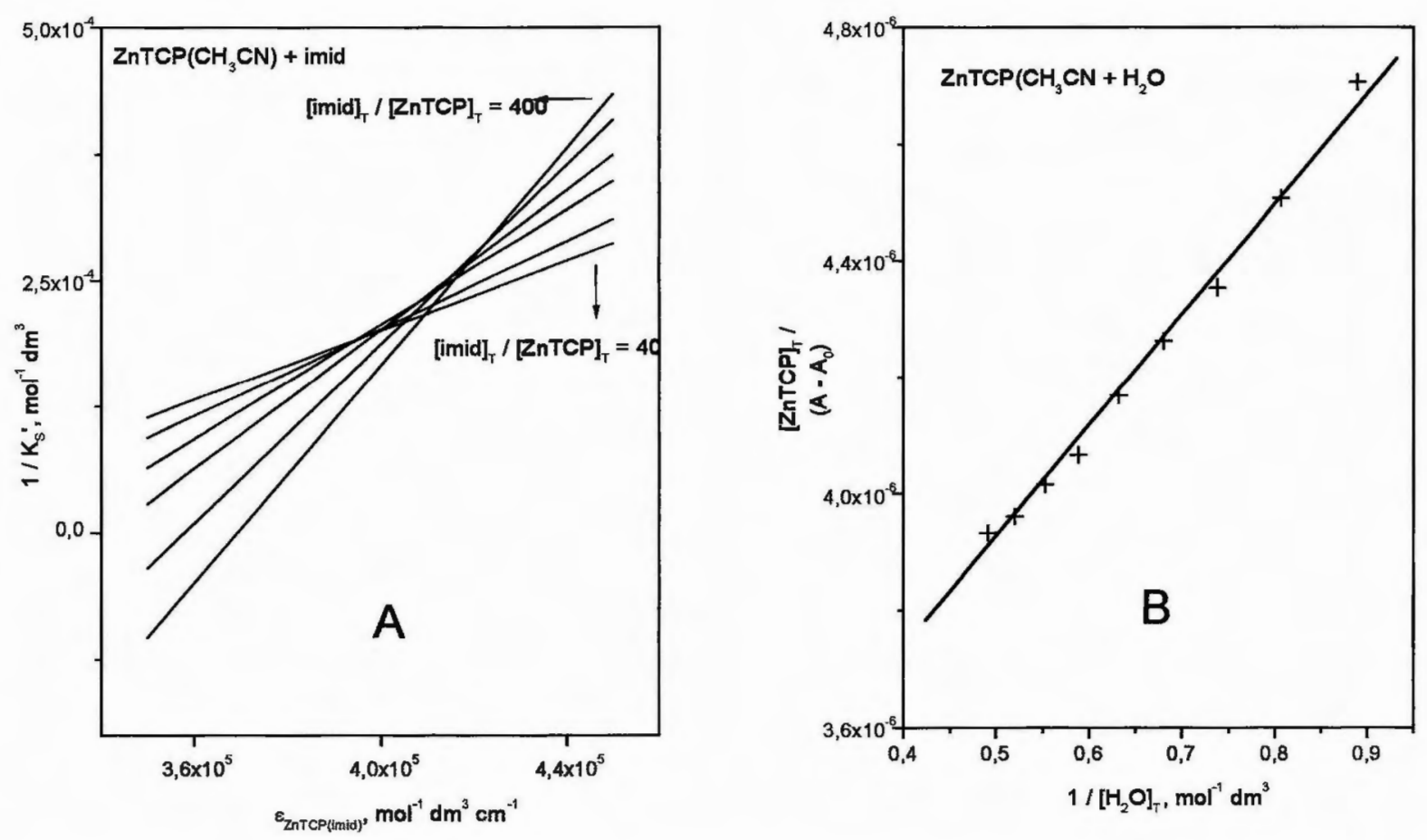

Figura 6.4 - A) Gráfico Rose-Drago adaptado para a reação de substituição de $\mathrm{CH}_{3} \mathrm{CN}$ por imidazol em $\left[\mathrm{ZnTCP}\left(\mathrm{CH}_{3} \mathrm{CN}\right)\right]\left(\mathrm{PF}_{6}\right)_{4}$. B) Gráfico $[\mathrm{ZnTCP}]_{T} /\left(\mathrm{A}-\mathrm{A}_{0}\right)$ versus $1 /$ $\left[\mathrm{H}_{2} \mathrm{O}\right]_{\mathrm{T}}$ a partir dos dados obtidos em uma das titulações de $\mathrm{ZnTCP}\left(\mathrm{CH}_{3} \mathrm{CN}\right)^{4+}$ com $\mathrm{H}_{2} \mathrm{O}$ (solvente $=\mathrm{CH}_{3} \mathrm{CN}$ ). Temperatura em ambos os casos: $25^{\circ} \mathrm{C}$. 


\subsubsection{Resultados}

A tabela 6.1 apresenta os resultados obtidos para as constantes de equilíbrio de formação de $\mathrm{ZnTCP}\left(\mathrm{CH}_{3} \mathrm{CN}\right)^{4+}$, $\mathrm{ZnTCP}(\text { py })^{4+}$ e $\mathrm{ZnTCP}(\mathrm{im})^{4+}$ em DCM a $25^{\circ} \mathrm{C}$, junto a outros coletados na literatura para ZnTPP e ZnTPyP. Incluída nesta tabela estão alguns dos vários métodos utilizados no cálculo destas constantes, tornando-se necessário algumas breves considerações a respeito desta variedade de abordagens, uma vez que tal situação pode colaborar para a discrepância entre resultados de sistemas idênticos tratados por diferentes métodos de cálculo.

Tabela 6.1 - Constantes de equilíbrio de formação $K_{F}$ de $Z n T P P(L), Z n T P y P(L)$ e $[\mathrm{ZnTCP}(\mathrm{L})]^{4+}$, a $25^{\circ} \mathrm{C}$.

\begin{tabular}{|c|c|c|c|c|c|c|c|}
\hline & $\mathrm{ZnP}$ & $\begin{array}{c}\text { Ligante } \\
\text { axial }\end{array}$ & $\begin{array}{c}\text { pKa } \\
\text { lig. axial }\end{array}$ & Solvente & $\begin{array}{c}\mathrm{K}_{\mathrm{F}} \\
\left(\mathrm{mol}^{-1} \mathrm{dm}^{3}\right)\end{array}$ & $\begin{array}{c}\text { Cálculo } \\
\text { de } K_{F}\end{array}$ & Ref. \\
\hline 1 & ZnTPP & py & 5,29 & $\mathrm{C}_{6} \mathrm{H}_{6}$ & $(6,03 \pm 0,01) \times 10^{3 c}$ & Rose-Drago & 202 \\
\hline 2 & ZnTPP & py & 5,29 & $\mathrm{C}_{6} \mathrm{H}_{6}$ & $(4,8 \pm 0,1) \times 10^{3}$ & Miller-Dorough & 203 \\
\hline 3 & ZnTPP & py & 5,29 & $\mathrm{C}_{6} \mathrm{H}_{6}$ & $(5,3 \pm 0,2) \times 10^{3}$ & Rose-Drago & 204 \\
\hline 4 & ZnTPP & py & 5,29 & $\mathrm{C}_{6} \mathrm{H}_{6}$ & $(3,9 \pm 0,5) \times 10^{3}$ & Miller-Dorough & 205 \\
\hline 5 & ZnTPP & py & 5,29 & $\mathrm{C}_{6} \mathrm{H}_{6}$ & $(6,0 \pm 0,3) \times 10^{3}$ & Miller-Dorough & 197 \\
\hline 6 & ZnTPP & 4-amino-py & 9,17 & $\mathrm{C}_{6} \mathrm{H}_{6}$ & $(4,5 \pm 0,4) \times 10^{4}$ & Miller-Dorough & 197 \\
\hline 7 & ZnTPP & 4-ciano-py & 1,91 & $\mathrm{C}_{6} \mathrm{H}_{6}$ & $(6,3 \pm 0,6) \times 10^{2}$ & Miller-Dorough & 197 \\
\hline 8 & $\mathrm{ZnT}(4 \mathrm{ClP}) \mathrm{P}^{\mathrm{a}}$ & py & 5,29 & $\mathrm{C}_{6} \mathrm{H}_{6}$ & $(1,10 \pm 0,06) \times 10^{4}$ & Rose-Drago & 204 \\
\hline 9 & $\mathrm{ZnT}(4 \mathrm{MeOP}) \mathrm{P}^{\mathrm{D}}$ & py & 5,29 & $\mathrm{C}_{6} \mathrm{H}_{6}$ & $(4,90 \pm 0,02) \times 10^{3}$ & Rose-Drago & 204 \\
\hline 10 & ZnTPP & py & 5,29 & $\mathrm{DCM}$ & $(6,9 \pm 0,4) \times 10^{3}$ & Miller-Dorough & 198 \\
\hline 11 & ZnTPP & py & 5,29 & DCM & $(6,6 \pm 0,8) \times 10^{3}$ & SQUAD & 206 \\
\hline 12 & ZnTPP & py & 5,29 & DCM & $(6,9 \pm 0,2) \times 10^{3}$ & B-H & 207 \\
\hline 13 & ZnTPP & $\mathrm{im}$ & 6,65 & $\mathrm{DCM}$ & $(1,9 \pm 0,4) \times 10^{5}$ & SQUAD & 206 \\
\hline 14 & ZnTPyP & py & 5,29 & $\mathrm{CHCl}_{3}$ & $5,8 \times 10^{3}$ & Miller-Dorough & 208 \\
\hline 15 & $\mathrm{ZnTCP}{ }^{4+}$ & $\mathrm{CH}_{3} \mathrm{CN}$ & * & DCM & $4,5 \pm 0,2$ & Rose-Drago & d \\
\hline 16 & $\mathrm{ZnTCP}{ }^{4+}$ & py & 5,29 & DCM & $(4,8 \pm 0,4) \times 10^{4}$ & Rose-Drago & d \\
\hline 17 & $\mathrm{ZnTCP}{ }^{4+}$ & im & 6,65 & DCM & $(1,7 \pm 1,6) \times 10^{7}$ & Rose-Drago & d \\
\hline
\end{tabular}

a) Tetra(4-clorofenil)porfirina de zinco. b) Tetra(4-metóxifenil)porfirina de zinco. c) $\mathrm{K}_{\mathrm{F}}$ calculado a partir dos dados experimentais da referência 203 (linha 2 da tabela). d) Este trabalho.

Uma comparação entre o método Rose-Drago e o método $\mathrm{B}-\mathrm{H}$ já foi discutida no item anterior. Uma forma da equação de B-H, denominada equação de Hill ${ }^{209}$ (não 
incluída na tabela) e que assume as mesmas aproximações, têm sido utilizada em alguns estudos ${ }^{210,211}$. Já o método Miller-Dorough ${ }^{203}$ é, essencialmente, a adaptação do método $\mathrm{B}-\mathrm{H}$ quando a condição $[\mathrm{L}] \gg[\mathrm{ML}]$ não é satisfeita. Embora disponha-se hoje de facilidades promovidas pelo uso de computadores que permitem que programas sejam criados, por exemplo, para o cálculo de $\mathrm{K}$ e $\varepsilon$ na equação Rose-Drago ${ }^{202}$, o uso não criterioso de programas específicos para o cálculo de constantes de equilibrio pode conduzir a resultados questionáveis, como o apresentado por Rebouças et $a^{207}$, em que sugeriu-se a formação de $\operatorname{ZnTPP}(p y)_{2}$ em solução. $O$ mesmo sistema tratado por Kadish et $a^{206}$ pelo mesmo programa (denominado "SQUAD"), em condições experimentais idênticas, conduziu ao usual complexo ZnTPP(py).

A interação entre porfirinas de zinco e bases nitrogenadas pode ser encarada como uma reação ácido-base de Lewis: a relação direta entre as constantes de equilíbrio de formação $K_{F}$ e $\circ$ pKa do ligante nitrogenado evidencia este comportamento (linhas 5 a 7 da tabela 6.1). Adicionalmente, Vogel e Beckmann ${ }^{204}$, ao estudarem derivados de ZnTPP fenil-substituídos, demonstraram que, em geral, há um aumento na constante $\mathrm{K}_{\mathrm{F}}$ com o aumento do caráter elétron-aceitador do fenilsubstituinte (linhas 3,8 e 9). Posteriomente, McDermott e Walker ${ }^{212}$, estudando derivados de ZnTPP simétrica e assimetricamente fenil-substituídos, concluíram que os efeitos eletrônicos de substituintes assimetricamente dispostos produzem um efeito médio sobre a acidez do íon $\mathrm{Zn}^{2+}$, efeito este dependente da soma dos efeitos eletrônicos, mas independente da simetria de sua distribuiçăo. Cite-se, ainda, que Bhyrappa et $a f^{213}$ observaram que os valores de $\mathrm{K}_{\mathrm{F}}$ de um derivado de ZnTPP apresentando átomos de bromo ligados diretamente aos carbonos $\beta$-pirrólicos eram uma ordem de magnitude maiores que os correspondentes valores para ZnTPP.

Embora o número de ligantes $L$ utilizado no presente estudo tenha sido pequeno $e$, portanto, uma correlação $K_{F}$ versus $p K_{\text {(ligante axial) }}$ mais abrangente não tenha sido realizada, os valores de $K_{F}$ obtidos para $[\mathrm{ZnTCP}(\mathrm{L})]^{4+}$ (linhas 15 a 17) sugerem, tendo em vista o que foi discutido, que a acidez de Lewis do íon $\mathrm{Zn}^{2+}$ foi significativamente aumentada quando comparada à acidez do íon $Z^{2+}$ de ZnTPP (linhas 1 a 13) e ZnTPyP (linha 14), evidenciando que os clusters periféricos atuam como espécies elétron-aceitadoras.

A tabela 6.2 exibe os valores obtidos para as constantes de equilíbrio de substituição axial $\mathrm{K}_{s}^{\prime}$ de $\left[\mathrm{ZnTCP}\left(\mathrm{CH}_{3} \mathrm{CN}\right)\right]^{4+}$ : o mesmo comportamento é observado (dependência de $\mathrm{K}_{s}$ ' em relação ao pKa do ligante de entrada), mas os valores são 
bem menores do que os valores de $\mathrm{K}_{\mathrm{F}}$ uma vez que $\mathrm{CH}_{3} \mathrm{CN}$ compete com o ligante de entrada pela posição axial.

Tabela 6.2 - Constantes de equilíbrio de substituição axial $\mathrm{K}_{s}{ }^{\prime}$ de $\left[\mathrm{ZnTCP}\left(\mathrm{CH}_{3} \mathrm{CN}\right)\right]^{4+}$ em $\mathrm{CH}_{3} \mathrm{CN} . \mathrm{T}=25^{\circ} \mathrm{C}$.

\begin{tabular}{ccc}
\hline Ligante axial & pKa lig. axial & $\mathrm{Ks}^{\prime}\left(\mathrm{mol}^{-1} \mathrm{dm}^{3}\right)$ \\
\hline $\mathrm{H}_{2} \mathrm{O}$ & ${ }^{*}$ & $1,6 \pm 0,1$ \\
py & 5,29 & $(1,5 \pm 0,3) \times 10^{2}$ \\
im & 6,65 & $(4 \pm 1) \times 10^{3}$ \\
\hline
\end{tabular}




\section{2 $\mathrm{MnTCP}^{5+}$ : comportamento catalítico na oxidação de substratos orgânicos em fase homogênea}

6.2.1 Oxidação de cicloocteno a ciclooctano-óxido.

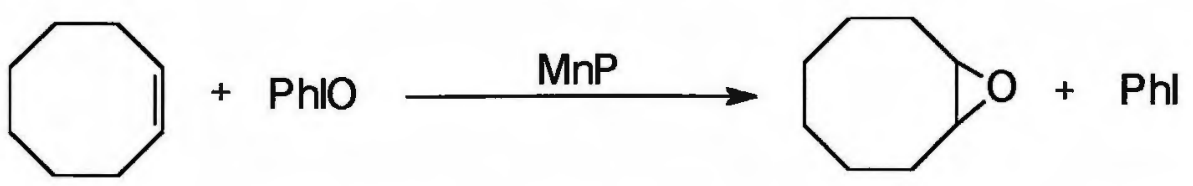

A oxidação de cicloocteno a ciclooctano-óxido, utilizando-se iodosilbenzeno (PhIO) como doador de oxigênio e $\mathrm{CH}_{3} \mathrm{CN}$ como solvente, na presença de MnTPyP ${ }^{+}$ou de $\mathrm{MnTCP}^{5+}$, foi usada inicialmente para uma primeira avaliação do potencial catalítico da supermolécula. Após uma hora de reação, obteve-se um rendimento de $80 \%$ com ambos os catalisadores (tabela 6.3).

Tabela 6.3 - Rendimentos na oxidação de cicloocteno. Solvente: $\mathrm{CH}_{3} \mathrm{CN}(3 \mathrm{~mL})$. Tempo de reação: $1 \mathrm{~h}$. Temperatura $25^{\circ} \mathrm{C}$. Agitação: magnética. $[\mathrm{MnP}]=1,6 \times 10^{-4} \mathrm{~mol}$ $\mathrm{dm}^{-3}$.

\begin{tabular}{ccccc}
\hline & [Catalisador] $/$ & [Catalisador] $/$ & \multicolumn{2}{c}{ Rendimentos (\%) } \\
\cline { 4 - 5 } Catalisador & [Cicloocteno] & [PhlO] & Phl & Oxido \\
\hline MnTPyP $^{+}$ & $1 / 2400$ & $1 / 72$ & 100 & 80 \\
MnTCP $^{5+}$ & $1 / 2200$ & $1 / 48$ & 100 & 82 \\
\hline
\end{tabular}

* Baseados na quantidade de PhIO utilizada.

6.2.2 Oxidação de ciclohexano a ciclohexanol e ciclohexanona.

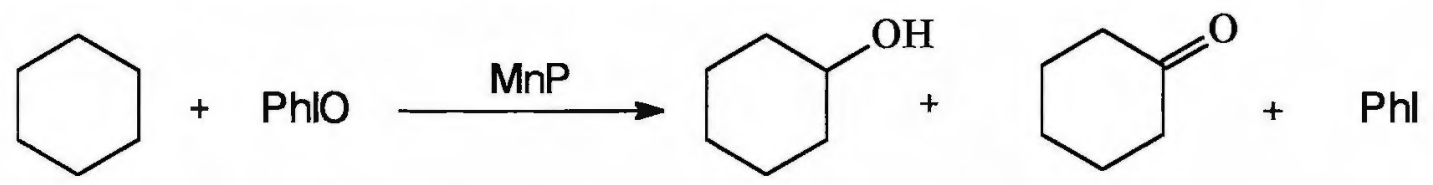

Frente a reação de oxidação de um substrato menos reativo em fase homogênea (1,2-dicloroetano, DCE, como solvente), o comportamento dos catalisadores diferenciou-se: a reação catalisada por $\mathrm{MnTCP}^{5+}$ mostrou-se mais rápida e seletiva, não detectando-se ciclohexanona nos produtos, como indicado na tabela 6.4 , onde podemos notar também que após $2 \mathrm{~h}$ de reação, $\mathrm{MnTCP}^{5+}$ consumiu praticamente quase todo PhlO, fato que implica a ocorrência de reações paralelas. Adicionalmente, através de espectroscopia UV-visível não foi detectada degradação dos catalisadores. 
Tabela 6.4 - Rendimentos na oxidação de ciclohexano em fase homogênea. Solvente: DCE $(1,5 \mathrm{~mL})$. Temperatura: $25^{\circ} \mathrm{C}$. Agitação:magnética. Ciclohexano: $1,5 \mathrm{~mL}(0,0139$ mol). [MnP] / [PhlO] / [ciclohexano]: 1 / 20 / 30000.

\begin{tabular}{cccc|ccc} 
& \multicolumn{5}{c}{ Rendimentos (\%) $^{\text {a }}$} \\
\cline { 2 - 7 } & \multicolumn{7}{c}{$2 \mathrm{~h}$} & \multicolumn{2}{c}{$5 \mathrm{~h}$} \\
\hline Catalisador & C-ol $^{\text {b }}$ & C-ona $^{\text {c }}$ & Phl & C-ol $^{\text {b }}$ & C-ona $^{\text {c }}$ & Phl \\
\hline MnTPyP $^{+}$ & 27 & 13 & 62 & 40 & 17 & 81 \\
MnTCP $^{5+}$ & 45 & n. d. ${ }^{\text {d }}$ & 92 & 44 & n. d. $^{\text {d }}$ & 94 \\
\hline
\end{tabular}

${ }^{a}$ Baseados na quantidade de PhIO utilizada.

${ }^{b}$ Ciclohexanol.

c Ciclohexanona.

${ }^{d}$ Não detectado.

6.2.3 Algumas considerações a respeito de oxidações catalisadas por porfirinas de $M n^{\prime \prime \prime}$.

A despeito do grande número de estudo envolvendo porfirinas de manganês como catalisadores em reações de substratos orgânicos, um absoluto conhecimento sobre os mecanismos pelos quais ocorrem estes processos ainda permanece inatingido $^{94,214,215}$. Basicamente, as atuais discussões centralizam-se em dois aspectos: a estrutura das espécies manganês-oxo de alta valência geradas pela reação entre um doador de oxigênio e a porfirina de manganês, e o mecanismo pelo qual o oxigênio é transferido destas espécies ao substrato.

Quanto ao primeiro aspecto, embora a exata natureza da espécie ativa de alta valência dependa da porfirina de manganês e do oxidante ${ }^{94}$, é geralmente aceito que dois intermediários, $\left(M n^{\mathbb{V}=}=\right) P$ e $\left(M n^{V}=O\right) P(P=$ porfirina $)$, possam ser formados, dependendo das condições de reação ${ }^{215}$. Enquanto o primeiro intermediário, relativamente estável, já tenha sido isolado e caracterizado ${ }^{216,217}$, a espécie $\left(M^{\vee}=0\right) P$, altamente reativa, embora invocada insistentemente nos caminhos reacionais ${ }^{14,15}$, apenas recentemente pôde ser detectada e caracterizada em ambiente catalítico ${ }^{214,218}$.

Quanto ao segundo aspecto, no caso de oxidações de alcenos uma variedade de mecanismos têm sido propostos, nos quais sugeriram-se intermediários como, por exemplo, metal-oxo-etano, cátion $\pi$-radical, carbocátion e carbono radical; sugeriu-se, ainda, a ocorrência de um mecanismo envolvendo a inserção de um "oxeno" na dupla 
ligação do alceno ${ }^{219}$ (figura 6.5). Entre as muitas variáveis que afetam as cinéticas das reações de epoxidação e a distribuição dos produtos citam-se: o caráter eletrônico e estérico do substrato e da porfirina de manganês (incluindo-se efeitos de coordenação axial), o potencial redox do complexo porfirina de manganês-oxo e do alceno, a natureza do doador de oxigênio e o solvente ${ }^{15,18,219}$. Acredita-se que a aproximação da olefina à espécie porfirina de manganês-oxo, que precede a transferência do átomo de oxigênio, é realizada lateral e paralelamente ao anel porfirínico ${ }^{18,112,220}$, ponto importante para a catálise seletiva.
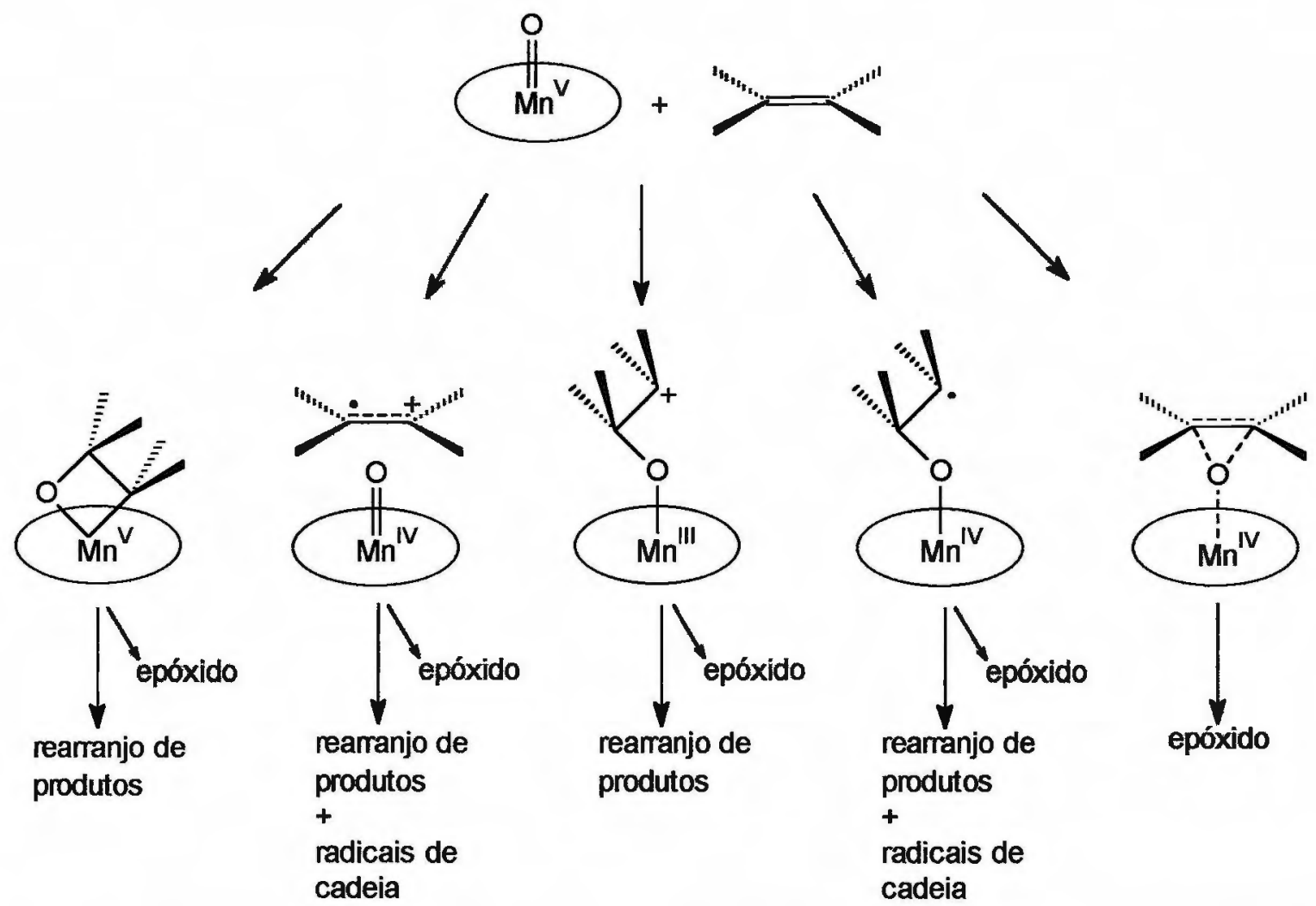
produtos

$+$

radicais de cadeia

Figura 6.5 - Alguns mecanismos de oxidações de alcenos catalisadas por porfirinas de manganês $^{219}$.

No caso das oxidações de alcanos, há várias evidências para o envolvimento de radicais livres como, por exemplo, a detecção de diciclohexil na oxidação de ciclohexano e de ciclohexilbenzeno quando a mesma reação foi conduzida em benzeno $^{15}$. A figura 6.6 mostra um mecanismo plausível para a formação de álcool a partir de alcano, baseado em um estudo detalhado de Smegal e Hill ${ }^{221}$. A ocorrência de efeitos isotópicos primários ${ }^{222}$ contribui para evidenciar um mecanismo de recombinação de oxigênio, de maneira semelhante às hidroxilações promovidas pelas 
citocromo P-450 que têm como pontos chave nos processos que mediam, como vimos no Capítulo 1, item 1.4.3: (i) a formação de uma espécie ferro-oxo de alta valência resultante da clivagem heterolítica de um intermediário ferro-peróxido e (ii) a abstração do hidrogênio de uma ligação $\mathrm{C}-\mathrm{H}$ pelo complexo eletrofílico ferro-oxo, seguida de rápida recombinação do radical formado com a espécie $\left(\mathrm{Fe}^{\mathrm{IV}}-\mathrm{OH}\right) \mathrm{P}$, produzindo o álcool e mantendo a configuração do carbono que sofreu o ataque ${ }^{223}$. 0 escape de radicais antes da recombinação do oxigênio pode resultar em subprodutos, embora uma rota envolvendo a reação do radical com $\left(\mathrm{Mn}^{\mathrm{III}}-\mathrm{OH}\right) \mathrm{P}$ ou $\left(\mathrm{Mn}^{\mathrm{IV}}-\mathrm{OH}\right) \mathrm{P}$ conduzindo à formação do álcool também tenha sido considerada.

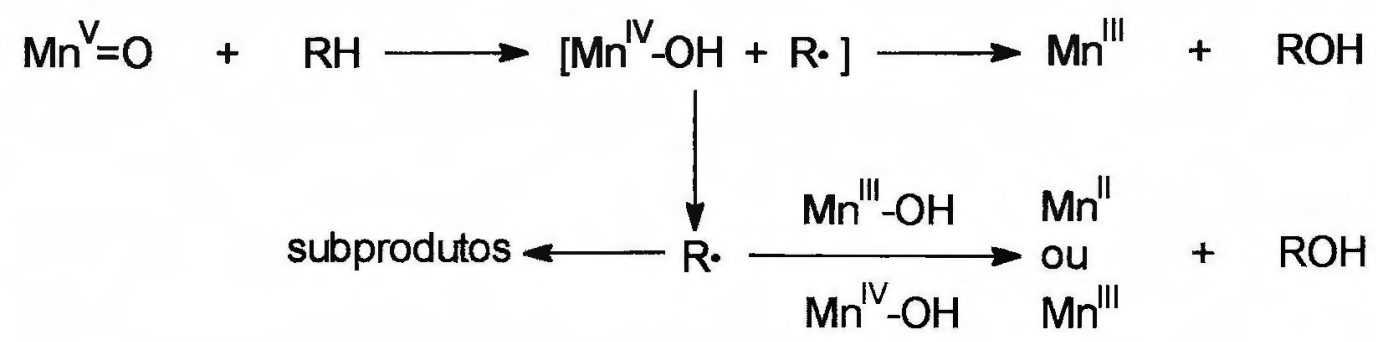

Figura 6.6 - Um mecanismo de hidroxilação de alcano ${ }^{221}$.

No que diz respeito ao doador de oxigênio utilizado nos ensaios catalíticos de $\mathrm{MnTPyP}^{+}$e $^{\mathrm{MnTCP}}{ }^{5+}$, são também necessárias algumas considerações. No início dos anos 80 , sugeriu-se que o agente ativo na promoção das oxidações tendo PhlO como oxidante poderia ser um complexo metaloporfirina-iodosobenzeno ${ }^{221}$. Posteriormente, Cook et $a f^{224}$, utilizando diferentes oxidantes e observando seletividades similares nas hidroxilações de alcanos, afirmaram que as prováveis espécies cataliticamente ativas geradas por porfirinas de manganês e $\mathrm{PhlO}$ seriam idênticas às geradas pelos outros oxidantes, ou seja, nas reações catalisadas por porfirinas de manganês e PhIO a etapa inicial é a completa transferência do átomo de oxigênio de PhlO para a porfirina de manganês, formando a espécie porfirina de manganês-oxo de alta valência; Battioni et $a^{225}$ chegaram a esta mesma conclusão para os sistemas MnTDCPP(Cl) / PhlO e $\operatorname{MnTDCPP}(\mathrm{Cl}) \quad / \mathrm{H}_{2} \mathrm{O}_{2}$ (MnTDCPP ${ }^{+}=5,10,15,20$-tetra(2,6-diclorofenil)porfirina de manganês). No entanto, Sorokin et $\mathrm{a}^{222}$, observaram efeitos cinéticos isotópicos muito mais pronunciados para porfirinas de ferro em comparação com porfirinas de manganês em sistemas similares, o que os levou a sugerir duas possiveis geometrias de estados de transição (figura 6.7): (i) uma linear, envolvendo uma espécie ativa metal-oxo "pura", seria provável no caso dos sistemas FeP / PhIO e FeP / NaOCl, onde 
o grupo de saída do doador de oxigênio não está envolvido no momento da abstração do hidrogênio do alcano; (ii) a outra, inclinada quando comparada à primeira e envolvendo espécies "pseudo" metal-oxo, seria provável nos sistemas FeP ou MnP I $\mathrm{KHSO}_{5}, \mathrm{MnP} / \mathrm{PhIO}$ e MnP / NaOCl, onde o grupo de saída do doador de oxigênio está possivelmente envolvido no estado de transição.

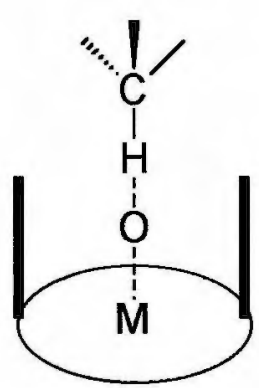

$\mathrm{FeP} / \mathrm{NaOCl}$ FeP/PhiO

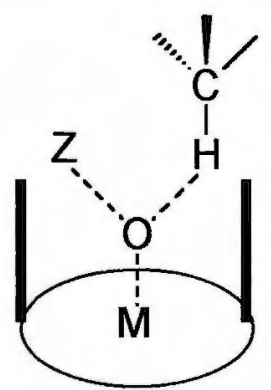

$\mathrm{FeP} / \mathrm{KHSO}_{5}$ $\mathrm{MnP} / \mathrm{KHSO}_{5}, \mathrm{PhlO}, \mathrm{NaOCl}$

Figura 6.7 - Possiveis geometrias de estados de transição em reações de hidroxilação catalisadas por porfirinas de ferro $(\mathrm{FeP})$ e de manganês $(\mathrm{MnP})^{222} . \mathrm{Z}=$ grupo de saída do doador de oxigênio.

Independentemente da maneira como o iodosilbenzeno interage (ou não) com a metaloporfirina no estado de transição, são reconhecidas como competitivas à oxidação do substrato a (i) reação de formação de iodoxibenzeno $\left(\mathrm{PhIO}_{2}\right)$ e a (ii) oxidação (destruição) do catalisador ${ }^{226,227}$.

Finalmente, o efeito da presença de bases nitrogenadas atuando como ligantes axiais de porfirinas de manganês nas reações de oxidação (aumento de eficiência e seletividade) tem sido reconhecido desde a década de $80^{14,15,225,228,229}$ e atribuído à um favorecimento para a formação da espécie $\left(M^{\vee}=0\right) P$. Adicionalmente, em oxidações envolvendo $\mathrm{H}_{2} \mathrm{O}_{2}$ e imidazol, tem se fornecido evidências de um duplo papel para este último: (i) ligante proximal, axialmente coordenado à porfirina de manganês e (ii) ligante distal, com a função de catalisador ácido-base de modo a favorecer a clivagem heterolítica da ligação $0-0^{225}$. 
6.2.4 Acompanhamento por espectroscopia eletrônica das reações de oxidação de ciclohexano catalisadas por MnTPyP $P^{+}$e MnTCP $P^{5+}$.

No intuito de se obter alguma informação a respeito das diferenças de seletividade observadas entre $\mathrm{MnTPyP}^{+}$e $\mathrm{MnTCP}^{5+}$ nas reações de oxidação de ciclohexano, foram feitos ensaios que consistiam simplesmente em monitorar por espectroscopia UV-visível as transformações sofridas por cada catalisador no decorrer das reações. Num ensaio típico, $2 \mathrm{~mL}$ de uma solução do catalisador em 1,2dicloroetano (DCE) era adicionada sobre $1 \mathrm{~mL}$ de uma solução de PhlO em ciclohexano e, após rápida homogeneização, espectros eram obtidos em intervalos de tempo, a $25^{\circ} \mathrm{C}$.

A figura 6.8 apresenta os espectros obtidos na reação entre $\mathrm{MnTPyP}^{+}\left(2,3 \times 10^{-8}\right.$ mols em DCE) e PhlO / ciclohexano ([MnTPyP $\left.{ }^{+}\right]$/ [PhIO] = $\left.1 / 35\right)$. Embora a presença de PhlO provoque turbidez (que pode ser notada claramente na região acima de 550 $\mathrm{nm}$, diminuindo à medida que a reação prossegue), pode-se observar nos 15 minutos iniciais um decréscimo nas intensidades das bandas de $\mathrm{MnTPyP}^{+}$com máximos em $476 \mathrm{~nm}$ e $375 \mathrm{~nm}$ (bandas $\mathrm{V}$ e Vl, respectivamente, na designação de Boucher ${ }^{107}$ ), enquanto uma banda larga, visivelmente composta, é formada, com máximo em 412 $\mathrm{nm}$ a 15 minutos de reação. A seguir, de 15 a 60 minutos, observa-se comportamento inverso: o aumento de intensidade da banda $V$ e na região abaixo de $400 \mathrm{~nm}$, e diminuição na intensidade da banda em $412 \mathrm{~nm}$, sugere reconstituição do catalisador à sua forma inicial (antes da reação).

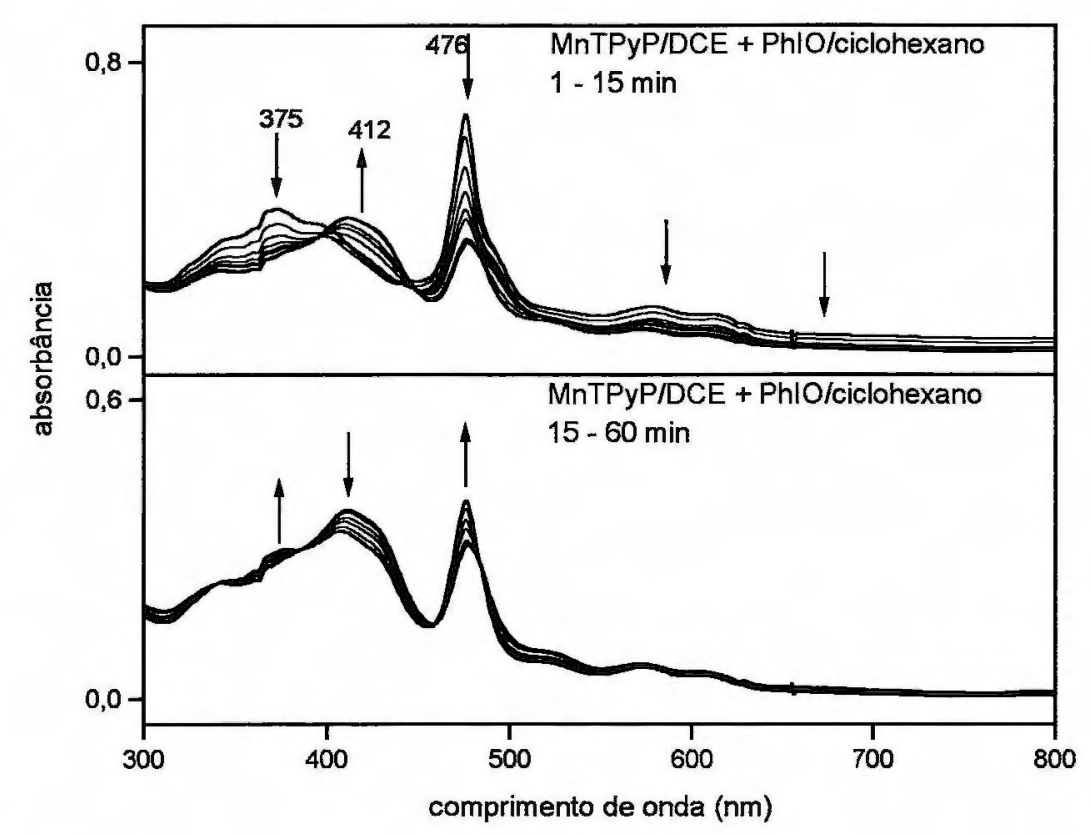

Figura 6.8 - Espectros eletrônicos a $25^{\circ} \mathrm{C}$ da solução obtida pela adição de MnTPyP $^{+}$ $\left(2,3 \times 10^{-8}\right.$ moles em $2 \mathrm{~mL}$ de DCE) sobre $1 \mathrm{~mL}$ ciclohexano contendo $\mathrm{PhlO}$ ([MnTPyP ${ }^{+} /$[PhlO] = $1 /$ 35). Acima, de 1 a 15 minutos de reação. Abaixo, de 15 a 60 minutos de reação. 
A banda larga, com máximo em $412 \mathrm{~nm}$, provavelmente é o resultado da sobreposição dos espectros de duas ou mais espécies, dentre as quais poder-se-ia citar $\mathrm{Mn}^{\text {III'TPyP }}{ }^{+}$(presença evidenciada pela significativa absorção residual da banda V), $\left(M^{\mathrm{IV}}-\mathrm{OH}\right)$ TPyP e $\left(\mathrm{Mn}^{\mathrm{IV}}=0\right)$ TPyP, ou mesmo um aduto $\left(\mathrm{Mn}^{\mathrm{IV}}-\mathrm{O}-\mathrm{Phl}\right)$ TPyP. A ausência de absorção em torno de $700 \mathrm{~nm}$ não suporta formulações que envolvam TPyP- $\pi$-cátion radical ${ }^{187,218}$. Esta situação pode ser simplificada se a reação for conduzida com uma maior quantidade de PhIO (figura 6.9): ocorre o desaparecimento da banda $\mathrm{V}$ e a formação nítida de uma banda larga com máximo em 427 nm, resultando em um espectro de perfil bastante similar ao atribuído por Groves et $\left.a\right|^{218}$ à espécie $\left(\mathrm{Mn}^{\mathrm{IV}}=0\right)$ T4MPyP $(\mathrm{T} 4 \mathrm{MPyP}=$ tetra( $N$-metil-4-piridil)porfirina $)$.

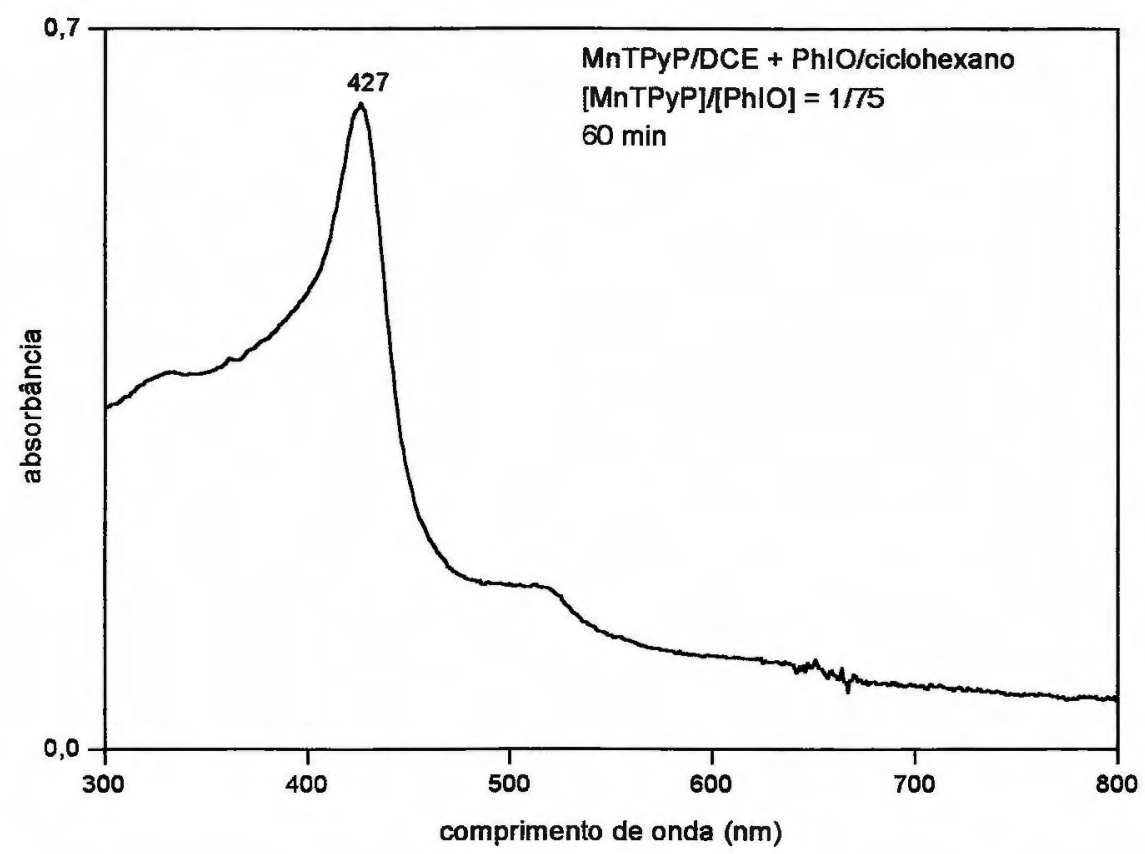

Figura 6.9 - Espectro eletrônico a $25^{\circ} \mathrm{C}$ da solução obtida pela adição de MnTPyP ${ }^{+}$ $\left(4,7 \times 10^{-8}\right.$ moles em $2 \mathrm{~mL}$ de DCE) sobre $1 \mathrm{~mL}$ ciclohexano contendo PhIO ([MnTPyP ${ }^{+}$, $[\mathrm{PhIO}]=1 / 75)$. Tempo de reação: 60 minutos.

$\mathrm{Na}$ reação em condições idênticas entre $\mathrm{MnTCP}^{5+} / \mathrm{DCE}$ e PhlO/ciclohexano (figura 6.10), não se observa alteração significativa no espectro eletrônico de $\mathrm{MnTCP}^{5+}$, exceto uma diminuição gradual de absorbância em todos os comprimentos de onda monitorados, fato que pode ser atribuído ao consumo de PhlO que faz diminuir a turbidez do meio reacional. 


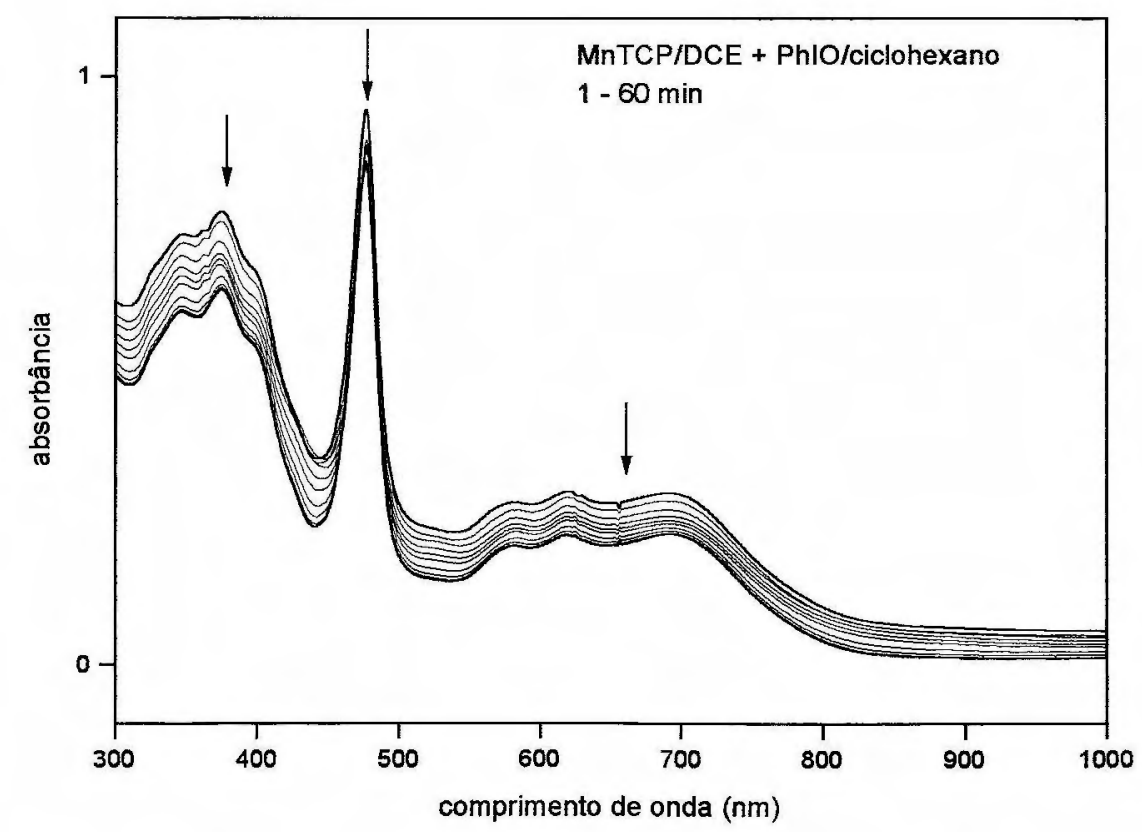

Figura 6.10 - Espectros eletrônicos a $25^{\circ} \mathrm{C}$ da solução obtida pela adição de $\mathrm{MnTCP}^{5+}$ $\left(2,6 \times 10^{-8}\right.$ moles em $2 \mathrm{~mL}$ de DCE) sobre $1 \mathrm{~mL}$ ciclohexano contendo PhIO ([MnTCP $\left.{ }^{5+}\right]$ / $[\mathrm{PhIO}]=1 / 35)$, de 1 a 60 minutos de reação.

Segundo estudo de Groves et al ${ }^{218}$ utilizando espectrofotometria "stopped flow", a reação entre Mn'IIMMPyP ( $\lambda_{\text {banda } V}=462 \mathrm{~nm}$ ) e uma variedade de oxidantes (ácido m-cloroperoxibenzóico, $\mathrm{HSO}_{5}{ }^{-}$e $\mathrm{ClO}^{-}$) em pH 7,4 (tampão fosfato), produz o mesmo intermediário, $\left(\mathrm{Mn}^{\mathrm{V}}=0\right) \mathrm{T} 4 \mathrm{MPyP}\left(\lambda_{\text {banda }} \mathrm{v}=443 \mathrm{~nm}\right)$, que rapidamente converte-se em $\left(\mathrm{Mn}^{\mathrm{IV}}=0\right)$ T4MPyP $\left(\lambda_{\text {banda }}=428 \mathrm{~nm}\right)$, relativamente estável nas condições de reação; a concentração deste, por sua vez, decai lentamente para reconstituir Mn ${ }^{\text {IIIT}}$ T4MPyP. Na presença de uma olefina, ocorre epoxidação com bom rendimento ( $93 \%$, baseado na quantidade de oxidante); neste caso, os espectros eletrônicos informam uma parcial acumulação de $\left(\mathrm{Mn}^{\mathrm{V}}=\mathrm{O}\right)$ T4MPyP entre 0 e 0,006 segundos, seguida de conversão direta ao complexo inicial $\mathrm{Mn}^{\mathrm{Il}} \mathrm{T} 4 \mathrm{MPyP}$, não detectando-se a formação de $\left(M^{I V}=0\right) T 4 M P y P$. Mais recentemente, a espécie estável $\left(M^{\mathrm{V}}=0\right)$ T2MPyP foi caracterizada por $\mathrm{RMN}^{-}{ }^{1} \mathrm{H}^{214}$.

Tendo-se isso em mente e assumindo-se que o mecanismo de recombinação do oxigênio é plausível para as reações envolvendo $\mathrm{MnTPyP}^{+}$e $\mathrm{MnTCP}^{5+}$ com PhIO I ciclohexano (ou seja, formação de uma espécie manganês-oxo de alta valência, que abstrai o hidrogênio de uma ligação $\mathrm{C}-\mathrm{H}$, seguindo-se rápida recombinação com o radical formado, conforme descrito no item 6.2.3), a comparação entre as seletividades observadas e os espetros eletrônicos dos meios reacionais parecem sugerir que a reatividade da espécie gerada imediatamente antes da recombinação é maior no caso 
de $\mathrm{MnTCP}^{5+}$, tendo-se em vista a seletividade deste catalisador e a não detecção de qualquer espécie similar à estável $\left(\mathrm{Mn}^{\mathrm{IV}}=0\right) \mathrm{P}$.

Um interessante resultado é obtido quando a reação entre $\mathrm{MnTCP}^{5+}$ e PhlO é conduzida na ausência de ciclohexano (figura 6.11). Neste caso, observa-se o deslocamento da banda $V$ do núcleo porfirínico de 473 para $427 \mathrm{~nm}$ enquanto desaparecem as bandas III, IV e VI, resultando num perfil que é consistente com uma espécie envolvendo $\mathrm{Mn}^{\mathrm{IV}}=\mathrm{O}$; no entanto, um aumento significativo de absorção em torno de $800 \mathrm{~nm}$, paralelo a um pequeno decréscimo de intensidade das bandas associadas às transições internas nas unidades $\mathrm{Ru}_{3} \mathrm{O}$ dos clusters periféricos nos estados formais de oxidação $\mathrm{Ru}^{\text {III }} \mathrm{Ru}^{\mathrm{III}} \mathrm{Ru}^{\mathrm{III}}$ ( $\lambda_{\text {máximo }}$ em torno de $690 \mathrm{~nm}$ ), fortemente sugere a presença de clusters nos estados $\mathrm{Ru}^{\mathrm{IV}} \mathrm{Ru}^{\mathrm{III}} \mathrm{Ru}^{\mathrm{III}}$, como discutido no Capítulo 5, item 5.2. Portanto, o potencial formal de redução do par $\left(\mathrm{Mn}^{\mathrm{IV}}=0\right) \mathrm{TCP} / \mathrm{Mn}{ }^{\mathrm{II}} \mathrm{TCP}$ deve possuir um valor próximo ao do par $\mathrm{Ru}^{\mathrm{IV}} \mathrm{Ru}^{\mathrm{III}} \mathrm{Ru}^{\mathrm{III}} / \mathrm{Ru}^{\mathrm{III}} \mathrm{Ru}^{\mathrm{III}} \mathrm{Ru}^{\mathrm{III}}$ (1,28 V em DCE / TBAPF $_{6} 0,1 \mathrm{~mol} \mathrm{dm}^{-3}$ ). A eficiência e alta seletividade de $\mathrm{MnTCP}^{5+}$ é consistente com a atuação inicial da espécie ativa $\left(\mathrm{Mn}^{\vee}=0\right) \mathrm{TCP}$; consequentemente, o potencial do par $\left(M^{\mathrm{V}}=0\right)$ TCP / $\left(\mathrm{Mn}^{\mathrm{IV}}=0\right)$ TCP deve se situar em um valor mais positivo que o potencial

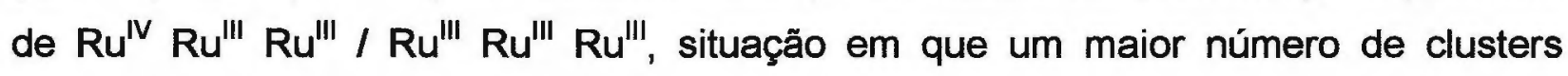
periféricos (senão todos) devem estar oxidados.

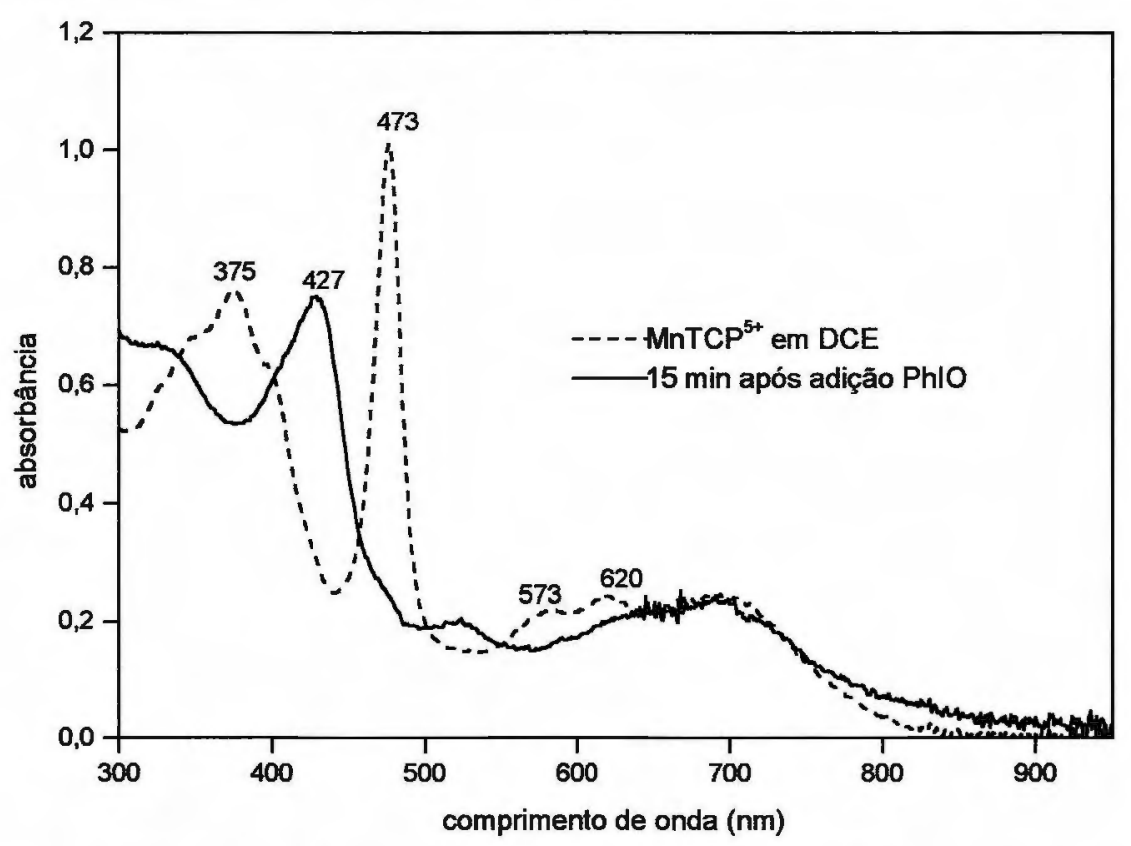

Figura 6.11 - Espectros eletrônicos a $25^{\circ} \mathrm{C}$ da solução obtida pela adição de $\mathrm{MnTCP}{ }^{5+}$ $\left(2,6 \times 10^{-8}\right.$ moles em $2 \mathrm{~mL}$ de DCE) sobre $1 \mathrm{~mL}$ de DCE contendo PhIO ([MnTCP $\left.{ }^{5+}\right]$ / $[\mathrm{PhlO}]=1 / 35$ ). Linha tracejada: antes da adição de PhIO / DCE. Linha cheia: 15 minutos após a adição. 
Seguindo este raciocínio, pode-se concluir que os clusters periféricos oxidados aumentam a atividade catalítica das espécies $\left(\mathrm{Mn}^{\mathrm{V}}=0\right) \mathrm{TCP}$, promovendo a hidroxilação seletiva de ciclohexano a ciclohexanol. Em analogia ao mecanismo de recombinação de oxigênio, um mecanismo concertado envolvendo transferência do oxigênio do $\mathrm{PhlO}$ e transferência eletrônica intramolecular clusters $\rightarrow$ porfirina pode ser sugerido, conduzindo à formação de um complexo ativado exibindo um alto grau de ligação O-H ( $\left.\mathrm{Mn}^{\mathrm{IV}}-\mathrm{OH}\right) \mathrm{TCP}$. Um experimento de espectrofotometria "stopped flow" deverá elucidar a extensão da oxidação dos clusters periféricos quando da formação de $\mathrm{Mn}^{\mathrm{V}}=\mathrm{O}$. 


\subsection{Filmes de $\mathrm{CoTCP}^{5+}$ : comportamento catalítico na redução tetraeletrônica de dioxigênio}

6.3.1 Preparação, voltametria cíclica e espectroeletroquímica de filme de CoTCP5+ sobre eletrodo de carbono vítreo.

Inicialmente, para a preparação dos filmes de CoTCP ${ }^{5+}$ sobre eletrodos de carbono vítreo, fêz-se a troca do contra-íon e do ligante axial acetato de [CoTCP $\left.(\mathrm{OAc})\left(\mathrm{H}_{2} \mathrm{O}\right)\right]\left(\mathrm{PF}_{6}\right)_{4}$ por cloreto, conforme descrito no item 2.3.3, Capítulo 2. $\mathrm{O}$ composto resultante, $\left[\mathrm{CoTCP}(\mathrm{Cl})\left(\mathrm{H}_{2} \mathrm{O}\right)\right] \mathrm{Cl}_{4}$, é solúvel em metanol, mas insolúvel em solução aquosa de $\mathrm{KNO}_{3} 0,50 \mathrm{~mol} \mathrm{dm}^{-3}$ após secagem. Esta propriedade foi explorada na preparação dos eletrodos modificados através da deposição de solução metanólica de $\left[\mathrm{CoTCP}(\mathrm{Cl})\left(\mathrm{H}_{2} \mathrm{O}\right)\right] \mathrm{Cl}_{4} 6 \times 10^{-4} \mathrm{~mol} \mathrm{dm}^{-3}$ sobre a superfície dos eletrodos, seguida de secagem ao ar.

Os voltamogramas cíclicos do eletrodo assim modificado (figura 6.12) mostraram um processo redox reversível entre $-0,28$ e $0,70 \mathrm{~V}$, com potenciais de pico anódico $\left(E_{P A}\right)$ e catódico $\left(E_{P C}\right)$ iguais a 0,24 e 0,20 V, respectivamente, cujas correntes de pico são diretamente proporcionais à velocidade de varredura (v), fato que contrasta com o comportamento difusional observado em voltametria cíclica de espécies em solução (correntes de pico proporcionais a $v^{1 / 2}$ ). Enquanto neste último caso já existe desde a década de 60 a descrição quantitativa dos voltamogramas cíclicos derivada por Nicholson e Shain ${ }^{230}$, a descrição dos voltamogramas cíclicos de espécies imobilizadas sobre a superfície de eletrodos é mais complexa.

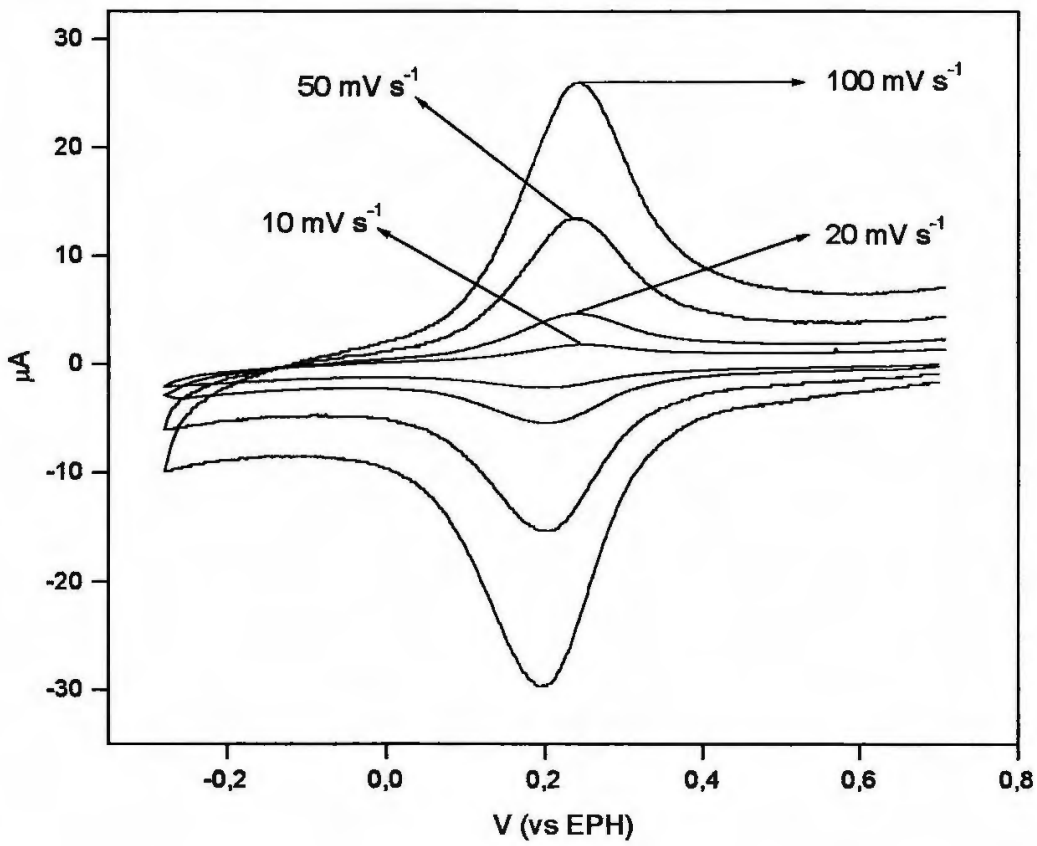

Figura 6.12 - Voltamogramas cíclicos, à várias velocidades de varredura, do eletrodo de carbono vítreo modificado pelo filme de CoTCP $^{5+}$ em solução aquosa de $\mathrm{KNO}_{3} 0,50 \mathrm{~mol} \mathrm{dm}^{-3}$ (tampão acetato $0,05 \mathrm{~mol} \mathrm{dm}^{-3}$, $\mathrm{pH}=4,7)$. 
Embora uma discussão mais detalhada sobre o problema de descrever quantitativamente os voltamogramas cíclicos de eletrodos modificados esteja a margem do escopo desta Tese, consideremos aqui o modelo mais simples utilizado na descrição de tais sistemas: o de uma espécie forte e irreversivelmente adsorvida sobre um eletrodo, na forma de uma monocamada ${ }^{231,232}$. Neste modelo, são assumidas as seguintes hipóteses:

a) todos os sítios de adsorção são equivalentes (a superfície modificada é homogênea);

b) não há nenhuma interação entre as espécies adsorvidas;

c) a reação redox segue um comportamento nernstiano (não há restrições de natureza cinética);

d) a quantidade de espécies adsorvidas é independente do potencial aplicado;

e) as atividades das espécies adsorvidas podem ser aproximadas às concentrações;

f) a corrente faradaica deve ser isolável da corrente capacitiva.

Algumas consequências do modelo: os potenciais de pico $E_{P A}$ e $E_{P C}$ têm $o$ mesmo valor $\left(\Delta \mathrm{E}_{\mathrm{P}}=0\right)$, e a corrente de pico (ip) é dada pela equação $6.12^{157,231-233}$,

$$
\mathrm{i}_{\mathrm{p}}=\frac{\mathrm{n}^{2} \mathrm{~F}^{2} \Gamma A v}{4 \mathrm{RT}}
$$

onde

$$
\begin{aligned}
& n=\text { número de elétrons } \\
& F=\text { constante de Faraday } \\
& \Gamma=\text { concentração superficial }\left(\mathrm{mol} \mathrm{cm} \mathrm{cm}^{-2}\right) \\
& \mathrm{A}=\text { área do eletrodo }\left(\mathrm{cm}^{2}\right) \\
& \mathrm{V}=\text { velocidade de varredura }\left(\mathrm{V} \mathrm{s}^{-1}\right) \\
& \mathrm{R}=\text { constante dos gases perfeitos } \\
& T=\text { temperatura absoluta }
\end{aligned}
$$

Um aumento na separação entre os potenciais de pico $\left(\Delta E_{P}>0\right)$ é associado à diminuição da reversibilidade da reação.

O filme de CoTCP $^{5+}$ apresenta uma dependência direta da corrente de pico com a velocidade de varredura, mas uma separação entre $E_{P A}$ e $E_{P C}$ de $40 \mathrm{mV}$. Pelo procedimento através do qual foi preparado, no filme devem estar envolvidas múltiplas camadas; neste caso, o formato e as propriedades dos voltamogramas dependem da 
velocidade de transferência eletrônica entre o eletrodo e a primeira camada do filme, e pela velocidade de transferência eletrônica no interior do filme. Irreversibilidade devido à reação eletroquímica no interior do filme produziria uma "cauda" após o pico, não chegando, porém, a causar um grande deslocamento nos valores de $\mathrm{EP}_{\mathrm{p}}{ }^{231}$.

A aderência e estabilidade dos filmes de $\operatorname{CoTCP}^{5+}$ revelaram-se muito satisfatórias, com apenas uma pequena perda de material após 100 ciclos sucessivos entre $-0,28$ e $0,72 \mathrm{~V}$ (figura 6.13). Interessante observar que Song et $\mathrm{a}^{234}$ verificaram que, devido à solubilidade de CoTPyP em meio ácido, filmes desta porfirina de cobalto sobre eletrodos de grafite pirolítico são instáveis.

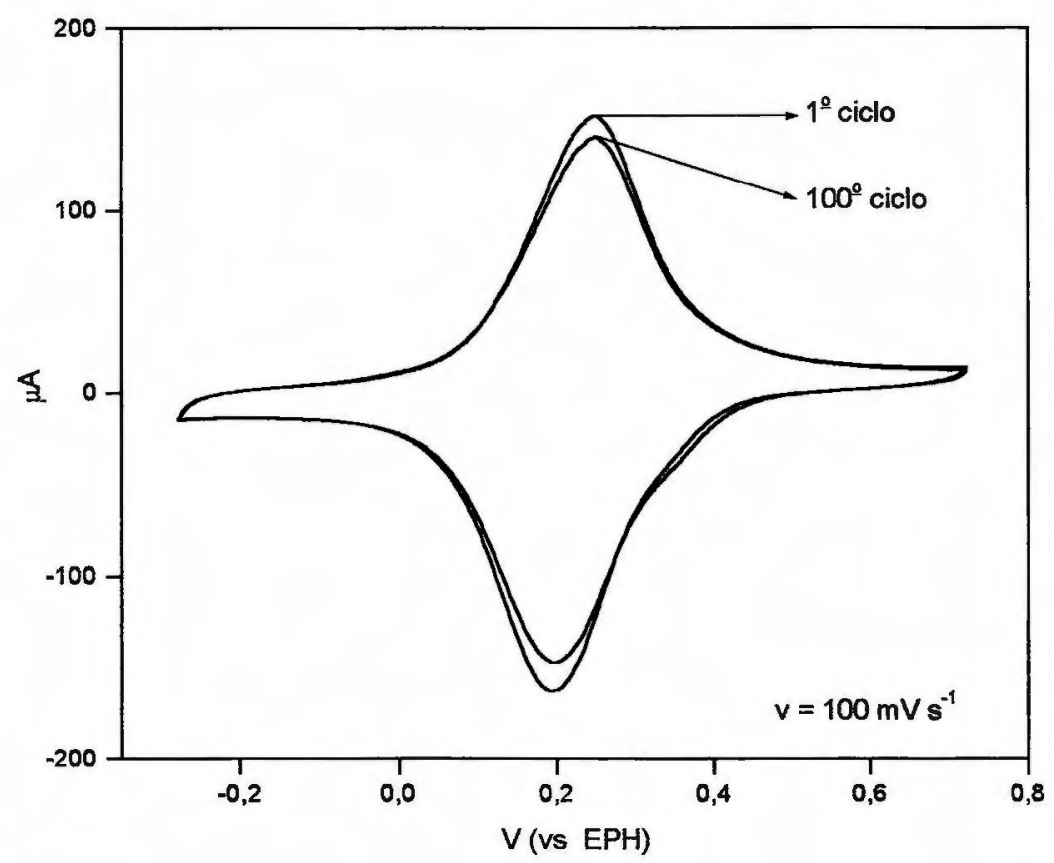

Figura 6.13 - Voltamogramas cíclicos sucessivos, a $100 \mathrm{mV}$ $\mathrm{s}^{-1}$, do eletrodo de carbono vítreo modificado pelo filme de CoTCP $^{5+}$ em solução aquosa de $\mathrm{KNO}_{3} \quad 0,50 \mathrm{~mol} \mathrm{dm}^{-3}$, tampão acetato $0,05 \mathrm{~mol} \mathrm{dm}^{-3}$, $\mathrm{pH}=4,7$. Apenas $\circ$ primeiro $\mathrm{e}$ - centésimo ciclo são mostrados.

O espectro eletrônico do filme de $\operatorname{CoTCP}^{5+}$ (figura 6.14), obtido por reflectância utilizando-se um espectrofotômetro de fibra ótica, é similar ao espectro da espécie em solução, com os máximos das bandas Soret, $Q_{(1,0)}$ e $Q_{(0,0)}$ localizados em 440, 555 e $610 \mathrm{~nm}$, respectivamente, enquanto a banda atribuída a transições internas nas unidades $\mathrm{Ru}_{3} \mathrm{O}$ tem seu máximo em $705 \mathrm{~nm}$.

A espectroeletroquímica entre 0,42 e $-0,06 \mathrm{~V}$ (figura 6.14) indicou a

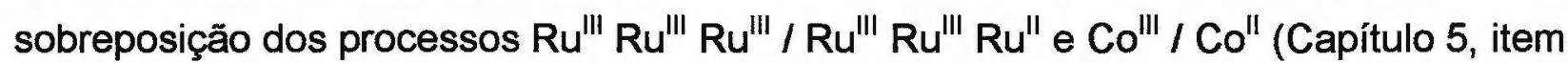
5.3); observa-se que a redução dos clusters periféricos antecede a redução do metal do núcleo porfirínico, comportamento inverso ao observado para a supermolécula em solução. Esta inversão pode ser devida, pelo menos em parte, à troca do sexto ligante axial que ocorre ao se alterar o solvente, de $\mathrm{CH}_{3} \mathrm{CN}$ para $\mathrm{H}_{2} \mathrm{O}$ : enquanto um ligante $\pi$ aceitador $\left(\mathrm{CH}_{3} \mathrm{CN}\right)$ estabilizaria estados menores de oxidação, um ligante mais duro 
$\left(\mathrm{H}_{2} \mathrm{O}\right)$ poderia favorecer estados maiores de oxidação, deslocando o potencial para valores mais negativos.
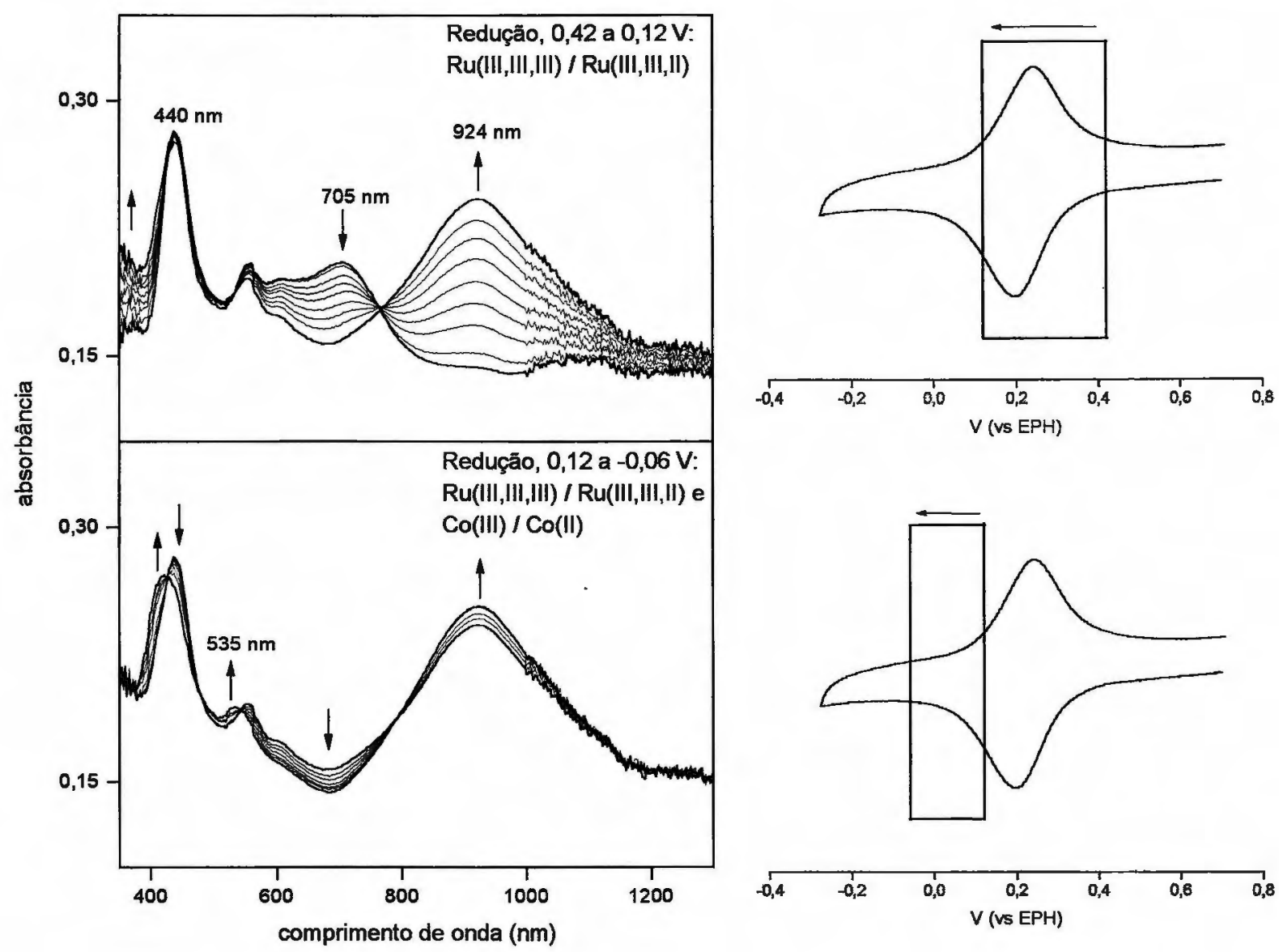

Figura 6.14 - À esquerda, espectroeletroquímica do filme de CoTCP ${ }^{5+}$ sobre eletrodo de carbono vítreo $\left(\mathrm{KNO}_{3} 0,50 \mathrm{~mol} \mathrm{dm}^{-3}\right.$, tampão acetato $\left.0,05 \mathrm{~mol} \mathrm{dm}^{-3}, \mathrm{pH}=4,7\right)$. À direita, indicação em voltamograma cíclico das respectivas regiões de potencial investigadas.

6.3.2 Redução de $\mathrm{O}_{2}$ pelo filme de CoTCP5 ${ }^{5+}$ : estudo por voltametria cíclica.

O voltamograma cíclico do filme de $\mathrm{CoTCP}^{5+}$ em solução aquosa saturada com $\mathrm{O}_{2}$ (figura 6.15-A) apresenta uma intensa e bem definida onda catódica ao redor de $0,20 \mathrm{~V}$, não se observando onda anódica associada. $\mathrm{A}$ intensidade de corrente de pico, além de variar de forma linear com a raiz quadrada da velocidade de varredura, é muito

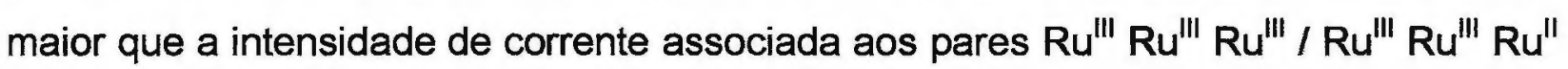
e Co'l' / Co"l na ausência de oxigênio (figura 6.15-B). Se o voltamograma cíclico é obtido nas mesmas condições $\left(\mathrm{KNO}_{3} 0,50 \mathrm{~mol} \mathrm{dm}{ }^{-3}\right.$, tampão acetato, $\mathrm{pH}=4,7$, 
saturação com $\mathrm{O}_{2}$ ), mas na ausência do filme (eletrodo de carbono vítreo), observa-se apenas um lento aumento na corrente catódica abaixo de 0,00 V.
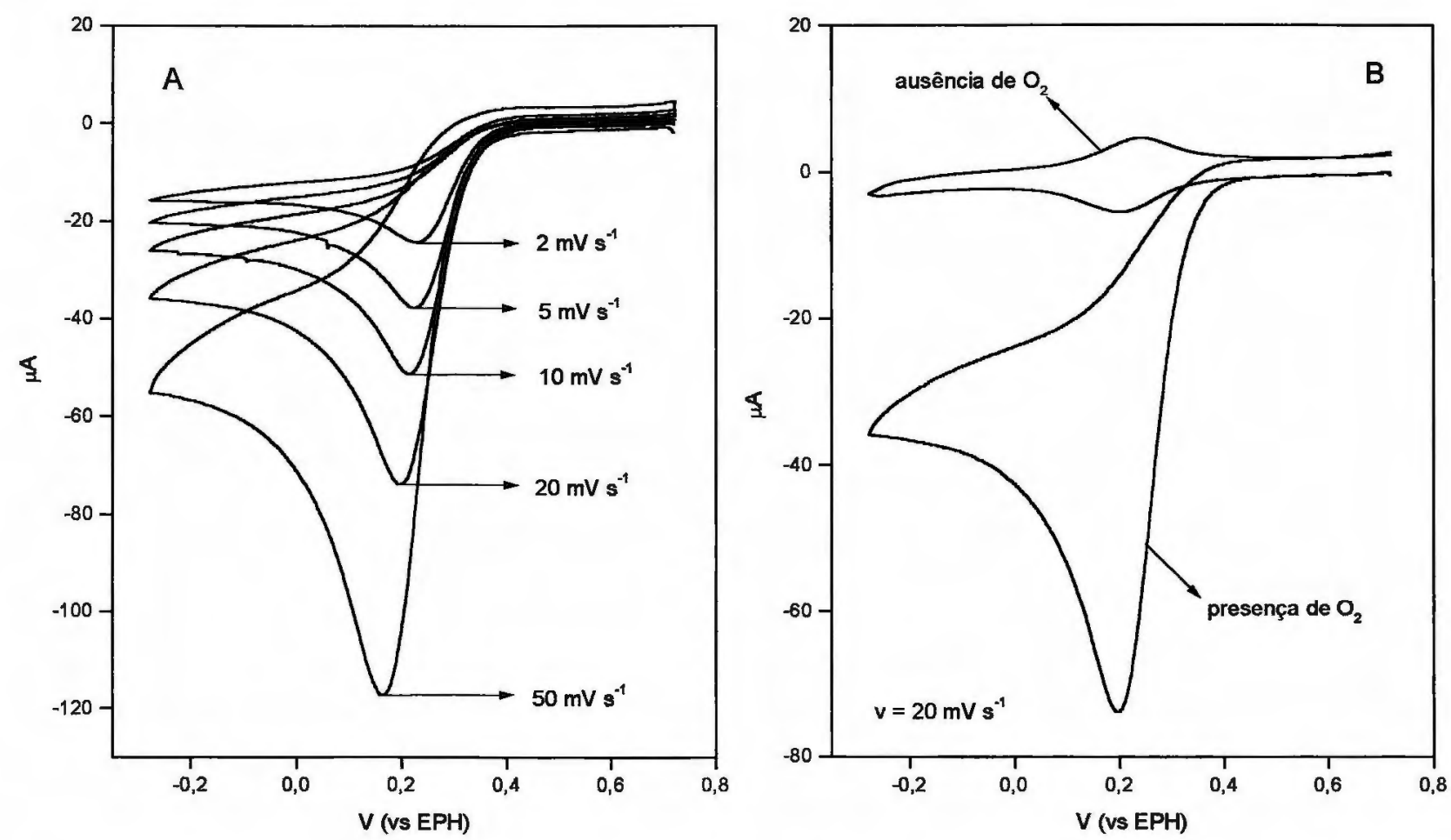

Figura 6.15 - A) Voltamogramas cíclicos do eletrodo modificado por filme de CoTCP ${ }^{5+}$ em solução aquosa $\left(\mathrm{KNO}_{3} 0,50 \mathrm{~mol} \mathrm{dm}^{-3}\right.$, tampão acetato $\left.0,05 \mathrm{~mol} \mathrm{dm}^{3}, \mathrm{pH}=4,7\right)$, na presença de $\mathrm{O}_{2}$. B) Voltamogramas cíclicos a $20 \mathrm{mV} \mathrm{s}^{-1}$ do eletrodo modificado por filme de CoTCP ${ }^{5+}$ na ausência e presença de $\mathrm{O}_{2}\left(\mathrm{KNO}_{3} 0,50 \mathrm{~mol} \mathrm{dm}^{-3}\right.$, tampão acetato $\left.0,05 \mathrm{~mol} \mathrm{dm}^{3}, \mathrm{pH}=4,7\right)$.

O papel dos clusters periféricos na atividade catalítica observada foi inicialmente investigado pela utilização de eletrodos identicamente modificados por filmes do análogo $\mathrm{ZnTCP}^{4+}$. Neste caso, apenas um pequeno aumento na corrente catódica abaixo de aproximadamente $0,20 \mathrm{~V}$ foi observado (figura 6.16), aumento este que se

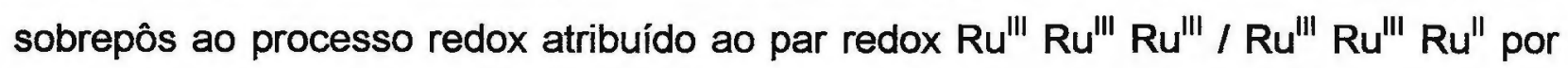
comparação com o voltamograma cíclico e a espectroeletroquímica de $\mathrm{ZnTCP}^{4+}$ em solução (Capítulo 5, item 5.1). Também de forma diferente ao filme de CoTCP ${ }^{5+}$, o voltamograma cíclico do filme de $\mathrm{ZnTCP}^{4+}$ sobre eletrodo de carbono vítreo apresenta onda anódica associada. A partir deste resultado pode-se inferir que o íon Coll está diretamente envolvido na reação de redução do oxigênio. 
Figura 6.16 - Voltamogramas cíclicos a $20 \mathrm{mV} \mathrm{s}^{-1}$ do eletrodo de carbono vítreo modificado por filme de $\mathrm{ZnTCP}^{4+}$ na ausência e presença de $\mathrm{O}_{2}\left(\mathrm{KNO}_{3} 0,50 \mathrm{~mol}\right.$ $\mathrm{dm}^{-3}$, tampão acetato $0,05 \mathrm{~mol}$ $\mathrm{dm}^{3}, \mathrm{pH}=4,7$ ).

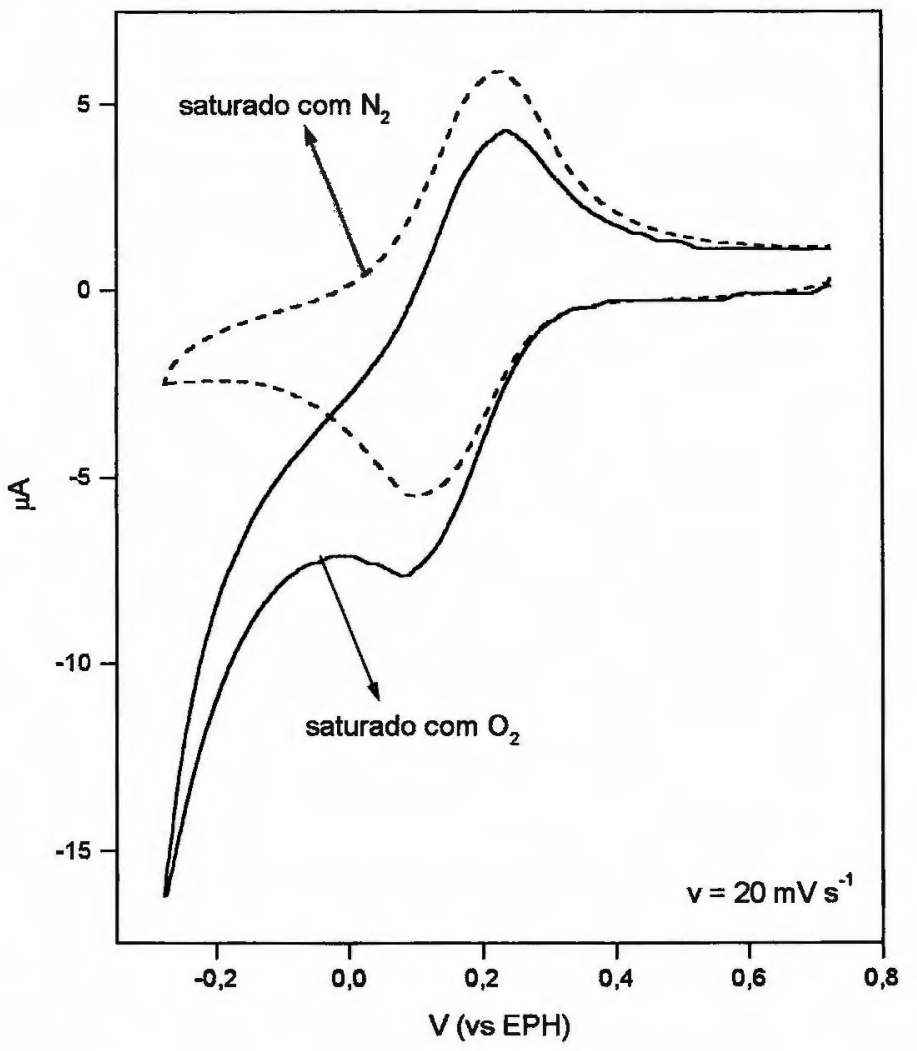

6.3.3 Redução de $\mathrm{O}_{2}$ pelo filme de $C o T C P^{5+}$ : estudo por voltametria de eletrodo de disco rotatório.

De maneira diferente à voltametria cíclica convencional, em que são utilizadas condições experimentais para que o transporte de massa se efetue essencialmente através da difusão, os métodos eletroquímicos hidrodinâmicos introduzem a convecção como mecanismo de transporte de massa. Estes métodos apresentam a vantagem de atingirem o estado estacionário rapidamente com intensificação das correntes, uma vez que uma quantidade maior de material eletroativo atinge a superfície do eletrodo ${ }^{157}$. Uma das maneiras de se produzir um regime convectivo reprodutível e matematicamente tratável é a utilização do eletrodo de disco rotatório (EDR), que consiste em um eletrodo de disco envolto coaxialmente por um material isolante de formato cilíndrico. Ao aplicar-se um movimento rotatório ao eletrodo a uma velocidade angular $\omega$ constante, produz-se uma força centrífuga que induz um fluxo radial da solução, ao mesmo tempo que um fluxo axial substitui a solução que é continuamente removida do centro do disco (figura 6.17).

Enquanto a utilização de um eletrodo estacionário resulta numa curva corrente versus potencial em formato de pico, quando submetido a varredura linear de potencial na presença de uma espécie eletroativa (voltametria convencional), a corrente no EDR 
aumenta quando se inicia o processo faradaico até atingir um patamar denominado corrente limite (i). Esta é definida pela equação de Levich (equação 6.13) ${ }^{157,233}$, válida quando o fluxo é laminar, não turbulento.

$$
\mathrm{i}_{\mathrm{l}}=0,620 \mathrm{nFAD} \mathrm{D}^{2 / 3} \omega^{1 / 2} \mathrm{v}_{\mathrm{c}}^{-1 / 6} \mathrm{C}
$$

$$
\text { onde: } \quad \begin{aligned}
\mathrm{i}_{1} & =\text { corrente limite }(\mathrm{mA}) \\
\mathrm{n} & =\text { número de elétrons } \\
\mathrm{F} & =\text { constante de Faraday } \\
\mathrm{A} & =\text { área do disco }\left(\mathrm{cm}^{2}\right) \\
\mathrm{D} & =\text { coeficiente de difusão da espécie eletroativa }\left(\mathrm{cm}^{2} \mathrm{~s}^{-1}\right) \\
\omega & =\text { velocidade angular }\left(\mathrm{rad} \mathrm{s}^{-1}\right) \\
\mathrm{V}_{\mathrm{c}} & =\text { viscosidade cinemática da solução }\left(\mathrm{cm} \mathrm{s}^{-1}\right) \\
\mathrm{C} & =\text { concentração da espécie eletroativa }\left(\mathrm{mol} \mathrm{dm}^{-3}\right)
\end{aligned}
$$
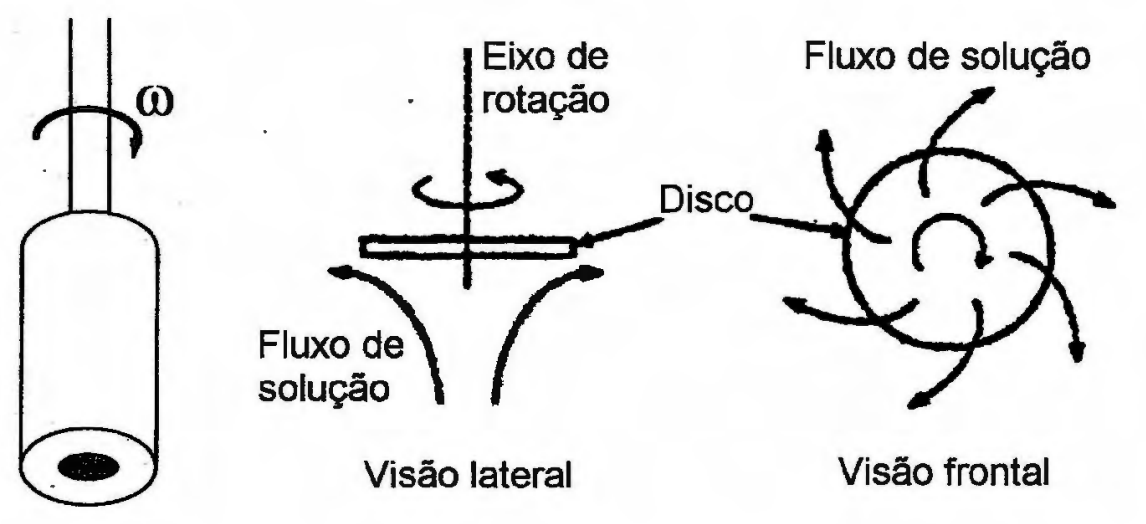

\section{Figura 6.17 - \\ Eletrodo de disco rotatório (EDR).}

A figura 6.18-A exibe os voltamogramas de EDR (carbono vítreo) modificado pelo filme de $\mathrm{CoTCP}^{5+}$ em solução aquosa saturada com $\mathrm{O}_{2}$. De forma bastante significativa, a corrente limite i, permaneceu como função linear de $\omega^{1 / 2}$ (figura 6.18-B), na faixa entre 100 e $3000 \mathrm{rpm}$ ( $\mathrm{rpm}=$ rotações por minuto), indicando que a velocidade da reação não é limitada pelo transporte de massa ou pela difusão de elétrons através do filme; no entanto, a reta no gráfico não apresenta coeficiente linear igual a zero, 0 que sugere o envolvimento de alguma etapa cinética na transferência eletrônica ${ }^{157}$. Anson et al ${ }^{136,144}$ têm utilizado o gráfico Koutecky-Levich $\left(1 / i_{\text {i versus }} 1 / \omega^{1 / 2}\right)$ para estimar a constante cinética $\mathrm{k}_{\mathrm{f}}$ para a formação do aduto $\mathrm{Co}-\mathrm{O}_{2}$, que consideraram como a etapa determinante da velocidade da redução do $\mathrm{O}_{2} \mathrm{e}$, portanto, da corrente 
limite no disco: o recíproco do intercepto no gráfico define a corrente $\mathrm{i}_{\mathrm{k}}$ (corrente na ausência de qualquer efeito de transferência de massa), dada pela equação $6.14^{136,144}$,

$$
\mathrm{i}_{\mathrm{k}}=\mathrm{nFAk} \mathrm{K}_{\mathrm{f}} \mathrm{Cat}_{\mathrm{O} 2}
$$

onde

$$
\begin{aligned}
& \mathrm{n}=\text { número de elétrons } \\
& \mathrm{F}=\text { constante de Faraday } \\
& \mathrm{A}=\text { área do eletrodo } \\
& \Gamma_{\text {cat }}=\text { concentração superficial do catalisador } \\
& \mathrm{C}_{\mathrm{O} 2}=\text { concentração de } \mathrm{O}_{2} \text { na solução } \\
& \mathrm{k}_{\mathrm{f}}=\text { constante de velocidade para a reação: } \mathrm{CoP}+\mathrm{O}_{2} \rightarrow \mathrm{PCoO}_{2}
\end{aligned}
$$

No gráfico Koutecky-Levich para a redução de $\mathrm{O}_{2}$ pelo eletrodo modificado por filme de $\mathrm{CoTCP}^{5+}$ (figura 6.18-C), o intercepto ocorre próximo à origem, fato que sugere um valor elevado para $\mathrm{k}_{\mathrm{f}}$.
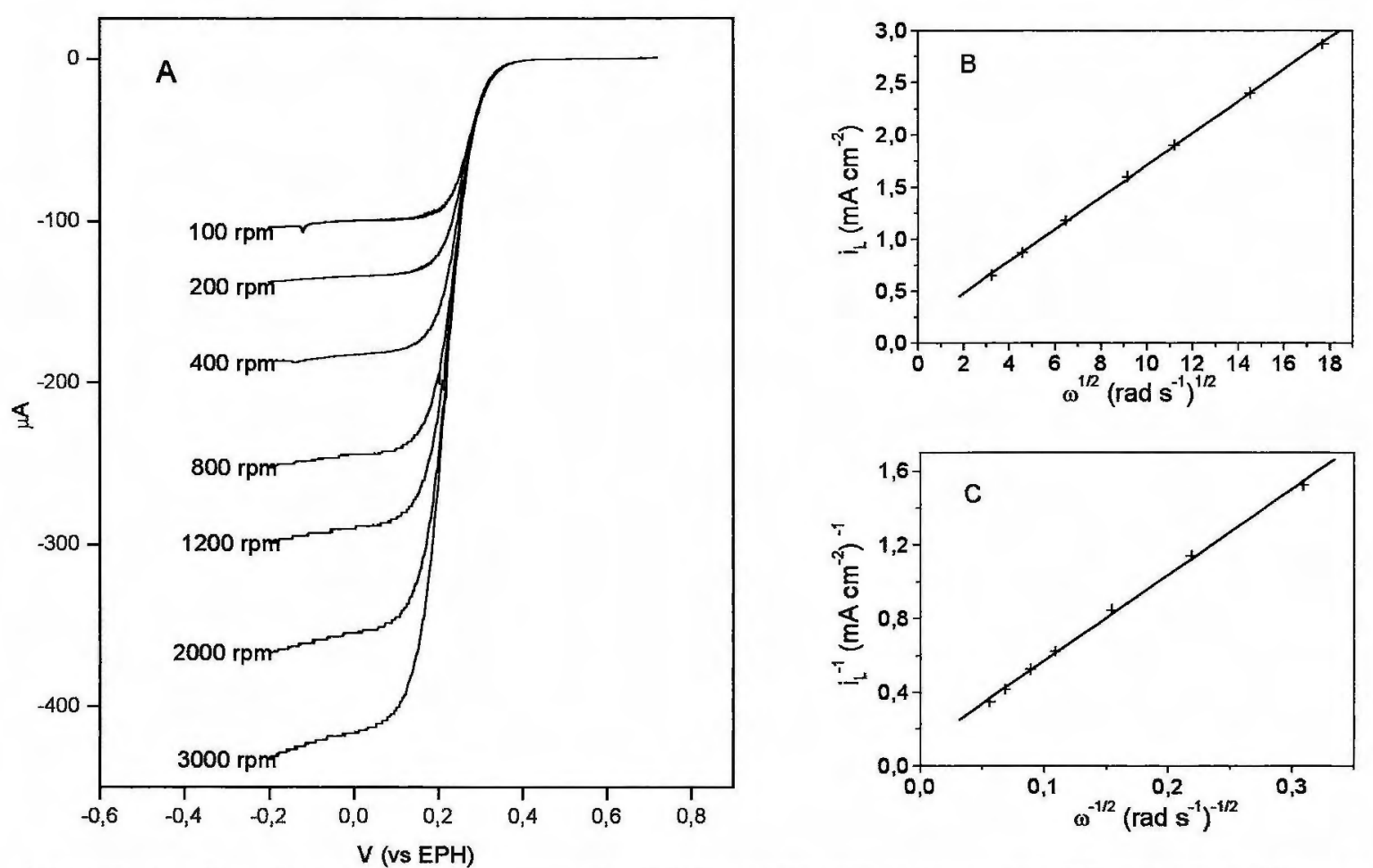

Figura 6.18 - A) Voltamogramas de EDR (carbono vítreo) modificado por filme de CoTCP ${ }^{5+}$ em solução aquosa saturada com $\mathrm{O}_{2}$, a várias velocidades angulares.

B) Gráfico de Levich: correntes limite (expressas como $\mathrm{mA} \mathrm{cm}^{-2}$ ) em função das velocidades angulares (expressas como rad $\mathrm{s}^{-1}$ ) dos voltamogramas de A). C) Gráfico Koutecky-Levich para os voltamogramas de A). 
Comportamento muito diferente foi apresentado pelo EDR modificado por filme de $\mathrm{ZnTCP}^{4+}$ (figura 6.19): o perfil do voltamograma é similar àquele obtido através da voltametria com eletrodo estacionário, sendo característico de uma espécie eletroquimicamente ativa imobilizada na superfície do eletrodo cuja atividade eletrocatalítica está ausente. Além disso, a menor corrente catódica do eletrodo com o filme de $\mathrm{ZnTCP}^{4+}$ sugere que este dificulta a difusão do $\mathrm{O}_{2}$ até a superfície do eletrodo.

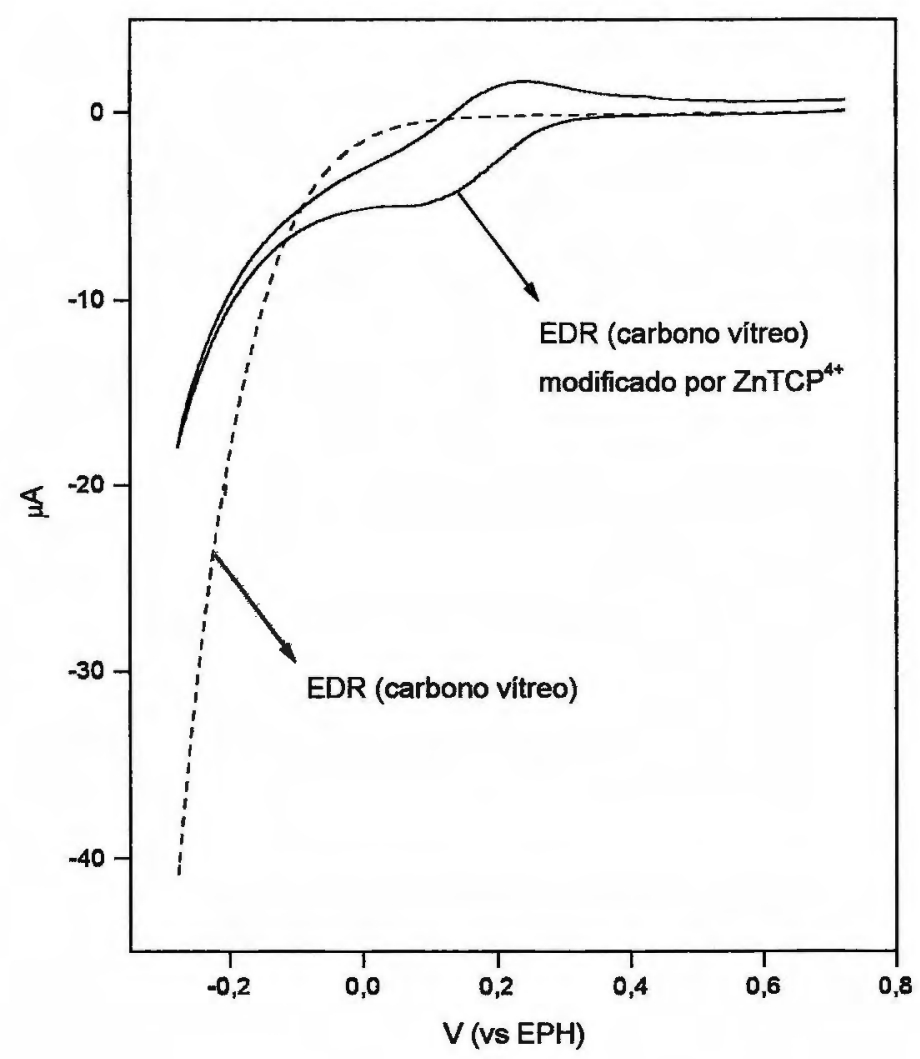

Figura 6.19 - Voltamogramas de EDR (linha tracejada) e EDR modificado por filme de $\mathrm{ZnTCP}^{4+}$ (linha cheia). Condições: $\left[\mathrm{KNO}_{3}\right]=$ $0,50 \mathrm{~mol} \mathrm{dm}^{-3}$, [tampão acetato] $=$ $0,05 \mathrm{~mol} \mathrm{dm}^{-3}, \mathrm{pH}=4,7 ; \mathrm{v}$ (disco) $=10 \mathrm{mv} \mathrm{s}^{-1}$.

6.3.4 Redução de $\mathrm{O}_{2}$ pelo filme de $C o T C P^{5+}$ : estudo por voltametria de eletrodo de anel e disco rotatórios.

Quando se compara o comportamento de catalisadores frente à redução de oxigênio, é comum o uso de eletrodo de anel e disco rotatórios (EADR) ${ }^{157}$. Os catalisadores de interesse são irreversivelmente adsorvidos em um eletrodo circular de grafite circunscrito por um eletrodo de platina concêntrico (anel), separados por um isolante (figura 6.20 , à esquerda). A rotação do eletrodo em torno do eixo perpendicular a uma velocidade angular $\omega$ constante faz com que os produtos da eletro-redução do $\mathrm{O}_{2}$ sejam impulsionados para a periferia do disco. $\mathrm{O}$ anel é ajustado a um potencial (tipicamente 1,2 a $1,4 \mathrm{~V}$ vs $\mathrm{EPH}^{133}$ ) de modo a oxidar a $\mathrm{O}_{2}$ qualquer molécula de $\mathrm{H}_{2} \mathrm{O}_{2}$ 
que o atinja, o que produziria uma corrente anódica. $\mathrm{H}_{2} \mathrm{O}$ não é oxidada neste potencial permitindo, assim, que $\mathrm{o}$ anel discrimine entre $\mathrm{H}_{2} \mathrm{O}$ e $\mathrm{H}_{2} \mathrm{O}_{2}$ os produtos da eletroredução do $\mathrm{O}_{2}$ na superfície do eletrodo modificado. Além disso, a magnitude relativa das correntes do anel e do disco fornece uma taxa quantitativa das frações das moléculas de oxigênio que foram reduzidas a $\mathrm{H}_{2} \mathrm{O}$ ou $\mathrm{H}_{2} \mathrm{O}_{2}$.

Um parâmetro importante neste tipo de eletrodo é a taxa de coleta $(\mathrm{N})$, que representa qual a fração da espécie gerada na reação redox no disco pode ser coletada no anel. A determinação de $\mathrm{N}$ pode ser feita, por exemplo, mantendo-se o potencial do disco suficientemente negativo para que ocorra a reação $O+e \rightarrow R$, enquanto se aplica no anel um potencial suficientemente positivo para reoxidar quantitativamente $\mathrm{R}$. $\mathrm{O}$ valor experimental de $\mathrm{N}$ é dado pela relação entre as corrente limites do anel e do disco: $N=i_{I, A} / i_{1, D}$. Aqui, a taxa de coleta foi determinada utilizandose uma solução aquosa $1,0 \times 10^{-3} \mathrm{~mol} \mathrm{dm}^{-3}$ de $\mathrm{K}_{3}\left[\mathrm{Fe}(\mathrm{CN})_{6}\right]$, obtendo-se o valor de 0,25 (figura 6.20, à direita). Esta taxa não apresentou alteração significativa com a variação da velocidade angular $\omega$.
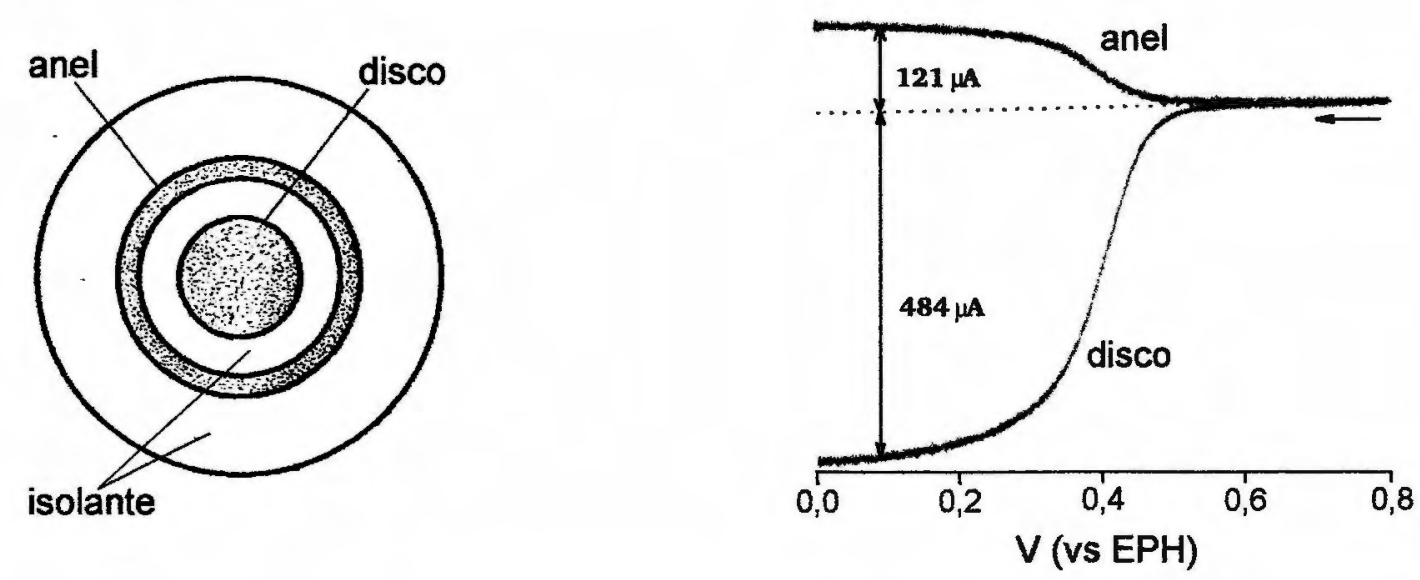

Figura 6.20 - À esquerda, visão frontal da base de um EADR. À direita, determinação da taxa de coleta através de voltamograma de EADR de solução aquosa de $\mathrm{K}_{3}\left[\mathrm{Fe}(\mathrm{CN})_{6}\right] 1,0 \times 10^{-3} \mathrm{~mol} \mathrm{dm}^{-3}$ (eletrólito suporte: $\mathrm{KNO}_{3} 0,50 \mathrm{~mol} \mathrm{dm}^{-3} ; \mathrm{T}=25^{\circ} \mathrm{C} ; \omega=$ $3000 \mathrm{rpm} ; \mathrm{v}_{\text {(disco) }}=10 \mathrm{mV} \mathrm{s}^{-1}$; potencial do anel $=0,80 \mathrm{~V}$ ).

Todos os voltamogramas de EADR de soluções aquosas saturadas com $\mathrm{O}_{2}$, apresentando o disco modificado pelo filme de $\mathrm{CoTCP}^{5+}$, exibiram correntes limite bem definidas no disco, ao lado de correntes muito baixas no anel, na faixa de velocidades angulares entre 100 e $3000 \mathrm{rpm}$ (figura 6.21), evidenciando que quase todas as moléculas de $\mathrm{O}_{2}$ foram reduzidas a $\mathrm{H}_{2} \mathrm{O}$ no disco. Torna-se importante citar que os filmes de CoTPyP descritos na literatura apresentam atividade catalítica apenas na 
redução bieletrônica $^{133,235}$, além de problemas de estabilidade ${ }^{234}$. O mecanismo pelo qual o filme de $\mathrm{CoTCP}^{5+}$ promove eficientemente a redução tetra-eletrônica de $\mathrm{O}_{2}$ permanece por ser elucidado. Enquanto a transferência eletrônica intramolecular dos clusters periféricos para o sítio catalítico apresenta-se como uma hipótese, efeitos de empacotamento e do próprio material do eletrodo podem contribuir para a atividade observada $^{137,142,145}$.

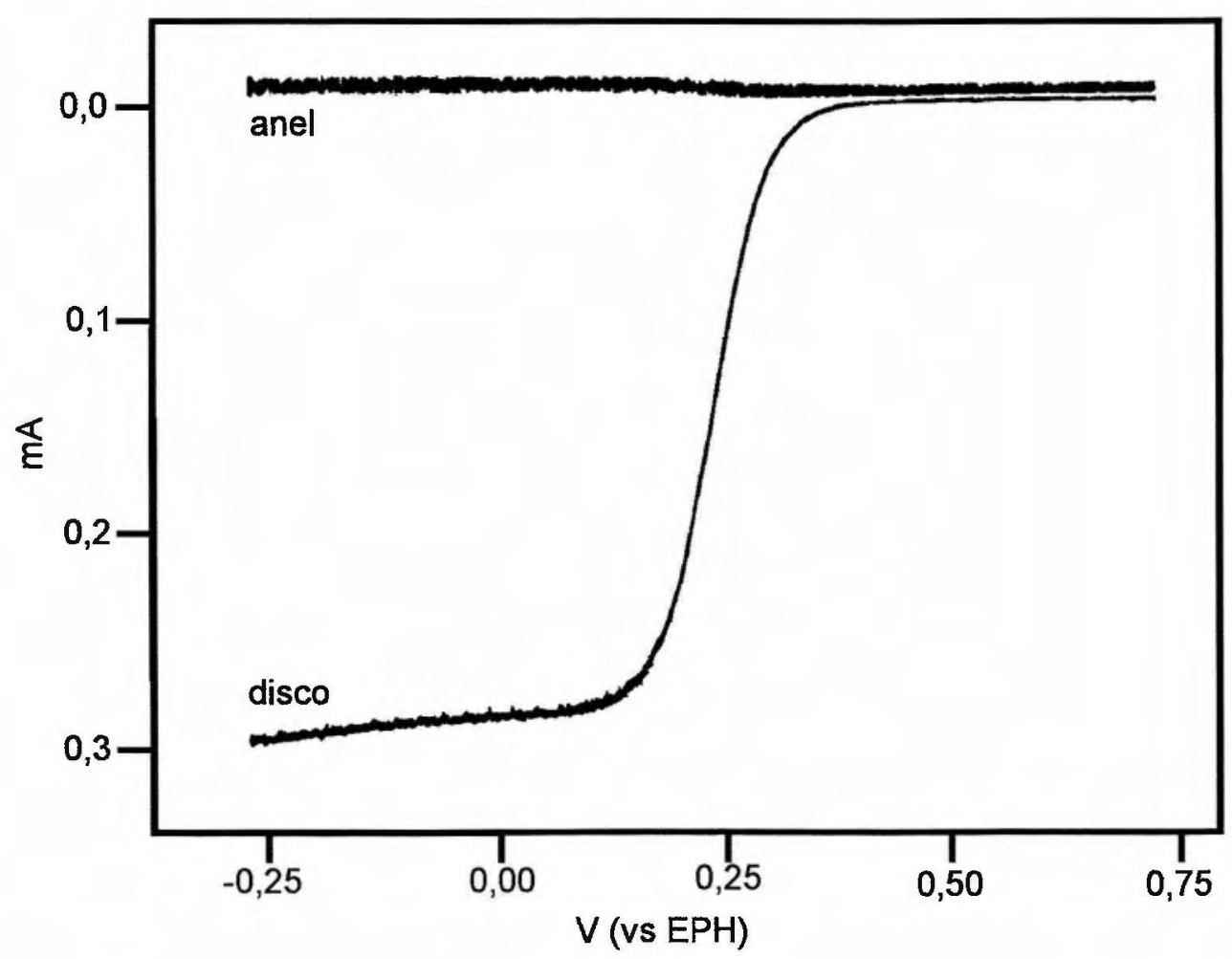

Figura 6.21 - Voltamograma de EADR de solução aquosa de $\mathrm{KNO}_{3} 0,50 \mathrm{~mol} \mathrm{dm}^{-3}$ saturada com $\mathrm{O}_{2}$. Disco: eletrodo de carbono vítreo modificado pelo filme de CoTCP ${ }^{5+}$. Velocidade de varredura no disco $=10 \mathrm{mV} \mathrm{s}^{-1} ; \omega=1000 \mathrm{rpm}$; [tampão acetato] $=0,05$ mol dm${ }^{-3} ; \mathrm{pH}=4,7 ; \mathrm{T}=25^{\circ} \mathrm{C} ;$ potencial no anel (platina) $=1,22 \mathrm{~V}$. 
CAPÍTULO 7

\section{CONSIDERAÇÕES FINAIS / PERSPECTIVAS}




\subsection{A respeito das supermoléculas $\mathrm{ZnTCP}^{4+}, \mathrm{MnTCP}^{5+}$ e CoTCP}

Dando prosseguimento aos trabalhos descritos nesta Tese, a atenção deverá voltar-se para estudos adicionais e possíveis aplicações das três supermoléculas.

No caso de $\mathrm{ZnTCP}^{4+}$, embora a coordenação dos clusters periféricos tenha promovido a supressão da luminescência do núcleo porfirínico, o que limita a utilização desta propriedade, o aumento significativo da acidez de Lewis do íon $\mathrm{Zn}^{2+}$ abre a perspectiva de utilizar este íon como um provável sítio de reconhecimento ou coordenação para bases nitrogenadas em sistemas supramoleculares mais elaborados como os descritos no item 1.4.5 do Capitulo 1, podendo atuar de forma cooperativa em sensores ou catalisadores seletivos ${ }^{236,237}$

No caso de $\mathrm{MnTCP}^{5+}$, o número reduzido de dados obtidos até o momento não permite afirmações mais seguras que as efetuadas no item 6.2.4 do Capítulo 6, a respeito de comportamento catalítico não usual frente à hidroxilação do ciclohexano. Como visto, o uso de espectrofotometria "stopped-flow" poderia comprovar a formação de $\left(\mathrm{Mn}^{\mathrm{V}}=\mathrm{O}\right) \mathrm{TCP}$ e, mais importante, verificar o comportamento dos clusters periféricos durante a formação desta espécie. Por outro lado, em reações envolvendo olefinas como o cis-1,2-difenileteno os resultados poderiam confirmar (ou não) a maior seletividade de $\mathrm{MnTCP}^{5+}$ (usualmente, porfirinas de manganês não são seletivas com este tipo de substrato, na ausência de um ligante axial nitrogenado, produzindo cis- e trans-epóxidos ${ }^{228,229}$ ). Assim, um estudo catalítico mais detalhado, incluindo reações com diversos substratos e diversos oxidantes (como hipoclorito, monopersulfato de potássio, perácidos, etc) e verificação da estabilidade, parece ser um passo natural no estudo de $\mathrm{MnTCP}^{5+}$. Soma-se a este estudo a possibilidade de utilizar filmes desta supermolécula sobre a superfície de eletrodos, o que poderia resultar em filmes eletrocatalíticos que façam uso de oxigênio molecular em oxidações biomiméticas ${ }^{130}$. É preciso salientar que a pesquisa sobre esta molécula não deve se restringir a processos oxidativos que têm como inspiração as citocromos $\mathrm{P}-450$, mas podem ser ampliadas as investigações, por exemplo, na direção de sua atividade frente à dismutação do íon superóxido e à decomposição do íon peroxinitrito, como sugerem recentes publicações ${ }^{238,239}$. Sob outra perspectiva, $\mathrm{MnTCP}^{5+}$ poderá ser investigado como sensor potenciométrico ${ }^{236,240,241}$.

Quanto à $\mathrm{CoTCP}^{5+}$, tendo em vista que os eletrodos modificados por filmes desta supermolécula apresentaram (i) eficiente atividade catalítica na redução tetra- 
eletrônica de oxigênio, (ii) estabilidade e (iii) reprodutibilidade, tais eletrodos são candidatos naturais à concepção de sensores eletroquímicos para oxigênio dissolvido em meio aquoso. Além desta possibilidade, sistemas poderão ser desenvolvidos para a determinação de outros analitos como, por exemplo, sulfito, nitrito, dopamina e NADH, à semelhança dos descritos por Toma et $a^{242,243}$, baseados em eletrodos modificados

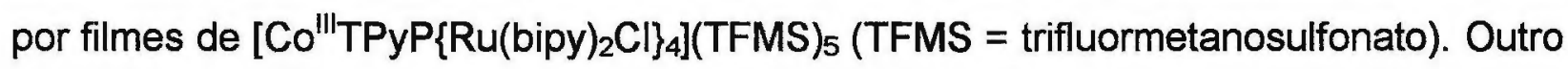
ponto interessante: a estabilidade dos filmes de $\mathrm{CoTCP}^{5+}$ poderá ainda ser melhorada pela formação de um novo material, um par iônico insolúvel constituído de $\mathrm{CoTCP}^{5+}$ e M-TPPS $(\mathrm{M}=\mathrm{Zn}$ ou $\mathrm{Cu}$, por exemplo; TPPS = meso-tetra(4sulfonatofenil)porfirina) ${ }^{99,147,244}$. Paralelamente, o mecanismo pelo qual filmes de CoTCP ${ }^{5+}$ efetuam a redução tetra-eletrônica de $\mathrm{O}_{2}$ deverá ser investigado, como sugerido ao final do Capitulo anterior (item 6.3.4). 


\subsection{A respeito de outros possíveis sistemas baseados em metaloporfirinas e clusters trinucleares de acetato de rutênio}

Com relação a sistemas análogos aos descritos nesta Tese, embora muitos metais possam ser inseridos no núcleo porfirínico, em particular o estudo de $\mathrm{FeTCP}^{5+}$ poderia ser muito interessante tendo em vista o paralelismo das investigações entre porfirinas de manganês e porfirinas de ferro no que tange a modelos biomiméticos das citocromos $\mathrm{P}-450^{14,15,17,18,21,116,245}$. $\mathrm{NiTCP}^{4+}$ é outro derivado análogo que mereceria uma investigação tendo em vista o seu potencial uso como sensor para $\mathrm{NO}^{236}$. No entanto, a alteração do metal $\mathrm{M}$ do núcleo porfirínico é apenas uma das várias possibilidades de alteração estrutural $e$, presumivelmente, de reatividade, em sistemas constituídos de metaloporfirinas e clusters trinucleares de rutênio, como pretende mostrar a figura 7.1.
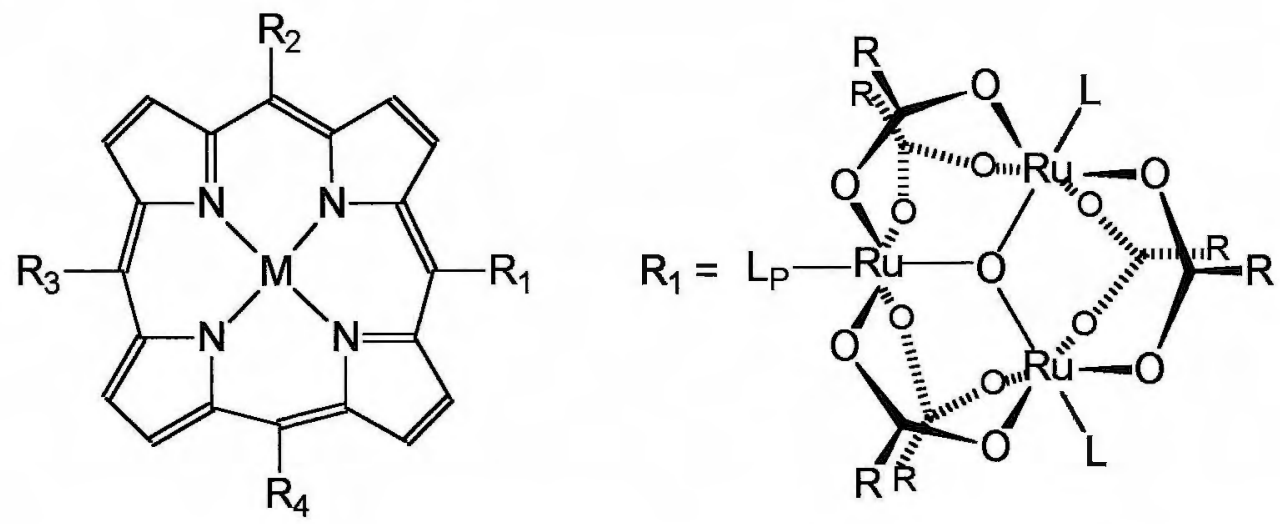

Figura 7.1 - Esquema para prováveis supermoléculas constituídas de metaloporfirinas e clusters trinucleares de rutênio.

Observando a figura, torna-se evidente que sítios catalíticos com arcabouços assimétricos podem ser obtidos fazendo-se, por exemplo, $\mathbf{R}_{\mathbf{1}} \neq \mathbf{R}_{\mathbf{2}} \neq \mathbf{R}_{\mathbf{3}} \neq \mathbf{R}_{\mathbf{4}}$, ponto importante em catálise regio- e enantioseletiva ${ }^{18}$. Por outro lado, os potenciais redox dos clusters periféricos podem ser modulados através da escolha adequada dos ligantes terminais $\mathrm{L}$ e das pontes de carboxilato $\mathrm{RCOO}^{-23}$; esta modulação permitirá investigar mais detalhadamente a interação entre as subunidades na supermolécula através do ligante em ponte $L_{p}$, com prováveis consequências sobre a reatividade. Ainda com relação às pontes de carboxilato, é possivel conceber cadeias $R$ 
funcionalizadas (com grupos $\mathrm{OH}$, por exemplo), o que permitiria adicionais sítios de reconhecimento molecular, atuando de forma cooperativa.

Muitos exemplos de reações bioquímicas são encontradas em sistemas enzimáticos que possuem mais de um metal no sítio ativo, dentre os quais pode-se citar: a ligação cooperativa de $\mathrm{O}_{2}$ pela hemoglobina (quatro grupos heme envolvidos), a redução tetra-eletrônica de $\mathrm{O}_{2}$ pelo complexo citocromo $\mathrm{c}$ oxidase (dois grupos heme e dois centros de cobre), e a evolução de oxigênio no fotossistema II (cluster tetranuclear de manganês) ${ }^{131,153}$. Tais sistemas constituem fonte de inspiração para estruturas como as indicadas na figura 7.2 .
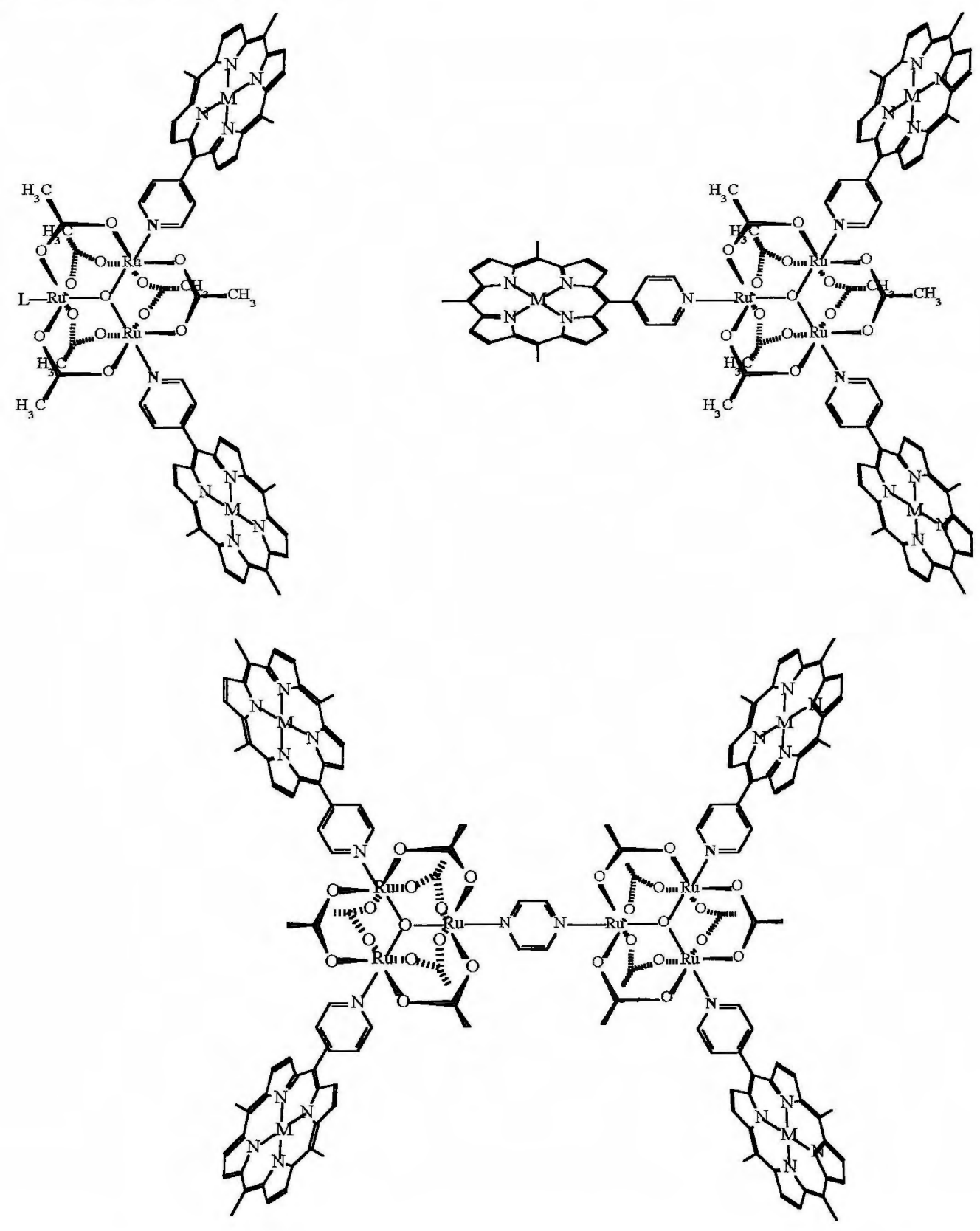

Figura 7.2 - Estruturas idealizadas para sítios catalíticos envolvendo mais de um metal. 
Assim, a presente Tese deve ser inserida no contexto da Química Supramolecular como parte inicial e, portanto, fundamental para a concepção e compreensão de sistemas supramoleculares envolvendo supermoléculas constituídas de metaloporfirinas e clusters trinucleares de carboxilatos de rutênio. Os resultados obtidos e que foram aqui apresentados, embora centralizados em aspectos básicos das supermoléculas como rotas de síntese, métodos de caracterização e alguns ensaios lidando com a reatividade, conferem um caráter promissor ao desenvolvimento posterior de novos sistemas, tal a alteração de reatividade constatada entre os precursores ZnTPyP, MnTPyP ${ }^{+}$e CoTPyP ${ }^{+}$, e as supermoléculas $\mathrm{ZnTCP}^{4+}, \mathrm{MnTCP}^{5+} \mathrm{e}$ CoTCP ${ }^{5+}$, respectivamente. 


\section{REFERÊNCIAS}

1)Lehn, J.-M. Angew. Chem. Int. Ed. Engl. 1988, 27, 89.

2)Cram, D. J. Angew. Chem. Int. Ed. Engl. 1988, 27, 1009.

3)Pedersen, C. J. Angew. Chem. Int. Ed. Engl. 1988, 27, 1021.

4)Comprehensive Supramolecular Chemistry, Elsevier: Oxford, 1996; Vol. 1-10.

5)Lehn, J. M. Supramolecular chemistry: concepts and perspectives; a personal account, VCH: Weinheim, 1995.

6)Desiraju, G. R. Angew. Chem. Int. Ed. Engl. 1995, 34, 2311.

7)Willis, C. L.; Wills, M. Organic Synthesis; Oxford University Press: New York, 1997.

8)Müller, A.; Reuter, H.; Dillinger, S. Angew. Chem. Int. Ed. Engl. 1995, 34, 2328.

9)Lehn, J.-M. Pure Appl. Chem. 1978, 50, 871.

10)Toma, H. E. Quím. Nova 1991, 14, 189.

11)Pedersen, C. J. J. Am. Chem. Soc. 1967, 89, 7017.

12)Lehn, J.-M.; Sirlin, C. J. Chem. Soc. Chem. Commun. 1978, 949.

13)Lehn, J.-M.; Sirlin, C. New J. Chem. 1987, 11, 693.

14)Meunier, B. Chem. Rev. 1992, 92, 1411.

15)Gunter, M. J.; Turner, P. Coord. Chem. Rev. 1991, 108, 115.

16)lamamoto, Y.; Assis, M. D.; Ciuffi, K. J.; Prado, C. M. C.; Prellwitz, B. Z.; Moraes, M.; Nascimento, O. R.; Sacco, H. C. J. Mol. Catal. A: Chem. 1997, 116, 365.

17)Mansuy, D. Pure Appl. Chem. 1990, 62, 741.

18)Collman, J. P.; Zhang, X.; Lee, V. J.; Uffelman, E. S.; Brauman, J. I. Science 1993, $261,1404$.

19)Feiters, M. C.; Gebbink, R. J. M. K.; Schenning, A. P. H. J.; Strijdonck, G. P. F.; Martens, C. F.; Nolte, R. J. M. Pure Appl. Chem. 1996, 68, 2163.

20)Ogoshi, H.; Mizutani, T. em Comprehensive Supramolecular Chemistry, Lehn, J.-M., Ed.; Elsevier: Oxford, 1996; Vol. 4, pp 337.

21)Mansuy, D. Pure Appl. Chem. 1987, 59, 759.

22)Esch, J.; Roks, M. F. M.; Nolte, R. J. M. J. Am. Chem. Soc. 1986, 108, 6093.

23)Alexiou, A. D. P.; Dovidauskas, S.; Toma, H. E. Quim. Nova 2000, 23, 785.

24)Mond, A. W. J. Chem. Soc. 1930, 1247.

25)Almog, O.; Bino, A.; Shweky, D. G.-J. Inorg. Chim. Acta 1993, 213, 99.

26)Spencer, A.; Wilkinson, G. J. Chem. Soc. Dalton 1972, 1570.

27)Baumann, J. A.; Salmon, D. J.; Wilson, S. T.; Meyer, T. J.; Hatfield, W. E. Inorg. Chem. 1978, 17, 3342. 
28)Toma, H. E.; Cunha, C. J.; Cipriano, C. Inorg. Chim. Acta 1988, 154, 63.

29)Zhilyaev, A. N.; Fomina, T. A.; Katser, S. B.; Baranovskii, I. B. Russ. J. Inorg. Chem. 1994, 39, 856.

30)Davis, S.; Drago, R. S. Inorg. Chem. 1988, 27, 4759.

31)Abe, M.; Sasaki, Y.; Yamaguchi, T.; Ito, T. Bull. Chem. Soc. Jpn. 1992, 65, 1585.

32)Ohto, A.; Tokiwa-Yamamoto, A.; Abe, M.; Ito, T.; Sasaki, Y.; Umakoshi, K.; Cannon, R. D. Chem. Lett. 1995, 97.

33)Abe, M.; Tanaka, M.; Umakoshi, K.; Sasaki, Y. Inorg. Chem. 1999, 38, 4146.

34)Ohto, A.; Sasaki, Y.; Ito, T. Inorg. Chem. 1994, 33, 1245.

35)Kobayashi, H.; Uryû, N.; Mogi, I.; Miyamoto, R.; Ohba, Y.; Iwaizumi, M.; Sasaki, Y.; Ohto, A.; Ito, T. Bull. Chem. Soc. Jpn 1995, 68, 2551.

36)Kobayashi, H.; Uryû, N.; Mogi, I.; Miyamoto, R.; Ohba, Y.; Iwaizumi, M.; Sasaki, Y.; Ohto, A.; Suwabe, M.; Ito, T. Bull. Chem. Soc. Jpn. 1996, 69, 3163.

37)Dong, T. Y.; Lee, H. S.; Lee, T. Y.; Hsieh, C. F. J. Chin. Chem. Soc. 1992, 39, 393.

38)Velayutham, M.; Gopinath, C. S.; Subramanian, S. Chem. Phys. Lett. 1996, 249, 7176.

39)Sasaki, Y.; Yoshida, Y.; Ohto, A.; Tokiwa, A.; Ito, T.; Kobayashi, H.; Uryu, N.; Mogi, I. Chem. Lett. 1993, 69.

40)Abe, M.; Sasaki, Y.; Yamada, Y.; Tsukahara, K.; Yano, S.; Ito, T. Inorg. Chem. 1995, $34,4490$.

41)Sasaki, Y.; Tokiwa, A.; Ito, T. J. Am. Chem. Soc. 1987, $109,6341$.

42)Sasaki, Y.; Nagasawa, A.; Tokiwa-Yamamoto, A.; Ito, T. Inorg. Chim. Acta 1993, $212,175$.

43)Simanova, S. A.; Belyaev, A. N.; Bashmakov, V. I.; Troshina, O. N.; Shchukarev, A. V.; Danilova, F. I. Russ. J. Gen. Chem. 1993, 63, 1378.

44)Belyaev, A. N.; Simanova, S. A.; Eremin, A. V.; Troshina, O. N. Russ. J. Inorg. Chem. 1995, 68, 1140.

45)Belyaev, A. N.; Simanova, S. A.; Eremin, A. V.; Shchukarev, A. V.; Troshina, O. N.; Bashmakov, V. I. Russ. J. Appl. Chem. 1995, 68, 65.

46)Belyaev, A. N.; Simanova, S. A.; Eremin, A. V.; Shchukarev, A. V. Russ. J. Appl. Chem. 1998, 71, 2104.

47)Simanova, S. A.; Bashmakov, V. I.; Troshina, O. N.; Belyaev, A. N. Russ. J. Appl. Chem. 1995, 68, 1543.

48)Johnson, M. K.; Powell, D. B.; Cannon, R. D. Spectrochim. Acta 1981, 37A, 995. 
49)Sasaki, Y.; Suzuki, M.; Nagasawa, A.; Tokiwa, A.; Ebihara, M.; Yamaguchi, T.; Kabuto, C.; Ochi, T.; Ito, T. Inorg. Chem. 1991, 30, 4903.

50)Spencer, A.; Wilkinson, G. J. Chem. Soc. Dalton 1974, 786.

51)Toma, H. E.; Cipriano, C. Monats. Chem. 1989, $120,815$.

52)Toma, H. E.; Cunha, C. J. Can. J. Chem. 1989, 67, 1632.

53)Cosnier, S.; Deronzier, A.; Llobet, A. J. Electroanal. Chem. 1990, 280, 213.

54)Toma, H. E.; Olive, M. A. L. Polyhedron 1994, 13, 2647.

55)Alexiou, A. D. P.; Toma, H. E. J. Chem. Res. (S) 1993, 464.

56)Baumann, J. A.; Salmon, D. J.; Wilson, S. T.; Meyer, T. J. Inorg. Chem. 1979, 18, 2472.

57)Nagase, K.; Yokobayashi, H.; Watanabe, A.; Ishikawa, H.; Matsumoto, T.; Kido, H.; Ito, T. Netsu Sokutei 1993, 20, 66.

58)Abe, M.; Sasaki, Y.; Yamada, Y.; Tsukahara, K.; Yano, S.; Yamaguchi, T.; Tominaga, M.; Taniguchi, I.; Ito, T. Inorg. Chem. 1996, 35, 6724.

59)Toma, H. E.; Alexiou, A. D. P. Electrochim. Acta 1993, 38, 975.

60)AraujoJr., J.; Nikolaou, S.; Alexiou, A. D. P.; Toma, H. E. Monats. Chem. 1997, 128, 759.

61)Alexiou, A. D. P.; Toma, H. E. J. Chem. Res. (S) 1997, 338.

62)Kido, H.; Nagino, H.; Ito, T. Chem. Lett. 1996, 745.

63)Ito, T.; Hamaguchi, T.; Nagino, H.; Yamaguchi, T.; Washington, J.; Kubiak, C. P. Science 1997, 277, 660.

64)Powell, G.; Richens, D. T.; Bino, A. Inorg. Chim. Acta 1995, 232, 167.

65)Walsh, J. L.; Baumann, J. A.; Meyer, T. J. Inorg. Chem. 1980, 19, 2145.

66)Ota, K.; Sasaki, H.; Matsui, T.; Hamaguchi, T.; Yamaguchi, T.; Ito, T.; Kido, H.; Kubiak, C. P. Inorg. Chem. 1999, 38, 4070.

67)Cotton, F. A.; Jr, J. G. N. Inorg. Chim. Acta 1972, 6, 411.

68)Toma, H. E.; Alexiou, A. D. P. J. Chem. Res. (S) 1995, 134.

69)Toma, H. E.; Alexiou, A. D. P. J. Braz. Chem. Soc. 1995, 6, 267.

70)Abe, M.; Sasaki, Y.; Nagasawa, A.; Ito, T. Bull. Chem. Soc. Jpn 1992, 65, 1411.

71)Bilgrien, C.; Davis, S.; Drago, R. S. J. Am. Chem. Soc. 1987, 109, 3786.

72)Davis, S.; Drago, R. S. J. Chem. Soc., Chem. Commun. 1990, 250.

73)Toma, H. E.; Alexiou, A. D. P.; Nikolaou, S.; Dovidauskas, S. Magn. Reson. Chem. 1999, 37, 322. 
74)Cunha, C. J. Correlações Espectroscópicas e Eletroquímicas em Clusters Trigonais de Rutênio com Ligantes $\mathrm{N}$-Heterocíclicos; Dissertação de Mestrado, Instituto de Química - Universidade de São Paulo: São Paulo, 1989.

75)Alexiou, A. D. P. Síntese, Caracterização e Reatividade de Clusters Trigonais de Acetato de Rutênio; Tese de Doutorado, Instituto de Química - Universidade de São Paulo: São Paulo, 1993.

76)Cotton, F. A.; Norman, J. G.; Spencer, A.; Wilkinson, G. Chem. Comm. 1971, 967. 77)Mukaida, M.; Kusakari, M.; Togano, T.; Isomae, T.; Nomura, T.; Ishimori, T. Bull. Chem. Soc. Jpn 1975, 48, 1095.

78)Kobayashi, H.; Uryû, N.; Tokiwa, A.; Yamaguchi, T.; Sasaki, Y.; Ito, T. Bull. Chem. Soc. Jpn 1992, 65, 198.

79)Sasaki, Y. J. Mol. Liq. 1995, 65/66, 253.

80)Sasaki, Y.; Umakoshi, K.; Imamura, T.; Kikuchi, A.; Kishimoto, A. Pure Appl. Chem. 1997, 69, 205.

81)Toma, H. E.; Cipriano, C. J. Electroanal. Chem. 1989, 263, 313.

82)Akashi, D.; Kido, H.; Sasaki, Y.; Ito, T. Chem. Lett. 1992, 143.

83)Toma, H. E.; Matsumoto, F. M.; Cipriano, C. J. Electroanal. Chem. 1993, 346, 261.

84)Wilson, S. T.; Bondurant, R. F.; Meyer, T. J.; Salmon, D. J. J. Am. Chem. Soc. 1975, 97, 2285.

85)Ito, T.; Hamaguchi, T.; Nagino, H.; Yamaguchi, T.; Kido, H.; Zavarine, I. S.; Richmond, T.; Washington, J.; Kubiak, C. P. J. Am. Chem. Soc. 1999, 121, 4625.

86)Baumann, J. A.; Wilson, S. T.; Salmon, D. J.; Hood, P. L.; Meyer, T. J. J. Am. Chem. Soc. 1979, 101, 2916.

87)Toma, H. E.; Nikolaou, S. J. Chem. Res. (S) 2000, 326.

88)Toma, H. E.; Araki, K.; Silva, E. O. Monats. Chem. 1998, 129, 975.

89)Toma, H. E.; Santos, P. S.; Cipriano, C. Spec. Lett. 1988, 21, 909.

90)Voet, D.; Voet, J. G. Biochemistry; 2 ed.; John Wiley \& Sons: New York, 1995.

91)Rothemund, P. J. Am. Chem. Soc. 1936, $58,625$.

92)Adler, A. D.; Longo, F. R.; Finarelli, J. D.; Goldmacher, J.; Assour, J.; Korsakoff, L. J. Org. Chem. 1967, 32, 476.

93)Lindsey, J. S.; Schereiman, I. C.; Hsu, H. C.; Kearney, P. C.; Marguerettaz, A. M. J. Org. Chem. 1987, 52, 827.

94)Dolphin, D.; Traylor, T. G.; Xie, L. Y. Acc. Chem. Res. 1997, 30, 251.

95)Gouterman, M. J. Chem. Phys. 1959, 30, 1139.

96)Gouterman, M. J. Mol. Spec. 1961, 6, 138. 
97)Gouterman, M.; Wagnière, G. H.; Snyder, L. C. J. Mol. Spec. 1963, 11, 108.

98)Gruhn, N. E.; Lichtenberger, D. L.; Ogura, H.; Walker, F. A. Inorg. Chem. 1999, 38, 4023.

99)Araki, K. Piridilporfirinas Supermoleculares Como Interfaces Eletroquímica e Fotoquímica; Tese de Livre Docência, Instituto de Química - Universidade de São Paulo: São Paulo, 2000.

100)Chantreel, S. J.; McAuliffe, C. A.; Munn, R. W.; Pratt, A. C. Coord. Chem. Rev. 1975, 16, 259.

101)Gouterman, M. em The Porphyrins; Dolphin, D., Ed.; Academic Press: New York, 1979; Vol. 3.

102)Kuhn, H. J. Chem. Phys. 1949, 17, 1198.

103)Simpson, W. T. J. Chem. Phys. 1949, 17, 1218.

104)Moffitt, W. J. Chem. Phys. 1954, 22, 320.

105)Moffitt, W. J. Chem. Phys. 1954, 22, 1820.

106)Longet-Higgins, H. C.; Rector, C. W.; Platt, J. R. J. Chem. Phys. 1950, 18, 1174.

107)Boucher, L. J. J. Am. Chem. Soc. 1968, 90, 6640.

108)Boucher, L. J. Coord. Chem Rev. 1972, 7, 289.

109)Gunter, M. J.; Turner, P. J. Mol. Catal. 1991, 66, 121.

110)Sacco, H. C. Atividade Catalítica de Manganêsporfirinas em Sistemas Homogêneos e Heterogêneos.; Tese de Doutorado, Instituto de Química - Universidade Estadual Paulista "Júlio de Mesquita Filho": Araraquara, 1999.

111)Gonsalves, A. M. d. A. R.; Pereira, M. M. J. Mol. Catal. A: Chem. 1996, 113, 209.

112)Campbell, L. A.; Kodadek, T. J. Mol. Catal. A: Chem. 1996, 113, 293.

113)Manso, C. M. C. P. Ferroporfirinas catiônicas cloro-substituídas em sistemas homogêneos e heterogeneizados: caracterização e atividade catalítica; Universidade de São Paulo: Ribeirão Preto, 1998.

114)Parton, R. F.; Vankelecom, I. F. J.; Tas, D.; Janssen, K. B. M.; Knops-Genits, P. P.; Jacobs, P. A. J. Mol. Catal. A: Chem. 1996, 113, 283.

115)Lehninger, A. L.; Nelson, D. L.; Cox, M. M. Principles of Biochemistry, 2 ed.; Worth: New York, 1993.

116)Mansuy, D. Coord. Chem. Rev. 1993, 125, 129.

117)Groves, J. T.; Nemo, T. S.; Myers, R. S. J. Am. Chem. Soc. 1979, 101, 1032.

118)Traylor, T. G.; Tsuchya, S. Inorg. Chem. 1987, 26, 1338.

119)Bartoli, J. F.; Brigaud, O.; Battioni, P.; Mansuy, D. J. Chem. Soc. Chem. Commun. $1991,440$. 
120)Mandon, D.; Ochsenbein, P.; Fischer, J.; Weiss, R.; Jayaraj, K.; Austin, R. N.; Gold, A.; White, P. S.; Brigaud, O.; Battioni, P.; Mansuy, D. Inorg. Chem. 1992, 31, 2044.

121)Brigaud, O.; Battioni, P.; Mansuy, D.; Giessner-Prettre, C. New J. Chem. 1992, 16, 1031.

122)Traylor, T. G.; Byun, Y. S.; Traylor, P. S.; Battioni, P.; Mansuy, D. J. Am. Chem. Soc. $1991,113,7821$.

123)Barloy, L.; Lallier, J. P.; Battioni, P.; Mansuy, D.; Piffard, Y.; Tournoux, M.; Valim, J. B.; Jones, W. New J. Chem. 1992, 16, 71.

124)Bedioui, F. Coord. Chem. Rev. 1995, 144, 39.

125)Chibwe, M.; Ukrainczyk, L.; Boyd, S. A.; Pinnavaia, T. J. J. Mol. Catal. A: Chem. 1996, 113, 249.

126)Battioni, P.; Bartoli, J. F.; Mansuy, D.; Byun, Y. S.; Traylor, T. G. J. Chem. Soc. Chem. Commun. 1992, 1051.

127)Hilal, H. S.; Jondi, W.; Khalaf, S.; Keilani, A.; Suleiman, M.; Schreiner, A. F. J. Mol. Catal. A: Chem. 1996, 113, 35.

128)Martinez-Lorente, M. A.; Battioni, P.; Kleemiss, W.; Bartoli, J. F.; Mansuy, D. J. Mol. Catal. A: Chem. 1996, 113, 343.

129)Bedioui, F.; Devynck, J.; Bied-Charreton, C. Acc. Chem. Res. 1995, 28, 30.

130)Bedioui, F.; Devynck, J.; Bied-Charreton, C. J. Mol. Catal. A: Chem. 1996, 113, 3.

131)Collman, J. P. Inorg. Chem. 1997, 36, 5145.

132)Wendt, H.; Götz, M.; Linardi, M. Quim. Nova 2000, 23, 538.

133)Anson, F. C.; Shi, C.; Steiger, B. Acc. Chem. Res. 1997, 30, 437.

134)Collman, J. P.; Marrocco, M.; Denisevich, P.; Koval, C.; Anson, F. C. J. Electroanal. Chem. 1979, 101, 117.

135)Collman, J. P.; Denisevich, P.; Konai, Y.; Marrocco, M.; Koval, C.; Anson, F. C. J. Am. Chem. Soc. 1980, 102, 6027.

136)DurandJr., R. R.; Bencosme, C. S.; Collman, J. P.; Anson, F. C. J. Am. Chem. Soc. 1983, 105, 2710.

137)Hutchison, J. E.; Postlethwaite, T. A.; Chen, C.; Hathcock, K. W.; Ingram, R. S.; Ou, W.; Linton, R. W.; Murray, R. W.; Tyvoll, D. A.; Chng, L. L.; Collman, J. P. Langmuir $1997,13,2143$.

138)Collman, J. P.; Wagenknecht, P. S.; Hutchison, J. E. Angew. Chem. Int. Ed. Engl. 1994, 33, 1537.

139)Yu, H.; Baskin, J. S.; Steiger, B.; Anson, F. C.; Zewail, A. H. J. Am. Chem. Soc. 1999, $121,484$. 
140)Steiger, B.; Anson, F. C. Inorg. Chem. 1997, 36, 4138.

141)Shi, C.; Anson, F. C. Inorg. Chem. 1996, 35, 7928.

142)Shi, C.; Anson, F. C. Inorg. Chem. 1995, 34, 4554.

143)Steiger, B.; Anson, F. C. Inorg. Chem. 1995, 34, 3355.

144)Shi, C.; Anson, F. C. Inorg. Chim. Acta 1994, 225, 215.

145)Steiger, B.; Shi, C.; Anson, F. C. Inorg. Chem. 1993, 32, 2107.

146)Shi, C.; Anson, F. C. J. Am. Chem. Soc. 1991, 113, 9564.

147)Toma, H. E.; Araki, K. Coord. Chem. Rev. 2000, 196, 307.

148)Feiters, M. C. em Comprehensive Supramolecular Chemistry; Elsevier: Oxford, 1996; Vol. 10.

149)Anderson, S.; Anderson, H. L.; Sanders, J. K. M. J. Chem. Soc. Perkin Trans. 1 1995, 2255.

150)Anderson, H. L.; Walter, C. J.; Vidal-Ferran, A.; Hay, R. A.; Lowden, P. A.; Sanders, J. K. M. J. Chem. Soc. Perkin Trans. 1 1995, 2275.

151)Vicente, M. G. H.; Cancilla, M. T.; Lebrilla, C. B.; Smith, K. M. Chem. Commun. 1998, 2355.

152)Jaquinod, L.; Siri, O.; Khoury, R. G.; Smith, K. M. Chem. Commun. 1998, 1261.

153)Wojaczynski, J.; Latos-Grazynski, L. Coord. Chem. Rev. 2000, 204, 113.

154)Imamura, T.; Fukushima, K. Coord. Chem. Rev. 2000, 198, 133.

155)Juillard, J. em Recommended Methods for Purification of Solvents and Tests for Impurities; Coetzee, J. F., Ed.; Pergamon Press: New York, 1982, pp 32.

156)Sawyer, D. T.; RobertsJr, J. L. Experimental Electrochemistry for Chemists.; John Wiley \& Sons: New York, 1974.

157)Bard, A. J.; Faulkner, L. R. Electrochemical Methods; John Wiley \& Sons: New York, 1980.

158)Kratochvil, B.; Lorah, E.; Garber, C. Anal. Chem. 1969, 41, 1793.

159)Coetzee, J. F.; Campion, J. J. J. Am. Chem. Soc. 1967, 89, 2513.

160)Ramette, R. W. J. Chem. Educ. 1987, 64, 885.

161)Pavlishchuck, V. V.; Addison, A. W. Inorg. Chim. Acta 2000, 298, 97.

162)Collins, C. H.; Braga, G. L.; Bonato, P. S. Introdução a Métodos Cromatográficos; Editora da Unicamp: Campinas, 1997.

163)Cipriano, C. Estudo Espectroscópico e Eletroquímico do Clusters Polinucleares de Acetato de Rutênio.; Tese de Doutorado, Instituto de Química - Universidade de São Paulo: São Paulo, 1989. 
164)Olive, M. A. L. Estrutura e Reatividade de Clusters Polimetálicos de Rutênio com Aminopirazina; Instituto de Química - Universidade de São Paulo: São Paulo, 1994. 165)Buchler, J. W. em The Porphyrins; Dolphin, D., Ed.; Academic Press: New York, 1979; Vol. 1.

166)Turner, P.; Gunter, M. J. Inorg. Chem. 1994, 33, 1406.

167)Hariprasad, G.; Dahal, S.; Maiya, B. G. J. Chem. Soc. Dalton Trans. 1996, 3429.

168)Alessio, E.; Macchi, M.; Heath, S. L.; Marzilli, L. G. Inorg. Chem. 1997, 36, 5614.

169)Janson, T. R.; Katz, J. J. em The Porphyrins; Dolphin, D., Ed.; Academic Press: New York, 1979; Vol. 4.

170)Mar, G. N. L.; Walker, F. A. J. Am. Chem. Soc. 1975, 97, 5103.

171)The Sadtler Standard Spectra; Sadtler Research Laboratories: Philadelphia, 1969; Vol. Spectrum 6034.

172)Kelly, S. L.; Kadish, K. M. Inorg. Chem. 1982, 21, 3631.

173)Lin, M.; Marzilli, L. G. Inorg. Chem. 1994, 33, 5309.

174)Polam, J. R.; Shokhireva, T. K.; Raffii, K.; Simonis, U.; Walker, F. A. Inorg. Chim. Acta 1997, 263, 109.

175)Huet, J.; Gaudemer, A.; Boucly-Goester, C.; Boucly, P. Inorg. Chem. 1982, 21, 3413.

176)Wall, M. H.; Akimoto, S.; Yamazaki, T.; Ohta, N.; Yamazaki, I.; Sakuma, T.; Kido, H. Bull. Chem. Soc. Jpn. 1999, 72, 1475.

177)Gosser, D. K. Cyclic Voltammetry: Simulation and Analysis of Reaction Mechanisms; VCH: New York, 1993.

178)Mabbott, G. A. J. Chem. Educ. 1983, 60, 697.

179)Evans, D. H.; O'Connell, K. M.; Petersen, R. A.; Kelly, M. J. J. Chem. Educ. 1983, $60,290$.

180)Benschoten, J. J. V.; Lewis, J. Y.; Heineman, W. R.; Roston, D. A.; Kissinger, P. T. J. Chem. Educ. 1983, 60, 772.

181)Kissinger, P. T.; Heineman, W. R. J. Chem. Educ. 1983, 60, 702.

182)Toma, H. E.; Araki, K.; Dovidauskas, S. J. Chem. Educ. 2000, 77, 1351.

183)Heineman, W. R. J. Chem. Educ. 1983, 60, 305.

184)Flanagan, J. B.; Margel, S.; Bard, A. J.; Anson, F. C. J. Am. Chem. Soc. 1978, 100, 4248.

185)Araki, K.; Toma, H. E. J. Photochem. Photobiol. A: Chem 1994, 83, 245.

186)Caemelbecke, E. V.; Kutner, W.; Kadish, K. M. Inorg. Chem. 1993, 32, 438.

187)Mu, X. H.; Schultz, F. A. Inorg. Chem. 1992, 31, 3351. 
188)Perré-Fauvet, M.; Gaudemer, A.; Bonvoisin, J.; Girerd, J. J.; Boucly-Goester, C.; Boucly, P. Inorg. Chem. 1989, 28, 3533.

189)Valentine, J. S.; Quinn, A. E. Inorg. Chem. 1976, 15, 1997.

190)Paula, M. M. S.; Franco, C. V. J. Coord. Chem. 1995, 36, 247.

191)Kadish, K. M. Prog. Inorg. Chem. 1986, 34, 435.

192)Kirner, J. F.; Reed, C. A.; Scheidt, W. R. J. Am. Chem. Soc. 1977, 99, 2557.

193)Gonzalez, B.; Kouba, J.; Yee, S.; Reed, C. A.; Kirner, J. F.; Scheidt, W. R. J. Am. Chem. Soc. 1975, 97, 3247.

194)Truxillo, L. A.; Davis, D. G. Anal. Chem. 1975, 47, 2260.

195)Kobayashi, H.; Hara, T.; Kaizu, Y. Bull. Chem. Soc. Jpn. 1972, 45, 2148.

196)Araki, K.; Toma, H. E. J. Coord. Chem. 1993, 30, 9.

197)Kirksey, C. M.; Hambright, P.; Storm, C. B. Inorg. Chem. 1969, 8, 2141.

198)Nappa, M.; Valentine, J. S. J. Am. Chem. Soc. 1978, 100, 5075.

199)Uemori, Y.; Takinami, S.; Takahashi, A.; Munakata, H.; Imai, H.; Nakagawa, S.; Kyuno, E. Inorg. Chim. Acta 1994, 224, 157.

200)Rose, N. J.; Drago, R. S. J. Am. Chem. Soc. 1959, 81, 6138.

201)Benesi, H. A.; Hildebrand, J. H. J. Am. Chem. Soc. 1949, 71, 2703.

202)Vogel, G. C.; Seraby, L. A. Inorg. Chem. 1973, 12, 936.

203)Miller, J. R.; Dorough, G. D. J. Am. Chem. Soc. 1952, 74, 3977.

204)Vogel, G. C.; Beckmann, B. A. Inorg. Chem. 1976, 15, 483.

205)Cole, S. J.; Curthoys, G. C.; Magnusson, E. A.; Phillips, J. N. Inorg. Chem. 1972, $11,1024$.

206)Kadish, K. M.; Shiue, L. R.; Rhodes, R. K.; Bottomley, L. A. Inorg. Chem. 1981, 20, 1274.

207)Rebouças, J. S.; Carvalho, M. E. D.; Idemori, Y. M. Livro de Resumos, 22a. Reunião Anual da SBQ 1999, 1, QI-174.

208)Hambright, P. Chem. Commun. 1967, 470.

209)Rillema, D. P.; Wicker, C. M.; Morgan, R. D.; Barringer, L. F.; Scism, L. A. J. Am. Chem. Soc. 1982, 104, 1276.

210)Imai, H.; Kyuno, E. Inorg. Chem. 1990, 29, 2416.

211)Imai, H.; Nakagawa, S.; Kyuno, E. J. Am. Chem. Soc. 1992, 114, 6719.

212)McDermott, G. A.; Walker, F. A. Inorg. Chim. Acta 1984, 91, 95.

213)Bhyrappa, P.; Krishnan, V.; Nethaji, M. J. Chem. Soc. Dalton Trans. 1993, 1901.

214)Jin, N.; Groves, J. T. J. Am. Chem. Soc. 1999, 121, 2923. 
215)Banfi, S.; Cavazzini, M.; Coppa, F.; Barkanova, S. V.; Kaliya, O. L. J. Chem. Soc. Perkin Trans. 2 1997, 1577.

216)Groves, J. T.; Stern, M. K. J. Am. Chem. Soc. 1988, 110, 8628.

217)Czernuszewicz, R. S.; Su, Y. O.; Stern, M. K.; Macor, K. A.; Kim, D.; Groves, J. T.; Spiro, T. G. J. Am. Chem. Soc. 1988, 110, 4158.

218)Groves, J. T.; Lee, J.; Marla, S. S. J. Am. Chem. Soc. 1997, 119, 6269.

219)Arasasingham, R. D.; He, G.-X.; Bruice, T. C. J. Am. Chem. Soc. 1993, 115, 7985.

220)Groves, J. T.; Nemo, T. E. J. Am. Chem. Soc. 1983, 105, 5786.

221)Smegal, J. A.; Hill, C. L. J. Am. Chem. Soc. 1983, 105, 3515.

222)Sorokin, A.; Robert, A.; Meunier, B. J. Am. Chem. Soc. 1993, 115, 7293.

223)Balahura, R. J.; Sorokin, A.; Bernadou, J.; Meunier, B. Inorg. Chem. 1997, 36, 3488.

224)Cook, B. R.; Reinert, T. J.; Suslick, K. S. J. Am. Chem. Soc. 1986, 108, 7281.

225)Battioni, P.; Renauld, J. P.; Bartoli, J. F.; Reina-Artiles, M.; Fort, M.; Mansuy, D. J. Am. Chem. Soc. 1988, 110, 8462.

226)Nappa, M. J.; Tolman, C. A. Inorg. Chem. 1985, 24, 4711.

227)Appleton, A. J.; Evans, S.; Smith, J. R. L. J. Chem. Soc. Perkin Trans. 2 1996, 281. 228)Meunier, B.; Guilmet, E.; Carvalho, M. E.; Poilblanc, R. J. Am. Chem. Soc. 1984, 106,6668 .

229)Meunier, B.; Carvalho, M. E.; Bortolini, O.; Momenteau, M. Inorg. Chem. 1988, 27, 161.

230)Nicholson, R. S.; Shain, I. Anal. Chem. 1964, 36, 706.

231)Laviron, E. Electroanalytical Chemistry; M. Dekker: New York, 1982; Vol. 12.

232)Matsumoto, F. M. Eletrodos Quimicamente Modificados com Filmes de Pentacianoferratos; Tese de Doutorado, Instituto de Química - Universidade de São Paulo: São Paulo, 1995.

233)Brett, C. M. A.; Brett, A. M. O. Electrochemistry: Principles, Methods and Applications.; Oxford University Press: Oxford, 1996.

234)Song, E.; Shi, C.; Anson, F. C. Langmuir 1998, 14, 4315.

235)Bettelheim, A.; Chan, R. J. H.; Kuwana, T. J. Electroanal. Chem. 1979, 99, 391.

236)Biesaga, M.; Pyrzynska, K.; Trojanowicz, M. Talanta 2000, 51, 209.

237)Robertson, A.; Shinkai, S. Coord. Chem. Rev. 2000, 205, 157.

238)Lee, J.; Hunt, J. A.; Groves, J. T. J. Am. Chem. Soc. 1998, 120, 6053.

239)Haberle, I. B.; Benov, L.; Spasojevic, I.; Fridovich, I. J. Biol. Chem. 1998, 273, 24521. 
240)Amini, M. K.; Shahrokhian, S.; Tangestaninejad, S. Anal. Chem. 1999, 71, 2502. 241)Amini, M. K.; Shahrokhian, S.; Tangestaninejad, S. Analyst 1999, 124, 1319. 242)Araki, K.; Angnes, L.; Azevedo, C. M. N.; Toma, H. E. J. Electroanal. Chem. 1995, 397, 205.

243)Angnes, L.; Azevedo, C. M. N.; Araki, K.; Toma, H. E. Anal. Chim. Acta 1996, 329, 91.

244)Azevedo, C. M. N.; Araki, K.; Angnes, L.; Toma, H. E. Electroanalysis 1998, 10, 467.

245)Castellino, A. J.; Bruice, T. C. J. Am. Chem. Soc. 1988, 110, 158. 